\title{
EXERGY ANALYSIS FOR SUSTAINABLE INVENTORY AND LOGISTICS SYSTEMS
}

\author{
by \\ Hussam K. Jawad \\ Master of Science in Mechanical Mechanical and Industrial Engineering, \\ Ryerson University, Toronto, Canada, 2012 \\ Bachelor of Science in Mechanical Engineering, \\ University of Baghdad, Baghdad, Iraq, 1988 \\ A dissertation \\ presented to Ryerson University \\ in partial fulfillment of the \\ requirement for the degree of \\ Doctor of Philosophy \\ in the Program of \\ Mechanical and Industrial Engineering
}

Toronto, Ontario, Canada, 2017

(C) Hussam Jawad 2017 


\section{AUTHOR'S DECLARATION FOR ELECTRONIC SUBMISSION OF A DISSERTATION}

I hereby declare that I am the sole author of this dissertation. This is a true copy of the dissertation, including any required final revisions, as accepted by my examiners.

I authorize Ryerson University to lend this dissertation to other institutions or individuals for the purpose of scholarly research.

I further authorize Ryerson University to reproduce this dissertation by photocopying or by other means, in total or in part, at the request of other institutions or individuals for the purpose of scholarly research.

I understand that my dissertation may be made electronically available to the public. 


\title{
EXERGY ANALYSIS FOR SUSTAINABLE INVENTORY AND LOGISTICS SYSTEMS
}

Doctor of Philosophy, 2017

Hussam K. Jawad

Mechanical and Industrial Engineering

Ryerson University

\begin{abstract}
Inventory systems may be modelled analogously to thermal systems involving multiple flows of capital, labour, energy, and materials among the members of a supply chain. The laws of thermodynamics can be employed to analyze the efficiency of such physical systems by implementing "Exergy Analysis," a powerful technique which can be used to assess and improve the efficiency of a process, device, and system and to enhance their environmental and economic performance.

Traditional exergy analysis methods may not be sufficient for the analysis of certain systems because they do not account for the non-energetic factors such as capital, labour, and environment protection. Extended exergy analysis assigns exergetic equivalents to such non-energetic externalities.
\end{abstract}

Sustainable development is about securing the requirements of today while guarding the needs of future generations. Its target is the improvement of the living styles of humans by protecting their health and environment, and the efficient resources' consumption while advancing long-term economic growth. In other words, it is the integration of social, environmental, and economic aspects into regulations and policies, which requires actions from everyone on this planet.

The production, inventory and logistics of goods have contributed, among other things, towards making our world less sustainable. This thesis, therefore, aims to provide 
models, methods and decision support tools that can assist in achieving a better level of sustainability through the whole processes of inventory systems. The overall objectives are to analyze the importance of the wise consumptions of physical and human resources in inventory systems.

The results of this thesis have significant implications in shifting the "classical" paradigm of inventory systems that are based on the economic performance, which can be measured with financial criteria, such as total costs and profit, to the "non-classical" paradigm that considers the three pillars of sustainable development. The results showed the importance of accounting for the consumed exergy rather than just considering the values in term of monetary units. Computing the exergetic costs can provide more flexibility for managers of supply chains to compute the quantity based on the available resources and not confining this to the capital only. 


\section{ACKNOWLEDGMENT}

This thesis would not have been possible without the guidance and the help of several individuals who in one way or another contributed and extended their valuable assistance in the preparation and completion of this study. It is a pleasure to convey my gratitude to them all in my humble acknowledgment.

First and foremost, I would like to express my sincere gratitude to my supervisor Prof. Mohamad Y. Jaber for the continuous support of my Ph.D. study and research, for his patience, motivation, enthusiasm, and immense knowledge. His guidance helped me in all the time of research and writing of this thesis.

Many thanks go in particular to Dr. Maurice Bonney (Nottingham University Business School, University of Nottingham), Dr. Marc A. Rosen (Faculty of Engineering and Applied Science, University of Ontario Institute of Technology) and Dr. R.Y. Nuwayhid (Department of Mechanical Engineering, Rafik Hariri University) for their valuable advices and comments on the work in this thesis.

I gratefully acknowledge the funding sources that made my Ph.D. work possible. I was funded by the Natural Sciences and Engineering Research Council of Canada (NSERC). Ryerson University also supported my work.

I also wish to thank the chair and all the staff members of the Department of Mechanical and Industrial Engineering at Ryerson University for their continuous support and assistance.

A special thank for all of my colleagues and friends at Ryerson University for their support and advice during my study with them.

Lastly, I would like to thank my family for all their love and encouragement. For my parents, who raised me with a love of science and supported me in all my pursuits. 
This dissertation is dedicated to my beloved father (in memorian) and mother, my family and faithful friends, and all teachers in my life. 


\section{Table of Contents}

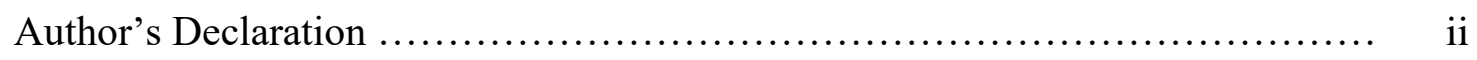

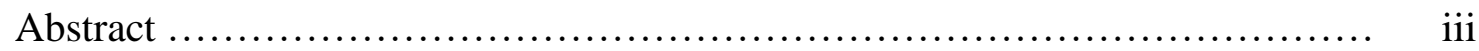

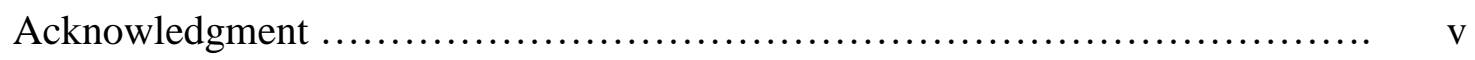

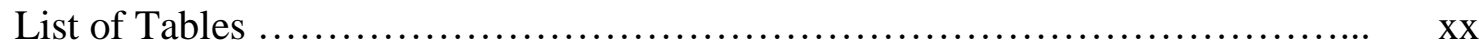

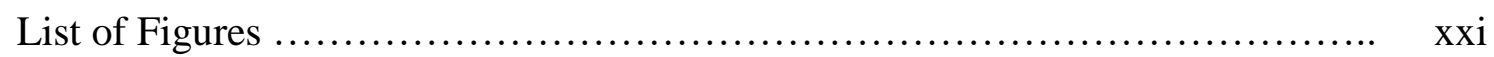

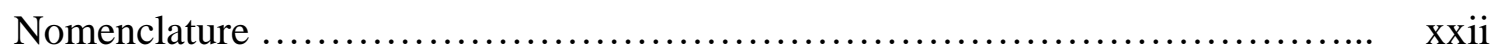

Chapter (1) - Introduction to supply chain management ........................ 1

1.1 Green Supply Chain Management Paradigm ............................... 4

1.2 Sustainable Supply Chain Management Paradigm ........................ 11

1.2.1 How to achieve a sustainable supply chain? ......................... 17

1.3 Review of the Literature ............................................... 19

1.3.1 Literature Review on Green Supply Chain ......................... 19

1.3.2 Literature Review on Sustainable Supply Chain ...................... 23

1.4 Research Gaps .......................................................... 31

1.5 Research Limitations ..................................................... 34

1.6 Research Questions ........................................................ 35

1.7 Objectives of The Research ........................................ 36

1.8 Thesis Organization and Scholarly Output ............................... 37

Chapter (2) -Thermodynamics and sustainability .......................... 40

2.1 Could Thermodynamics Solve The Problem Of Sustainability? .............. 40

2.2 What is Exergy? ................................................... 45

2.2.1 What are the Most Important Features of Exergy? ................... 47

2.2.2 Why is Exergy Important? ........................................ 48

2.2.3 How can Exergy be linked to sustainability? ........................ $\quad 50$

2.2.4 How can Exergy be linked to inventory management? ................ 54

2.2.5 Extended Exergy Accounting (EEA) .............................. 58

2.2.6 How to Compute the Extended ..................................... 60

2.2.7 Exergy of Capital .............................................. 61

2.2.8 Exergy of Labour ............................................... 63

2.2.9 Exergy of Environmental Remediation .......................... 66

2.2.10 Limitations and obstacles of EEA .............................. 67

Chapter (3) - Exergy analysis: a new paradigm for modelling inventory systems $\quad 69$

3.1 Introduction ......................................................... 69

3.2 Exergo-Economics and Inventory Systems ….......................... 71

3.3 Application of the Exergetic Model ................................... 73

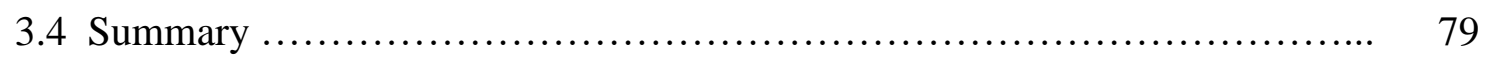


Chapter (4) - The economic order quantity model revisited: an extended exergy

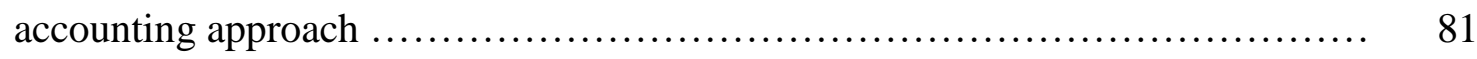

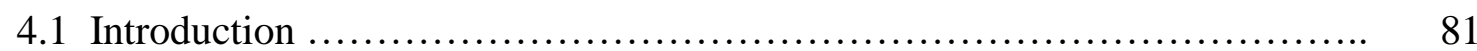

4.2 Inventory Theory Under The EOQ Model .............................. 83

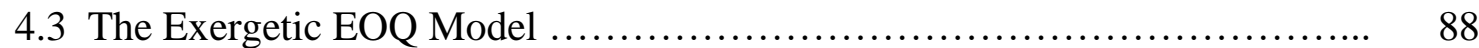

4.3.1 Mass and Energy Balances and Exergy Flow in an Inventory System $\quad 89$

4.3.2 The Exergetic Model ........................................... 90

4.4 A Numerical Example .............................................. 91

4.5 Results and Discussion ............................................... 95

Summary and Conclusions ............................................... 98

Chapter (5) - deriving an exergetic economic production quantity model for

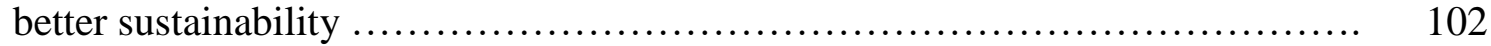

5.1 Introduction ...................................................... 102

5.2 Exergy, Thermodynamics Laws, and Their Applications ................... 104

5.3 Thermal EPQ Model ................................................ 107

5.4 Exergetic Inventory Approach ........................................ 108

5.4 .1 Main Assumptions .......................................... 113

5.4.2 Model Development ......................................... 113

5.4 .3 Entropic Inventory Approach $\ldots \ldots \ldots \ldots \ldots \ldots \ldots \ldots \ldots \ldots \ldots \ldots \ldots ., 118$

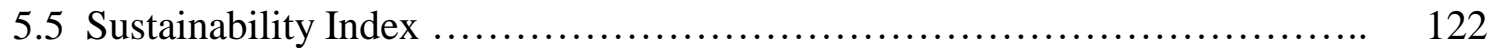

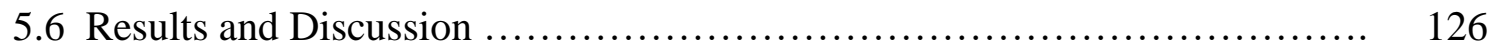

5.7 Economic Manufacture Quantity (EMQ) Vs. Just-In-Time (JIT) ............. 138

5.8 Summary and Conclusions .......................................... 139

Chapter (6) - Improving supply chain sustainability using exergy analysis ....... 142

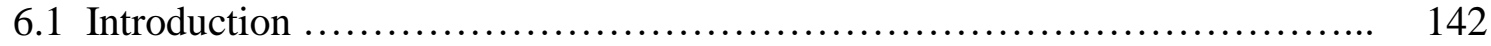

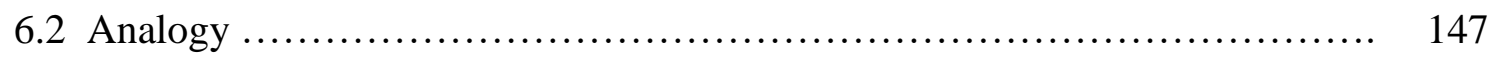

6.2.1 Entropy generation and exergy destruction of a heat pump system ..... 147

6.2.2 A heat pump system as a supply chain ......................... 150

6.3 An Exergetic Supply Chain Model ..................................... 154

6.3.1 Entropy model assumptions and decision variables ................. 154

6.3.2 The mathematical model ..................................... 155

6.4 Domestic Vs. Global Supply Chains ................................. 158

6.5 Consignment Stock Policy in an Integrated Supply Chain ................. 161

6.6 Application of the Exergetic Model .................................. 163

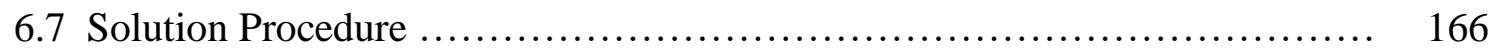

6.8 Results and Discussion .............................................. 167

6.8.1 Case 1 - Hill's policy for a domestic supply chain ................. 167

6.8.2 Case 2 - A domestic supply chain operates under CS policy .......... 179

6.8.3 Case 3 - Global supply chain............................... 182 


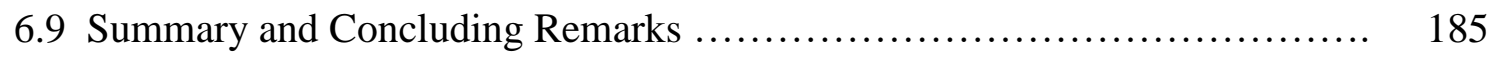

Chapter (7) - Summary and conclusions ............................... 188

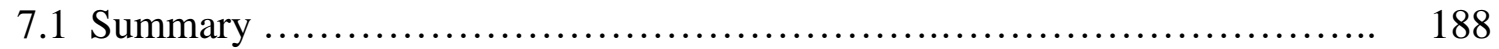

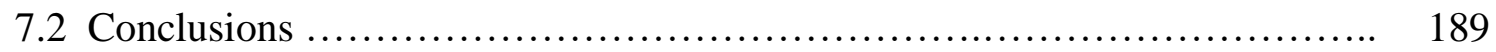

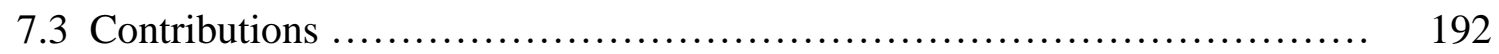

7.4 Recommendations for Future Works .................................... 194

Appendix (A) ..................................................... 195

References ........................................................ 205 


\section{List of Tables}

Table 1.1. Some of the studies that have considered the term of "sustainability."

Table 4.1. The parameters used in the inventory analysis.

Table 4.2. The exergetic parameters used in the inventory analysis.

Table 4.3. The exergetic values of $A, c_{U}$, and $h$. (values in MJ).

Table 4.4. Exergetic inventory policies for the three firms.

Table 5.1. Optimal order policy for the developed model with varying, but known, price, $P$

Table 6.1. List of input parameters and their respective values.

Table 6.2. Cost per ton-mile (in 2010 cents) for transportation external costs

Table 6.3 a. A sample search for the optimal solution when minimizing $T C_{S C}\left(P=81, t_{c}=500\right)$

Table $6.3 \mathrm{~b}$. A sample search for the optimal solution when minimizing TExC $\left(P=81, t_{c}=500\right)$

Table 6.4. Optimal policy for model $\mathrm{J}=$ hill when optimizing $T C_{J}$ and $T E x C_{J}$, respectively.

Table 6.5. Calculated values of $e e_{K}$ and $e e_{L}$ for Canada for years 2005-2009

Table 6.6. Optimal policy for model $\mathrm{J}=$ hill when optimizing $T C_{J}$ and $T E x C_{J}$, respectively, for $e e_{K}=44.36$ and $e e_{L}=2.41$, and $t c=500$

Table 6.7. Optimal policy for the model $\mathrm{J}=\mathrm{CS}$ when optimizing $T C_{J}$ and $T E x C_{J}$ respectively

Table 6.8. Optimal policy for the CS model when optimizing $T C_{C S}$ and $T E x C_{C S}$, respectively

Table 6.9. Optimal policy for the hill-overseas (ho) model when optimizing $T C_{H-O}$ and $T E x C_{H-O}$, respectively $\left(t c=250 ; h_{r}=10.5, h_{m}=8\right)$ 


\section{List of Figures}

Figure 1.1. A simple schematic diagram of a supply chain. 2

$\begin{array}{ll}\text { Figure 1.2. The reverse logistics process for an arbitrary product. } & 8\end{array}$

Figure 1.3. Schematic diagram illustrates the LCA for an arbitrary product. 11

Figure 1.4. Practices that should be considered to move towards a sustainable supply $\begin{array}{ll}\text { chain } & 18\end{array}$

Figure 2.1. Schematic diagram illustrates the relation between energy and exergy. 46

Figure 2.2. Schematic diagram illustrates the principles of ExCL for an arbitrary product.

Figure 2.3. Input and output stream of a production system.

Figure 4.1. Inventory profile over time for the EOQ model.

Figure 4.2. Basic inventory cost trade-offs (ordering and holding costs) as a function of the order quantity.

Figure 5.1. Schematic of a one-node thermal model for a system exchanging heat with a reservoir.

Figure 5.2. Schematic diagram of the cooling cycle of a heat pump.

Figure 5.3. Schematic diagrams of (a) thermal power cycle, and (b) production system.

Figure 5.4. The behavior of inventory over time for the EPQ model.

Figure 5.5. Steady-state heat pump with finite hot-end and cold-end thermal conductance.

Figure 5.6. The relation between profitability and ExSI with commodity price for the developed model.

Figure 6.1. Schematic diagram of a thermal cycle consisting of two heat pump systems connected in series.

Figure 6.2. Schematic diagrams of a two-level supply chain (system-surrounding boundaries depicted as a dotted line).

Figure 6.3. The relation between $\dot{S}_{g e n}^{C}, e(P)$ and $P$.

\section{Nomenclature}




$\begin{array}{ll}\text { Subscripts } & \\ H & \text { hot } \\ C & \text { cold } \\ T r & \text { in-transit period } \\ t r & \text { transportation } \\ r, m & \text { retailer, manufacturer } \\ H d & \text { Holding or stocking } \\ \text { Or } & \text { Ordering or setup } \\ P C & \text { Purchasing } \\ K & \text { Capital } \\ L & \text { Labour } \\ \text { Env } & \text { Environmental }\end{array}$

Input

Parameters

$E x_{j}^{*} \quad$ CExC burdening the production of the $j$-th output

$E x_{i}^{*} \quad C E x C$ burdening the production of the $i$-th input element of the considered system

$\mathrm{Exo}_{j} \quad$ Exergy of the resources delivered from the environment of the investigated system

$f_{i j} \quad$ Represents the consumption fraction of the $i$-th resource by the $j$-th process

$E x_{M} \quad$ Exergy of material (exergy is the sum of the physical and chemical contents of the raw materials used in the production of a product) 


\begin{tabular}{|c|c|}
\hline$E x_{E n}$ & $\begin{array}{l}\text { Exergy of the energy carrier (the sum of the exergy of energy flows } \\
\text { entering the production of a product; heat, mechanical work, electrical } \\
\text { energy, chemical energy, etc.). The sum of } E x_{M} \text { and } E x_{E n} \text { represents } \\
\text { the cumulative exergy consumption (in } \mathrm{j} / \mathrm{kg} \text { or } \mathrm{j} / \mathrm{j} \text { ). }\end{array}$ \\
\hline$E E x_{K}$ & $\begin{array}{l}\text { Equivalent exergy of capital (the total net budgetary influx into the } \\
\text { system, in } \mathrm{J} / \$ \text { ). }\end{array}$ \\
\hline$E E x_{L}$ & $\begin{array}{l}\text { Equivalent exergy of labour (the sum of the labour contributions into } \\
\text { the system, in J/Work hour). }\end{array}$ \\
\hline$E E x_{E n v}$ & $\begin{array}{l}\text { Equivalent exergy of environmental remediation (the total extended } \\
\text { exergetic cost necessary to bring the effluents to a state of equilibrium } \\
\text { with the environment, in } \mathrm{J} / \$ \text { ). }\end{array}$ \\
\hline Exin & The total influx of exergy into a system (society). \\
\hline$m u$ & Represents any monetary unit such as $\$, £, ¥, €$, etc \\
\hline Cref & $\begin{array}{l}\text { The reference amount of the monetary assets available in that system } \\
\text { for a specific period. }\end{array}$ \\
\hline$e e_{K}$ & The specific exergy equivalent of one monetary unit (V, $\$, £, ¥$, etc.) \\
\hline$e e_{L}$ & The unit equivalent exergy of labour (MJ/hour) \\
\hline$\alpha$ & The creation of wealth exclusively from financial activities \\
\hline$(N W H)_{t o t}$ & The total amount of work-hours performed in the entire system. \\
\hline$\beta$ & Represents the portion of the primary exergy embodied in labour. \\
\hline $\mathcal{F}$ & $\begin{array}{l}\text { The coefficient that explains the fact that modern life standards } \\
\text { require an exergy use much more than the minimum survival. }\end{array}$ \\
\hline$N_{h}$ & The population size. \\
\hline$e_{\text {surv }}$ & $\begin{array}{l}\text { The minimum exergy requirement for survival }\left(e_{\text {surv }} \approx 107\right. \\
\mathrm{J} /(\text { person*day })) \text {. }\end{array}$ \\
\hline
\end{tabular}




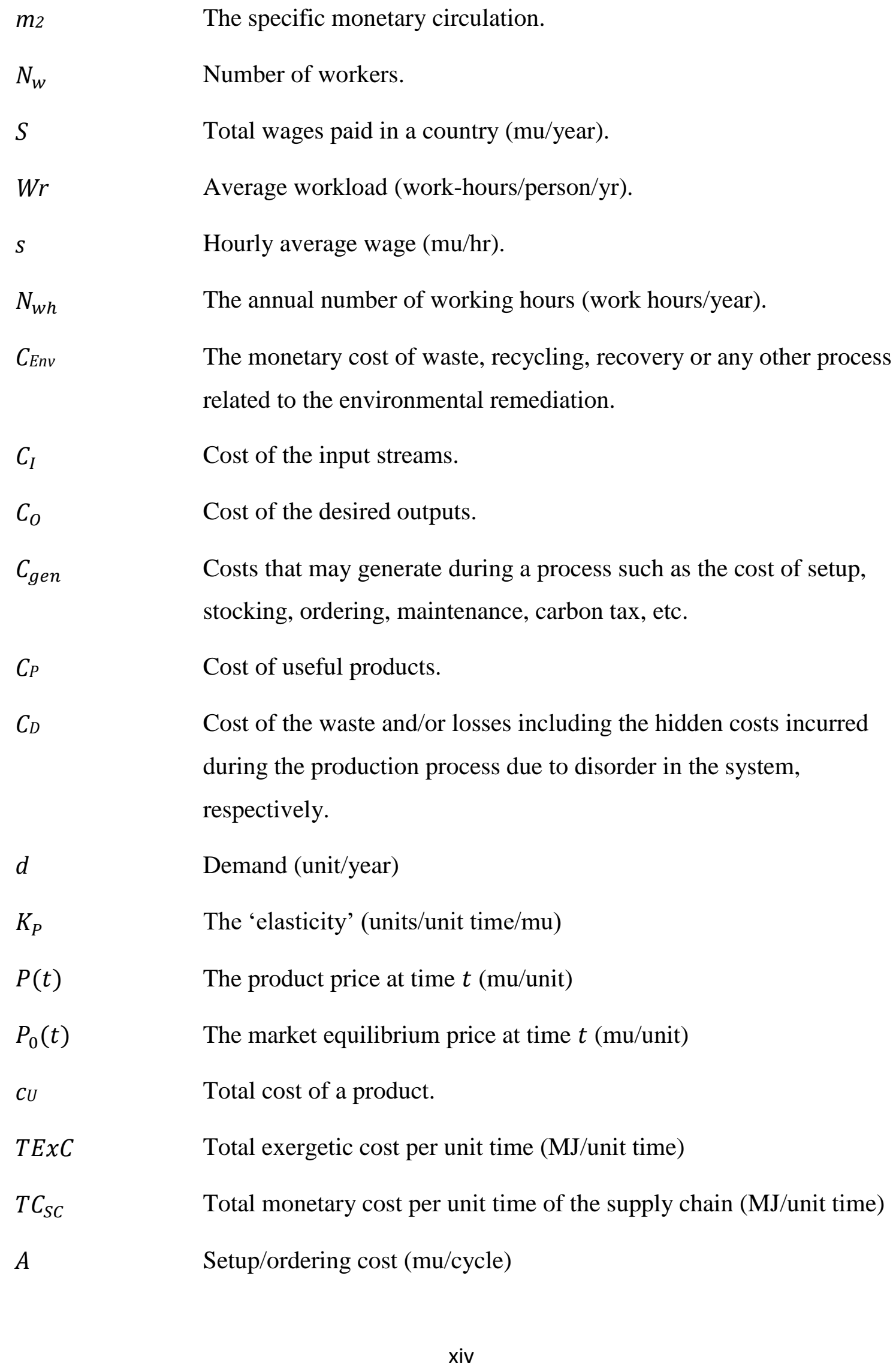




\begin{tabular}{|c|c|}
\hline$h$ & Unit holding cost (mu/unit/year) \\
\hline$T_{P}$ & Production period length (year). \\
\hline$T_{d}$ & Demand period length (year). \\
\hline$T_{d}$ & Production cycle time (year) \\
\hline$I$ & Inventory level (unit) \\
\hline$q$ & Order quantity (unit/cycle) \\
\hline$K_{n}$ & Represents the generalized thermal conductance (W/m.K) \\
\hline$\hat{C}_{P}$ & The system's heat capacity at constant pressure (J/kg.K) \\
\hline$T_{0}$ & The temperature of the surroundings (Kelvin, K) \\
\hline$T$ & The system temperature (Kelvin, K) \\
\hline$W$ & Work \\
\hline$Q$ & Heat energy \\
\hline$E x_{\text {dest }}$ & Destructed (wasted) exergy \\
\hline$\eta_{I I}$ & The second-law efficiency \\
\hline$\eta_{e x}$ & The exergetic efficiency \\
\hline$c_{m}$ & Unit manufacturing cost (mu/unit) \\
\hline$c_{w}$ & Unit manufacturing cost excluding raw material (mu/unit) \\
\hline$c_{m t r}$ & Unit raw material cost (mu/unit) \\
\hline$c_{m t r 0}$ & Unit market (equilibrium)purchase cost of raw material (mu/unit) \\
\hline$c_{L}$ & Unit labour cost (mu/unit) \\
\hline$c_{e s}$ & Emission cost per unit (mu/ton-CO2) \\
\hline$c_{\text {eng }}$ & Energy cost per unit (mu/kWh) \\
\hline$\dot{\sigma}_{g e n}$ & Entropy generated in an inventory system (unit/year) \\
\hline
\end{tabular}




$\begin{array}{ll}S_{g e n}^{C} & \text { Entropy generated in a combined system (unit/year). It is similar to } \\ & \dot{\sigma}_{g e n} \\ T_{i} & \text { The length of cycle } i(i=1,2,3 \ldots \mathrm{m}) \\ C_{t-i n t}(q) & \text { Internal cost of transportation (mu/year) } \\ C_{t-e x t}(q) & \text { External cost of transportation (mu/year) } \\ n & \text { Number of shipments per cycle, where } n \geq l \text { and integer } \\ \rho & \text { Production rate (unit/unit time) } \\ E_{p} & \text { Entropy cost (mu/unit time), it represents the wasted exergy } \\ E x S I & \text { Exergetic Sustainable Indicator } \\ e(P) & \text { The cost of controlling one unit of product, } e(P)=-E_{p} / K_{P}\left(P-P_{0}\right) \\ T C & \text { Total cost (mu/year) } \\ a, b \text { and } c & \text { Positive parameters } \\ f & \text { Fixed cost of transportation (mu) } \\ f_{t} & \text { Variable cost of transportation (mu/unit) } \\ f_{t, i} & \text { In-transit time in years (=days/365) } \\ D_{t} & \text { The required energy per unit time when manufacturing is idle } \\ & \text { (kwh/year) } \\ k_{0} & \text { The required energy at the machine to manufacture one unit } \\ & \text { (kwh/unit) } \\ & \text { Distance (km) }\end{array}$


$T E x C^{\varnothing} \quad$ Exergetic cost without accounting for entropy (MJ/year)

TExC Exergetic cost when accounting for entropy (MJ/year)

$\operatorname{Em}(\rho) \quad$ Per unit emissions from production (ton-CO2/unit)

$E_{g}(\rho) \quad$ Per unit required energy to produce one unit(kwh or MJ/unit, where $\mathrm{kwh}=3.6 \mathrm{MJ}$ ) 


\section{CHAPTER (1) - INTRODUCTION TO SUPPLY CHAIN MANAGEMENT}

The group of organizations and activities that are involved in transferring raw materials into a finished product, which will be used by the end user (customer) is called a supply chain. It may involve delivering a service instead of providing a physical product to the customer. Numerous parties (organizations) are usually involved in the task of fulfilling customer demand for a certain product or service to create a supply chain together. The main parties may consist of, but are not limited to, raw materials suppliers, manufacturers, transporters, distribution centers, warehouses, retailers and the customers who are the main target of this supply chain. These parties will certainly need other parties that also may play major roles in fulfilling customers demand. They may need financial institutions, inspection firms, environmental organizations, information technology firms, media and other firms depending on the nature and attributes of the product or service. Figure (1.1) is a simple schematic diagram of a supply chain. It shows that the demand for a certain product or service arises from the customers. To fulfill this demand, supplies from the other members (supplier, manufacturer, distributor, retailer, etc.) move forward until they meet the customer's request. There are three types of flows; the first one is the downstream flow of items and components from the start point of the raw material supplier to customers in the form of finished products. The second flow is the upstream flow of funds (capital), which flow in the opposite direction of the product flow. The third stream is a two-way flow of information and data among the members, which may include payments, invoices, stocks data, forecasting, decisions, etc. All activities and processes across the supply chain can be efficiently integrated using Supply Chain Management (SCM) tools. The term SCM was 
first introduced in 1982 by a group of logistics consultants (Simchi-Levi, Kaminsky, \& Simchi-Levi, 2008).

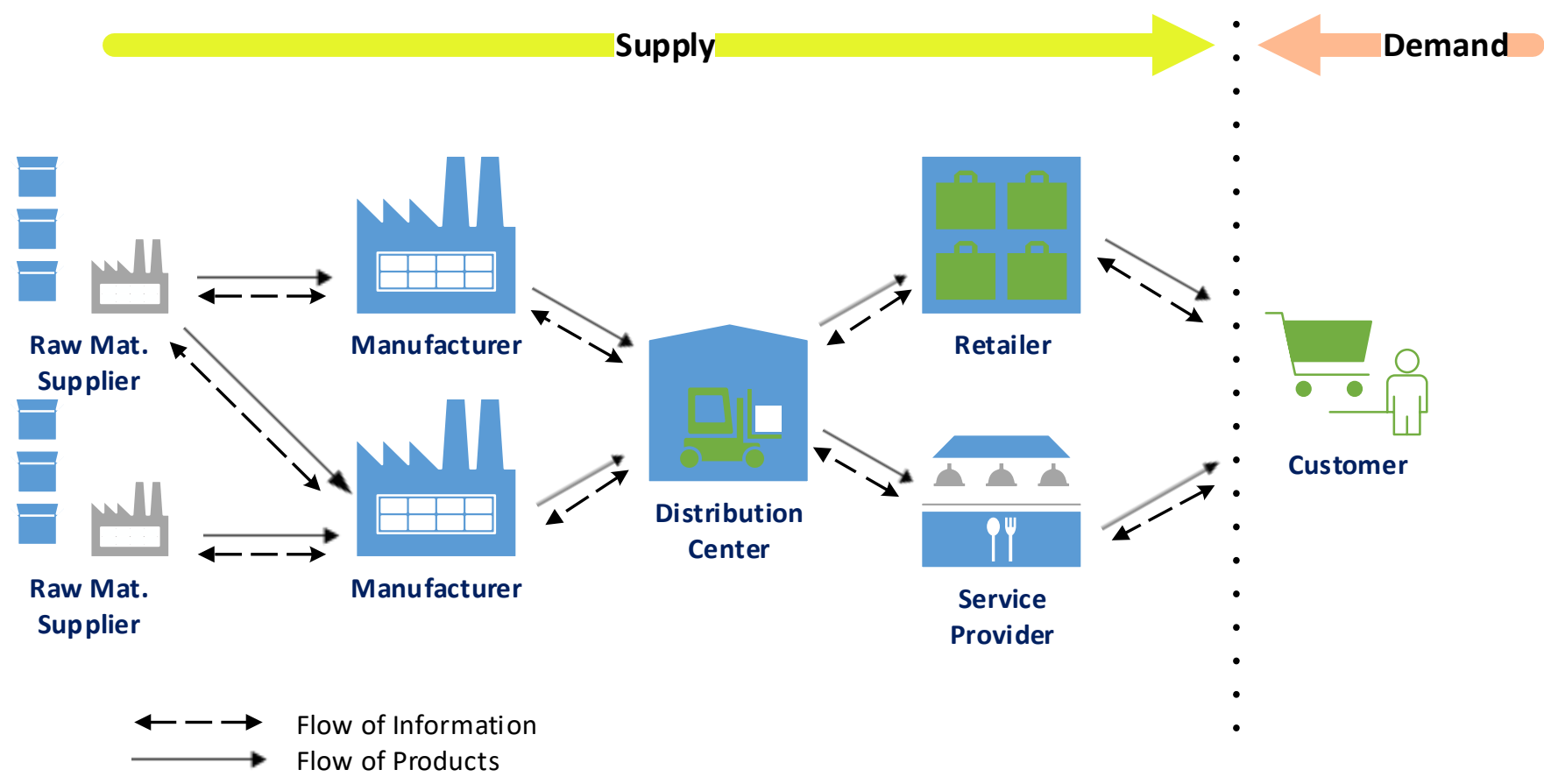

Figure 1.1. A simple schematic diagram of a supply chain.

Supply Chain Management is defined as "a set of approaches utilized to efficiently integrate suppliers, manufacturers, warehouses, and stores, so that merchandise is produced and distributed in the right quantities, to the right locations, and at the right time, in order to minimize system-wide costs while satisfying service level requirements"((Simchi-Levi, Kaminsky, \& Simchi-Levi, 2002), pp1). Several other definitions are found in literature, e.g. (Charles Scott \& Roy Westbrook, 1991); (Ross, 
1998); (Rhonda R. Lummus \& Robert J. Vokurka, 1999); (Mentzer et al., 2001); (Stank, Keller, \& Daugherty, 2001).

Even with some variations in these definitions, the main objective of SCM has always been to maximize the profitability for its members and reduce their total costs. This task can be achieved by modifying and controlling policies related to pricing, setting order quantities and the number of shipments. Hence, the most important task of SCM is increasing the inventory turnover by selling products faster, which improves the cash flow. Accordingly, as return on capital increases, the pressure on working capital decreases.

SCM has many advantages starting with the suppliers of raw materials and ending with final products delivered to customers. Some of these advantages are:

- Sharing information improves supply and demand forecasts along a supply chain and subsequently improves delivery performance and product availability.

- Better planning of supply chain activities reduce administrative and operational costs.

- Minimizing the cycle time by reducing the delay time spent to obtain raw materials, semifinished products, parts, tools, etc. This is called the "Traditional" paradigm of SCM, where the challenges are limited to lowering costs and increasing profits and the satisfaction of customers.

Due to the backdrop of today's globalization, business firms are required to rearchitect, re-evaluate and even remodel their activities and performance just to keep up with the demands of the industry. Practitioners and academicians have already devoted years of practice and research to develop initiatives, models, and solutions for new paradigms of supply chain management (Seuring \& Müller, 2008). A major requirement for new 
paradigms of SCM is to perform positively based on the environmental and societal impacts, as well as to reduce operating costs and maximize the profit. It used to be an easy decision for a customer to choose between similar products; a customer just needed to compare the cost and quality and then pick the product of interest. Nowadays, this traditional theme is limited because customer satisfaction is starting to include the environmental impact of the product of interest (O’Brien \& Teisl, 2004; Azevedo, Carvalho, \& Cruz Machado, 2011; Abdallah, 2012).

Besides customer satisfaction, pressures from governments and other stakeholders have led business organizations to realize that there is a need to adopt better strategies and tools that can minimize the negative environmental and social effects that their operations produce while seeking economic profitability (Jawad, Jaber, \& Bonney, 2015). Therefore, traditional supply chains need to pay more attention to the environment and society and to switch to the green SCM and later to the sustainable SCM. This thesis defines a society as "a community, nation, or broad grouping of people having common traditions, institutions, and collective activities and interests." ("MERRIAM-WEBSTER," n.d.) According to the same reference, people of a specific society live together in organized communities with shared laws, traditions, and values.

\subsection{Green Supply Chain Management Paradigm}

As a result of climate change, especially global warming, the protection of the environment has become a challenging issue for economic and business organizations. Because the major effects of organizations on the environment frequently occur in their 
supply chain networks, great attention has been paid to rethinking supply chain activities. Organizations face pressure from customers, governments, NGOs and other stakeholders to improve the environmental performance across their supply chains. Environmental performance can be evaluated by using Environmental Performance Indicators (EPIs), which are explained in ISO 14031. EPIs represent the foundation of a Green Supply Chain Management (GSCM) Performance Measurement System (PMS). GSCM is defined as "integration of environmental thinking in supply-chain management, including product design, material sourcing, and selection, manufacturing processes, delivery of the final product to the consumers as well as end-of-life management of the product after its useful life” (Srivastava, 2007, pp. 54-55). However, there are some of the challenges in applying EPI across the supply chain, including overcoming mistrust, lack of understanding, lack of control, different goals and objectives, lack of standardized performance measures, information systems, difficulty in linking measures to customer value (Brewer \& Speh, 2001).

The design focus of the supply chain can be considered as the major tool to differentiate traditional supply chain and green supply chain. Traditional supply chain's objective is to minimize the total cost. On the other hand, a green supply chain strives to minimize its ecological footprint. Ecological footprint simply can be defined as the effect of a person or society on the environment. It can be expressed as the amount of land required to sustain their use of natural resources ("Oxford Dictionaries," n.d.).

GSCM is a corporate strategic priority to assist firms to achieve their objectives of profit and market share by reducing the negative environmental impact while improving the environmental performance of these firms (Lai \& Cheng, 2009). Accordingly, GSCM differs 
from the traditional SCM by giving the attribute of "green" to the activities that are performed within a supply chain. For example (Villanueva, García, \& Adame, 2013):

\section{- Green procurement}

It involves the selection of products and services that can minimize the negative environmental impact. It also includes maintaining environmental requirements in contracts or sub-contracts.

\section{- Green design}

The green product design project evaluation provides the decision-making basis, the improvement direction and the information for the product design that requires developing the best product design proposal to satisfy the user, the firm, the environment, and the society (Zhou, Zhang, Zhang, \& Li, 2008).

\section{- Green manufacturing (production)}

It can be viewed in two ways. The first is by using green or intelligent materials, using recycled materials, and minimizing emissions of harmful gasses and discharge of wastes on land and in water. The second way is to manufacture green products that have less negative environmental impacts.

\section{- Green distribution}

It can be achieved by implementing green practices such as:

- Using transportation modes and routes that can minimize the GHG emissions.

- Building distribution centers close to the production plants.

- Scheduling deliveries during non-congested times. 
- Using alternative fuels for transportation and energy resources (wind, solar, etc.) for the distribution centers.

An important strategy in GSCM is Reverse Logistics (RL), which stands for the flow of materials or products back to the supply chain. It includes all the activities that are involved in transferring unwanted, damaged or imperfect products into new materials or products that have a market value. These activities may include reusing, repairing, refurbishing, remanufacturing, upgrading, and recycling. Some of these activities are shown in Figure (1.2). The supply chain can obtain some benefits from RL strategy such as reducing the resource consumption, which can add value from the products' recovery or from reducing the cost of disposal (Ravi, Shankar, \& Tiwari, 2005). Companies can benefit from the implementation of the GSCM through gaining more revenue, reduced costs, or improving the usage of assets, and enhance their reputation and image, thus resulting in better relationships with customers and enhancing the product or service innovations (“BPIR," n.d.). Societies also can gain great benefits from implementation of GSCM best practices. Environmentally, societies can benefit from the reduced waste, increased energy efficiencies, reduced air and water emissions, and reduced fuel consumption; and socially, from the reduced community impacts, minimized traffic congestion through improved transportation management, and better health and safety ("BPIR," n.d.). 


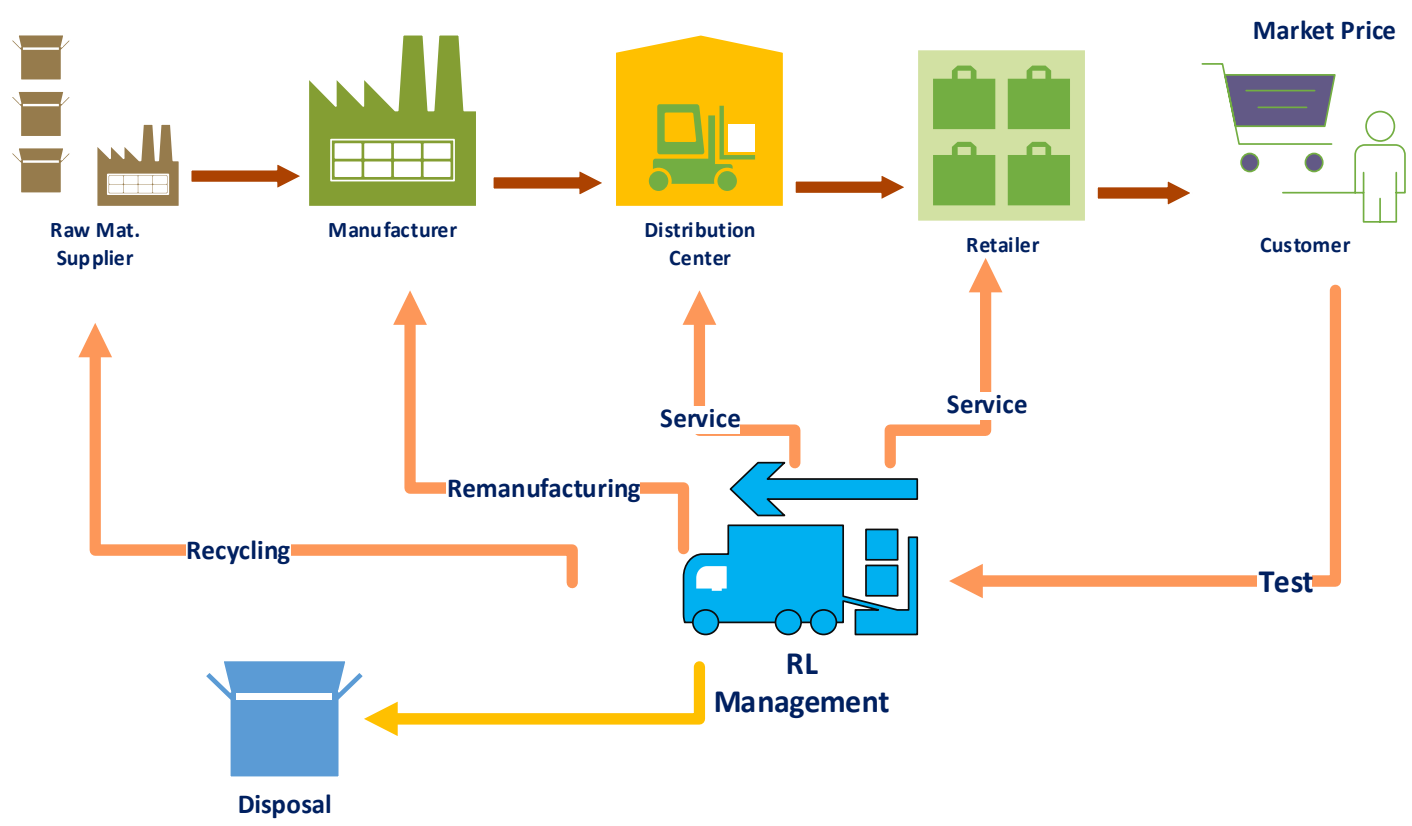

Figure 1.2. The reverse logistics process for an arbitrary product.

Studies that have investigated green supply chain and performance measure systems (PMS) have listed important measures and metrics to help organizations evaluate their environmental performance (e.g., Li, 2011; Shukla, Deshmukh, \& Kanda, 2009; Wu, Ding, \& Chen, 2012).

Benchmarking is a methodology that used to measure and improve organizational performance by comparing an organization's performance with the best of the same industry (Stapenhurst, 2009). There are two types of benchmarking (Kingdom, 1998):

- Metric benchmarking: a quantitative analysis that enables organizations to monitor their internal performance and, then, compare it to the performance of similar organizations. From such comparison targets to be achieved can be defined; 
- Process benchmarking: this type of benchmarks involve the identification of specific processes that need to be improved through step-by-step process mapping and subsequent location of external examples of excellence in the same process to identify the performance level to be achieved.

Ahi and Searcy (2015) developed a conceptual framework for measuring performance in green and sustainable supply chains. The authors stated that it is of importance to admit that no one metric, or set of metrics, will apply equally well in all situations. While the developed conceptual framework provides a clear starting point for this process, it leaves the prioritization of specific metrics to the decision-makers in the focal firm.

Hervani, Helms, \& Sarkis (2005) developed a model to assist organizations to evaluate their environmental performance which lays a foundation of the GSCM/PMS by using the ISO 14031 guidelines. The authors introduced a wide range of metrics related to environmental performance, such as:

- The discharges to water streams, lands, publicly owned treatment works and underground by injection.

- The source reduction activities.

- Improve habitats and minimize damage to habitats that arise from the organization's operations.

- The amount of unfinished product returned to the process by recycling or reusing.

- The evaluation of life cycle impacts. 
- Take actions to avoid or reduce the negative impacts of the products and services provided.

- Design the product or service to have less negative life cycle impacts.

A major technique to evaluate the environmental performance of a product is the Life Cycle Assessment (LCA). The life cycle of a product embraces all of the activities that go into making, transporting, using and disposing of that product. The typical life cycle consists of a series of stages running from extraction of raw materials, through design and formulation, processing, manufacturing, packaging, distribution, use, re-use, recycling and, ultimately, waste disposal (Jensen, Hoffman, Møller, \& Schmidt, 1998, pp. 9). LCA is a useful technique to determine both the material and energy inputs and outputs to and from the environment throughout the product's life. From the definition of LCA, it can be concluded that the best green product has fewer emissions of pollutants (to air, water, and soil) in addition to a lower consumption of raw materials, and/or other natural resources. Figure (1.3) shows a schematic diagram of an LCA for an arbitrary product.

Some of the LCA benefits may include, but are not limited to, the ability to evaluate the material and energy efficiency of a system, identify pollution shifts between operations as well as other trade-offs in materials, energy, and discharges, and the ability to provide benchmarks for improvement (Owens, 1997). Implementation of the LCA can assist supply chains to discover which areas of their product's life cycle can be improved. Even though LCA is a powerful tool to assess the environmental impacts of products/services, some important limitations have been identified: data quality and collection, the definition of the 
system, time boundaries, and process modeling (De Benedetto \& Klemeš, 2009). However, my study does not focus on the LCA approach, which might be considered for future work.

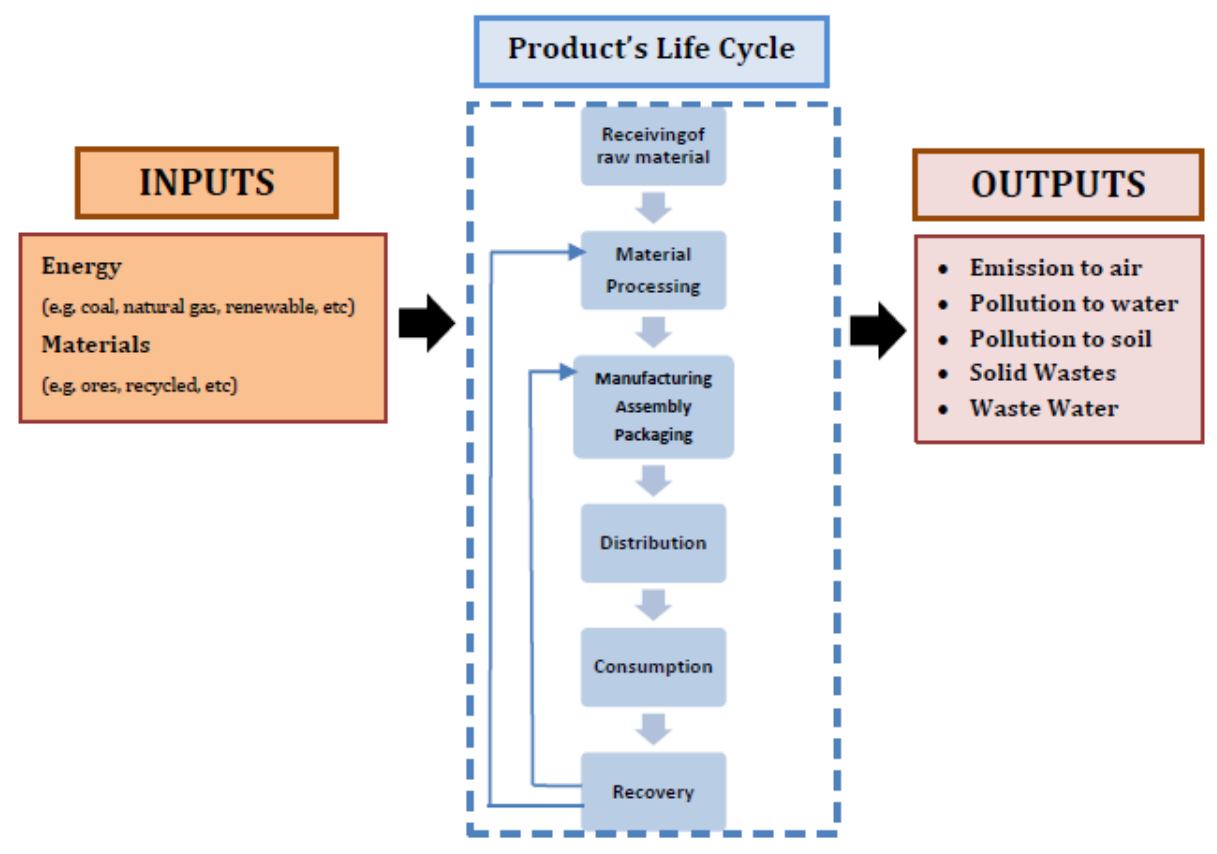

Figure 1.3. Schematic diagram illustrates the LCA for an arbitrary product.

\subsection{Sustainable Supply Chain Management Paradigm}

Dealing with money and the environment may raise the following questions:

Where is the human aspect in these strategies?

Is it wise to neglect the reciprocal impact and effect of humans and businesses on each other?

In 1972, the UN called for the United Nations Conference on the Human Environment, which was held in Stockholm (Sweden), to bring the attention of the 
developing and industrialized countries to define the human rights to a healthy and energetic environment. This conference can be considered as one of the first steps taken towards the Sustainable Development (SD). SD was defined by the World Commission on Environment and Development (WCED) as the " development which meets the needs of the present without compromising the ability of future generations to meet their own needs" (McGregor, Barker, \& Evans, 1998, pp.6).

Sustainability means creating an economic system that provides for quality of life while renewing the environment and its resources ("Sustainability Store," n.d.). Hence, a sustainable society is one that resembles a living system where all the resources (human, natural, and economic) are renewed and in balance for perpetuity ("Sustainability Store," n.d.).

The "big three" reasons for addressing the sustainability today can be detailed as follows (Mckee, Kemp, \& Spence, 2012):

(1) The global economic crises that are caused by changes in some important financial policies in certain areas around the world, which negatively impacted societies and businesses.

(2) Climate change and the potential impacts of it on societies and businesses.

(3) The ruined lives of many people that are caused due to the unethical business practices and lack of wise judgments.

The above "big three" reasons address the importance behind the SD, which focuses on the growth of the following three aspects in an equitable manner:

(1) Economic growth: mostly focuses on balancing the economy with ecosystems; 
(2) Environment growth: raises concerns about environment protection;

(3) Social growth: focuses on the social prosperity of humans.

In the turbulent environment of today's business, stakeholders of an organization may play a major role in long-term value creation (Maurer \& Sachs, 2005). It is worth explaining briefly the stakeholders' role related to the performance of a business organization, and accordingly to the supply chain. Freeman and Reed (Freeman \& Reed, 1983) proposed two definitions for "stakeholders," wide and narrow sense of stakeholders. They defined the wide sense of stakeholders as "any identifiable group or individual who can affect the achievement of an organization's objectives, or is affected by the achievements of an organization's objectives” (Freeman \& Reed, 1983, pp. 91). Examples of this broad category are the public interest groups, protest groups, government agencies, trade associations, competitors, unions, as well as employees, customers, and shareholders. While, the narrow sense has been defined as "any group or individual on which the company is dependent for its continued survival" (Freeman \& Reed, 1983, pp. 91). This type of stakeholder may include employees, banks, and financial institutions, shareholders (for publicly-held corporations), suppliers, customers, local communities where their facilities are located.

Developing sustainable actions in the supply chain networks is a key issue for global business firms. Due to the pressures from governments, customers, and other stakeholders, business firms begin seeking new initiatives to moderate their negative environmental and social impacts while at the same time remaining profitable. The pressure from various stakeholders encourages these networks to implement the major principles of Supply Chain 
Sustainability (SCS). These principles are based on the ten principles of the UN Global Compact, which are classified as such ("UN Global Compact," n.d.-a):

- $\quad$ Human Rights

- Principle 1: Businesses should support and respect the protection of internationally proclaimed human rights.

- Principle 2: Make sure that businesses are not complicit in human rights abuses.

- Labour

- Principle 3: Businesses should uphold the freedom of association and the effective recognition of the right to collective bargaining.

- Principle 4: The elimination of all forms of forced and compulsory labour.

- Principle 5: The effective abolition of child labour.

Principle 6: The elimination of discrimination in respect of employment and occupation.

\section{- Environment}

- Principle 7: Businesses should support a precautionary approach to environmental challenges. A precautionary approach can be a systematic application of risk assessment, management, and communication. In another word, when there is reasonable suspicion of harm, decision-makers need to apply precaution and consider the degree of uncertainty that appears from scientific evaluation (Kingdom, 1998).

- Principle 8: Undertake initiatives to promote greater environmental responsibility.

Principle 9: Encourage the development and diffusion of environmentally friendly technologies. 


\section{- Anti-Corruption}

Principle 10: Businesses should work against corruption in all its forms, including extortion and bribery.

With the integration of the Global Compact principles into strategies, policies, and procedures, and promoting a culture of integrity, business firms can uphold their basic responsibilities to people and planet, as well as set the stage for long-term success ("UN Global Compact," n.d.-b).

There are also many incentives that promote the implementation of sustainable practices. Such incentives are tax exemptions, loan assistance, government grants, equipment purchasing assistance, public recognition of participants, the use of a program logo, individualized technical assistance, free advertising and others (Kimberly S. Goetz, 2010). Several studies motivated the push for sustainable supply chains (e.g., Adriana, 2009; Foerstl, Reuter, Hartmann, \& Blome, 2010). These include, but are not limited to, the following factors:

- Pressure from investors, consumers, and NGOs.

- Regulations, rules, and laws.

- Environmental and social crisis.

- Links between sustainability and health, safety, and productivity of staff.

- Links between sustainability, product sales, business competition, and reduced costs and increased operational efficiency associated with the SCS.

A systematic review, synthesizing 194 studies spanning 25 years of research on sustainable supply chains (Brammer, Homose, \& Millington, 2011), by the Network for 
Business Sustainability (NBS) has claimed that several factors can play a role in shaping the desire of business firms to address sustainability in their supply chains. Amongst the most prevalent motivations are a desire to maintain customer satisfaction (26\%), risk management (19\%), compliance with regulation/legislation (14\%), managing a firm's reputation (14\%), and creating a competitive advantage (7\%). They also claimed additional factors, which include cost reduction, moral obligation, protecting the brand, responding to social pressure, market access and improved productivity/efficiency. Although some definitions of sustainable supply chain management (SSCM) provide noticeable overlap with definitions of green supply chain management (GSCM), it is evident that SSCM is an extension of GSCM (Ahi \& Searcy, 2013). The authors also stated that while the integration of environmental aspect into SCM policies have been found to be the major concern in most of the definitions of GSCM, the definitions of SSCM adopted a deeper triple bottom line perspective.

Sustainable supply chain management is generated by the joint implementation of both the socially responsible supply chain management (SRSCM) and the environmental (green) supply chain management (ESCM) and the organizational financial performance ( Wang \& Sarkis, 2013). They defined SRSCM and ESCM as the activities that are performed by an organization to manage the supply chain system, from material sources to customer service, to be socially and environmentally responsive, respectively. Although many definitions of SSCM can be found in the literature, this study adopts the definition of the "Business for Social Responsibility - UN Global Compact" (United Nations Global Compact, 2011), who defined SSCM as: 
The management of environmental, social and economic effects and the encouragement of good governance practices, throughout the lifecycles of products and services.

Formentini \& Taticchi (2016) defined the sustainable supply chain governance mechanisms as any practice, initiative and process that are used by the central organization to manage relationships with (1) internal functions and departments (internal governance) and (2) their supply chain members and stakeholders (external governance) with the objective of implementing their organization's sustainability strategy in a successful way. Governance is not a decision-making nor management style; it is a framework where decision making is made for any system (Crisan, Parpucea, \& Ilies, 2011).

\subsubsection{How to achieve a sustainable supply chain?}

A major concern for a business organization is to maximize profits for both the organization and its stakeholders. On the other hand, with the development of globalization and international business implementation, the concept of sustainability has become more necessary for organizations ( $\mathrm{Li} \& \mathrm{Ye}, 2014)$. There is no single globally defined and accepted strategy to achieve business sustainability. It is an open door for business organizations to innovate and create efficient strategies towards sustainability to gain the approval of customers and other stakeholders. Accordingly, it seems hard to set a specific strategy that can be followed to achieve the sustainable supply chain. However, the potential impacts of any activity across the entire supply chain should be considered and analyzed under "all" three pillars of sustainable development: economic, social and environmental. Supply chain management can be improved in numerous ways that differ in the level of 
complexity and technology, and the required investment. But they all need important factors that on there own can make essential changes: individuals and their attitudes towards managing effects rather than ignoring impacts, encouraging learning rather than assuming ignorance, and improving standards rather than minimizing expectation (Cuthbertson et al., 2011). Figure (1.4) gives some "examples" of the practices that should be considered across a supply chain to move towards sustainability. These practices are not only internal to an organization within a supply chain, but also external to consider the entire supply chain.

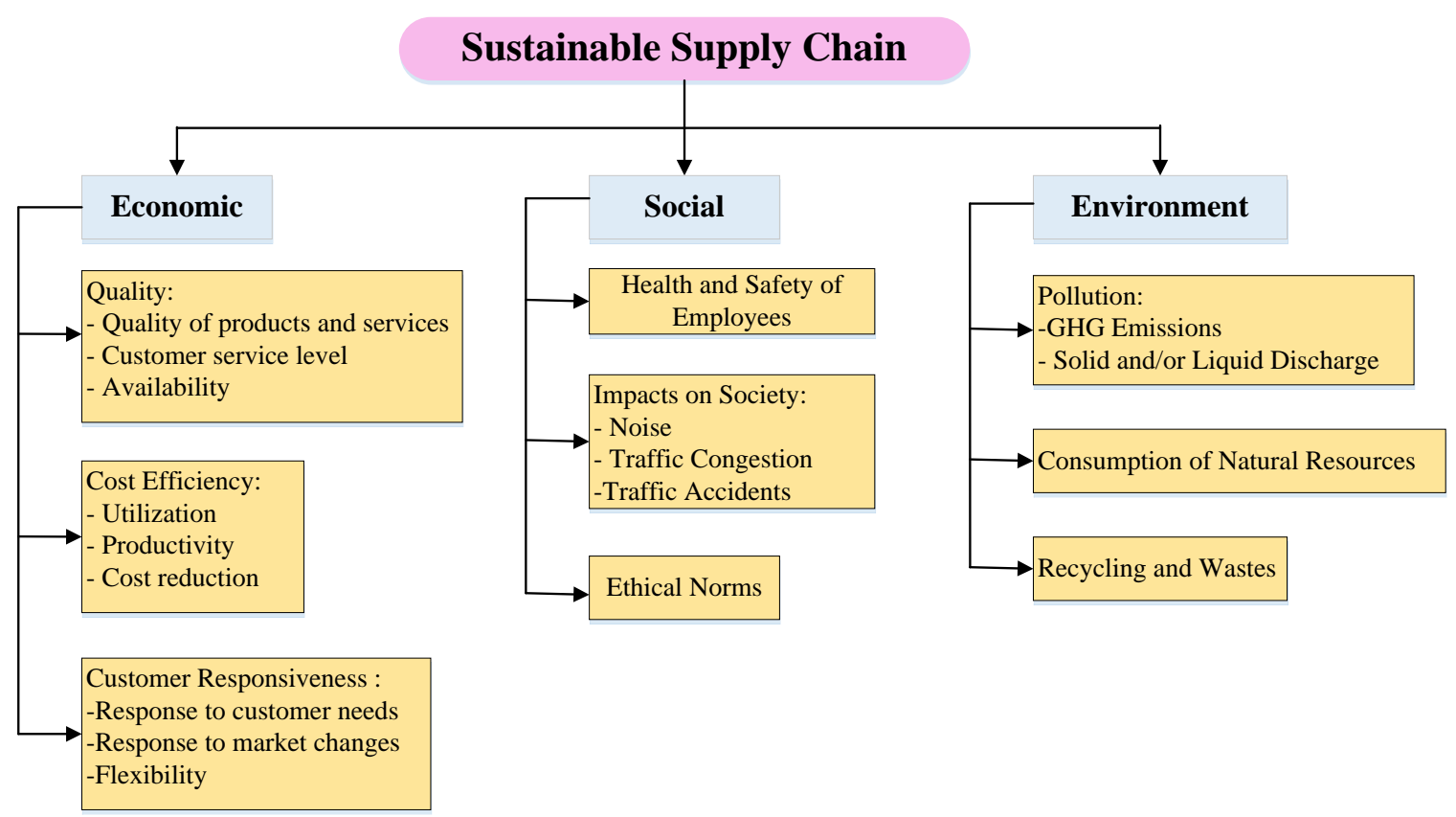

Figure 1.4. Practices that should be considered to move towards a sustainable supply chain (based on (Cuthbertson et al., 2011). 


\subsection{Review of the Literature}

\subsubsection{Literature Review on Green Supply Chain}

In this section, some relevant literature has been reviewed, and the important and relevant information to this dissertation is summarized. Although terms such as "environment" or "greening" have an ambiguous meaning in various fields, these terms -in business- mean the integration of the environmental performance measures of an organization with the expectations of its stockholders in addition to establishing new sources of competitive advantage such as lower costs and expanded market share (Gupta, 1995).

Gurtu, Searcy, \& Jaber (2015) analyzed the keywords used in the literature relating to supply chains with a focus on environmental issues. The authors reviewed 629 papers that were identified through searches of 13 keywords on green supply chains, such as the most frequently used journals/keywords, their frequencies, citation frequency, and research contribution from different disciplines/countries. They found that the use of the terms "green supply chains" and "sustainable supply chains" is increasing, and the use of "reverse logistics" is decreasing. They claimed that the increase in the usage of the term "green supply chains" indicates that there has been an increase in focus on environmental issues in supply chains.

Seuring (2013) provided a review of the status of research on sustainable supply chain management that applies mathematical modeling techniques for the period 1998-2013. More than 300 research papers have been published in which they discussed the subject of green or sustainable supply chains, whereas only 36 papers applied quantitative models. A fraction (4/36) of papers are the only ones who mentioned the social aspect of sustainable 
supply chain management. The author claimed that the environmental dimension clearly dominates, and social aspects are widely ignored or interpreted in an unusual manner. LCA type studies and respective data form the cornerstone of the environmental debate in the studies, while minimization of the cost dominates the economic dimension.

Searcy (2016b) conceptualized enterprise sustainability as being deeper than the concept of corporate sustainability. The author claimed that enterprise sustainability requires the consideration of the focal firm, its supply chain and the sustainability context within which the firm operates. Accordingly, efforts to determine enterprise sustainability must account for all three of the above components. The paper provided a summary of the key requirements and 35 associated sub-requirements. These requirements were derived based on the proposed definitions of the enterprise sustainability and the enterprise sustainability performance measurement systems (ESPMS).

Arslan \& Turkay (2013) revised the EOQ model to account for added environmental and social dimensions of sustainability as well as the economic one. To account for the social impact in modified EOQ model they used working hours as a social metric, while they used $\mathrm{CO}_{2}$ emissions an environmental metric. The authors showed how these additional metrics could be attached to the traditional cost to achieve the sustainable supply chain management. They proposed several managerial insights that can be useful for decision and policy makers.

Tachizawa \& Wong (2014) provided a framework for studying sustainability in multi-tier supply chains that surpass the one-tier buyer-seller relationships to provide a roadmap for future studies on this topic. They also provided theoretical propositions that explain the effects of merging various governance mechanisms, practices, and contingency 
factors to the sustainable supply chain management. The paper addressed several issues that face supply chain and sustainability managers, especially when it comes to the power of a lead firm in influencing the lower-tier suppliers, the effective ways the relationships with the lower-tier suppliers can be managed, and the different capabilities required when managing multiple parties. The authors pointed out some of the critical managerial implications such as supplier selection, purchasing processes, and production location.

van Hoek (1999) stated that all members of a supply chain could play a role in greening the supply chain. He claimed that the ecological footprint of a supply chain is far broader than to be only nation-based, so the footprint should be measured against different indicators than the original footprint measure. Hence, a set of performance measures relevant to the performed activities should be identified for each member. Examples of such measures include materials that can be selected against emissions rate and energy consumption standards, and their-use of materials can be measured against the percentage of "virgin" or new materials used in items production.

Chen, Benjaafar, \& Elomri (2013) analytically supported the concept that it may be possible, by operational adjustments alone, to notably reduce $\mathrm{CO}_{2}$ emissions without greatly increasing cost. Employing the EOQ model, the authors provided a condition that can assist in reducing $\mathrm{CO}_{2}$ emissions by modifying order quantities. They also provided conditions causing a relative reduction in $\mathrm{CO}_{2}$ emissions greater than the relative increase in cost and discuss some factors that affect the difference in the magnitude of emission reduction and cost increase. The results showed that it is possible to reduce $\mathrm{CO}_{2}$ emissions through operational adjustments as far the operational drivers of emissions are different from the operational drivers of costs. 
Tsoulfas \& Pappis (2008) developed a model that defines several environmental performance indicators that cover most activities in a typical supply chain to evaluate its environmental performance. The authors stated that evaluating the environmental performance of a supply chain based merely on the proposed environmental performance indicators is not sufficient to provide the effective environmental evaluation of the supply chain that can support managerial decision-making. Hence, they introduced a multi-criteria decision-making methodology that can provide the required support for managerial analysis and decision-making.

El Saadany, Jaber, \& Bonney (2011) employed a coordinated two-level (vendor and buyer) supply chain model to present a creative technique that optimizes profits while considering green features of the supply chain by reducing the environmental costs and improving the system's environmental performance. The authors developed a model that studies the relation between the supply chain and environment needs. The model considered a supply chain profit function where demand is price and quality dependent. They integrated mathematical relations that related to the environmental effects. Results found that accounting for hard-to-quantify environmental costs leads to a minimum price that does not necessarily correspond to maximum profit. However, as environmental costs decrease the total profit increases and the total cost decreases. This shows the importance of lowering the environmental costs. The results also showed that traditional cost accounting methods lack the flexibility to consider qualitative environmental measures.

Abdallah (2012) considered carbon trading and green procurement to present an approach to greening the supply chain. The authors formulated a mixed integer program that minimizes the sum of the traditional supply chain costs and carbon trading costs for three 
different scenarios. The results showed that greener supply chains tend to be decentralized with smaller facilities. On the other hand, the life cycle assessment indicated that production plants are where most of the carbon emissions and resource consumption occur. Consequently, big industrial plants should focus on greening their supply chain by the implementation of green manufacturing technologies and reducing the environmental effects of their transportation. However, as the carbon price increases, there are more rewards for supply chains to consider mounting solar photovoltaics to their facilities.

Pan, Ballot, \& Fontane (2013) studied the environmental impact of pooling on the supply chain. They proposed a supply network-pooling model to reduce the greenhouse gas emissions from freight transport. The optimization model consists of two large retail chains used to compute carbon dioxide $\left(\mathrm{CO}_{2}\right)$ emissions from transport. They concluded that joint road and rail transport is a significant way to reduce $\mathrm{CO}_{2}$ emissions.

\subsubsection{Literature Review on Sustainable Supply Chain}

Ahi, Searcy, \& Jaber (2016) identified and analyzed the metrics that have been used to address energy-related issues in GSCM and SSCM. They identified a total of 113 energyrelated metrics obtained from the analysis of 115 peer-reviewed articles. The authors found that only three metrics were used more than ten times, which are: "energy use" (24 times), “energy consumption" (21 times), and "energy efficiency" (11 times). Most the metrics were used only once ( 73 metrics) or twice ( 29 metrics). The authors also found that there is a lack of agreement on how energy-related issues should be measured in GSCM and SSCM. 
Carter \& Rogers (2008) introduced the concept of sustainability to the logistics literature by integrating the environmental, social, and economic aspects that can assist an organization in reaching long-term economic growth. The authors presented a framework of SSCM that comprised the concepts of both sustainability and SCM, which can provide a starting point for a common understanding of SSCM among supply chain managers. The proposed framework is based on the triple aspects of sustainability and four supporting features of sustainability that includes risk management, transparency, strategy, and culture.

Vachon \& Mao (2008) defined supply chain strength as the availability and quality of the organizations that compose the supply chain, in addition to the value added by the interaction among them. After that, authors established a link between supply chain strength and the three aspects of sustainable development namely environmental performance, corporate environmental practices, and social sustainability at the country level. They found that supply chain strength is positively linked to all three dimensions of sustainable development.

Carter \& Easton (2011) claimed that the advantageous position of supply chain managers, in particular, can affect - positively or negatively - environmental and social performance of the supply chain. For instance, supply chain managers can play a role in the selection and development of suppliers, selection of transportation modal and carrier, vehicle routing, location decisions, and packaging choices. They described SSCM as the enduring strategy. Furthermore, based on the deep concept of sustainability and the key interfaces that sustainability has with supply chain management, the authors suggested that sustainability should be a license to do business in the twenty-first century. Moreover, SSCM is to be an integral element of this license. 
Hassini, Surti, \& Searcy (2012) provided a definition for SSCM as the management of operations, resources, information, and funds through the supply chain to maximize the profitability, minimizing the environmental effects and maximizing the social well-being (how the supply chain treats its employees, customers and the community at large). Therefore, organizations that practice sustainable supply chain management strive to satisfy multiple, but possibly conflicting objectives that can add to the supply chain's operational costs. Furthermore, they have reviewed research on sustainable supply chain management with a focus on studies that were published in the last decade. Based on the results of the reviewed literature they have developed a framework for sustainable supply chain management.

Zailani, Jeyaraman, Vengadasan, \& Premkumar (2012) stated that SSCM could be a good strategy for supply chains to extend their responsibility. SSCM can assist in switching from being reactive in reducing emissions and waste and other sustainable related tasks, to proactive by undertaking full responsibility for their products from the supply of raw materials to the final disposal of the products from a sustainability scene. The author claimed that SSCM practices could bring value to both organizations and the environment. They will lead to a reduction in resources, materials, and waste, which enables better resource utilization, and plays a major role in achieving the "triple bottom line" of social, environmental, and economic performance. Thus, SSCM can contribute to the sustainable development of the nation where the supply chain is located.

Ortas, Moneva, \& Álvarez (2014) investigated the link between a sustainable supply chain performance and organizations' financial performance and provided empirical evidence about the relationship between these two constructs. The authors showed that the 
relation between sustainable supply chain performance and financial performance is not constant but changes with the conditions of the macroeconomic and geographic location. They found general bidirectional causality between sustainable supply chain performance and organizations' margins and revenue. They also found that a sustainable supply chain could perform as a driver with a considerable impact on financial performance. Moreover, they claimed that organizations could gain some benefits from increasing sustainable supply chain performance. The benefits include increased efficiency, higher product quality, lead on competitors and legislation, access to new markets, increased employee motivation and satisfaction, and improved public relations.

Xu \& Gursoy (2015) suggested that all sustainability practices of a supply chain could increase customer satisfaction, which can cause higher customer loyalty, and eventually an increased willingness to pay higher prices. They stated that despite the higher costs for a supply chain in the short term to implement any sustainability practices, organizations might gain some benefits in the long term due to the improved performance of the organization.

Tseng \& Hung (2014) highlighted the effects of considering the social costs of carbon dioxide $\left(\mathrm{CO}_{2}\right)$ emissions caused by the process of production and transportation of a product in a supply chain. They have presented a generic mathematical model considering both the operational and social costs of $\mathrm{CO}_{2}$ emissions to assist decision makers in supply chain management in estimating more practical operational costs. The authors claimed that the proposed model could serve as a useful reference for legislators in estimating the monetary loss resulting from $\mathrm{CO}_{2}$ emissions in the operations of supply chain networks. 
The results also suggested that legislation compelling the organizations to afford the social costs of $\mathrm{CO}_{2}$ emissions resulting from their economic activities is an effective approach to reducing carbon dioxide emissions. Also, it has been shown that the higher the social cost rate of carbon dioxide emissions, the lower the amount of the emission of carbon dioxide.

Ni, Li, \& Tang (2010) integrated Corporate Social Responsibility (CSR) in a twoechelon supply chain consisting of a supplier and a buyer that is engaged by a wholesale price contract. The authors conducted some game-theoretical analyses resulting from different interaction schemes between the supplier and the buyer to derive their corresponding equilibriums. Also, they carried out comparative institutional analyses to determine the optimal social responsibility distributions based on both economic and CSR performance criteria. The following results have been found: (1) the supplier is to hold the responsibility with convenient restrictions on the corresponding rights to measure the wholesale price; (2) a conflict between the economic and CSR performance criteria, which causes the two maxima cannot be achieved together; (3) the total profit of the supply chain can be improved by implementing optimal social responsibility distribution schemes.

Hutchins \& Sutherland (2008) reviewed numerous metrics and indicators of social sustainability and corporate social responsibility as well as their classifications. They linked the monetary activity of supply chains to the indicators of social sustainability on a national scale. The author demonstrated that an individual corporate decision could affect national measures of sustainability. The authors proposed several indicators of corporate social sustainability, which were subsequently employed in an example to demonstrate how decisions can be made to improve the social sustainability of a supply chain. Their study contributed to the literature by explaining the techniques of merging the social dimension of 
sustainability into business decision-making. They strongly suggested characterizing the relationship between business activities and social impacts by identifying the critical variables, establishing the conditions under which the models are valid, and developing a process for weighting the indicators. They claimed that the only way to make progress on the path to sustainability is through a better understanding of the linkages between business and society.

Awaysheh \& Klassen (2010) explored the integration of social issues in the management of supply chains from an operations management perspective. The authors developed and empirically validated some scales to measure multiple dimensions of socially responsible supplier practices. They identified four dimensions of socially responsible practices that are related to the supplier; human rights, labour practices, code of conduct, and social audits. They found that increasing transparency, as indicated in greater product visibility by the costumers, was related to the increased usage of supplier human rights, which in turn can assist in protecting an organization's brand. Empirically, they found that firms located closer to the raw material supplier are more likely to put the supplier code of conduct in place. They also claimed that when all members of a supply chain are located in societies with similar cultures, possible changes to operations are straightforward as managers in all firms (members) are from similar cultural experiences. In contrast, if the central firm is located in a society that is different than that of the other members (e.g. developed vs. developing countries), then it must conform to cultural expectations (and regulations) in its local market, which may not be understood by suppliers.

Cruz (2013) investigated the effects of the globalization of a supply chain on corporate social responsibility (CSR). The author developed a framework for the modeling 
and analysis of a global supply chain network with corporate social responsibility (CSR) through integrated environmental decision-making and risk management. He modeled a multi-criteria decision-making behavior of the various supply chain's members such as manufacturers, retailers, and costumers. The model maximizes profit and minimizes emissions and risk then measure the impact of globalization on supply chains' CSR decisionmaking and analyzes the effects of CSR on product prices and flows, and the global supply chains efficiency. Results show that a socially responsible global supply chain network is more efficient than a less responsible one, and the higher is the level of social responsibility of the supply chain the lower is the price of the product, and therefore the higher is the demand for the product.

Pascale (2012) claimed that energy is important for economic growth because production is a function of capital, labour, and energy, which is at odds with the mainstream growth models or some biophysical production models would indicate. The author explained that there are two opposing points of view of economists: first is that of mainstream economists who think that technological innovation can solve the degradation in the quality of both energy and materials and that therefore growth can go on forever. Second, are biophysical economists who employ the thermodynamic laws to prove that mainstream economists do not integrate long-term sustainability in their models. She claimed that accounting for the entropy generation in all economic models would show different results of the efficiency of standard industrial processes, and the only way to achieve sustainable development is by improving the quality of economic growth instead of encouraging just economic growth. 
Abraham, Suganthi, \& Samuel (2006) presented an environmental tax based on exergy analysis as proportional to the exergy loss (entropy generated), and it becomes an incentive for the manufacturers to introduce proper modifications in the design of components and/or equipment they produce to reduce the exergy losses or entropy generated. They called it Entropy Added Tax (EAT). Consumers could benefit from EAT by comparing its value to similar products and judge about their environmental impact.

Stougie \& van der Kooi (2016) criticized some of the major sustainability assessment techniques found in the literature to appear as incomplete on the list of requirements. The environmental LCA methods are partially objective because they use weighting factors, and no consensus exists about all models used for quantifying environmental impact. The economic methods exclude some indirect costs, and their indicators change over time because of market developments. The social methods experience the lack of data and their qualitative nature. The exergy analysis techniques found in the literature do not account for all aspects of sustainability and/or they employ indicators, equations and weighting factors that are not accepted. The author, therefore, developed a new exergy analysis method based on the calculation of exergy losses and it accounts for all exergy losses that are caused by the technological system including its supply chains. It has been named the Total Cumulative Exergy Loss (TCExL) method.

Gurtu, Searcy, \& Jaber (2016) analyzed the effects of overseas outsourcing at a macro level for a society to address the research question if overseas outsourcing correlates with economic growth and prosperity of the people at large and in the long run for an outsourcing society, by analyzing various economic indicators. As an example, the author used the USA and Germany, to explain how the financial condition of society (e.g., increase 
in national debt and budget deficit) can be affected by the overseas outsourcing and how this affects society. Particularly, the authors focused on the changes in employment and imports related to overseas outsourcing. The analyses showed that while imports related to offshore outsourcing have been increasing, a steady decline in employment in manufacturing, as well as a decline in collection of revenue from import duties, is evident. They suggest the need to promote local/regional manufacturing in/near the country of consumption.

\subsection{Research Gaps}

Although sustainable supply chains have become an established line of research whose coverage can improve several areas, including the consumption of natural and human resources, and destination of sourcing and hidden costs in term of wastes, several research gaps still exist, such as:

1. Lack of inventory models that account for "all" of the three pillars of sustainability. Excluding the social aspect from such models makes any developed inventory model to tend to become more "Green" than the "Sustainable" model. There is no exergy analysis method in the literature that takes into account all relevant aspects of the life cycle of a process or product (Sciubba, Manfrida, \& Desideri, 2012).

2. Selection between domestic and overseas sources is mostly based on the paid cost of products only. Other selection criteria such as environmental and social costs are of less attention.

3. Lack of metrics or indexes that numerically measure the sustainability across a supply chain. Such metrics or indexes are of importance to determine the level of 
sustainability a supply chain has. It can also provide oversight for the areas where improvement of the level of sustainability is needed.

Table (1.1) shows the relevant studies that have considered the term of "Sustainability" and how they differ from the work in this thesis. Most of these studies did not introduce analytical models that can deal with all the three pillars of sustainability together. Exergy as a thermal property was the core of the few studies that investigated in SCM. A significant number of studies considered only the economic and environmental aspects of sustainability without considering the social aspect. However, there are some recognized studies that implemented the rules of heat transfer in inventory and logistics systems. Despite this, they did not implement the laws of thermodynamics and exergy analysis, but their results were significant for the studies which will be presented in the coming chapters.

The headings of Table (1.1) have been selected carefully to show a meaningful comparison between what has been done in literature with the work of this dissertation and to show the importance of the items mentioned in the headings in the journey towards a sustainable world. The importance of these items has been studied and investigated in this dissertation. 
Table 1.1. Some of the studies that have considered the term of "Sustainability."

\begin{tabular}{|c|c|c|c|c|c|c|c|c|c|c|c|c|c|}
\hline Paper & 离 & 秥 & $\sum_{n}$ & 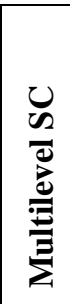 & 总 & 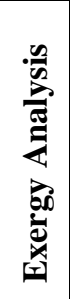 & 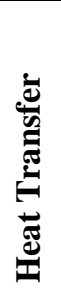 & 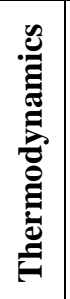 & 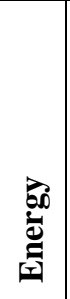 & 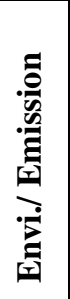 & 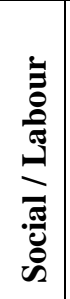 & 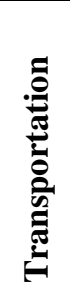 & 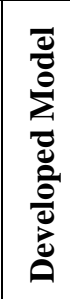 \\
\hline $\begin{array}{l}\text { Apaiah, Linnemann, \& van } \\
\text { der Kooi (2006a) }\end{array}$ & $\checkmark$ & & $\checkmark$ & & & $\checkmark$ & & & & & & & \\
\hline $\begin{array}{l}\text { Stougie, Van der Kooi, \& } \\
\text { Stikkelman (2012) }\end{array}$ & $\checkmark$ & & $\checkmark$ & & & $\checkmark$ & & & $\checkmark$ & $\checkmark$ & $\checkmark$ & & \\
\hline $\begin{array}{l}\text { Jaber, Nuwayhid, \& Rosen } \\
\text { (2004) }\end{array}$ & & & $\checkmark$ & & $\checkmark$ & & $\checkmark$ & & & & & & $\checkmark$ \\
\hline $\begin{array}{l}\text { Nuwayhid, Jaber, Rosen, \& } \\
\text { Sassine (2006) }\end{array}$ & & & & & $\checkmark$ & & $\checkmark$ & & & & & & $\checkmark$ \\
\hline Arslan \& Turkay (2013) & & & $\checkmark$ & & & & & & $\checkmark$ & $\checkmark$ & $\checkmark$ & & $\checkmark$ \\
\hline $\begin{array}{l}\text { Jaber, Nuwayhid, \& Rosen } \\
\text { (2006) }\end{array}$ & & & $\checkmark$ & $\checkmark$ & $\checkmark$ & & $\checkmark$ & & & & & & $\checkmark$ \\
\hline $\begin{array}{l}\text { Battini, Persona, \& } \\
\text { Sgarbossa (2014) }\end{array}$ & & & $\checkmark$ & & & & & & $\checkmark$ & $\checkmark$ & & $\checkmark$ & $\checkmark$ \\
\hline $\begin{array}{l}\text { Jaber, Saadany, \& Rosen } \\
\text { (2011) }\end{array}$ & & & $\checkmark$ & & $\checkmark$ & & $\checkmark$ & & & & & & $\checkmark$ \\
\hline Jaber \& Zolfaghari (2008) & & & $\checkmark$ & $\checkmark$ & $\checkmark$ & & $\checkmark$ & & & & & & $\checkmark$ \\
\hline $\begin{array}{l}\text { Bouchery, Ghaffari, Jemai, } \\
\text { \& Dallery (2012) }\end{array}$ & & & $\checkmark$ & $\checkmark$ & & & & & & $\checkmark$ & $\checkmark$ & & $\checkmark$ \\
\hline $\begin{array}{l}\text { Jaber, Bonney, \& Moualek } \\
\text { (2009) }\end{array}$ & & & $\checkmark$ & & $\checkmark$ & & $\checkmark$ & & & & & & $\checkmark$ \\
\hline $\begin{array}{l}\text { Jaber, Zanoni, \& Zavanella } \\
\text { (2013) }\end{array}$ & & & $\checkmark$ & & $\checkmark$ & & $\checkmark$ & & & & & & $\checkmark$ \\
\hline
\end{tabular}




\begin{tabular}{|c|c|c|c|c|c|c|c|c|c|c|c|c|c|}
\hline Paper & $\begin{array}{l}\text { X } \\
\text { U }\end{array}$ & 저조․ & 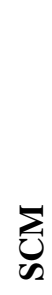 & 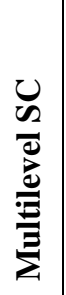 & 产 & 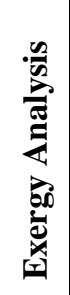 & 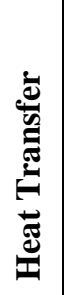 & 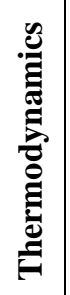 & 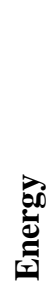 & 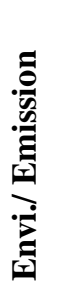 & 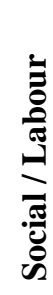 & 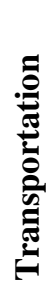 & 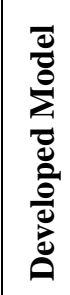 \\
\hline $\begin{array}{l}\text { Chaabane, Ramudhin, \& } \\
\text { Paquet (2010) }\end{array}$ & & & $\checkmark$ & & & & & & & $\checkmark$ & & & $\checkmark$ \\
\hline $\begin{array}{l}\text { Jaber, Zanoni, \& Zavanella } \\
\text { (2014b) }\end{array}$ & & & $\checkmark$ & $\checkmark$ & $\checkmark$ & & $\checkmark$ & & & & & & $\checkmark$ \\
\hline $\begin{array}{l}\text { Bazan, Jaber, \& Zanoni } \\
\text { (2015) }\end{array}$ & & & $\checkmark$ & $\checkmark$ & & & & & $\checkmark$ & $\checkmark$ & $\checkmark$ & $\checkmark$ & $\checkmark$ \\
\hline This Dissertation & $\checkmark$ & $\checkmark$ & $\checkmark$ & $\checkmark$ & $\checkmark$ & $\checkmark$ & $\checkmark$ & $\checkmark$ & $\checkmark$ & $\checkmark$ & $\checkmark$ & $\checkmark$ & $\checkmark$ \\
\hline
\end{tabular}

\subsection{Research Limitations}

- The accuracy of the assumptions has been made for each inventory model.

- The accuracy of the results depends on the assumptions made when applying EEA to the inventory system.

- The lack of data related to the calculation of the total exergy input of society, the amount of exergy embodied in the labour force, and the exergy of the raw materials and energy used to produce a product. However, those data, despite their shortage, are of a reasonable accuracy that can result in accurate results that can provide a reasonable level of confidence to the models developed in this thesis.

However, the works presented in this thesis have been validated with Jaber et al. (2004) to present the analogy between thermal and inventory systems. On the other hand, the concept of EEA has been validated with the works of Rocco, Colombo, \& Sciubba 
(2014); Sciubba, Bastianoni, \& Tiezzi (2008); Peiró, Méndez, Sciubba, \& i Durany (2010) and Chen \& Chen (2009). The model is valid from a thermodynamic point of view (Andresen \& Gordon, 1992; Grubbström \& Hultman, 1989). The validation process typically involves answering questions such as (Simchi-Levi et al. 2008): does the model make sense, is the data consistent? Can the modeled results be fully explained? Was sensitivity analysis performed? These questions have been considering while establishing the models presented in my study.

A Dynamic validation method is often quantitative and includes evaluating the numerical results and the data of the executable model (Koivula, 2015). Sensitivity analysis is an example of dynamic validation methods. It analyzes the range and variability in the model's results, which can be compared to a simulated parameter using the same input values (Koivula, 2015). It can also be used to evaluate the response of a model to any error that may found in the input and to establish which input has a greater effect on the output results (Sokolowski \& Banks, 2011; Salciccioli, Crutain, Komorowski, \& Marshall, 2016). This technique has been used to validate the models presented in this thesis, and the outcomes of these models have been discussed in the coming chapters.

\subsection{Research Questions}

This thesis was guided by some questions that are related to inventory systems, thermodynamic systems, and sustainability. The followings are main research questions that I intend to answer them through my studies; 
- How inventory and thermodynamic concepts can help in the design, planning, and management of sustainable SC?

- Why pricing a product in Joule instead of currency is more realistic in today's sustainable world?

- Is there any mechanism that can assist in measuring and identifying the level of sustainability through a supply chain?

- Which sourcing method is more sustainable; domestic or overseas sourcing?

- Can sustainability be profitable?

\subsection{Objectives of The Research}

The objective of this research is to integrate the three pillars of sustainability (economic, environmental and social) into mathematical inventory and logistics models. That is, to develop models that help in determining inventory policies that could help firms in being sustainable. The research in this thesis continues along the line that advocates that there are similarities between production and inventory systems and thermodynamics systems. Such a parallel suggests that production systems may be improved by applying the first and second laws of thermodynamics to reduce the entropy (disorder) of an inventory system.

Another objective of this thesis is to develop new inventory models based on EEA and to calculate the total exergetic cost associated with a product for firms in different countries (societies). The proposed models use equivalent exergetic values assigned to the non-energetic externalities: capital, labour, and environmental remediation costs of the 
system as to be added to the energetic factors: energy and material. The thesis uses the second-law of efficiency in thermodynamics to develop an exergetic sustainable indicator. It tells a firm how sustainable is its inventory policy. Additionally, this thesis aims to assist supply chain managers in the decision of selecting which "local" coordination policy can improve the production and ordering a product based on the amount of the consumed resources. The models developed in this thesis will assist supply chain managers in deciding the coordination policy that minimises costs and the amount of the consumed resources. They will also provide some guidance to managers who wish to decide whether to produce domestically or outsource their production or buy local or import.

\subsection{Thesis Organization and Scholarly Output}

Exergy analysis has been shown to be a powerful tool for measuring sustainability based on the consumption of resources. It has been applied in many contexts. However, exergy has not been applied in the context of inventory, production and supply chain contexts, except for a single paper (Jaber, Saadany, \& Rosen, 2011) which does not use the approach in this thesis. Researchers in inventory management have been trying to incorporate sustainability into some models to factor sustainable thinking into the inventory decisions. There approaches to this problem remain to be classic, when it should not. This thesis benefits from exergy analysis and the Extended Exergy Accounting (EEA) approach, to develop models that are on based the amount of resources consumed. In this regard, this thesis modifies the EOQ and EMQ models and develops a simple supply chain model to gain insights on how EEA could benefit managers in making sustainable decisions. This 
thesis uses thermodynamic concepts to draw a parallel between inventory and production systems and thermal systems. Existing methods are adjusted and further developed to perform this type of analysis.

The remainder of this thesis is organized as follows. Chapter 2 provides a concise background to the principles of thermodynamics and the relationship between thermodynamics and sustainability, which is based on exergy analysis principles. Chapter 3 discusses the need for using a resource-based approach to calculating the unit cost of a product. Chapter 4 uses the Extended Exergy Analysis to identify the hidden costs of inventory and modifies the classical economic order quantity (EOQ) model to include the three pillars of sustainability: economic, environmental, and social. Chapter 5 builds on the concepts of Chapter 4 by measuring the exergy consumed when producing a product during the production of a commodity by modifying the economic order quantity (EOQ) model. Chapter 6 draws a parallel between a heat pump and a two-level supply chain and uses the concepts developed in earlier chapters. Chapter 7 provides a summary of the thesis, main conclusion, and recommendations for future research. The following papers, on which the author of this thesis is the lead author, are based on the work herein:

1. Chapter 3: H. Jawad and M. Y. Jaber, "Exergy analysis: A new paradigm for modelling inventory systems," presented at The 45th International Conference on Computers \& Industrial Engineering (CIE45), Metz, France, 2015.2.

2. Chapter 4: H. Jawad, M. Y. Jaber, and M. Bonney, "The Economic Order Quantity model revisited: An Extended Exergy Accounting approach,” J. Clean. Prod., vol. 105, pp. 64-73, Oct. 2015. 
3. Chapter 5: H. Jawad, M. Y. Jaber, M. Bonney, and M. A. Rosen, "Deriving an exergetic economic production quantity model for better sustainability,” Appl. Math. Model., vol. 40, no. 11-12, pp. 6026-6039, Jun. 2016.

4. Chapter 6: H. Jawad, M. Y. Jaber, R.Y. Nuwayhid, "Improving supply chain sustainability using exergy analysis," Special Issue: Trends in Operational Research Approaches for Sustainability, submitted for review in the European Journal of Operational Research, Elsevier B.V.

5. Appendix A: Jaber. M.Y., Jawad, H. "An entropic comparison between the economic production quantity (EPQ) and just-in-time (JIT) models," The 45th International Conference on Computer and Industrial Engineering (CIE 45) Proceedings, 28-30 October 2015, Metz / France.

The above paper has been selected to be published in a special issue as the followings:

M. Y. Jaber, M. Bonney, and H. Jawad, “Comparison between economic order/manufacture quantity and just-in-time models from a thermodynamics point of view," Comput. Ind. Eng., Aug. 2016. 


\section{CHAPTER (2) -THERMODYNAMICS AND SUSTAINABILITY}

\subsection{Could Thermodynamics Solve The Problem Of Sustainability?}

Everything in the universe may be described in terms of energy. Galaxies, stars, molecules, and atoms may be regarded as organizations of energy (the capacity of performing work) (White, 1943, pp. 335).

Energy is defined as the capacity or ability of a system to perform work or produce heat (Elwenspoek \& Jansen, 2004). It is obvious from its definition; energy is transferred across the boundary of a system by either heat or work. People have been striving for centuries to improve their living conditions, which can be measured by a "universal currency" called "energy." In a similar manner, Norde (1997) stated that the entire physical world that surrounds us is energy and both of the living and non-living systems represent matter, which is energy, plus work that can be added to produce or maintain them. The author also stated that increasing the flows of energy and matter through a society can cause more consumption of the available energy and matter or generate more entropy (disorder).

Over the course of history, energy has been a concern of humankind; there has always been a journey to look for, discover, and apply new forms of energy. Studying the history of energy can lead to the fact that the consumption of energy is parallel to the complexity of the lifestyle and society. The more complicated the lifestyle is, the more energy is consumed. Therefore, energy plays a major role in the development of the human society. For example, White (White, 1943) showed the importance of energy in cultural development by employing culture functions as a connector between the community and its 
development. He stated two laws of cultural development, where cultural development is linked with consumed energy, produced product and efficiency of the mechanical means with which the energy is consumed. The author of the book entitled "The Evolution of Culture: The Development of Civilization to the Fall of Rome" claimed that culture is a thermodynamics system that serves the needs of humans (White, 2016). Energy is used to do work. Based on that he introduced the formula: Energy consumed $\mathrm{x}$ efficiency in utilizing energy harnessed $=$ degree of cultural development in terms of product produced.

The first law states: "Other things being equal, the degree of cultural development varies directly as the amount of energy per capita per year harnessed and put to work."(White, 1943, pp 338). While the second law states: "Other things being equal, the degree of cultural development varies directly as the efficiency of the technological means with which the harnessed energy is put to work." Based on these two laws of cultural development, the author concluded that culture develops when either one or both of the amount of energy consumed by a person per capita per year, or the efficiency of the technological means of putting this energy to work, is increased. Schlör, Fischer, \& Hake (2009) claimed that "sustainability" is the third law of cultural development, which states: "The degree of cultural development varies directly with the ability of society to avoid negative environmental, social and economic impacts by using energy services. " The United Nations Educational, Scientific and Cultural Organization (UNESCO) state in their mission that: "Placing culture at the heart of development policy constitutes an essential investment in the world's future and a pre-condition to successful globalization processes that take into account the principles of cultural diversity." ("UNESCO," n.d.) 
Climate change, financial crisis, increasing the rate of poverty around the world, are obvious evidence that humans are dealing with complex natural-economical-social systems, which no longer can be monitored within the traditional paradigmatic framework of physics and engineering science.

Among the hundreds of laws that characterize the universe, the laws of thermodynamics are the mightiest (Atkins, 2007). Thermodynamics is the branch of science that formulates the rules for the conversion of energy and matter from one form into another. It determines the physical limits for the growth of and development in the world that surrounds us (Norde, 1997). The name "thermodynamics" came from the Greek words therme (heat) and dynamis (power), which can show the early efforts of humankind to convert heat into power. Nowadays, thermodynamics is universally understood and explained to include all forms of energy and energy conversions, such as power generation, refrigeration, and relationships among the properties of matter (Cengel \& Boles, 2010).

The principles of thermodynamics have existed since the formation of our planet. However, thermodynamics did not come up as a science till the appearance and operation of the steam engines in England by Thomas Savery in 1697 and Thomas Newcomen in 1712, which are considered as the first attempt to develop a new scienc ("Thermodynamics," 2009). The most important laws involving energy are the laws of thermodynamics. The first law of thermodynamics (the conservation of energy principle), states that "energy cannot be created nor destroyed during a process, but it can only change its form" (Cengel \& Boles, 2010). It means that the energy lost through a process should be equal to the energy gained by the surrounding environment. Hence, the total energy is always constant if considered in 
term of quantity, and this is the reason why it called the law of conservation of matter-energy (Hussen, 2004).

The second law of thermodynamics provides the required methods that measure the quality (useful versus useless energy) as well as the degree of degeneration of energy during a process (Cengel \& Boles, 2010). The authors claimed that second law states, "heat cannot be converted to work entirely, and thus the work potential of internal energy must be less than the internal energy itself." In other words, when energy is converted from one form to another; there is always less energy available in the second form than there was in the first one. For example, the electrical energy required to make a light bulb illuminates is converted to two types of energy. The first one is the useful part which causes the bulb to light. The second is the part that dissipates to the surroundings in the form of heat, which is a degraded energy. The degraded (useless) part of the energy is called "entropy," and is concerned with the second law of thermodynamics, alias the entropy law (Georgescu-Roegen, 1971).

The following points may reflect the importance of the second law of thermodynamics in our daily life (Hussen, 2004):

- Energy can be varied based on its quality or ability to perform work.

- In all the processes that convert energy to work, there will always be a certain amount of waste or loss of energy quality.

- It explains why eco-systems (where living and non-living things work together in the same environment) need an enduring energy from external sources. This is due to the impossibility of completely recycling energy. 
Practitioners in a variety of disciplines have employed the concepts that derive from the laws of thermodynamics, with interests in economy, environment, and social topics. For instance, the concerns from energy conversion technologies and their impact on the environment due to emission, waste disposal, and signs of global warming have pushed towards the creation of new disciplines that can assist in improving the design and operation of energy systems and prevent waste to damage the environment (Valero \& Cuadra, 2004). One of these new disciplines is "Thermo-economics," which is the science that links physics with the economy by utilizing the second law of thermodynamics (Valero \& Cuadra, 2004). Entropy is the physical property that connects thermodynamic and economics (Cuadra, Valero, Delgado, \& Ramírez, 2009).

In contradiction to the mechanical approach, the laws of thermodynamics indicate that economic growth leads to increasing disorder (entropy) (Norde, 1997). The author claimed that increasing the flow of energy and material through a society could cause an extensive depletion of available natural resources, which in turn increases entropy in the form of greenhouse effects, ozone holes, and environmental pollution.

Entropy, as a measure of system disorder, has been utilized in establishing another new discipline called "Social Entropy," which is based on the application of the second law of thermodynamics to the human social behavior (Infante \& Lawler, 2002). This is due to the assumption that social entropy is equivalent to the degree of social dissatisfaction in and of certain social, economic, or political systems. The authors obtained a formula that gives a rough estimation of the amount of the relative social entropy in a specific place and time and concluded that the second law of thermodynamics might be applied to any society taking it as a system. Bera \& Acharya (2013) studied the analogy between the thermodynamics and 
social entropies. They modeled the social entropy in a similar manner of the thermodynamics. They claimed that motivation and achievement in a social system are analogous to heat energy and temperature in a thermal system, respectively. In another word, they argued that when the gap between motivation and accomplishment increases, social entropy increases. Chang (2013) has listed many literature that studied the topic of social entropy and human thermodynamics. He studied some variables and aspects related to social physics and connected them with social thermodynamics.

\subsection{What is Exergy?}

To grade the tasks for which the energy is used for, the term of "energy quality" is used. Energy quality refers to the available amount of energy that can perform work (Miller \& Spoolman, 2014).

Cleveland, Kaufmann, \& Stern (2000) defined the "energy quality" from an economic perspective as the relative economic usefulness per unit of heat equivalent of different fuels and electricity. The authors also claimed that an important consideration had been given to the quality of electricity due to its effect on the productivity of labour and capital and on the quantity of energy required to produce a unit of GDP.

Higher quality energy can be totally converted into potential work, while the lower quality energy can only be, partially, converted to needed work (Sahu, 2014). Accordingly, a general statement for all types of energy can be stated that energy has two parts: first is available for conversion into useful work, which is called the "available energy." The second is the part that cannot convert into useful work, which is referred to as the "non-available 
energy." The useful fraction of any energy form or the potential work that can be obtained from a system using reversible processes when the system equilibrates with the environment is called "exergy" (Sahu, 2014).

In thermodynamics, exergy is defined as "the work potential of a system in a specified environment and represents the maximum amount of useful work that can be obtained as the system is brought to equilibrium with the environment."(Cengel \& Boles, 2010). Available energy is often used as a synonym to exergy because it represents the available portion of energy that can be converted into useful work, while the other portion of energy is unavailable to do any work as illustrated in Figure (2.1).

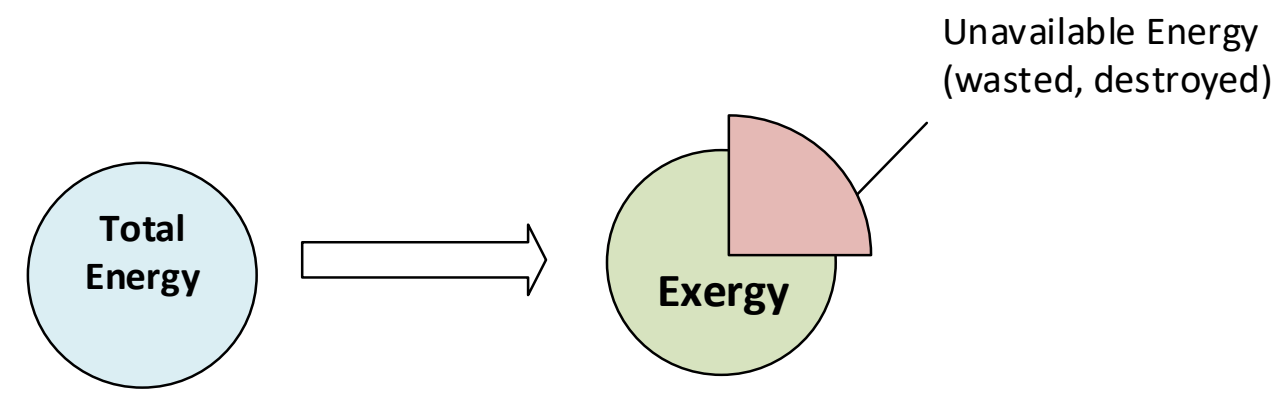

Figure 2.1. Schematic diagram illustrates the relation between energy and exergy.

The maximum amount of work output from any process can be obtained when it is performed in a reversible mode. The reversible mode can be achieved when the entire system in thermodynamic equilibrium with the environment (no interaction between the system and environment). This state of no interaction is called the "dead state," where the system is in thermodynamic (also, in mechanical and chemical) equilibrium with its environment. The ability of the system to produce work is caused by the differences between the system and 
environment. In another word, the greater the deviation of the system from the dead state indicates the largest availability of energy to perform work. At the dead state, a system has no kinetic or potential energy relative to its environment. Therefore, a system has no exergy (or availability) at the dead state and yields maximum possible work only when it follows a reversible process from its state to the state of its environment.

To explain the dead state, consider when the valve of a gas cylinder is turned on, the gas moves from the cylinder to the surroundings because of the pressure difference between the gas in the cylinder and the surroundings (environment). On the other hand, when the pressure inside a cylinder reaches an equilibrium point with its surroundings, the gas inside the cylinder stops escaping. This state is the dead state where the cylinder can do no more work because the work done has reached its peak value.

\subsubsection{What are the Most Important Features of Exergy?}

Exergy is an extensive property (a property of a system that depends on the amount of material in the system or the size of the system). Some of the distinct "thermal" features of exergy are (Moran, Shapiro, Boettner, \& Bailey, 2010):

- Exergy is a characteristic of the system and the environment together because it is responsible for the departure of the state of the system from that of the environment.

- The system will experience an inevitable change if it is not in a dead state.

- Exergy cannot be conserved. A complete loss of exergy can happen when a system experiences a spontaneous change to the dead state without an apparatus to perform work. 
- Exergy is the minimum amount of work that needs to be applied to change the system from the dead state to the specified state.

- The value of exergy can be zero, but not negative.

\subsubsection{Why is Exergy Important?}

Energy plays a major role in how nature and society interacts, and it is an essential factor for economic growth. There is no source of energy that is neutral with respect to the environment. Based on that, energy has an integrative nature that can cover sustainable development and environmental impact (Dincer, 2002).

As a part of the energy, exergy gained its importance in thermodynamics due to its relationship with the second law of thermodynamics. Exergy is employed to measure the quality of energy or compare the energy sources from a qualitative point of view. This point may explain the importance of exergy.

Since exergy is an efficient tool to measure the quality of the energy available, it has gained considerable attention from those in research, industry, and government communities. Some of the key points to highlight the importance of the exergy and its essential utilization are (Dincer, 2002):

- It is the main tool for dealing with the impact of using an energy resource on the environment.

- It is an effective technique that uses the principles of energy and mass conservation along with the second law of thermodynamics to design and analyze energy systems. 
- It is an appropriate method to seek more efficient uses of energy and material resources because it allows the determination of the locations, types, and amounts of waste and real losses.

- It is an effective technique which can detect whether or not and how much it is possible to design more efficient energy systems by minimizing the inefficiencies in the existing systems.

- It is a major factor in obtaining sustainable development.

On the other hand, there are some drawbacks of using exergy such as (Dincer \& Rosen, 2012):

- The need to choose a reference environment in exergy analysis is considered by some to render the technique too challenging.

- The difficulty in interpreting, understanding and utilizing the results of exergy analyses.

- Many potential users are simply unfamiliar with exergy, being educated about energy and therefore more comfortable with it.

- Some practicing engineers have simply not found exergy methods to lead to tangible and direct results.

To overcome these weaknesses, the same authors (Dincer \& Rosen, 2012) clarified the important roles of the media as a reflection of the public in understanding exergy. They claimed that members of the media including the press, television, and radio need to be informed, at least at a basic level, about exergy and its roles. Additionally, educating through the media can be a powerful tool to increase public awareness about exergy. They claimed 
that educating students about exergy can be considered as a tool of directly and indirectly educating the public, in the long term, about exergy. They found that there is a lack of coverage of exergy in thermodynamics education. Exergy, where it forms part of the curriculum, is usually delivered to students of the colleges and universities only. However, the authors recommend that exergy should be covered in primary and/or secondary education levels too. Finally, the authors recommend that for exergy methods to become more widely used and beneficially exploited, those who study and work in technical fields, especially when thermodynamics is applied, should have a basic understanding of exergy. Also, technical managers and decision makers require at least an appreciation of what exergy is and how it is used, if they are to make proper decisions on matters where exergy is, or should be, considered.

\subsubsection{How can Exergy be linked to sustainability?}

So far, two major aspects of exergy have been mentioned. First, exergy represents the available energy to convert into potential work. Second, exergy is an efficient tool to measure the quality of energy. These aspects can be employed to link exergy and sustainability. Moreover, Wall (1994) claimed that to optimize real-world processes involving energy, matter, and people; all these items must be included. Otherwise, it will only be a partial optimization bound to fail. The real economic factors that are included in the second law of thermodynamics are (1) exergy is not conserved and (2) exergy can be used as a common measure of the resources (materials and energy) quality and quantity together (Ayres, 1998). 
Zurcher (2011) stated that the human body could be considered as a type of heat engine, while the food can be seen as the fuel for this engine. Therefore, and as a living system, a human can generate and consume exergy. Obviously, thermodynamics through its laws, especially the second law of thermodynamics, has some essential aspects of our daily life. Some of these aspects that related directly to humans are explained in a book entitled "Principles of Environmental Economics" (Hussen, 2004) and here are some of them:

- In daily life, the exergy of a human can be viewed as the best job that human can perform under the most favorable conditions.

- A human at a specific condition (time and place) has an amount of exergy equal to the maximum amount of work that can be performed by him/ her in that status.

- Training (including education and schooling) increases the exergy of a human while aging decreases the human's exergy.

- The exergy of a person is a function of time, and it can be wasted if it is not used at the time it is needed. This is unlike most mechanical devices.

The question is, how can the principles of exergy meet the requirements of the three pillars of sustainability? The answer to this question is in the following points:

I. Economically: Energy is a valuable property that is employed in the every day life activities of society: agriculture, residential, commercial, industrial, research, domestic, transportation, etc. Due to its importance in the social and economic life of humanity, energy has gained extensive attention from politicians, economists, business firms, and academicians. This is reflected in energy acquiring high monetary and economic value. The stability and security of energy resources and raw materials can create strong 
economies for societies that contain such resources. A strong economy is the one that can support the growth of its society to achieve a better living standard.

II. Environmentally: The sources of energy and raw materials are located in the environment. The emission of GHG or discharge of material takes place in the same environment. Hence, the process of extracting, using and disposing of energy and raw materials has an environmental impact. In Figure (2.2), input and output streams, as well as the product itself, have exergy content because they are forms of either energy or material. Another type of analysis called the "Exergetic Life Cycle Assessment (ExLCA)" employs exergy analysis of the entire life cycle. Both LCA and ExLCA use the same structure but ExLCA analyses the exergy flows (inputs and outputs) focusing on minimizing the destruction of exergy to improve the efficiency of the whole process.

III. Socially: Human Development Index (HDI) measures the average achievement or the standard of living of a specific country in three basic factors related to human development: health, knowledge and a decent standard of living as measured by GNP per capita (PPP USD) (Rayner, 2010). The relation between HDI and energy per capita is complex, but generally, consumption of energy improves the level of HDI as mentioned in World Energy Outlook book "a higher HDI goes hand in hand with increased per capita energy use." (World Energy Outlook, 2004, pp. 334,) Many methods may compute economic progress. Gross Domestic Product (GDP) is currently the most commonly used. For a given year, GDP is the sum of all value added to raw materials by labour and capital at each stage of production (Daly \& Farley, 2010). It can be concluded that more added value can be obtained with less capital when labour is more efficient (i.e. GDP is proportional to labour efficiency). 
To better understand the relation between exergy and sustainable development and the models have been employed, readers can visit the book titled "EXERGY: Energy, Environment and Sustainable Development" by (Dincer \& Rosen, 2012). The authors claimed that during the past two decades' revolutionary changes were witnessed in the way thermodynamics is taught, researched and practiced. The methods of exergy analysis, entropy generation minimization and thermoeconomics are the most visible and established forms of this change. Today there is a much stronger emphasis on exergy aspects of systems and processes. The emphasis is now on system analysis and thermodynamic optimization, not only in the mainstream of engineering but also in physics, biology, economics, and management. Because of these recent changes and advances, exergy has gone beyond thermodynamics and become a new distinct discipline because of its interdisciplinary character as the confluence of energy, environment, and sustainable development.

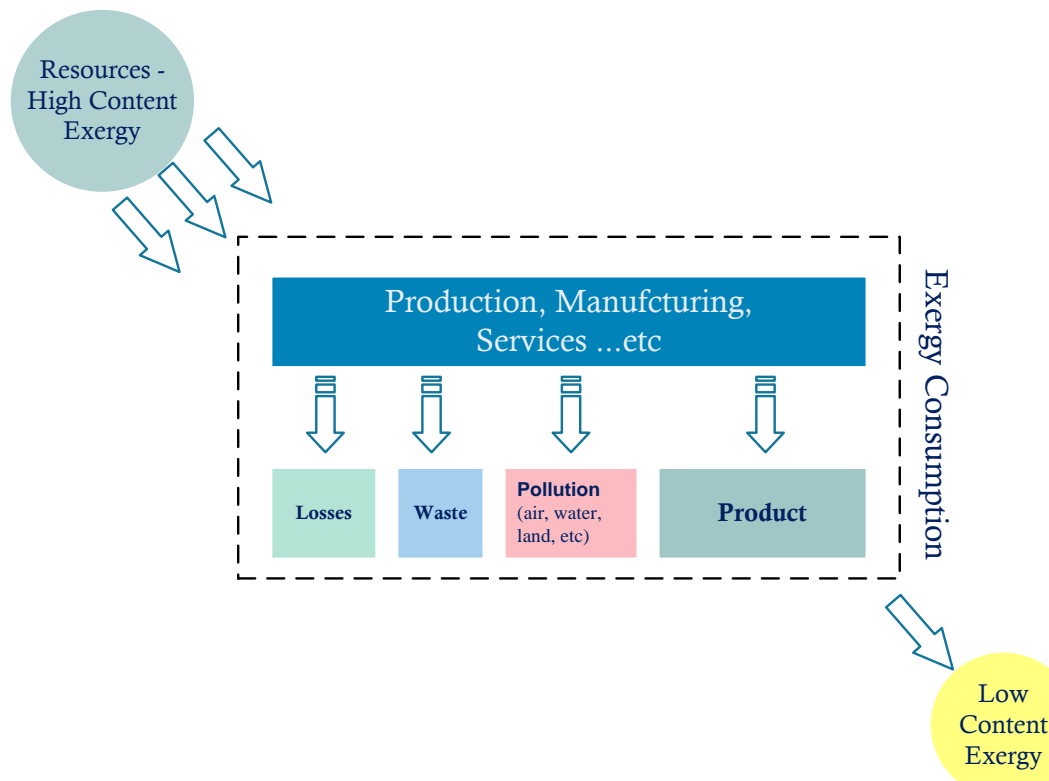

Figure 2.2. Schematic diagram illustrates the principles of ExLCA for an arbitrary product. 


\subsubsection{How can Exergy be linked to inventory management?}

To answer this question, we need to know the relation between thermodynamics laws and physical systems such as inventory management, and secondly, how to implement exergy analysis into inventory systems. This section merges these two topics. Mainly, thermodynamics considers energy (work) and its related subjects, such as energy transfer, conversion between its different kinds, its efficiencies, etc. Almost all industrial processes contain at least one thermal process to perform its task.

Accordingly, principles of thermodynamics, fluid mechanics, and heat transfer are required beside the principles of engineering economics to design any industrial process or system. Moreover, some of these processes or systems need to employ the principles of "thermo-economics" to combine the "exergy" with the engineering economics. Hence, thermo-economics can be called "Exergo-economics" (Abusoglu \& Kanoglu, 2009), which is an exergy based method that assists in identification and calculation of the location, magnitude, causes and costs of thermodynamic efficiencies in an energy conversion system (Petrakopoulou, Lara, Morosuk, \& Boyano, 2012). This can show the importance of exergy, which represents the product of real thermodynamics value; hence, exergy is the optimal basis for assigning monetary values (Gaggioli \& Reini, 2014). The importance of connecting thermodynamics and economy in exergo-economics comes from the placing of "purpose" and efficiency in the heart of thermodynamics as shown by (Valero, Usón, Torres, \& Valero, 2010):

$$
\text { Resources(Fuel)- Products }- \text { Wastes }=\text { Irreversibilities }>0
$$




\section{Exergy Input - Exergy output $=$ Irreversibilities $>0$}

The above formula can be considered as the first step for the identification of the cost formation process of products and wastes consists of building a productive platform that clarifies the distribution of resources throughout the plant (Valero et al., 2010). This approach is closely related to input-output analysis, which describes and explains, on the macroscopic level, the output of each sector involved in the building of a given national economy with regards to its relations to the identical levels of activities in all the other sectors (Leontief, 1970). Similarly, input-output analysis has been an effective tool to represent the conversion of input streams into output products on microscopic economic levels. Obviously, from the above formula, the cost of producing a product or providing a service is equal to the resources required to produced or provide it plus the cost of the waste (entropy) generated.

Grubbström \& Hultman (1989) pioneered the study of inventory problem regarding energy. They presented economic models for exergy and heat storage, expressing that economic and inventory policies depend on both the variation in energy demand and thermodynamics properties. They also showed that temperature discounted prices are essential factors in the optimal inventory policies.

Jaber et al. (2004) studied the analogy between thermodynamic and physical systems in a deeper manner. They claimed that the performance of production systems could be improved by modeling them as thermodynamic systems where heat flows are similar to the demand of a product's flow, and the system temperature in a thermal system is analogous to the product price. Consequently, some studies could develop different models (e.g. EOQ 
( Jaber et al., 2006) and reverse and forward logistics ( Jaber et al., 2011)) which introduced a new hidden cost that is called "entropy cost." The entropy cost is based on computing the cost of disorder in the system that can appear in the form of material processing delays, items waiting to be delivered, unreliable machines, idle workers, etc. (Drechsler, 1968).

Since exergy represents the available energy that can be converted into useful work, and entropy generation can reduce the amount of available energy, they are related to each other. As per the second law of thermodynamics, which concerns the quality of energy, the entropy generation in a system is always accompanied with exergy destruction. Hence, an effective method is required to investigate and examine the exergetic input and output streams of a system and to reveal where and how to improve the system's efficiency. A promising technique that has been used for such a task is called "Exergy Analysis." It defines and measures all the input and output streams of a system, including the destroyed and wasted exergy to improve the system's efficiency using thermodynamics concepts. Exergy Analysis is a powerful thermodynamic methodology that can be employed to assess and improve the effectiveness of a process, device, and system and to enhance their environmental and economic performance. The applications of exergy are observed in various sectors, such as mechanical and chemical engineering, economics, management, physics, and biology. Accordingly, exergy analysis is used increasingly by industrial and governmental organizations worldwide, principally in improving energy sustainability (Buytaert et al., 2011). Exergy analysis is linked to the industry sector using "Industrial Ecology (IE)," which is concerned about the flow of energy and materials through an industrial system to address the concerns about resources consumption and waste management. IE is an approach to the industrial design of a product with the implementation 
of sustainable production strategies by viewing the industrial system, not in isolation from its surrounding systems, but in concert with them (Jelinski, Graedel, Laudise, McCall, \& Patel, 1992).

Exergy analysis has been widely used in many industrial and production systems to improve their efficiencies and environmental and economic performance, such as aluminum (Balomenos, Panias, \& Paspaliaris, 2011), food industries (Apaiah, Linnemann, \& van der Kooi, 2006b), cement (Madlool, Saidur, Rahim, Islam, \& Hossian, 2012), manufacturing processes (Gutowski et al., 2009) and waste management (Gaudreau, Fraser, \& Murphy, 2009).

A common exergy analysis method that is used in industrial systems is the method of Cumulative Exergy Consumption (CExC), of Szargut et al. ( Szargut, Morris, \& Steward, 1987). CExC computes the total amount of the consumed exergy embodied in raw material and energy used in all processes to produce a product and links exergy concepts with the life cycle assessment (LCA).

The major resources that the consumed exergy can be extracted from are energy, raw materials, finished or semi-finished products and byproducts of another sub-system. The general form of the CExC balance equation can be given as (Budnik \& Stanek, 2011):

$$
E x_{j}^{*}=\sum_{i} f_{i j} E x_{i}^{*}+E x_{o j}
$$

To address the importance of capital, labour and environmental remediation costs in computing the real cost of a product or service, Sciubba (1999) formulated a new exergy analysis method called Extended Exergy Accounting (EEA). EEA is based on an extension 
of the traditional CExC method to include the economic, social and environmental aspects in addition to the energy and materials. The next section discusses EEA in detail.

\subsubsection{Extended Exergy Accounting (EEA)}

The major input and output streams for a production system are illustrated schematically in Figure (2.3). The input stream may include some or all labour, energy, materials and equipment. While output streams may include one or more of final products, byproducts, waste, emissions, etc. Moreover, most industrial processes are accompanied by energy losses and discharge of physical waste and emissions of GHG into the environment. Additionally, non-physical waste may arise in these processes in the form of the disorder (entropy), such as delays in material processing, items waiting to be delivered, unreliable machines, idle workers, etc., (Drechsler, 1968).

Extended Exergy Accounting (EEA) is formulated by considering the economic systems as ecosystems. Energy and raw materials are the prime-movers for an eco-system to function properly, and also to keeping human activities continuing in such an eco-system (Sciubba, 1999). 


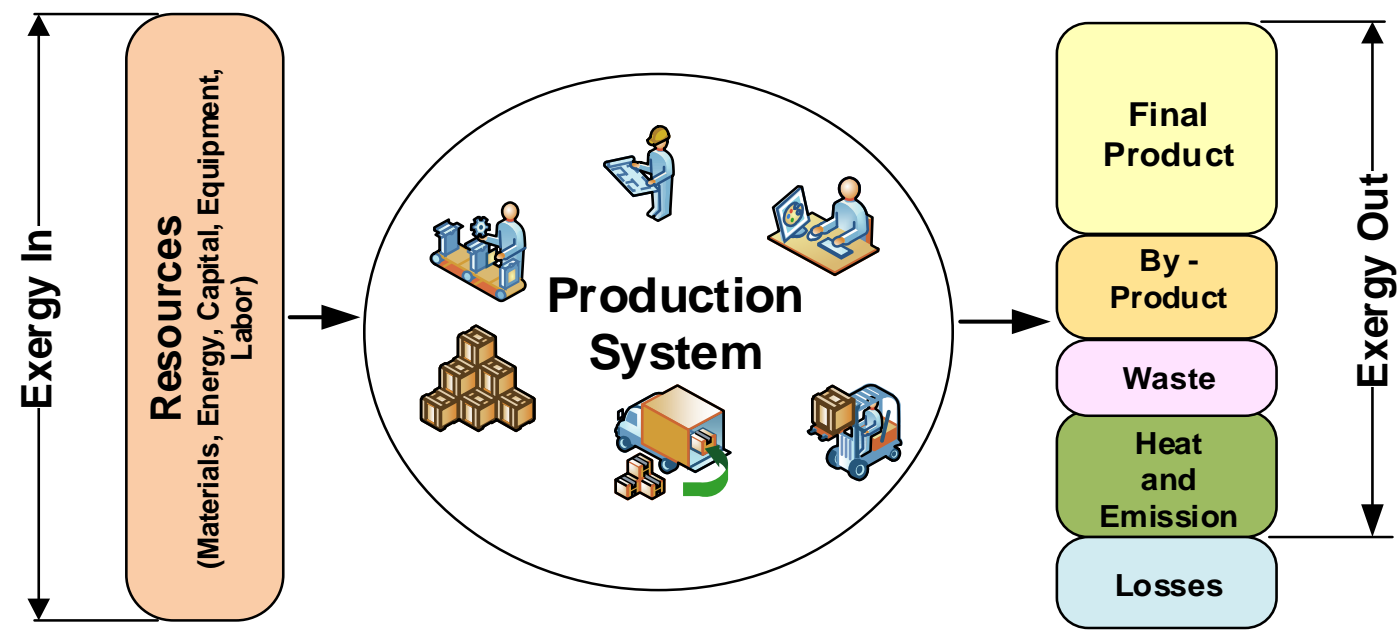

Figure 2.3 Input and output stream of a production system.

EEA adopts the traditional exergy analysis of CExC, but it is an "extended" version to include the expenditures of energy, materials, and environment remediation along the whole life cycle of the system (Rocco et al., 2014).

EEA may be considered as a compound of the pre-existing policies and procedures of engineering cost analysis because of its most important aspects, link with some of the former methods (Sciubba, 2004) as shown below:

- Like thermodynamics, EEA employs exergy cost balances as a quantifier of the real amount of all energy and material flows within the system under consideration.

- The time span of an EEA calculation covers the whole life cycle of the plant and/or product.

- Like CExC, EEA measures cumulative exergy that is embodied in all the inputs that are used in the production of a product. 
According to EEA, the exergetic cost of a product can be obtained by adding the exergetic equivalents of the "non-energetic externalities" and "energetic items" as expressed by the following formula:

$$
E E A_{\text {Commidity }}=E x_{M}+E x_{E n}+E E x_{K}+E E x_{L}+E E x_{E n v}
$$

\subsubsection{How to Compute the Extended Exergy Accounting (EEA)?}

The first step in calculating the EEA of a product is to consider the society where the considered production/inventory system is located. For a very large and complex system (VLCS), such as a country, the system is subdivided into sectors, such as transportation, industry, extraction, domestic, tertiary, agriculture, and conversion (Chen \& Chen, 2009). Also, all fluxes that flow among the sectors, and/or between a sector and its surroundings within the system boundary should be considered in the calculation steps.

The product of subtracting the exergy consumed by the system from the total amount of exergy that enters the system either from the environment or other systems is called the total influx of exergy into a system $\left(E x_{i n}\right)$. In other words, $E x_{i n}$ embodies the total amount of exergy received by a system not only the exergy consumed when producing products. It includes investment, labour, and environmental remediation in addition to the wasted and destroyed exergy. Some of the influxes and outfluxes that play major roles in computing $E x_{i n}$ are: 
- Influxes: extracted minerals, ores, nuclear materials, unrefined fuels, imported parts and products, natural resources such as renewable energy, water, solar energy, unrefined fuels, etc.

- Out-fluxes: any exported parts or products, otherwise, this flux can be zero.

Clearly, one can conclude that $E x_{i n}$ is a function of the geographic and economic conditions of a society. Other factors that may affect $E x_{i n}$ include one or more of regulations of renewable energy techniques and environment protection policies, employment rate, wages and salaries, policies that arrange and control the exploitation of natural resources, and business regulations that can affect the export and import activities.

There are three main externalities considered in the calculations of EEA: exergy of capital, labour, and environment remediation.

\subsubsection{Exergy of Capital}

Electricity is a high-quality type of energy which can be considered as a pure exergy type of energy. All the electricity generated worldwide comes from non-renewable (coal, oil, and natural gas) or renewable (the wind, solar, geothermal, biomass and hydropower) resources. These resources have exergy content, which is consumed to produce the required electrical energy. Customers buy the electric power as a final product, which is a function of its price and quality and represented by its final exergetic content. Hence, it can be seen there is a relation between money and exergy, and it can be expressed as a unit of mu/Joule. This supports the idea of assigning an exergetic value for any "mu." 
Additionally, as previously mentioned, energy and materials are the prime-mover for any ecosystem to function properly, in addition to keeping human activities continuing in such an eco-system. Any business throughout the world, regardless of the time and place, cannot be performed without using biophysical resources obtained from a reservoir of a limited mass capacity but of practically unlimited exergy capacity. So, it is clear that exergetic content, and not capital, is the right measure of the value of a product or service, and that the monetary price has to reflect this measure of resource consumption (Sciubba, 2004). In a recent article entitled "The Joule Standard" by McConnell (McConnell, 2013), he stated that the Joule had been the unit of measuring energy since the 1800s. Therefore, he advised using the Joule in commercial measurement instead of monetary units. To perform such a task, the author advises to follow these steps: (1) display products' prices by units of mu/Joule instead of mu only, and (2) compute the amount of energy consumed at each stage of the supply chain using the joule standard. Currency exchange rates affect the prices of goods imported from and exported to certain countries. Unfortunately, politics govern the exchange rates making some overvalued and others under valued. This affects international trade and the financial heath of trading companies. This thesis recommends using the "Joule" as a common currency as it is a resource based. This might be a noble cause, but not impossible. Prior to the Bretton Woods agreement exchange rates where based on each country's reserve of gold. The Bretton Woods system required countries to commit to a monetary policy that sustains a fixed exchange rates of their currencies for a specified equivalence in gold (Telò, 2016). According to the EEA method, the unitary exergy embodied in capital (exergy of one mu unit) can be computed as: 


$$
e e_{K}=\frac{E x_{i n}}{C_{r e f}}
$$

Selecting the proper $C_{\text {ref }}$ is challenging, depending on the availability of economic data on society. For instance, Money Supply (M2) has been chosen as the proper $C_{r e f}$ measure in many studies (e.g., Gasparatos, El-Haram, \& Horner, 2009; Seckin \& Bayulken, 2013; Milia \& Sciubba, 2006). Basically, M2 is the currency outside the banks (including paper money and metallic coins) + chequing accounts + personal savings deposits + non-personal notice deposits (The World Bank, n.d.). On the other hand, Bligh \& Ugursal (2012) selected the Gross Domestic Product (GDP) for the Nova Scotia province and multiplied the median of the 12 monthly values of M2 for all of Canada by the share of Nova Scotia's GDP relative to the total Canadian GDP. Chen \& Chen (2009) preferred to select the GDP as the proper $C_{r e f}$ measure due to the dissimilarity between China and western countries in banking activities such as restrictions on cashing checks in China, and most of the M2 in China is time deposits and saving deposits. The exergy embodied in a specific amount of capital $V$ (investment) can be computed by multiplying $V$ by the $e e_{K}$ obtained from Equation (2.3), i.e.:

$$
E E x_{K}=V e e_{K}
$$

\subsubsection{Exergy of Labour}

Thermodynamically, a human may be considered as an open system (a system that continuously interacts with its surroundings) and described as a heat engine that produces 
and consumes energy, and delivers work. A human can deliver two types of work (exergy): physical (muscular work) and intellectual (mental) exergies, which are functions of time and place. Like any thermal device, the exergy of a human can be wasted if it is not utilized properly. Labour is one of the major factors that contributes to the production function, which states that the cost of a commodity $(c)$ is an aggregation of material $(M)$, energy $(E)$, Labour $(L)$, capital $(K)$ and environmental remediation $(O)$ costs; i.e., $c=f(M, E, L, K, O)$ (Sciubba et al., 2008).

Since the exergy of human (labour, $E E x_{L}$ ) is a part of the total exergy influx to the system $\left(E x_{i n}\right)$, which is consumed by human (labour), then $E E x_{L}$ can be written as:

$$
E E x_{L}=\alpha E x_{i n}
$$

The unitary exergy embodied in one work-hour of a worker can be expressed as:

$$
e e_{L}=\frac{E E x_{L}}{(N W H)_{t o t}}=\frac{\alpha E x_{i n}}{(N W H)_{t o t}}
$$

The exergy embodied in a specific amount of work hours can be computed by multiplying $N W H$ by the $e e_{L}$ obtained from Eq. (2.7), i.e.:

$$
E E x_{L}=N W H e e_{L}
$$

When labour delivers exergy (work) to perform an assigned job, it receives monetary units in forms of salary, wage, fees or any other type of benefits. Hence, the exergy of labour can be linked into exergy of money (capital) by the following relation: 
$E E x_{K}=\beta E E x_{L}$

Accordingly, Equation (2.3) can be rewritten as (Sciubba, 2011):

$e e_{K}=\alpha \beta \frac{E x_{i n}}{C_{r e f}}$

The calculation of the coefficients $\alpha$ and $\beta$ depends on some essential factors, such as the location of the system, the type of the societal organization, the historical period of study, the technological level, and the per-capita resource consumption. In other words, both coefficients are time and space dependent model constants. The values of $\alpha$ and $\beta$ usually calculated from econometric data. The values of $\alpha$ and $\beta$ can be calculated using the following formulas (Sciubba, 2011):

$$
\begin{aligned}
& \alpha=\frac{\mathcal{F} N_{h} e_{\text {surv }}}{E_{\text {xin }}} \\
& \beta=\frac{m_{2} N_{h}}{S}=\frac{C_{r e f}}{s W r N_{w h}}
\end{aligned}
$$

Where $\mathcal{F}$ is a coefficient that explains the fact that modern life standards require an exergy use much more than the minimum survival, it can be computed from the following formula:

$$
\mathcal{F}=\frac{H D I}{H D I_{0}}
$$

$H D I$ is the Human Development Index and $H D I_{0}$ is that of a primitive society (=0.055) (Peiró et al., 2010). Neither has an exergy analysis method been found in the literature that fully considers all three pillars of sustainability. However, EEA method it may 
differ from the other methods by considering the economic, environmental and social aspects of sustainability. One of the most interested facts of EEA is the accounting of the HDI which was developed by the United Nations as a metric to assess the social and economic development levels of countries to measure the standard of living styles of them.

\subsubsection{Exergy of Environmental Remediation}

The cost of environment protection includes the expenses of all practices that are involved in the protection of air, water, and land from any activity that may cause environmental degradation. It also may include any action required to control the consumption of the natural resources extracted from the environment. The aim of such practices and activities is to bring the system into a state of equilibrium with the environment. To achieve the target of a zero or low level of impact, the effluents must be brought to a state of thermodynamic and/or chemical equilibrium with the surrounding environment. The expenses of such a task will include the costs of labour, investment, material, equipment and many other items required to facilitate this task. Examples of such practices and activities are regulations like taxes or caps, installing special equipment that can treat pollutant streams, and use special materials that can minimize the environmental impact of some processes.

According to EEA, such practices and activities can be represented by the environmental remediation equivalent exergy $\left(E E x_{e n v}\right)$ which represents the exergetic expenditures required to bring the system into a state of equilibrium with the environment. Such exergetic expenditures may include the exergy embodied in capital $\left(E E x_{K}\right)$, labour 
$\left(E E x_{L}\right)$, energy $\left(E x_{E n}\right)$, and material $\left(E x_{M}\right)$ that employed in the processes of environment remediation. Since these exergetic expenditures have other monetary values, then $E E x_{\text {env }}$ can be computed by transferring the invested monetary capital required to bring the system into a state of equilibrium with the environment into an exergetic value by multiplying the invested capital by the unitary specific exergy equivalent of one monetary unit $\left(e e_{K}\right)$. Hence, the exergy equivalent of environmental remediation $\left(E E x_{e n v}\right)$ can be computed as:

$$
E E x_{e n v}=C_{E n v} e e_{K}
$$

$C_{E n v}$ can include any payments to obtain labour, capital, material and any other items used to minimize the negative environmental impact of producing a product, operating a supply chain or delivering some other service.

\subsubsection{Limitations and obstacles of EEA}

The EEA paradigm is a novel systematic approach that can effectively be employed to obtain reasonably accurate data for the consumption of the natural and physical resources at any given time and place. However, it is not without some limitations and obstacles that may affect its implementation. Some of these limitations are listed below (Belli \& Sciubba, 2007):

a) The shortage and accuracy of the data related to the calculation of the total exergy input of society, the amount of exergy embodied in the labour force and the exergy of the raw materials and energy used to produce a product. These data require the cooperation of a full team of scientists from different fields of science, such as 
chemists, economists, physicists, human resources management, etc. Also, the extended exergy equivalent of capital and labour are computed based on two global system data (M2 or GDP, and $E x_{i n}$ ), which are not available for most societies and are too 'large-scale' in their character to provide high enough accuracy for 'domestic' calculations (for instance, to a city, for which the EEA analysis must be performed using the M2 or GDP and the Ex $x_{i n}$ of the country in which the city is located).

b) The extended exergy equivalent of labour is an aggregated value that provides reasonable accuracy for cases in which the examined system receives the contribution of the labour of widely different qualifications.

c) Like all Complex System assessment techniques, the accuracy of an EEA analysis is a highly dependent of the disaggregation level (collected numerical and/or nonnumerical data) at which the analysis is performed.

There are two primary sources of data errors that impact the results of a model (Jalil, Zuidwijk, Fleischmann, \& van Nunen, 2009). One has to do with the assumptions and approximations made during the modelling process. The other has to do with data acquisition or sampling errors that affect the values of a model's input parameters. A sensitivity analysis helps in determining and assessing the effects of different values of an independent variable on a dependent variable for a set of assumptions. A structural analysis of the model can also be performed to determine and asses the different parameters and components that compose the system under study to find out the relationships and relative importance in target realization. 


\section{CHAPTER (3) - EXERGY ANALYSIS: A NEW PARADIGM FOR MODELLING INVENTORY SYSTEMS}

\subsection{Introduction}

Engineers have been performing economic analysis using cost accounting techniques. Any reference to the resource basis is absent from such techniques. Researchers in thermo-economics, a branch of engineering that combines the laws of thermodynamic analysis and economic principles to design cost-effective systems (Bejan \& Tsatsaronis, 1996), advocate that using classical cost accounting techniques distort the picture of analyzing complex engineering systems that are entirely resource based. Reducing a system's thermo-economic costs is very useful in making a system more effective and efficient in delivering final products. The second law of thermodynamics, i.e. entropy or disorder law, asserts that in addition to its quantity, energy can have quality too. The thermal property 'Exergy' is a measure of this, which is described as the useful amount of energy that can be obtained from a system. An increase in entropy generation results in a destruction of exergy. Hence, thermo-economics is also called exergo-economics science. It is strongly related to the 'Sustainable Development' by connecting the consumption of energy and material resources with production and distribution of a commodity. Developing sustainable actions in the supply chain networks is a key issue for firms. Facing the pressure from governments, customers, and other stakeholders, firms have begun seeking new initiatives to moderate their negative environmental and social impact while at the same time remaining profitable. 
The Economic Production/Order Quantity (EPQ/EOQ) model has been widely used by academicians and practitioners (Glock, Grosse, \& Ries, 2014). Most of the inventory models that appear in the literature adopt a traditional approach to modelling and analyzing inventory and logistics systems, choosing the order/production quantity to minimize the sum of a combination of different costs (setup/order, holding, production, shortage, maintenance, rework, scrap, etc.). Some researchers have called for thinking outside the traditional box of inventory and logistics management. For example, Chikán (2011) argued that the classical models no longer describe today's inventory and logistics situations because of the fundamental changes in business. Jaber et al. (2011) introduced the concept of exergy cost in a reverse logistics context to amount for useful energy (work) wasted. They employed the advantages of thermodynamic analysis beyond inventory management to include linking the exploitation of natural resources, entropy and exergy concepts, and production and remanufacturing strategies. These studies are a few of many examples that aim to make the EPQ/EOQ model more representative of real situations.

Sustainable development has interested many parties in investigating and developing better techniques to reduce the consumption of natural resources; e.g., energy, raw material, and water (Bonney \& Jaber, 2011). One promising technique in this regard is "Exergy Analysis," which has been used to reduce the depletion of natural resources and the excessive use of energy. It is a universal method that analyzes the inputs and outputs of a system along with the destroyed and wasted exergy in order to improve the system's efficiency and evaluate the use of resources. Exergy analysis helps in eliminating inefficiencies in systems. Studying exergy provides knowledge about the efficient and balanced consumption of physical resource in our society (Dincer, 2002). 


\subsection{Exergo-Economics and Inventory Systems}

An inventory of a firm usually consists of produced goods, raw materials, WIP items and all the essential items needed in performing its business, making inventory an asset to a firm. Hence, inventory turnover represents the speed at which revenue and earnings are generated to benefit shareholders (Bonney, 1994); e.g., customers, retailers, manufacturers, suppliers, etc. Market dynamics and continuous changes in consumer behavior result in pushing products with short lives faster across supply chains, thus led to alarming depletion rates of natural resources and increasing the generation of solid waste. Government legislations and societal concerns forced many firms to green their supply chain activities, using strategies such as product design, material sourcing, manufacturing processes, delivery, as well as end-life management of the product after its useful life ends (Srivastava, 2007).

From a thermodynamic point of view, a supply chain is a sub-system of the "anthroposphere" that is part of the environment that is made or modified by humans (Speth, Christoph, \& Diekkrüger, 2010), which consists of components, processes and interactions that "convert resources into products" (Gutowski et al., 2009). These resources are either natural resources (e.g. raw materials) that can be used directly or physical resources such as machines. Demirel (2007) claimed that all useful products produced by industrial plants are the results of a complex network of interconnected processes that require the supply of natural resources, such as raw materials and energies, with exergy being the property that evaluates their quality. Szargut et al. (1987) stated that the consumption of exergy during the production of a commodity appears not only in a production plant but also in all plants delivering raw materials and semi-finished products required for the final production 
process. The balance equation of the inputs-outputs for a production-inventory system can be given as:

$$
\sum_{i} I=\sum_{j} O-\sum_{l} D
$$

Where $I, O$, and $D$ represent the input resources, desired outputs, and losses respectively. Similarly, the 'cost' balance equation of a system can be expressed as (Rosen, 2008):

$$
C_{I}+C_{g e n}=C_{O}
$$

Accounting for the cost of waste and/or losses, the 'cost' balance equation of a system can be expressed as:

$$
C_{I}+C_{g e n}=C_{P}+C_{D}
$$

Since it was showed that for each input and output item there is an equivalent value of exergy, then the output exergies are linked to those of the input as (Sciubba, 2004):

$$
E x_{O}=\Pi E x_{I} \Rightarrow\left[\begin{array}{l}
E x_{O 1} \\
E x_{O 2}
\end{array}\right]=\Pi\left[\begin{array}{l}
E x_{I 1} \\
E x_{I 2} \\
E x_{I 3} \\
E x_{I 4} \\
E x_{I n}
\end{array}\right]
$$

Where $\Pi$ is a metrical factor that links input to output streams. Since total cost (as a potential work) is considered as the effort needed to convert a unit of material/component into a unit of output, then destroyed exergy during the converting process could be translated as lost production. That is, if inefficiencies in the system equal zero, then the production capability of a firm should be at its peak quantity of $\rho$. This is theoretically accepted, because most 
systems end up with less production capability that equals to the demand $(d)$ only, where $\rho>d$. As a result, firms potentially lost a revenue of $[P \times(\rho-d)]$, which may be the value of destroyed exergy.

\subsection{Application of the Exergetic Model}

Sciubba (2004) modified Cubb-Douglas function and stated that the total cost of a product $\left(c_{U}\right)$ is generally defined by a "production function", which is the sum of the costs that cover the material $(M)$, energy $(E)$, labour force $(L)$, capital $(K)$, and environment remediation $(E R)$ if it is applicable; i.e., $c_{U}=f(M, E, L, K, E R)$. The energy and material in the previous formula represent the factor of "land" as it is the major source for natural resources. So, it is indirectly factored into the production function. In this thesis, the previous function has been modified to account for the cost of exergy destroyed (the cost of entropy); i.e. $c_{U}=f(M, E, L, K, E n v, E p)$, which is given as:

$$
c_{U}=M^{\theta 1} E^{\theta 2} L^{\theta 3} K^{\theta 4} E R^{\theta 5} E_{p}^{\theta 6}
$$

Note that if $\theta_{1}+\theta_{2}+\theta_{3}+\theta_{4}+\theta_{5}+\theta_{6}=1$, then the production function has a constant return to scale. Encyclopedia Britannica ("Encyclopedia Britannica," 2016) defined the term "returns to scale" as the quantitative change in the output of an organization or industry caused by a proportionate increase in all inputs. If the output increases by a larger proportion than the increase in the inputs, then the production process has increasing returns to scale. This type of scale may occur due to the greater efficiency obtained as the organization moves from small to large-scale operations ("Encyclopedia Britannica," 2016). If the outputs are 
less than of inputs, then the production process has decreasing returns to scale. Such a type of scale may occur when the production process becomes less efficient as production is extended, such as when an organization becomes too large to be managed effectively as a single unit ("Encyclopedia Britannica," 2016). In a similar manner to Eq. (3.4), the total cost of a production-inventory system can be expressed as:

$$
\left[C_{T}\right]=\Pi\left[\begin{array}{c}
\text { Capital } \\
\text { Labour } \\
\text { Energy } \\
\text { Environment Remid }
\end{array}\right]=\Pi\left[\begin{array}{c}
C_{\text {or }}(q) \\
C_{P r / P C}(q) \\
C_{H d}(q) \\
C_{E x D}(q) \\
C_{L}(q) \\
C_{E n g}(q) \\
C_{E m}(q)
\end{array}\right]
$$

Where $C_{o r}, C_{P r / P C}, C_{H d}, C_{E x D}, C_{L}, C_{E n v}, \quad$ and $C_{E m}$ are the costs of ordering, production/purchasing, holding, destructed exergy, labour, emission and energy. It has been, assumed that cost of purchasing raw materials is included in the term capital.

To convert the monetary value of the total cost into an equavelent exergetic value, the terms in the RHS of Equation (3.6) need to be converted into equavelent exergetic values. Since these terms are measured by different units, then replace $\Pi$ with one row matrix that consists of three major items; $e e_{K}, e e_{L}$ and 1 .

$$
T E x C=\left[\begin{array}{ll}
e e_{K} e e_{L} & 1
\end{array}\right]\left[\begin{array}{l}
\text { Capital } \\
\text { Labour } \\
\text { Energy }
\end{array}\right]
$$

Note here that 1 muliplied by the term of energy because energy is already measured in units of Joule/year, which is the same unit of TExC. The total exergy consumed during 
production-inventory processes of a product can be represented by TExC (in MJ/unit time), which is the exergietic form of $T C_{S C}$ and can be written as:

$$
\begin{aligned}
& T E x C=e e_{K}[\text { Capital }]+e e_{L}[\text { Labour }]+[\text { Energy }] \\
& \begin{aligned}
T E x C=e e_{K}\left[C_{O r}(q)+C_{P r / P C}(q)+C_{H}(q)+C_{E x D}(q)+C_{E m}(q)\right]+e e_{L} \frac{C_{L}(q)}{s} \\
\quad+3.6 E x_{E n g}(q)
\end{aligned}
\end{aligned}
$$

The number 3.6 represents the conversion factor between $\mathrm{kWh}$ and $\mathrm{MJ}$, where $1 \mathrm{kWh}$ $=3.6 \mathrm{MJ}$. Hence, to price a commodity, the costs of the followings are needed to be included in the computation methods:

- The key-elements that play a major role in the production of the product, such as labour force, knowledge, energy, materials, machinery, etc.

- Negative impacts on society and environment that need to be treated to minimize the effects of them, such as pollution, GHG emissions, labour stress, traffic congestion, etc. This is in line with (Sciubba, 2004, p.27) who stated that the "exergetic content and not capital is the correct measure of the worth of a commodity."

Retailers (as an example) post the price of products they offer in term of monetary units (currency) that gives the monetary value of the product only. Labeling a product is of great importance to both customer and seller. The label of a product that describes the product is a gate between a business firm and a consumer to do business. It can assist the manufacturer/retailer to sell the product. It transfers all data needed by a customer such as product's usage, construction, care, performance, and other features. For instance, a food 
label may include product illustrations, weight, dating and storage information, ingredients, and product guarantees (Farese, Kimbrell, \& Woloszyk, 2001).

Some products may have what is called "Eco-labeling" (or environmentally friendly labeling), which informs the customer about the environmental attributes of a product. Ecolabeling is a market-based approach that utilized to improve the environmental performance of products through consumer choice. The objective of eco-labeling is to provide customers with credible information which can lead to an increased demand for environmentally friendly products (Delmas \& Grant, 2014). The authors gave examples of eco-labeling such as the organic label for agricultural commodities, the Energy Star label for energy appliances, and the Forest Sustainable Stewardship label for lumber. Based on its definition and objectives, eco-labeling would engage in an LCA analysis of a product from the initial stages till it used by the customer to provide customers with information about the production's overall ecological footprint (Czarnezki, 2011). Today, there is 37,000 products sold in the European Union (EU) market bear the EU Ecolabel ("European Commission EU Ecolabel,” 2016).

A question may be raised "is that sufficient to find a sustainable product? How much energy and exergy have been consumed, and what were the labour condition during the production stages of the product?" Let's take the example of Energy Star appliances mentioned above. According to Natural Resources Canada, an ENERGY STAR certified product can save energy without compromising performance in any way ("ENERGY STAR in Canada," 2017). That looks useful for a customer who wants to buy a new appliance, and it will provide a customer with interpretable information about the saving of energy in the future if this product is used. But as a customer, do you know how much energy was 
consumed at every stage of the supply chain that produced the ENERGY STAR certified product that you intended to buy, or how many metric tons of $\mathrm{CO}_{2}$-equivalent were emitted in the production of this product? Or, what were the labour conditions in the societies where parts of this product have been produced? The answer is "NO," simply because there is nothing on the label of the product that can tell these facts yet.

An interesting article entitled The Cheeseburger Footprint, it is written by Jamais Cascio (Cascio, 2007), claims that to produce "one" burger, the emitted amount of $\mathrm{CO}_{2}$ is 3.6 - $6.1 \mathrm{~kg}$ of $\mathrm{CO}_{2}$-equivalent, which can result in total of $65,250,000$ annual metric tons of $\mathrm{CO}_{2}$-equivalent for all US burgers (an average of one burger per week for each one US citizen). The author found that this amount is equal to the emitted amount of $\mathrm{CO}_{2}$ from 6.5 million Hummer H3 SUVs. It is a practical and real example that should be implemented on each product that humans use in their daily life to move towards real steps of sustainable development. Moreover, a product's label should address the social aspects of the product on its label to provide the actual information about the social conditions associated with the production of the product. It is worthy mentioning that for an input data that ranges between lower and upper bounds, output results depend on the selected values of the input parameters.

This dissertation strongly suggests that to address the three pillars of sustainability in a product, the unit of thermodynamics (Joule) should be used as a supplemental measure along with monetary units. This suggestion is based on the following:

- It has been showed that all the pillars of sustainability, economy, environment and social aspects could be modeled by utilizing the principles of thermodynamics laws. 
- Energy is the prime mover of, or at least is required for, all our daily life's activities, from the alarm that wakes up in the morning to the light turned off before sleeping at the end of our everyday lives cycle. Also, energy plays a vital role in the economic and business activities

The product's label has to change the customer's decision from being accustomed to thinking about the product's monetary value, to be accustomed to thinking about its societal and energy use impacts as well. The works presented in this thesis show the importance of establishing a sustainable label that introduces the amount of exergy consumed to produce a product. For example, a sustainable label may show the data that occurred during the production, stocking and distributing a product such as the amount of energy used, the amount of GHG emitted, the consumed human exergy, equivalent exergy of the capital. The label could also show the rate of the product from a sustainable point of view. A sustainability measure system named as "Exergetic Sustainability Index (ExSI)" is introduced in Chapter (5). ExSI aims to rate a firm or product based on the consumed exergy during all stages of production, stocking, and distribution of the product. For example, the rate can be in the range $0-1$, where $0(0 \%)$ represent the worse rate of sustainability, while $1(100 \%)$ is the best rate. Recently, Timberland, a US-based manufacturer, marketer and retailer of footwear and apparel, started using what looks like a "nutritional label" printed on the boxes of product. The purpose of it is to inform customers the impact on the environment. The label shows the percentage of footwear that uses alternatives to PVC plastic, the total usage of renewable, organic and recycled materials, and the number of trees planted by the company in a given year (Government of Canada, n.d.). 
Pricing a product based on the amount of exergy consumed has its limitation. A major limitation is that the term exergy most probably will confuse the average consumer. People are more familiar with the term energy. To alleviate exergy to the appropriate level will take a great effort in marketing and educating the public.

\subsection{Summary}

This chapter aims to stress using a resource-based approach when estimating the cost of a product in inventory and production systems. This approach is in line with sustainable development efforts as it can be employed with the second law of thermodynamics to estimate the real, not market, the cost of inventory/production systems. In this regard, "Exergy Analysis" has been suggested to compute the exergetic cost of a commodity, and to detect the inefficiencies in the system as well as measuring the cost of depleting natural resources.

Using the proposed approach may result in inventory policies that are different from those of the classical approach, and are a more effective step towards sustainable business. Estimating the cost of producing and the selling price of a commodity based on the consumption of resources may help in having globally unified sustainability performance measure(s). It can also enable firms to match the amount of the produced product with the required resources to achieve the desired level of sustainability.

It is expected that the results from operationalizing the method suggested in the chapter will show that firms may register savings while also being sustainable and environmentally accountable. The accuracy of the results may be limited by the availability 
of data needed to calculate the exergy of society, and the exergies embodied in the capital and labour force. 


\section{CHAPTER (4) - THE ECONOMIC ORDER QUANTITY MODEL REVISITED: AN EXTENDED EXERGY ACCOUNTING APPROACH}

\subsection{Introduction}

One of the core problems that face business firms when ordering a product of concern is what the suitable lot size is to order and at what time interval they need the product to arrive at their warehouse. One of the simplest and oldest models followed by business firms is the Economic Order Quantity (EOQ) model. EOQ model aims to find the minimum total cost that a firm can experience for ordering a single-product over a period that consists of a number of cycles.

The EOQ model of Harris ((Harris, 1990); a reprint of the 1913 paper) was the first scientific treatment of inventory systems. Thus, it is a fundamental model of inventory and logistics management. Since its inception, the EOQ model has under gone extensive investigation and development to fit various requirements (e.g., Schwaller, 1988; Drezner, Gurnani, \& Pasternack, 1995; Chen \& Jo Min, 1991). The applicability of the EOQ model has been queried despite its broad use. Woolsey (1990) criticized the classical EOQ model and recommended business firms to think more before using it. He totally disagreed with the EOQ assumptions (see Section 4.3) regarding fixed price, demand and average quantity in stock. Selen and Wood (1987) stated that the EOQ model produces poor results because of poor definition and estimation of its input parameters. They noted that the difficulty in calculating the variable set-up and holding costs was because the financial accounting rules were not examined. Zangwill (1987) showed that the EOQ with zero inventory (ZI) could 
be mistaken in its assertion that inventory reduces when set-up time and/or cost reduces. The classical EOQ model also has other limitations. It neglects some aspects of practical situations. For instance, it assumes that all units of a specific product or the material used in producing it are of perfect quality with steady demand (Khan \& Jaber, 2011). Salameh \& Jaber (2000) modified the classical EOQ model to consider the imperfect quality of products. They showed that the size of the EOQ increases as the average percentage of imperfect quality items increases.

Facing pressures from governments, customers, and other stakeholders, business firms have realized that there is a need to adopt better strategies and tools to minimize the negative environmental and social effects that their operations produce while seeking economic profitability. Bonney \& Jaber (2011) presented a detailed discussion and analysis of the need to design responsible inventory systems. They examined the importance of inventory planning to the environment. For illustrative purposes, they developed an analytical inventory model, a variation of the EOQ, and concluded that items should be ordered in larger quantities less frequently than the classical EOQ model recommends with a view to reduce the transportation cost and, consequently, $\mathrm{CO}_{2}$ emissions. Recently, Jaber et al. (2011) modified the EOQ model and used it to investigate a simple reverse logistic model in the presence of the "exergy cost." They used exergy to measure the cost of lost potential to produce/recover new/used items because of entropy effects. Their results showed that an integrated policy of production and recovery is profitable, a result that may encourage firms to implement green inventory management practices.

To the knowledge of the author, no available study in the open literature combines the environmental, social and economic aspects in the EOQ model and there is no research 
that uses EEA to analyse inventory systems. The aim of this chapter is to develop a new EOQ model based on EEA and to calculate the total exergetic cost associated with the inventories of a product for firms located in the developed economies of the USA, Germany, and China.

\subsection{Inventory Theory Under the EOQ Model}

Economic Order Quantity (EOQ) minimizes the sum of two conflicting inventory costs: ordering (setup) and holding costs. The ordering cost (OC) of inventory is the cost of placing an order to acquire a product form the supplier. It may include the administrative costs of preparing purchase orders such as invoices and communication, documentation cost, the cost of inspection of received items, etc. it computed by dividing the cost of placing an order by the number of orders as follows:

$$
O C=\frac{A d}{q}
$$

On the other hand, the holding cost (HC) of inventory represents all the costs related to storing inventory before it is sold to the end user. Holding costs, also called carrying costs, may include but not limited to the followings ("unleashedsoftware.com," 2015):

- Inventory financing costs also called capital costs, which includes all the costs that related to the investment made in stock, including costs like interest on working capital. 
- The opportunity cost of the capital invested in inventory, which represents the benefits lost from other alternatives of tying money up in inventory, such as investing in term deposits or mutual funds.

- Storage space costs, which includes all the costs that associated with the place where the inventory is stored such as the expense of the storage facility itself, or lease payments if it is not owned, facility maintenance costs such as lighting, heating, ventilation, and property taxes.

- Inventory services costs that include the cost of the physical handling of the products, insurance, security, and IT hardware, and applications if these are used.

- Inventory risk costs that include the cost of shrinkage, which is the loss of products between purchasing from the supplier and final sale due to any reason, such as theft, vendor fraud, shipping errors, damage in transit or storage. Also, this cost may include the cost of obsolescence, which is the cost of products passed their usage by dates, or otherwise becoming outdated.

To compute the holding cost per unit time, one needs first computing the average inventory per one cycle. Since each cycle is identical to any other cycle, the average inventory per unit time is the same as the average inventory per cycle. The holding cost equals the average inventory per unit time times the holding cost of one unit of product in inventory for this period of time. Figure (4.1) shows the inventory profile of the EOQ model as a function of time, where $q$ is the order quantity, and $t=q / d$ is the cycle length. To find the average inventory per cycle we need to find the area under $\mathrm{ABC}$ and divide it by the cycle length, i.e.: 


$$
\text { Average inventory per cycle }=\frac{\text { Area of } A B C}{\text { Cycle length }}=\frac{\frac{1}{2} q t}{t}=\frac{q}{2}
$$

Since each unit of product in inventory costs $h$ (in mu/unit/unit of time) to stock it for one unit of time. Therefore the holding cost per unit time equals to:

$$
H C=h \frac{q}{2}
$$

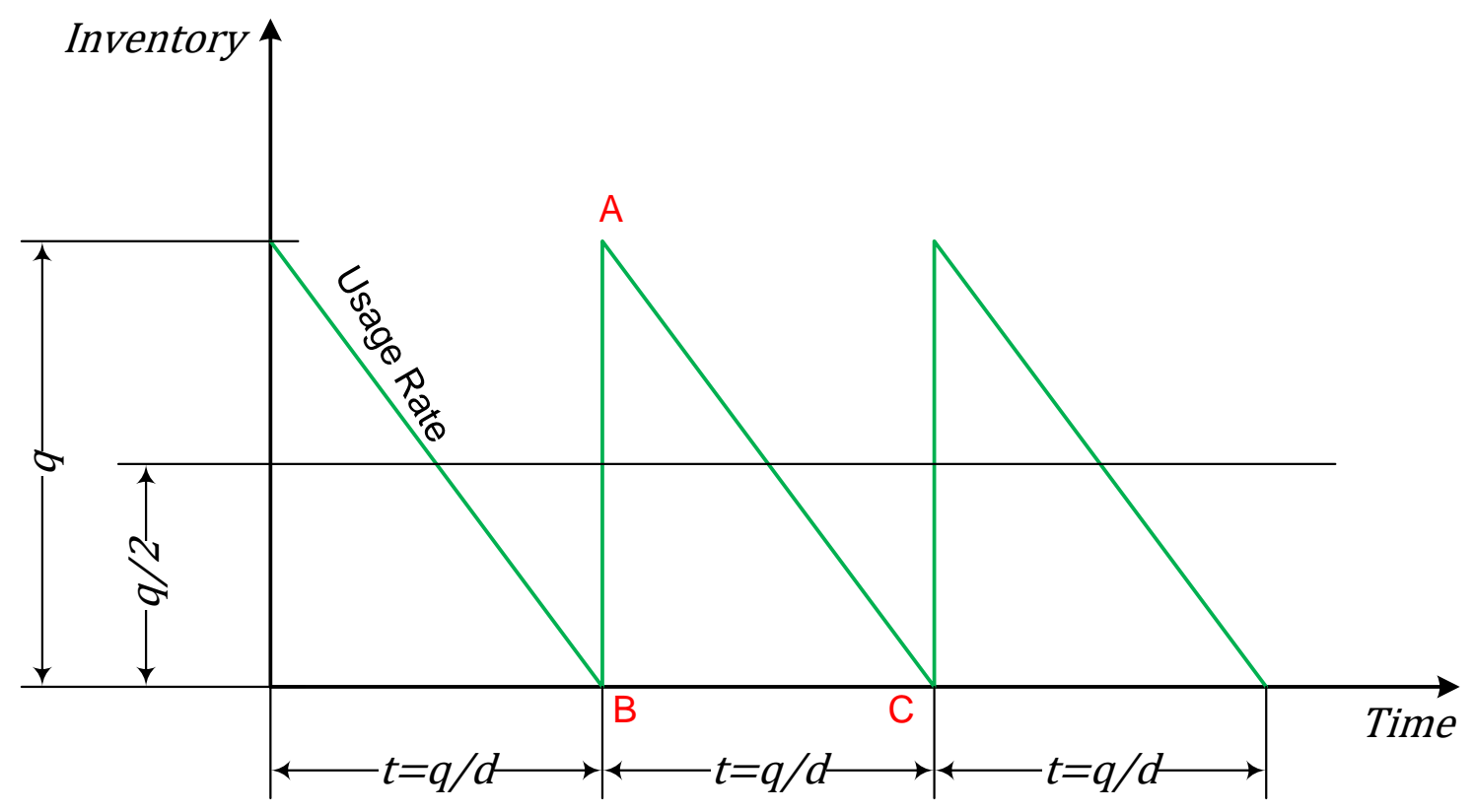

Figure 4.1. Inventory profile over time for the EOQ model.

A business firm that carries an inventory of an arbitrary product needs to pay for the price that charged by suppliers for one unit of the product, which is called the Purchasing cost (PC) or Unit cost. If the firm produces the product itself, then it called Production cost. 
This type of cost calculated by multiplying the cost or price of purchasing one unit of the product by the demand per unit time, i.e.:

$$
P C=c_{U} d
$$

Hence, the single-item EOQ formula that finds the minimum point of that minimizes all the inventory cost can be expressed as:

$$
T C=O C+P C+H C=\frac{A d}{q}+c_{U} d+h \frac{q}{2}
$$

It has been found that in most literature the unit-of-time purchasing cost is ignored when it does not affect $q$. The value of $q$ is determined by minimizing the sum of two different unit-of-time costs, holding cost (Eq. 4.1) and ordering cost (Eq. 4.3). Mathematically, the optimal economic order quantity, $q^{*}$, can be computed by setting the first derivative of Equation (4.5) equal to zero to get:

$$
q^{*}=\sqrt{\frac{2 A d}{h}}
$$

To gain more insights, let us explore additional properties the optimal solution possesses. Figure (4.2) shows the behavior of the average per unit time ordering cost and holding cost as functions of $q$. As seen from the plot, when fewer orders are placed, the average per unit time ordering cost decreases as $q$ increases. On the other hand, the total cost of holding an inventory increases. Therefore, $q$ affects the two types of costs (OC and $\mathrm{HC}$ ) in opposite ways. The per unit time ordering cost is minimized by making $q$ as large as 
possible, but the holding cost is minimized by having $q$ as small as possible (Muckstadt \& Sapra, 2009).

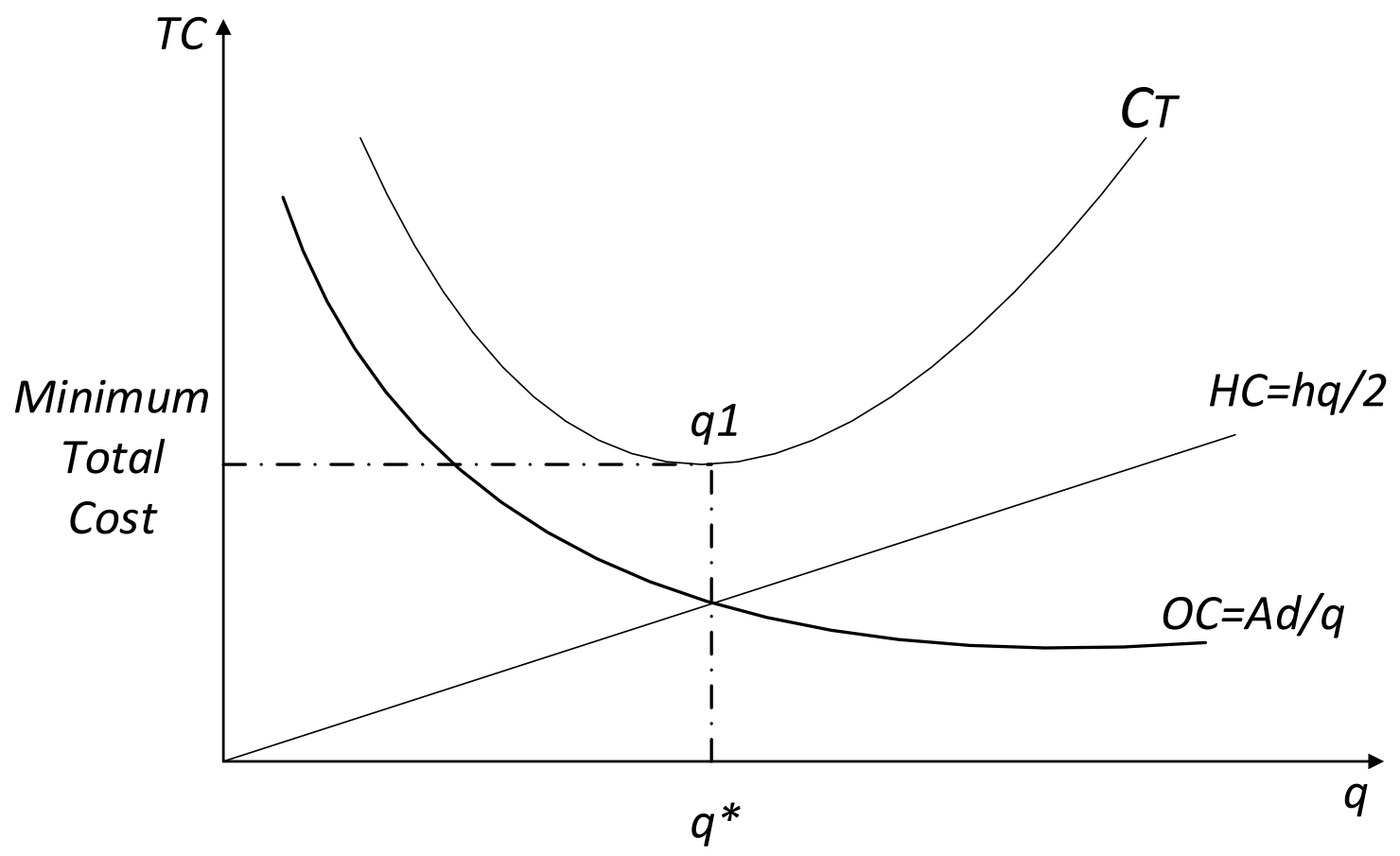

Figure 4.2. Basic inventory cost trade-offs (ordering and holding costs) as a function of the order quantity.

From Figure (4.2), the two curves of $\mathrm{OC}$ and $\mathrm{HC}$ intersect at $q=q_{1}$, which yield to $\frac{A d}{q}=h \frac{q}{2}$, leads to $q=q^{*}$. Since $\mathrm{OC}=\mathrm{HC}$ at $q^{*}$, then, the optimal total cost per unit time can be expressed, after subsisting Equation (4.5), as:

$$
T C=c_{U} d+\sqrt{2 d A h}
$$


Inventory related costs account for up to $50 \%$ of a supply chain's total cost (Jaber \& Zolfaghari, 2008). The EOQ model has been fundamental to many models in the literature due to its earliest inception and simple mathematics. The EOQ model assumes that:

- A product faces a constant demand (unit/unit time),

- Fixed ordering (mu) and holding costs (mu/unit/unit of time),

- Instantaneous replenishment, i.e. the whole lot size (batch) to be delivered at once.

- No shortages,

- No defects, and

- An infinite planning horizon.

\subsection{The Exergetic EOQ Model}

The EOQ model has been extended in many directions and been critiqued. In its $100^{\text {th }}$ anniversary, a book has just been published (Choi, 2013) and a special issue of the Int. J. Prod. Econ. includes a nice and concise review by (Andriolo, Battini, Grubbström, Persona, \& Sgarbossa, 2014). One interesting extension is the work of ( Jaber et al., 2004), who modelled commodity flow as a heat flow in a thermodynamic system and used the second law of thermodynamics to determine a third cost component, the entropy cost to add to the other two, OC and HC. They have applied their concept in different inventory and logistics situations. Jaber et al. (2011) extended the work of ( Jaber et al., 2004) in a different direction. They added an exergy cost (from destroying efforts/resources) due to entropy. Their total system cost per unit time, $T C(t)$, for an order quantity is the summation of the ordering, holding, entropy and the exergy unit-of-time costs. This chapter includes the 
purchasing cost and modifies the entropy cost to include it in the exergy cost, since entropy is equivalent to exergy destruction. Hence, the "general" form of the total system cost per unit time including the exergetic cost can be written as:

$$
T C(t)=O C(t)+c_{U} d+H C(t)+E x C(t)
$$

The Extended Exergy Analysis (EEA) needed to stock a product is the sum of the equivalent exergetic inputs required in the production of that product as shown in Equation (2.2). To apply the EEA methodology to an inventory system, all associated costs need to be converted into equivalent exergetic values. The ordering $(O)$, purchasing $(P)$ and holding $(H)$ costs can be classified into three exergic values: $E E x_{K, i}, E E x_{L, i}$, and $E E x_{E n v, i}$, where $i=$ $O, P$, or $H$ are measured in $\mathrm{J} /$ order, $\mathrm{J} /$ unit and $\mathrm{J} /$ unit/year, respectively.

\subsubsection{Mass and Energy Balances and Exergy Flow in an Inventory System}

"ISO 13600:1997" has defined an Energy Carrier as a "substance or phenomenon that can be used to produce mechanical work or heat, or to operate chemical or physical processes." (Khalil, 2013). Energy carriers in supply chain processes take different forms; electrical energy, thermal (heat) energy, mechanical work and/or chemical energy. The term $E x_{E n}$ in Eq. (2.2) represents the sum of the amounts of exergy generated by energy carriers entering a production process. These amounts are either computed using the first or second laws of thermodynamics or determined directly from published tables (for a substance or material). Wall (Göran Wall, 1977) classified energy carriers by their energy quality, starting from "extra superior" such as electrical and nuclear energies to "valueless" such as the heat 
radiation from the earth. The extra superior energy carriers, which have pure exergy, can be totally transformed into all other forms of energy. Like the quality of energy carriers, the quality of a certain material can also be expressed as the amount of exergy (per unit) inherent in that material. For example, materials such as silver and copper have $100 \%$ of pure exergy, while minerals dissolved in soil solution have $0 \%$ of exergy. The exergy content of a material can always be computed using the approach of ( Szargut, Morris, \& Steward, 1988).

\subsubsection{The Exergetic Model}

Similar to Eq. (2.2), substituting the exergetic equivalent values of $A, h$ and $c_{U}$ in Equation (4.4) gives:

$$
\begin{aligned}
\operatorname{TExC}(q)= & \frac{E E x_{K, O r}+E E x_{L, O r}+E E x_{E n v, O r}}{q} d \\
& +\left(E E x_{K, P c}+E E x_{L, P c}+E E x_{E n v, P c}\right) d \\
& +\left(E E x_{K, H d}+E E x_{L, H d}+E E x_{E n v, H d}\right) \frac{q}{2} \\
= & \frac{E x_{O r}}{q} d+\frac{E x_{H d}}{2} q+E x_{P C} d
\end{aligned}
$$

The optimal order quantity that minimizes Eq. (4.9) is determined by setting its first derivative to zero and solving for the exergetic $q$ to get:

$$
q_{X}^{*}=\sqrt{\frac{2 d E E x_{O r}}{E E x_{H d}}}
$$

Substituting $q^{*}$ in $T E x C(q)$, reduces Eq. (4.9) to: 


$$
T E x C^{*}=\sqrt{2 d E E x_{O r} E E x_{H d}}+E E x_{P c} d
$$

Equation (4.11) has a similar behavior to the classical EOQ cost function, $T C=$ $\sqrt{2 d A h}+c_{U} d$, that is as $d, A, h$ and $c_{U}$ increase, the total cost also increases. Similarly, as $E E x_{O r}, E E x_{H d}, E E x_{P c}$ and $d$ increase, $T E x C^{*}$ increases.

Let us say one wishes to compare two firms that produce the same product with the same inventory input parameters, but the firms are located in two different countries, $j$ and $k$. If one uses the classical EOQ approach, the inventory policies for both firms are identical, but may not be so if one uses the exergetic approach, i.e.:

$T E x C_{j} \geq T E x C_{k}$

Where,

$$
\sqrt{2 d_{j} E E x_{O r, j} E E x_{H d, j}}-\sqrt{2 d_{k} E E x_{O r, k} E E x_{H d, k}} \geq E E x_{P c, k} d_{k}-E E x_{P c, j} d_{j}
$$

\subsection{A Numerical Example}

This section presents a numerical study that uses the exergetic costs and derives the optimum EOQ for an arbitrary product produced at the same time in three different firms located in the USA, Germany, and China. First, the optimum EOQ and costs need to be calculated using the classical model. Then, the EOQ and costs need to be computed using the exergetic model and compare the results with the result obtained from the conventional model. Table (4.1) provides the input parameters used in the analysis. Note that under the 
heading Monetary Values, and for example, $A_{K}+A_{L}+A_{E n v}=60+120+20=200$. The other two parameters, $h$ and $c_{U}$, are partitioned similarly. The classical EOQ model uses the equations provided in Section 4.2 that suggest ordering 1155 units every 0.6 years with a total cost of $4692.82 € /$ year of which $692.82 € /$ year are the ordering and holding costs.

Table 4.1. The parameters used in the inventory analysis.

\begin{tabular}{|c|c|c|c|c|c|}
\hline Parameter & Value & Units & \multicolumn{3}{|c|}{ Monetary Values } \\
\hline Labour cost & 10 & $€ / \mathrm{hr}$ & Cap. & Labour & Env. \\
\hline$A$ & 200 & $€ /$ Order & 60 & 120 & 20 \\
\hline$c_{U}$ & 2.00 & $€ /$ unit & 0.75 & 1 & 0.25 \\
\hline$h$ & 0.60 & $€ /$ unit/year & 0.2 & 0.3 & 0.1 \\
\hline$d$ & 2000 & unit/year & & & \\
\hline
\end{tabular}

To determine the exergetic EOQ policy, the calculation uses the classical inventory parameters in Table (4.1) and the exergetic values relating to the three countries in Table (4.2) where the three firms operate. Table (4.2) does not list $e e_{E n v}$ as no data is provided. However, the approach of Chen and Chen (G. Q. Chen \& Chen, 2009) has been used to estimate $E E x_{E n v}$, where it is determined by multiplying the money allocated for environmental remediation by $e e_{K}$. The values are computed using the discussion and equations provided in Chapter 2, and their corresponding $E E x_{i}$ values are summarised in Table (4.3).

Note that in Table (4.3), the subscript $i=O r, P c$, and $H d$ (see Eq. (4.9)), where $O r$ stands for ordering and associated with the order cost $A, P$ for purchasing and associated 
with the unit purchase cost $c_{U}$, and $H d$ stands for holding cost and associated with the unit purchase cost $h$. For example, for the USA $E E x_{K, O}=171 \mathrm{MJ}$, for Germany $E E x_{L, P}=6.83 \mathrm{MJ}$, and for China $E E x_{E n v, H d}=1.4 \mathrm{MJ}\left(1\right.$ joule $\left.=10^{-6} \mathrm{MJ}\right)$. To facilitate the comparison, the example assumes that the three firms are producing the same product and have the same inventory input parameters, which are of $A, c_{U}, h$ and $d$.

Table 4.2. The exergetic parameters used in the inventory analysis.

\begin{tabular}{|l|l|l|l|l|}
\hline Property & Unit & USA & Germany & China $^{\mathbf{a}}$ \\
\hline$E x_{\text {in }}$ & MJ/Year & $4.78 \mathrm{E}+16$ & $9.83 \mathrm{E}+13^{\mathrm{b}}$ & $4.67 \mathrm{E}+16$ \\
\hline$M 2$ & $\mathrm{~B} € /$ Year & $7.01 \mathrm{E}+3$ & $2.27 \mathrm{E}+4^{\mathrm{c}}$ & $2.39 \mathrm{E}+3$ \\
\hline$\alpha$ & - & 0.145 & 0.557 & 0.0015 \\
\hline$\beta$ & - & 1.43 & 1.31 & 0.477 \\
\hline$e e_{K}$ & $\mathrm{MJ} / €$ & 2.85 & 3.16 & 14.01 \\
\hline$e e_{L}$ & $\mathrm{~J} / \mathrm{WHr}$ & 72.80 & 68.30 & 48.70 \\
\hline
\end{tabular}

a - From the electronic annexes of (Peiró et al., 2010)

b - Calculated by using Eq. (2.9) and data from (Sciubba, 2011)

c - From (Sciubba, 2011)

Table (4.4) summarises the optimal exergetic inventory policies for the three firms listed respectively in the USA, Germany, and China, which obtained by employing Equations (4-9) - (4.11). 
Table 4.3. The exergetic values of $A, c_{U}$, and $h$. (Values are in MJ).

\begin{tabular}{|l|l|l|l|l|l|}
\hline \multicolumn{2}{|l|}{ Country } & $\boldsymbol{E} E \boldsymbol{x}_{\boldsymbol{K}, \boldsymbol{i}}$ & $\boldsymbol{E} \boldsymbol{E} \boldsymbol{x}_{\boldsymbol{L}, \boldsymbol{i}}$ & $\boldsymbol{E} \boldsymbol{E} \boldsymbol{x}_{\boldsymbol{E n v}, \boldsymbol{i}}$ & Total \\
\hline \multirow{4}{*}{ USA } & $A$ & 171.00 & 873.840 & 57.00 & 1102.84 \\
\cline { 2 - 6 } & $c_{U}$ & 2.14 & 7.28 & 0.71 & 10.13 \\
\cline { 2 - 6 } & $h$ & 0.57 & 2.18 & 0.29 & 3.04 \\
\hline \multirow{4}{*}{ Germany } & $A$ & 189.60 & 819.00 & 63.20 & 1071.80 \\
\cline { 2 - 6 } & $c_{U}$ & 2.37 & 6.83 & 0.79 & 9.99 \\
\cline { 2 - 6 } & $h$ & 0.63 & 2.05 & 0.32 & 3.00 \\
\hline \multirow{4}{*}{ China } & $A$ & 840.60 & 535.26 & 420.30 & 1796.16 \\
\cline { 2 - 6 } & $c_{U}$ & 10.51 & 4.87 & 3.50 & 18.88 \\
\cline { 2 - 6 } & $h$ & 2.80 & 1.46 & 1.40 & 5.66 \\
\hline
\end{tabular}

Table 4.4. Exergetic inventory policies for the three firms.

\begin{tabular}{|l|l|l|l|}
\cline { 2 - 4 } \multicolumn{1}{c|}{} & \multicolumn{1}{c|}{ USA } & Germany & \multicolumn{1}{c|}{ China } \\
\hline EOQ (units) & 1204 & 1196 & 1126 \\
\hline Cycle time (yearr) & 0.60 & 0.60 & 0.55 \\
\hline TExC (MJ/year) & 23924.14 & 23553.62 & 44130.50 \\
\hline
\end{tabular}

To gain further insights, varied the percentages that capital, labour, and environmental remediation represent of the order cost, $A$, the unit purchase $\operatorname{cost}, c_{U}$, and the unit holding cost, $h$, e.g. when $50 \%, 30 \%$, and $20 \%$ and $A=200, A_{K}=0.5 \times 200=100, A_{L}=$ $0.3 \times 200=60$, and $A_{E n v}=0.2 \times 200=60$. The other two parameters, $c_{U}$ and $h$, are partitioned using the same set of percentages. This allows the three firms to have the same $q_{x}{ }^{*}=q=$ 1155. For each set, compute the total exergetic costs for the three firms operating in the USA, Germany and China. The sets where (50\%, 30\%, and 20\%), (20\%, 50\%, and 30\%), 
$(30 \%, 20 \%$, and $50 \%), \ldots$, etc., with one set where the percentages are equal; i.e., $(33.33 \%$, $33.33 \%$, and $33.33 \%$ ). The results showed the firm located in the USA had lower TExC than that in Germany for sets $(50 \%, 30 \%, 20 \%),(50 \%, 20 \%, 30 \%),(20 \%, 30 \%, 50 \%),(30 \%$, $20 \%, 50 \%)$, and $(33.33 \%, 33.33 \%, 33.33 \%)$, which were $19614.11,17534.25,19614.11$, 17534.245, and 20307.40, respectively. While those of Germany, for the same sets of percentages were 19989.07, 18269.15, 19989.07, 18269.15 and 20562.37. The results showed that the firm located in Germany had lower TExC than that in the USA for sets $(20 \%, 50 \%, 30 \%)$ and $(30 \%, 50 \%, 20 \%)$, which were 23428.91 (for the USA 23773.83) for

both. The TExC values for China were the highest for all sets of percentages; however, it worth noting that China had its lowest TExC value, 44290.84 , for sets $(20 \%, 50 \%, 30 \%)$ and $(30 \%, 50 \%, 20 \%)$, and the highest, 57164.18 , for sets $(50 \%, 20 \%, 30 \%)$ and $(30 \%, 20 \%$,

$50 \%$ ). The results of this simple analysis show that the components of the order cost, $A$, the unit purchase cost, $c_{U}$, and the unit holding cost, $h$, corresponding to capital, labour, and environmental remediation very much affect the exegetic performance of an inventory system. These results are in conformance with the condition noted following Eq. (4.11). So, a firm may have to look for possible improvements in the system that will reduce the waste whether that is in material, labour, pollution, energy, etc.

\subsection{Results and Discussion}

The results in Table (4.4) show that it is cheaper to produce in Germany than it is in the USA, which is cheaper than producing in China. This is contrary to the notion that producing in developing countries (such as China) is less costly than producing in Europe 
or North America because of the advantages that developing countries have (Puckett, 2003); (Curtis, 2010); (SERI, 2009), such as lower wages, cheaper technologies, inexpensive material, less government regulations, etc. Furthermore, countries like China, which have less stringent environmental regulations, have cities that are among the most polluted in the world (Cole, Elliott, \& Zhang, 2011). It is also evident that the lower production costs in developing countries (such as China) come at the expense of the global and local sustainability requirements. The results show that producing in an OECD country (e.g., USA or Germany) has less negative impact on global sustainability. This fact may encourage OECD countries to pay more attention to facilitating the establishment of local production businesses of whatever size is appropriate, including small to medium size enterprises (SME). Local businesses have several advantages:

- Better health, workplace safety, and environmental regulations. This means better product quality and worker welfare, less waste and GHG emissions, etc. (e.g., Field, 2012).

- Locally produced goods reduces GHG emissions by transporting and distributing goods. It enriches the economies of local communities and contributes to their social programs.

Considering sustainability on a global scale, the analysis suggests that producing in an OECD country is less expensive and more sustainable for a future GHG-constrained world. A sustainable world can be achieved by applying the right policies and regulations that would assist the continuity of life on this planet without depleting natural resources and destruction of habitats and the wildlife. Preserving the resources has a positive impact on the economic development of society. For instance, environmental sustainability makes resources more available at lower unit prices. Social sustainability results in better work 
environments and workers' welfare and health, less medical expenses, lower disability insurance premiums, job tenure and better productivity. The results of this study show that there is an alternative "price tag" of a product that can be computed based on its exergy content. This result is similar to that found by (Sciubba, 2013).

Contrary to the classical economic and business theories, the results of this study suggest that although it was assumed that the inventory parameters are the same for the three firms, savings could be realized as a consequence of the differences between the inflows and outflows of exergy among the three countries where the firms are located. Also, it was shown that the structure of the order, purchasing and holding costs corresponding to capital, labour, and environmental remediation affect the exergetic total cost of a firm. So, a firm may have to be more careful when allocating its resources and may have to look for opportunities that will reduce its exergetic cost without sacrificing its profits or market share.

These observations may encourage both developed and developing countries to take more advantage of applying the right sustainable policies without decelerating their economic development but with reducing unsustainable economic growth. It is worth mentioning that the availability of an appropriate database related to EEA can be beneficial for industries by integrating the exergetic content into the product's design and greening their supply chain activities. Hence, employing EEA by local environmental agencies could be more meaningful when evaluating the impact that some industries have on the environment. It may also provide useful measures to determine how environmentally friendly product is. Despite its popularity, the EOQ has been critiqued by few researchers in the basis that its assumptions are ever met (e.g., Jaber, 2009). The usage of the EOQ by practitioners is limited due to the inability of estimating its parameters accurately. Also 
because the EOQ model does not encompass all costs that could be incurred by a complex production system. Over the years, there have been many attempts to capture some of the hidden costs, which resulted in many variants of the EOQ model. Yet, there is no universal EOQ model. This thesis builds on the work of (Jaber et al., 2004) who used thermodynamic principles to estimate hidden and challenging to estimate costs. They suggested introducing a cost component into the EOQ cost function, entropy cost, that represent an umbrella under which the "unknown" or cost that may cause the EOQ to fail in practice fall. This research provides a step forward towards universalizing the EOQ, but more work is still needed in this regard. Unless the developed models are tested in different relevant real-world setting one cannot conclude the models developed in this thesis could be safely used by managers.

\subsection{Summary and Conclusions}

This chapter contributes to the literature by applying the principles of the Extended Exergy Analysis to inventory management to present some of its hidden costs. It modified the classical EOQ model to include the three pillars of sustainability: economic, environmental, and social. The exergetic EOQ model presented in this study is a more realistic representation of an inventory system that operates in a world where being economical, environmentally and socially sustainable has become the objective for many firms. The new exergetic EOQ model has been used to calculate and analyze the size of the EOQ and the total cost of three inventory systems located in the USA, Germany, and China.

It used Joules as a universal unit of measure instead of monetary units, which has traditionally been utilized in the inventory management literature. The rationale for using 
Joules is that energy is needed to drive all production and logistics activities. The results produce a different EOQ for the three countries because of the different equivalent exergy embodied in capital, labour, and environmental remediation costs. Accordingly, the total cost of inventory is different in the three countries. The results showed that the exergetic inventory model disagrees with the economic theories that countries/organisations currently follow because considering sustainability on the global scale, producing in an OECD country is less expensive and more sustainable for a future GHG - constrained world.

A major advantage of using the exergetic EOQ model is the meaningful comparison between firms that can produce the identical product in different places (societies) and time. Such a comparison makes it easier to determine where to locate product manufacture based on the amount of exergy in production and related processes consume. Hence, it may not always be beneficial to select a product that comes from a society with low wages as more exergy is consumed to produce it. This result is in agreement with the study of (Belli \& Sciubba, 2007) who argued that it may be of benefit to the planet to reduce the consumed exergy in producing products. Accordingly, the EEA methodology can be employed to evaluate the sustainable level of a product, system or society and provide a measure of their environmental impact in a world increasingly concerned about climate change. Limitations of the EEA model may include:

(a) The accuracy of the results depends on the assumptions made when applying EEA to the inventory system.

(b) The EEA methodology in inventory management may have limitations when more than a single society (country) is involved in the production process (or inventory system) of a product. 
(c) The lack of data related to the calculation of the total exergy input of society, the amount of exergy embodied in the labour force and the exergy of the raw materials and energy used to produce a product.

The Followings are the implications of limitations:

- For point (a), the values of the input parameters were taken from published studies as indicated in Table (4.2).

- For point (b), the equivalent extended exergy of labour is an aggregated value that calculates the contribution of workers with different skills. For example, a hospital which receives the contribution of a workforce of different skills, experience, knowledge, and qualification.

- The accuracy and time of collecting the Disaggregated data (data that has been taken from aggregated data and divided into smaller information units) can play a major role. This point is opposite to the above point of labour which obtained with Aggregate data (data that collected from two or more sources).

Some of the barriers for the results of this research are:

- The dominance of the classical economic theories that concern the monetary values only.

- The insufficient incentive that offered in developed countries to encourage firms to produce locally.

- The poor rules and law that deal with the implementation of the sustainability in businesses. 
- The knowledge of average consumers and other stakeholders about the sustainability in general and particularly related terms such as joule, exergy, thermodynamics, etc.

An interesting finding of this research is that the lowest cost solution could be the worst exergetic solution and that, in addition, a specific company can improve its 'efficiency' in an exergetic sense to help to overcome the macro advantages and disadvantages of specific locations. In other words, there are other parameters than those assessed in this research. Good management can usually identify niches that will overcome obvious inherent disadvantages. This research assumed that the three firms produce the same product for their local markets. That is, importing or exporting to and from a country has not been considered, and subsequently, no exergy transfer occurs in-between countries. That is, it would be interesting to investigate the problem of this paper when the firm in either China or Germany supplies semi-finished products or components to the (manufacturing) firm in the USA. The problem could also be extended to compare the exergetic performance of a domestic supply chain and a global one. 


\section{CHAPTER (5) - DERIVING AN EXERGETIC ECONOMIC PRODUCTION QUANTITY MODEL FOR BETTER SUSTAINABILITY}

\section{$5.1 \quad$ Introduction}

The Economic Production/Order Quantity (EPQ/EOQ) model has been widely used by academicians and practitioners (Glock et al., 2014). Many researchers have modified the model to fit specific manufacturing scenarios. Andriolo et al. (2014) and Bushuev, Guiffrida, Jaber, \& Khan (2015) provided concise reviews of these works. Some researchers have called for new thinking about inventory and logistics management. For example, Chikán (2011) argued that classical models no longer describe today's inventory and logistics situations because of the fundamental changes in business, while Bonney \& Jaber (2011) advocated the need to develop environmentally responsible inventory models. Jaber et al. (2004) suggested that one could improve production systems by applying the first and second laws of thermodynamics to reduce system entropy (disorder). They developed and incorporated a new cost component into the EPQ/EOQ model, "entropy cost," which may represent the sum of the hidden costs inherent in inventory systems that classical models do not consider. Jaber et al. (2011) introduced the concept of exergy cost, to represent the amount of useful energy wasted. "Exergy Analysis" is a promising method that has been used to reduce the depletion of natural resources and the excessive use of energy (Dincer \& Rosen, 2012). It analyzes the inputs and outputs of a system along with the wasted (lost/unused) exergy in order to improve the system's efficiency.

Production and inventory activities are among those responsible for greenhouse gas (GHG) emissions. The quantity of GHGs (especially $\mathrm{CO}_{2}$ ) emitted is sometimes used to 
evaluate the environmental performance of a business or a firm. An increase in environmental awareness and a desire to control GHG emissions means that various schemes of pricing emitted carbon have been introduced in recent years. The aim of such schemes is to encourage businesses and individuals to seek and utilize tools and strategies that reduce carbon emissions. Andriolo et al. (2014) and Bushuev et al. (2015) report investigations into how to reduce GHG emissions in inventory and logistics systems. In this regard, exergy analysis has sometimes been used to capture the exergetic cost of a GHG emission resulting from energy generated from non-renewable resources. This chapter introduces an exergetic version of the EPQ model to compute the amount of exergy consumed when producing and storing a product and uses it to select the proper level of sustainability. The study also uses thermodynamic concepts to derive a new exergetic sustainability indicator for a production-inventory system to answer whether "can sustainability be profitable?" In particular, the study uses the Extended Exergy Accounting (EEA) method introduced by (Sciubba, 2001), covering the basic production factors that are not usually considered in exergy analysis at the socio-economic scale, i.e., capital, labour, and environmental remediation (Chen \& Chen, 2009). Seckin, Sciubba, \& Bayulken (2013) and Rocco et al. (2014) report other relevant and interesting studies. The first, (Seckin et al., 2013), employs the extended exergetic efficiency, evaluated as the ratio of the sectoral output to input fluxes, to show the unsustainable structure of the transport sector in Turkey, while the second (Rocco et al., 2014) graphically presents the exergy cost function and the extended exergy consumed by a system during its life cycle. The authors claim that such graphs could be useful to compare the "degree of unsustainability" of alternative production 
lines and/or to determine the unsustainability of a commodity, as reflected by the amount of non-renewable resources embedded in a product.

\subsection{Exergy, Thermodynamics Laws, and Their Applications}

Generally, heat flows naturally from a system with a higher temperature (more energetic molecules) to one with a lower temperature (less energetic molecules). Heat transfer by conduction (for stationary objects) can be expressed in the following general form (Andresen \& Gordon, 1992) and as illustrated in Figure (5.1):

$$
Q=K_{n}\left(T_{0}-T\right)=\hat{C}_{P} \frac{d T}{d t}
$$

Here, $K_{n}$ represents the generalized thermal conductance (W/m.K), $\hat{C}_{P}$ is the system's heat capacity at constant pressure $(\mathrm{J} / \mathrm{kg} \cdot \mathrm{K}), T_{0}$ is the temperature of the surroundings, and $T$ is the system temperature (both in Kelvin, $\mathrm{K}$ ). The reservoir temperature $T_{0}(t)$ is a function of time and can interact without losses to heat or cool the system to the desired final temperature $T(t)$. At a specific time $\tau$, the proposed system will be heated from a known initial temperature $T(0)$ to $T(\tau)$, where $t \in[0, \tau]$.

Heat transfer occurs and is employed widely in our daily life, for example, when cooling a building occupied by a number of people in order to provide a comfortable environment. This process can be performed utilizing a heat pump (HP). A heat pump is a device that uses work, $W$, to "move" heat from a cold space to a warmer one. 


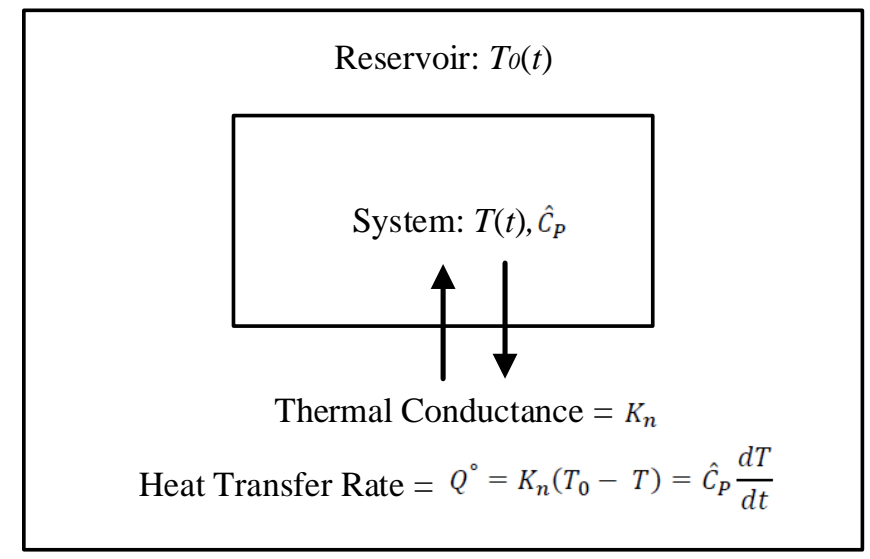

Figure 5.1. Schematic of a one-node thermal model for a system exchanging heat with a reservoir (based on (Andresen \& Gordon, 1992)).

When the number of occupants in a building increases, the cooling requirements for a comfortable environment increase. In this case, the building's temperature will rise and may reach $T=T_{H}$. This will activate the HP, which will obtain work from electricity, and cool the building to $T=T_{c}$. Hence, the heat transfer that occurs in this situation can be expressed according to Eq. (5.1) as: $Q_{c}=K\left(T_{H}-T_{c}\right)$, where $Q_{c}$ is the amount of heat that is extracted from the cold resource and input to the warmer environment. Figure (5.2) illustrates this cooling cycle of a heat pump.

For a generic cooling cycle, like the one shown in Figure (5.2), the energy balance when operating at steady state conditions can be written as:

$$
\dot{W}_{\text {in }}=\dot{Q}_{H}-\dot{Q}_{c}
$$

The total exergy wasted associated with this cooling cycle can be obtained by taking the difference between the exergy supplied (work input) and the exergy of the heat 
withdrawn from the low-temperature reservoir (exergy recovered) (Cengel \& Boles, 2010). This can be written as:

$$
\dot{E} x_{\text {waste }}=\dot{W}_{\text {in }}-\dot{E} x_{Q c}
$$

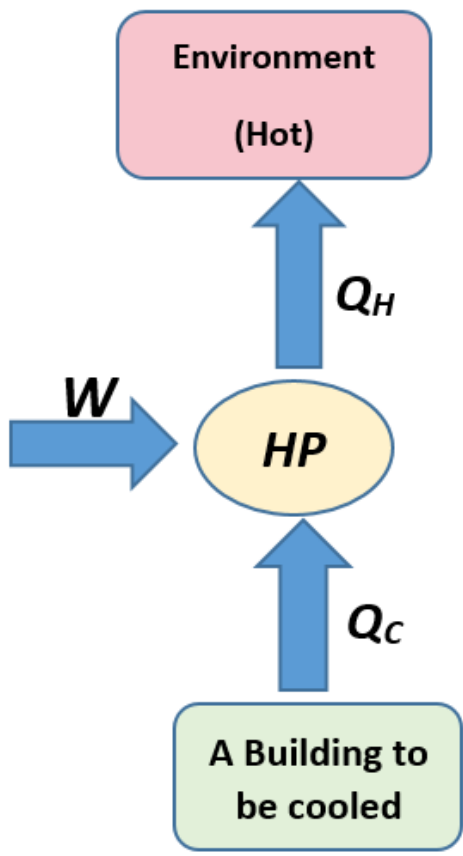

Figure 5.2. Schematic diagram of the cooling cycle of a heat pump.

The energy efficiency of the cooling cycle of a heat pump is measured by its coefficient of performance in cooling mode $(C O P C)$, which can be expressed as (Cengel \& Boles, 2010):

$$
C O P_{C}=\frac{\text { Desired Output }}{\text { Required Input }}=\frac{Q_{c}}{W_{\text {in }}}
$$


For a heat pump, the $C O P$ of the Carnot cycle (a fully reversible cycle) can be written as (Xu, 1992):

$$
C O P_{r e v}=\frac{Q_{c}}{W_{r e v}}=\frac{T_{c}}{T_{H}-T_{c}}
$$

Then, the exergy coefficient, $\eta_{\text {ex }}$, can be written as $(\mathrm{Xu}, 1992)$ :

$$
\eta_{e x}=\frac{W_{\text {rev }}}{W_{\text {in }}}=\frac{Q_{c}}{W_{\text {in }}\left(\frac{T_{c}}{T_{H}-T_{c}}\right)}
$$

Also, $\eta_{\text {ex }}$ can be written as (Cengel \& Boles, 2010):

$$
\eta_{\text {ex }}=1-\frac{E x_{\text {waste }}}{W_{\text {in }}}
$$

Since Eqs. (5.6) and (5.7) are equal, assuming $T_{H}=T_{0}$, where $T_{0}$ is the ambient temperature, it can be written as:

$$
E x_{\text {waste }}=W_{\text {in }}-Q_{c}\left(\frac{T_{0}}{T_{c}}-1\right)
$$

\subsection{Thermal EPQ Model}

The model presented in this section extends the simple model developed in Chapter

(4) by including the work to model the time of processing, the functional representations of GHG emissions and energy usage, the use of a sustainability index and assesses the exergy wasted in product production and diffusion process. 


\subsection{Exergetic Inventory Approach}

Various investigations link thermodynamics to economic systems in novel ways, e.g., introducing exergy and entropy concepts into evaluating economic systems (Jaber et al., 2004). Examples are employing the second law of thermodynamics to model the coordination in a two-level supply chain (Jaber et al., 2006), and employing the concept of entropy cost to evaluate the economic order quantity for repair and waste disposal ( Jaber \& Rosen, 2008). These studies discuss the analogy between thermal and inventory systems from a heat transfer (or thermodynamic) point of view. These studies mostly consider heat transfer by conduction but do not account for the energy transfer across the boundaries of a system involving work interactions.

Work transfers cross boundaries of a system can affect the internal energy of the system (Cengel \& Boles, 2010). One of the major dissimilarities between heat and work transfer, from a thermal view, is that heat is a low-grade energy while work is a high-grade energy (Rathore, 2010). This is because the value of organized energy is much more than disorganized one, and a major application area of thermodynamics is the conversion of disorganized energy (heat) into organized energy (work). Organized energy can all be converted to disorganized energy, but only a part of disorganized energy can be converted to organized energy (Cengel \& Boles, 2010).

The laws of thermodynamics govern the effect of work, energy, and entropy. Employing these laws assists in the study and analysis of the energy transfers by heat and work between a system and its surroundings. Therefore, this chapter employs the laws of thermodynamics, and uses the analogy between thermal and production systems, i.e. 
analogously to the manner in which heat is transferred from a hotter to a colder location; a product can flow from a production system to the market when its price is reduced below its market price. Price is an economic property analogous to temperature as a thermal property. Thus, Jaber et al. (Jaber et al., 2004) claimed that the commodity flux, or demand rate, $d(t)$, is analogous to the change in energy of a thermal system, and can be expressed as:

$$
d(t)=-K_{P}\left(P(t)-P_{0}(t)\right) d t
$$

The negative sign in Eq. (5.9) indicates that a flow occurs from the system to its surroundings when its price is lower than the market price; i.e., when $P(t)<P_{0}(t)$. The total demand in cycle $i$ of length $T_{i}, D\left(T_{i}\right)$, can be determined from Eq. (5.9) as (M. Y. Jaber et al., 2004):

$$
D\left(T_{i}\right)=\int_{0}^{T_{i}} d(t)=\int_{0}^{T_{i}}-K_{P}\left(P(t)-P_{0}(t)\right) d t
$$

Economically, market structure refers to the way industries organized based on the number of firms, type of products, ease of entry or exit, the amount of market power, and level of government intervention. Based on that, there are four main types of market structure, which are (O'Connor, 2004): perfect competition, monopolistic competition, oligopoly, monopoly. For further details about each type, the reader can visit the previous reference. This thesis considers a market to be of a "perfect competition" structure. It has the following features: (a) a significant number of firms operate independently and produce identical products, (b) firms feature low barriers to entry-factors that discourage or prevent firms from joining or leaving the market, (c) firms are "price takers", which means that the 
force of supply and demand not the pricing policy of a firm, determine the price of a product, and (d) the role of government in regulating price.

The unit purchase/production cost should be lower than $P$. The purchased/produced quantity can be analogous to $Q_{c}$ in a heat pump, which represents the amount of heat that is extracted from the cold region and put into the warmer region. Demand increases when the product's price, $P$, is less than the market price, $P<P_{0}$. Hence, this term is analogous to $T_{c}$ in a heat pump, while $P_{0}$ is analogous to $T_{H}$ (or $T_{0}$ since it was assumed $T_{H}=T_{0}$ ).40+3.26

In order for the heat (produced quantity) to be able to cool a hot market (satisfy demand), it needs an input of work (production) to create a flow (of items). The money invested, total annual costs or $T C(P)$, in production, inventory and delivery activities represent the work to be done by the system to satisfy demand. Other essential elements of the inventory/production process include, but are not limited to energy, raw materials, labour force, physical assets and equipment, and transportation. Each of these requirements should be included when determining the cost of the product. These requirements are needed to convert raw material into a product. Hence, they can be considered as the prime movers required for transforming a unit of material/component (unused parts) into a unit of output (useful product).

Figure (5.3) illustrates these requirements are similar to the work in thermal processes. Accordingly, it is reasonable to consider the total cost to be analogous to the work that a heat pump requires. 


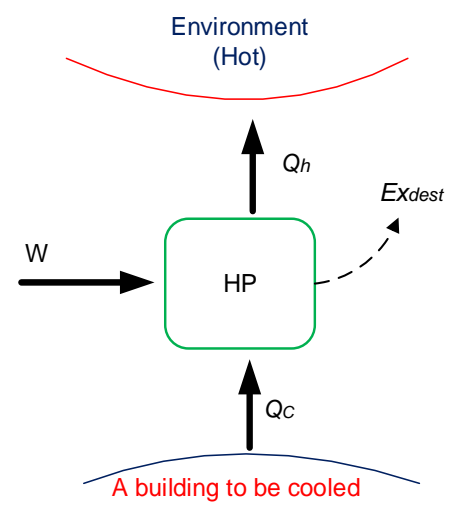

(a)

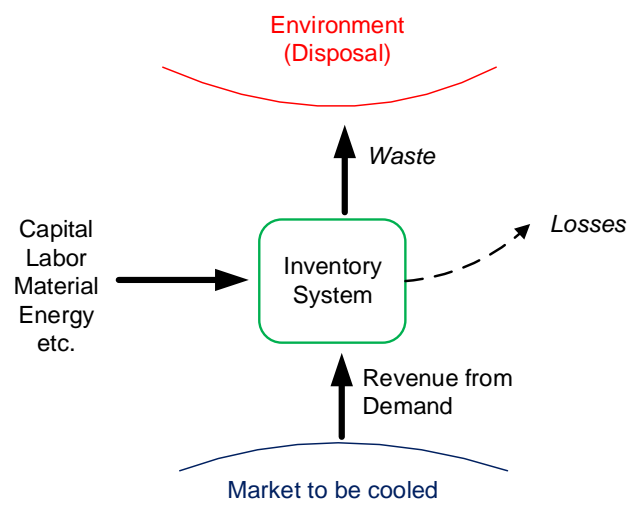

(b)

Figure 5.3. Schematic diagrams of (a) thermal power cycle, and (b) production system.

If the work rate (total cost invested per year) is considered analogous to the rate of effort that transforming a unit of material/component to a unit of output expends, then wasted exergy could be compared to lost production. For instance, if inefficiencies in the system total zero, then a firm should be able to stock or produce a quantity with a magnitude of $d^{*}$. However, if it ended up stocking or producing the demand $(d)$ only, where $d^{*}>d$, then potentially there is lost revenue of $\left[P \cdot\left(d^{*}-d\right)\right]$, which represents the value of wasted exergy.

Similar to the Carnot Factor, $C F$, which measures the thermal efficiency of a Carnot power cycle, a firm can measure its effectiveness in cooling the market by means of a Price Factor, $P F$. The lower the price at which a firm can offer its product into the market, the more efficient it is. Reducing the product's price, $P$, results in increasing the demand 
according to Eq. (5.9). This is similar to the process of extracting more heat from a hot building in order to cool it. The $P F$ can be expressed as:

$$
P F=\frac{P_{0}-P}{P}=\frac{P_{0}}{P}-1
$$

Eq. (5.11) shows that $P$ is inversely related to $P F$, and that the larger the gap between $P$ and $P_{0}$ the higher the rate of $P F$ a firm can have and vice versa (where $P_{0}$ is fixed for $\forall t$ ). For example, if a firm offers its product or service at the same market price $\left(P_{0}\right)$, then its $P F=0$, and it will experience a zero demand for its product. This means that the firm does not expend any effort in cooling the market demand for its product or service. Also, since $P$ is related to the product's cost, $c_{U}$, then reducing $c_{U}$ can lead to reducing $P$. Major strategies to reduce $c_{U}$ are to reduce energy and materials waste and to have wiser consumption of capital and labour. Since a demanded quantity will be sold to customers with a price $P$, then, as sales volume rises, revenue will flow into the system. Hence, $Q_{c}$ represents the sales volume (or revenue, i.e., demand $\times$ price).

Finally, the exergy balance (the cost of wasted exergy) of an inventory system in terms of monetary units can be written similarly to Eq. (5.8) as (if $P(t)=P$ and $P_{0}(t)=$ $P_{0}$ for $\left.\forall t\right)$ :

$$
\begin{gathered}
E x_{\text {waste }}=T C(\cdot)-d \cdot P\left(\frac{P_{0}}{P}-1\right)=T C(\cdot)-d\left(P_{0}-P\right) \\
=T C(P)-K\left(P_{0}-P\right)^{2}
\end{gathered}
$$

where $E x_{\text {waste }} \geq 0$, and $T C(\cdot)$ is the total cost function of the system. Here, the term $d \cdot P$ can be considered as the rate at which work is done, or energy is transmitted. 


\subsubsection{Main Assumptions}

1. $P_{0}>P>c_{U}$, where $P_{0}$ and $P$ are the market equilibrium price and the product's selling price (decision variable) respectively. The term $c_{U}=c_{p}(1+m)$, where $c_{p}$ is the unit production cost and $m$ is a markup decided by the company, represents the minimum acceptable unit price. $P_{0}, P, c_{U}$ and $c_{p}$ are in $\mathrm{mu} / \mathrm{unit}$.

2. $P_{0}$ is constant, which is analogous to the fixed "reservoir" temperature $T_{0}$.

3. A single product is to be produced at one location.

4. The demand rate, $d$, in units/year, is known and constant; i.e. Eq. (5.9), where $d(t)=d=-K_{P}\left(P(t)-P_{0}(t)\right)$ and $P(t)=P$ and $P_{0}(t)=P_{0} \forall t \geq 0$.

5. The production rate, $\rho$, in units/year, where $\rho>d$, is known and constant.

6. The planning horizon is infinite.

7. Shortages are not allowed.

8. All produced items are of perfect quality.

\subsubsection{Model Development}

The model's decision variable is the production quantity, $q$, which is produced during time $T_{P}$. The inventory level, $I$, builds at the rate $\rho-d$ until itreaches a maximum level where production stops. The accumulated inventory is depleted over time $T_{d}$. Figure (5.4) illustrates the behavior of the inventory level for the EPQ model over a cycle of length $T_{i}=T_{P}+T_{d}=q / d$. The total cost, $T C(q)$, per cycle of duration $T_{i}$ for the EPQ model is the sum of the setup cost, $A$, purchasing cost, $P C(q)$, and holding cost, $H C(q)$. The total cost per unit of time, $T C(q) / T_{i}$, is determined as (Waters, 2003): 


$$
\begin{aligned}
T C_{0}(q)= & \frac{A+P C(q)+H C(q)}{T_{i}} \\
= & \frac{1}{T_{i}}\left\{A+c_{U} q+h \int_{0}^{T_{P}}(\rho-d) t d t+h \int_{T_{P}}^{T_{i}}(q-d . t) d t\right\} \\
= & \frac{A d}{q}+c_{U} d+\frac{h}{2} q\left(1-\frac{d}{\rho}\right)
\end{aligned}
$$

where the subscript ' 0 ' denotes the classic EPQ cost function. Here, $A$ is fixed setup cost (mu), and $h$ is the unit holding cost (mu/unit/year).

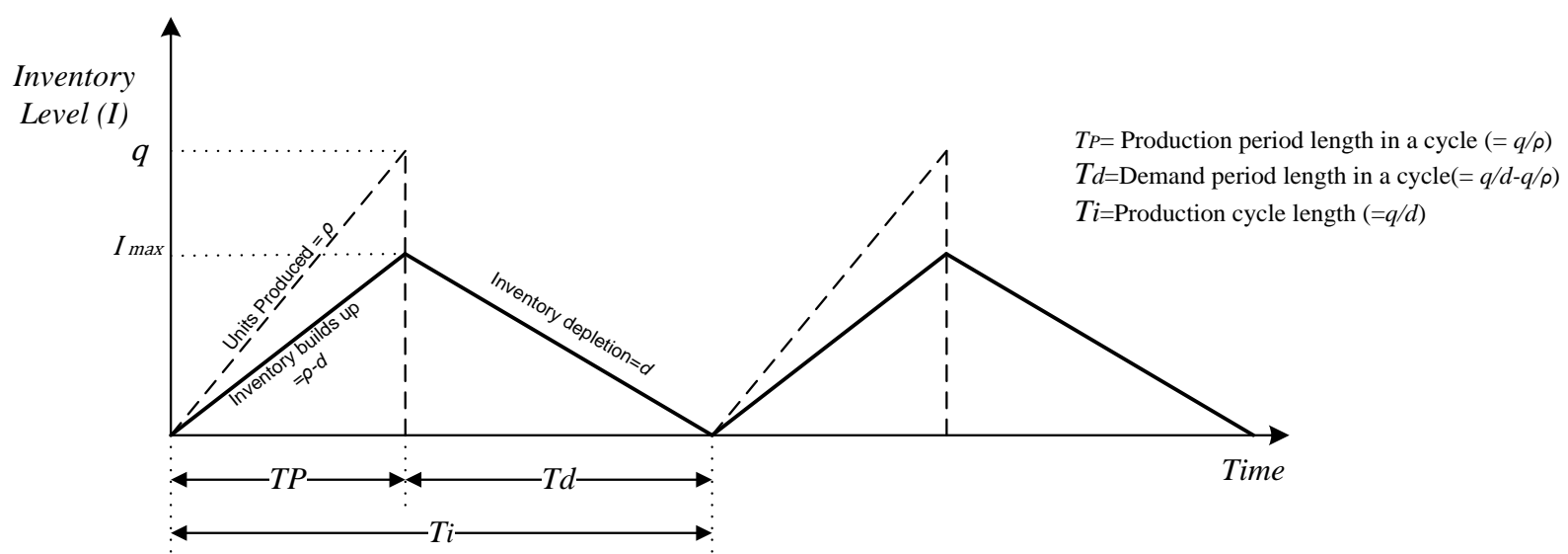

Figure 5.4. The behavior of inventory over time for the EPQ model.

Since labour, $\mathrm{CO}_{2}$ emissions and energy consumption are essential to sustainability; they are included in the model developed in this chapter. The per cycle costs of these can be expressed as (more details can found in Chapter 6): 
- Labour cost: $c_{L} \cdot q$, which includes the cost of any labour activity during the overall inventory process,

- The cost of $\mathrm{CO}_{2}$ emissions from production: $C_{p e}(\rho)=c_{e} q\left(a \rho^{2}-b \rho+c\right)$, in this chapter, $C_{p e}(\rho)$ is considered as the cost expended for the purpose of environmental remediation.

- Energy costs per cycle: $C_{\text {eng }}(q, \rho)=c_{\text {eng }}\left(k_{0}+\frac{k}{\rho}\right) q$

Adding these per unit time costs to Eq. (5.13), and substituting $d=-K_{P}\left(P-P_{0}\right)$, it can be written:

$$
\begin{aligned}
T C_{1}(q, P)= & \frac{A\left(-K_{P}\left(P-P_{0}\right)\right)}{q}+\left(c_{P}+c_{L}\right)\left(-K_{P}\left(P-P_{0}\right)\right) \\
& +\frac{h}{2} q\left(1-\frac{\left(-K_{P}\left(P-P_{0}\right)\right)}{\rho}\right) \\
& +c_{e}\left(-K_{P}\left(P-P_{0}\right)\right)\left(a \rho^{2}-b \rho+c\right) \\
& +c_{\text {eng }}\left(-K_{P}\left(P-P_{0}\right)\right)\left(k_{0}+\frac{k}{\rho}\right)
\end{aligned}
$$

Where the subscript ' 1 ' denotes the classic EPQ cost function added to it the costs of emissions and energy. Hence, the total cost per unit time a firm can experience, when accounting for the cost of wasted units in Eq. (5.12), can be expressed by adding Eq. (5.12) to Eq. (5.14) to get: 


$$
\begin{aligned}
T C_{2}(q, P)= & 2\left(\frac{A\left(-K_{P}\left(P-P_{0}\right)\right)}{q}+\left(c_{P}+c_{L}\right)\left(-K_{P}\left(P-P_{0}\right)\right)\right. \\
& +\frac{h}{2} q\left(1-\frac{\left(-K_{P}\left(P-P_{0}\right)\right)}{\rho}\right) \\
& +c_{e}\left(-K_{P}\left(P-P_{0}\right)\right)\left(a \rho^{2}-b \rho+c\right) \\
& \left.+c_{\text {eng }}\left(-K_{P}\left(P-P_{0}\right)\right)\left(k_{0}+\frac{k}{\rho}\right)\right)-\left(-K_{P}\left(P-P_{0}\right)\right)\left(P_{0}-P\right)
\end{aligned}
$$

Where the subscript ' 2 ' denotes the classic EPQ cost function added to it the costs of emissions, energy and wasted exergy. The optimal production quantity that minimizes Eq. (5.15) is obtained by setting the first derivative of Eq. (5.15) to zero and solving for $q$ to get:

$$
q(P)=\sqrt{\frac{2 A\left(-K_{P}\left(P-P_{0}\right)\right)}{h\left(1-\frac{\left(-K_{P}\left(P-P_{0}\right)\right)}{\rho}\right)}}
$$

Where $P$ is a decision variable. One can substitute Eq. (5.16) into Eq. (5.15) to reduce it to a function of a single variable as follows: 


$$
\begin{aligned}
T C_{2}(P)=2( & \sqrt{2 A h\left(-K_{P}\left(P-P_{0}\right)\right)\left(1-\frac{-K_{P}\left(P-P_{0}\right)}{\rho}\right)}+\left(c_{P}+c_{L}\right)\left(-K_{P}\left(P-P_{0}\right)\right) \\
& \left.+c_{e}\left(-K_{P}\left(P-P_{0}\right)\right)\left(a \rho^{2}-b \rho+c\right)+c_{e n g}\left(-K_{P}\left(P-P_{0}\right)\right)\left(k_{0}+\frac{k}{\rho}\right)\right) \\
& -\left(-K_{P}\left(P-P_{0}\right)\right)\left(P_{0}-P\right)
\end{aligned}
$$

Then, Eq. (5.17) can be optimized subject to $c_{U}<P<P_{0}$, where, from the condition $\rho>d$, then $\rho \geq \theta\left(-K_{P}\left(P-P_{0}\right)\right)$, which leads to $P \geq \max \left(P_{0}-\rho / \theta K_{P}, c_{U}\right)$, where $\theta>1$.

The total exergetic cost per unit of time, TExC, represents the total exergy consumed during all processes of a production-inventory system. This can be obtained by substituting equivalent exergetic values for each term in Eq. (5.17). Hence, the total exergetic cost per unit time, in $\mathrm{MJ} / \mathrm{year}$, can be expressed as:

$$
\begin{aligned}
\operatorname{TExC}(P)=2 & \left(\sqrt{2 A_{x} h_{x}\left(-K_{P}\left(P-P_{0}\right)\right)\left(1-\frac{-K_{P}\left(P-P_{0}\right)}{\rho}\right)}\right. \\
& +e e_{K}\left[c_{P}\left(-K_{P}\left(P-P_{0}\right)\right)+c_{e}\left(-K_{P}\left(P-P_{0}\right)\right)\left(a \rho^{2}-b \rho+c\right)\right] \\
& \left.+e e_{L}\left(-K_{P}\left(P-P_{0}\right)\right) \frac{c_{L}}{s}+\left(-K_{P}\left(P-P_{0}\right)\right)\left(k_{0}+\frac{k}{\rho}\right)\right) \\
& -e e_{K}\left(-K_{P}\left(P-P_{0}\right)\right)\left(P_{0}-P\right)
\end{aligned}
$$


$A_{x}$ and $h_{x}$ are the exergetic values of $A$ and $h$, which can be written as:

$$
\begin{aligned}
& A_{x}=e e_{K}\left(A_{K}+A_{E n v}\right)+\frac{e e_{L} A_{L}}{s} \\
& h_{x}=e e_{K}\left(h_{K}+h_{E n v}\right)+\frac{e e_{L} h_{L}}{s}
\end{aligned}
$$

Here, the subscripts $K, L$ and Env indicate the portion of capital, labour and environmental remediation of each cost $(A$ and $h)$, respectively. The exergetic version of $q$ in Eq. (5.16) can be written as:

$$
q_{x}(P)=\sqrt{\frac{2 A_{x}\left(-K_{P}\left(P-P_{0}\right)\right)}{h_{x}\left(1-\frac{\left(-K_{P}\left(P-P_{0}\right)\right)}{\rho}\right)}}
$$

\subsubsection{Entropic Inventory Approach}

The second law of thermodynamics shows that exergy waste is a measure of the irreversibility of a process and that it is proportional to the increase in entropy. Hence, a good understanding of entropy and the second law is necessary to investigate process inefficiencies. Exergy waste can be evaluated by determining the entropy increase. An investigation for the similarity between inventory and thermal systems following the approach using the "entropy balance" to be done in this study.

Consider the steady-state heat pump illustrated in Figure (5.5). Heat is transferred

through the hot-end heat exchanger due to the temperature difference $\Delta T=T_{H}-$ 
$\left(T_{H}-\Delta T_{H}\right)=\Delta T_{H}$. Similarly, at the cold-end heat exchanger, heat is transferred due to the temperature difference $\Delta T=\left(T_{c}+\Delta T_{c}\right)-T_{c}=\Delta T_{c}$. The entropy balance for such an irreversible system is:

$$
0=-\frac{\dot{Q}_{H}}{T_{H}}+\frac{\dot{Q}_{c}}{T_{c}}+\dot{S}_{g e n}
$$

Rearranging Eq. (5.21) and substituting $\dot{Q}_{H}=\dot{W}_{\text {in }}+\dot{Q}_{c}$ (from Eq. 5.2), to get

$$
\dot{S}_{g e n}=\frac{\dot{Q}_{H}}{T_{H}}-\frac{\dot{Q}_{c}}{T_{c}}=\frac{\dot{W}_{i n}}{T_{H}}+\frac{\dot{Q}_{c}}{T_{H}}-\frac{\dot{Q}_{c}}{T_{c}}
$$

Where $\dot{S}_{g e n}$ represents the entropy generated in the system due to irreversibility during its operation. $\dot{S}_{g e n}=0$, when the system operates under ideal condition, i.e. as a Carnot cycle, and $\dot{S}_{g e n}>0$ when the system departs from the reversible Carnot conditions.

Similar to the heat transfer in the system shown in Figure (5.5), demand drives the flow of items from an inventory system to the market. In inventory systems, commodity flows from the production facility to the finished items inventory due to the difference between $c_{U}$ and $P$ (production-end). In addition, items in the finished inventory flow to the market due to the difference between $P$ and $P_{0}$ (sales-end), where production and sales ends are analogous to the cold and hot ends shown in Figure (5.5). 


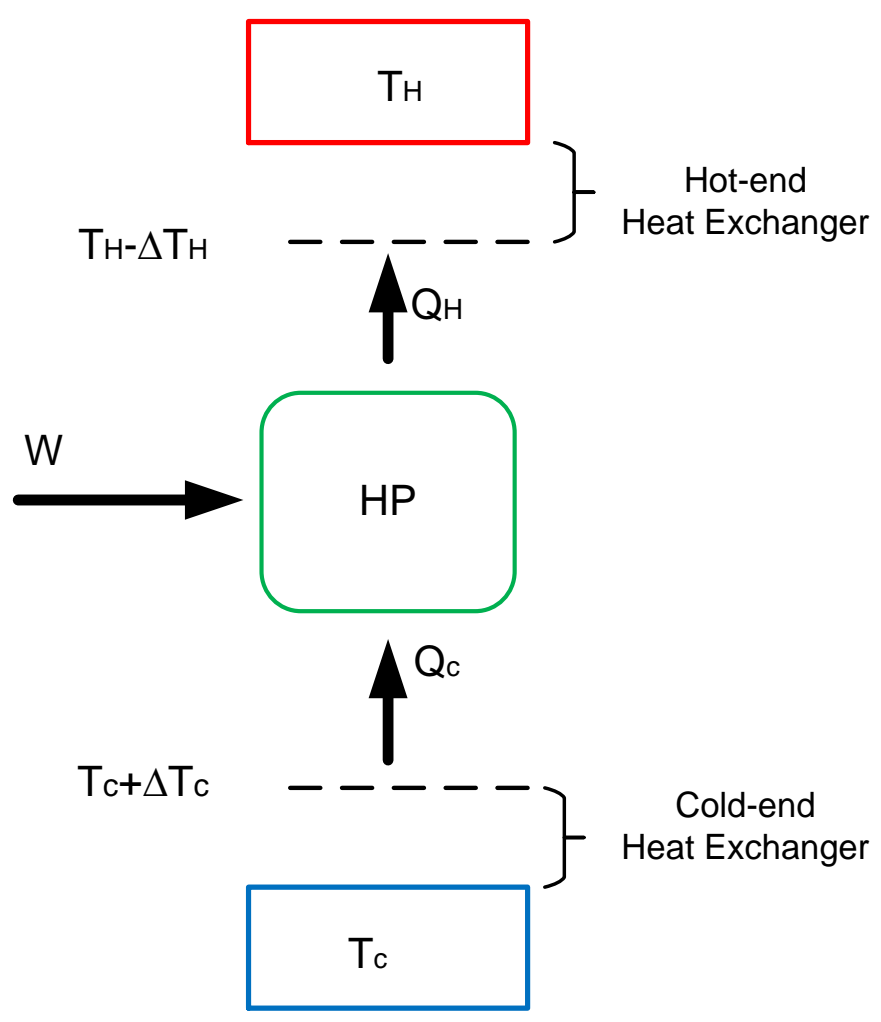

Figure 5.5. Steady-state heat pump with finite hot-end and cold-end thermal conductance (based on (Bejan, 1996))

The demand rate (flow) is fixed through the system, where the total value of goods increases as items (from $d . c_{U}$ to $d . P$ ) move from production to the market. Akin to an irreversible thermodynamic process, in an inventory system, the commodity flow process is irreversible too. That is, some wasted raw materials, energy and labour effort cannot be regenerated and are lost forever. This waste can be considered to be the entropy generated in the system, $\sigma_{g e n}^{\cdot}$. As with Eq. (5.22), $\sigma_{g e n}^{\cdot}$ is in units/unit time as:

$$
\dot{\sigma}_{g e n}=\frac{d c_{U}}{P_{0}}+\frac{d P}{P_{0}}-\frac{d P}{P}=-K_{P}\left(P-P_{0}\right)\left(\frac{c_{U}}{P_{0}}-1+\frac{P}{P_{0}}\right)
$$


where $d \cdot P / P_{0}$ represents the entropy generation associated with pushing the products to the market (entropy of sales), while $d \cdot c_{U} / P_{0}$ represents the entropy generation associated with producing/stocking the products (entropy of production/stocking).

Note that $\sigma_{g e n}^{\cdot}$ represents the total units wasted (i.e. which could have been produced but were lost because of entropy degradation effects). Continuing with the cost and thermodynamic analogy, the associated cost of the units wasted per unit time can be expressed in a similar way to the change in the entropy $\left(S_{g e n}^{*}\right)$ of a thermal system. Note also that Eq. (5.23) is equal to Eq. (5.12) divided by $P_{0}$, which is in agreement with the thermodynamic relation that states $\dot{S}_{g e n}=\frac{E x_{\text {waste }}}{T_{0}}$. Since, for purposes of optimization, $P_{0}$ will not be reached by a firm, the entropy cost per unit time in the forward (production) flow, $E_{p}$, can be expressed as:

$$
E_{p}=P \sigma_{\text {gen }}^{\cdot}=P\left(-K_{P}\left(P-P_{0}\right)\left(\frac{C_{U}}{P_{0}}-1+\frac{P}{P_{0}}\right)\right)
$$

Following the exergy approach, add the entropy cost to $T C_{2}(q, P)$, Eq. (5.14), to obtain: 


$$
\begin{aligned}
T C_{3}(q, P)= & \frac{A\left(-K_{P}\left(P-P_{0}\right)\right)}{q}+\left(c_{P}+c_{L}\right)\left(-K_{P}\left(P-P_{0}\right)\right) \\
& +\frac{h}{2} q\left(1-\frac{\left(-K_{P}\left(P-P_{0}\right)\right)}{\rho}\right) \\
& +c_{e}\left(-K_{P}\left(P-P_{0}\right)\right)\left(a \rho^{2}-b \rho+c\right) \\
& +c_{e n g}\left(-K_{P}\left(P-P_{0}\right)\right)\left(k_{0}+\frac{k}{\rho}\right) \\
& +P\left(-K_{P}\left(P-P_{0}\right)\left(\frac{c_{U}}{P_{0}}-1+\frac{P}{P_{0}}\right)\right)
\end{aligned}
$$

Where the subscript ' 3 ' denotes the classic EPQ cost function added to it the costs of labour, emissions, energy and generated entropy. In system theory such as thermodynamics, the system is at "steady state" when the variables that define its behavior do not vary over time. This thesis deals with a steady state or deterministic case. However, in a thermodynamic system, the ambient temperature and the work of the system may vary over time and so would the rate at which entropy, and subsequently exergy, is generated. A production and inventory system is also dynamic where the price of a product and the market price are time dependent. This thesis does not model such a behavior and, therefore, it is limited in this regard.

\subsection{Sustainability Index}

It is still unclear how the sustainability performance of a firm should be measured. A set of standardized metrics or indices is required for this purpose and for reporting sustainability. Such standardized metrics are necessary for the following reasons: (i) A 
reference point to improve comparability between firms, (ii) setting expectations of acceptable and unacceptable performance, and (iii) addressing information overload (Searcy, 2016a). This is because the wide availability of metrics may encourage firms to try and measure too much.

Searcy (2011) presented a conceptual framework that can assist decision-makers through the process of reviewing and updating their corporate sustainability performance measurement system (SPMS). The development of the framework was based on the following key assumptions, namely that the framework will be:

- Broadly applicable, i.e., the framework must accommodate the wide variety of circumstances faced by different firms around the world.

- Explicitly recognize the stakeholder-oriented nature of corporate sustainability, which means that the power, legitimacy, and urgency of stakeholder requirements must inform any updates to a corporate SPMS.

- Practice-oriented that provide practical and actionable advice, which would be understandable by all level of expertise on upgrading a corporate SPMS.

The second law of thermodynamics deals with the quality of energy and leads to the property of entropy, which is the measure of disorder in a system. The second law of thermodynamics assists in determining the best theoretical performance of cycles, engines, and devices. Cengel \& Boles (2010) suggest using the second-law efficiency $\eta_{I I}$, which is equivalent to $\eta_{\text {ex }}$ shown in Eq. (5.7) as the most realistic indicator for measuring the efficiency of a thermal system. They claim that the value of the second-law efficiency falls 
between zero for the case of the complete wasting of exergy and one, when there is no exergy wasted. Hence, the second-law efficiency can be expressed as:

$$
\eta_{I I}=\frac{\text { Recovered Exergy }}{\text { Supplied Exergy }}=1-\frac{\text { Wasted Exergy }}{\text { Supplied Exergy }}=1-\frac{\text { Ex } x_{\text {waste }}}{W_{\text {in }}}
$$

Using the relationship between exergy and the second law of thermodynamics explained in this section, and between exergy and sustainability, explained above, the introduced term "Exergetic Sustainable Indicator $(E x S I)$ " is equal to $\eta_{I I}$ in Eq. (5.26).

Exergy wasted can be translated into monetary units lost from a production firm. A system with lower entropy has more useful exergy and subsequently more potential to do work. A system with a lowe efficiency has more exergy wasted because of entropy creation and subsequently less potential to do work. The loss in production potential can be represented as a cost. The recovered exergy, $E x_{R}$, can represent the output of a production system that fulfils the customers' demand. Its exergetic content is equal to the total exergy that enters a system, $E x_{I}$, less the exergy wasted from the activities in a production-inventory system, $E x_{\text {waste }}$, which can be computed as: $P \dot{\sigma}_{g e n}$.

The total exergy that enters a system is the sum of the exergetic values of all the parameters that are used in the production of a product. That is, $E x_{I}$ is the sum of the exergetic values of the energy carrier, raw materials, capital, labour and environmental remediation, which is analogous to $W_{\text {in }}$ in thermal systems as explained in Section 3.1 (i.e. $\left.E x_{I}=W_{\text {in }}\right)$. The total "exergetic" value of these parameters can be expressed as $\operatorname{TExC}(P)^{\emptyset}$, which equals to $\operatorname{TExC}(P)$ (obtained from Eq. 5.18) excluding the term of 
entropy. Hence, it can be concluded that $\operatorname{Ex}_{I}$ equals $\operatorname{TExC}(P)^{\varnothing}$. The quantity $\operatorname{ExSI}$ can be written as:

$$
E x S I=\frac{E x_{R}}{E x_{I}}=1-\frac{e e_{K} E_{p}}{T E x C(P)^{\varnothing}}
$$

Considering ExSI as an exergy score of a firm, it can be improved by minimizing the destructed exergy in a system by wisely consuming the natural, physical and human resources.

Sustainability can be thought of as either "weak" or "strong" (Neumayer, 2003). Weak sustainability assumes that natural resources used in the production of goods are abundant and suggests that a decline in natural capital can be substituted by a buildup in the human-made capital. Strong sustainability suggests that a loss of natural capital cannot be replaced for by human-made capital and it is inevitable to use renewable resources and the environment as a sink for pollution as long as its absorptive capacity does not deteriorate over time (Neumayer, 2003).

Capital is defined as "stock that provides current and future utility" (Neumayer, 2003). The natural capital that can provide humans with "material and non-material utility" (Neumayer, 2003). On the other hand, Man-made capital includes factories, machinery, and roads. Weak sustainability states that man-made capital is more important than natural capital. In contrast, strong sustainability states that natural capital cannot be substituted by man-made capital. "Very strong" sustainability imply that every component of the natural environment must be preserved. This may look impossible, for the following reasons (Ayres, Bergh, \& Gowdy, 1998): 
- The dependence of our current industrial economy on primary resources.

- The species and ecosystems are subject to continuous processes of natural change, and while human activity accelerates some of these processes and inhibits others, humans are a part of nature.

The Capital Theory Approach (CTA) combines human-made capital (e.g. produced commodities), human capital (e.g. knowledge and skills), natural capital (e.g. natural resources), and social capital (e.g. relationships between individuals and institutions) (Figge \& Hahn, 2004). When the sustainability index in Eq. (5.27), which is based on CTA and EEA, is close to 1 , strong sustainability is achieved, whereas weak sustainability results when this index is close to zero.

\subsection{Results and Discussion}

The numerical example considers a production-inventory system that has the following input parameters (where here mu $=\$$ ): $\rho=4500$ unit/year, $P_{0}=\$ 55, P=\$ 40-50$ and $K_{P}=275$ units/year $/ \$$ corresponding to $d=4125-1375$ unit/year from Eq. (5.9), $c_{p}=18 \$$ unit, $m=0.5$ giving $c_{U}=27 \$ /$ unit, $c_{L}=2 \$ /$ unit, $s=18 \$ / \mathrm{hr}, h=5.40 \$ /$ unit/year $(0.3 \times 18), c_{e}=20$

$\$ /$ unit, $c_{\text {eng }}=0.1 \$ / \mathrm{kWh}, k_{0}=16 \mathrm{kWh} / \mathrm{unit}, k=30000 \mathrm{kWh} /$ year, $a=1.0 \mathrm{E}-7$ ton.year $2 / \mathrm{unit}^{3}$, $b=7.00 \mathrm{E}-04$ ton.year/unit ${ }^{2}$ and $c=1.32$ ton/unit, and $A=500 \$ /$ order. In the numerical examples, the minimum production rate is set to be at least $10 \%$ higher than the demand rate, $\theta=1.1$. Assuming that the firm is located in the U.S., then $e e_{K}=3.18 \mathrm{MJ} / \$$ and $e e_{L}=$ 72.8 MJ/WH (Jawad et al., 2015). Note that in order to convert $\mathrm{kWh}$ into MJ, the $\mathrm{kWh}$ amount is multiplied by a conversion factor of 3.6 (i.e $1 \mathrm{kWh}=3.6 \mathrm{MJ})$. 
The minimum total cost per unit time of the classical EPQ model, when $P=40$, is $T C_{0}=\$ 75,612$ (without accounting for the labour, emission and energy costs), which is computed from Eq. (5.13), occurring at $q=3028$ units from Eq. (5.16) and an optimal time of 0.73 years. If a firm uses Eq. (5.13), then that firm is underestimating its cost by 36,000 \$/year, which is the entropy cost (obtained from Eq. 5.24) of producing, storing, and delivering 3028 units to the market. At this price, when the firm does not account for the cost of entropy, the total consumed exergy, $\operatorname{TExC}(P)^{\emptyset}$, is $661807 \mathrm{MJ} /$ year (from Eq. 5.18 excluding wasted exergy), which underestimate by almost 109,300 MJ/year compared with when the entropy cost is included (from Eq. 5.24). Clearly, not accounting for entropy also affects the value of the profit the firm expects. Employing Eq. (5.20) assists a firm to compute its produced quantity based on the consumed exergy at each stage of setup and holding. If the firm decides to consider equal fractions for the capital, labour and environmental remediation at both stages, then $q=q_{x}$.

Heizer \& Render (2008) provided the following holding costs (and average) as a percent of inventory value: labour 3\% (3-5\%), housing 6\% (3-10\%), material handling 3\% (1-3.5\%), investment 11\% (6-24\%) and scrap 3\% (2-5\%). These percentages may translate, roughly, to at least $80 \%$ capital, $10 \%$ labour, and $10 \%$ environmental remediation costs of the unit production cost (splitting the 0.3 of the holding cost to $0.24,0.03$ and 0.03 , respectively). The setup cost, $A$, is divided into the following fractions: $65 \%$ for capital, $30 \%$ for labour efforts, and $5 \%$ for environmental remediation. Some technologies can be employed by firms to control $A$ such as using paperless orders and financial transactions, while the value of the holding cost, $h$, is usually intuitively set by managers rather than numerically computed (Andriolo et al., 2014). If the firm follows the above percentages, 
then $q_{x}=3107$ unit per cycle (from Eq. 5.20) and optimal cycle time $\left(t_{x}^{*}\right)$ is 0.75 year, leading to a total annual cost of 75612.44 \$year (without accounting for entropy in the system). These values result in producing 79 more units per cycle, which is extended by 0.02 year and paying a little more (73.60 \$/year) for the extra produced units. The cost of controlling one unit of product, $e\left(t^{*}\right)$, which can also be written as a function of $P$, per cycle can be found from the formula $e(t)=E p t / q$ or $e(P)=E p /-K_{P}\left(P-P_{0}\right)$ after substituting $t=$ $q / d$, where $d=-K_{P}\left(P-P_{0}\right)$. From Table (5.1), it can be seen that $e(P)$ increases as $P$ nears $P_{0}$. An additional benefit of using Eq. (5.20) is to reduce the cost of controlling one unit of product. Table (5.1) illustrates the optimal ordering policy for the developed model. From the foregoing, it is clear that the developed model can offer a wider area of selection between the desired level of sustainability and quantity to be produced. For a constant value of $P_{0}$, Eq. (5.24) is a decreasing function in $P$. When the value of $P$ approaches $P_{0}$, a lower rate of demand results, which in turn results in a lower rate of production and, accordingly, a higher rate of entropy generation and exergy wasted in the system. This behavior explains why ExSI decreases whenever $P$ nears $P_{0}$. Note that the accuracy of the results depends on some of the basic assumptions made in the specific application of EEA in the inventory system. One of the main barriers to a widespread application of EEA is the limited data and details related to the calculations of the EEA parameters. 
Table 5.1. Optimal order policy for the developed model with varying, but known, price, $P$.

\begin{tabular}{|c|c|c|c|c|c|c|c|c|c|c|}
\hline $\boldsymbol{P}$ & $\boldsymbol{q}(\boldsymbol{P})$ & $\boldsymbol{q}_{\boldsymbol{x}}(\boldsymbol{P})$ & $\boldsymbol{d}$ & $\boldsymbol{T C} \mathbf{1}(\boldsymbol{P})$ & $\boldsymbol{E}_{\boldsymbol{p}}$ & Profit & $\boldsymbol{e}(\boldsymbol{P})$ & $\boldsymbol{N W H}$ & $\boldsymbol{T E x C}(\boldsymbol{P})^{\varnothing}$ & $\boldsymbol{E x S I} \%$ \\
\hline 40 & 3028 & 3107 & 4125 & $\$ 109,300$ & $\$ 36,000$ & $\$ 19,700$ & 8.73 & 458.33 & 661807 & 82.70 \\
\hline 41 & 2222 & 2280 & 3850 & $\$ 102,475$ & $\$ 37,310$ & $\$ 18,065$ & 9.69 & 427.78 & 619232 & 80.84 \\
\hline 42 & 1795 & 1842 & 3575 & $\$ 95,538$ & $\$ 38,220$ & $\$ 16,392$ & 10.69 & 397.22 & 576285 & 78.91 \\
\hline 43 & 1514 & 1553 & 3300 & $\$ 88,530$ & $\$ 38,700$ & $\$ 14,670$ & 11.73 & 366.67 & 533098 & 76.91 \\
\hline 44 & 1308 & 1342 & 3025 & $\$ 81,468$ & $\$ 38,720$ & $\$ 12,912$ & 12.80 & 336.11 & 489732 & 74.86 \\
\hline 45 & 1145 & 1174 & 2750 & $\$ 74,362$ & $\$ 38,250$ & $\$ 11,139$ & 13.91 & 305.56 & 446215 & 72.74 \\
\hline 46 & 1010 & 1036 & 2475 & $\$ 67,215$ & $\$ 37,260$ & $\$ 93,75$ & 15.05 & 275.00 & 402564 & 70.57 \\
\hline 47 & 893 & 916 & 2200 & $\$ 60,031$ & $\$ 35,720$ & $\$ 76,49$ & 16.24 & 244.44 & 358787 & 68.34 \\
\hline 48 & 789 & 810 & 1925 & $\$ 52,810$ & $\$ 33,600$ & $\$ 59,90$ & 17.45 & 213.89 & 314887 & 66.07 \\
\hline 49 & 695 & 713 & 1650 & $\$ 45,551$ & $\$ 30,870$ & $\$ 44,30$ & 18.71 & 183.33 & 270858 & 63.76 \\
\hline 50 & 606 & 621 & 1375 & $\$ 38,250$ & $\$ 27,500$ & $\$ 30,00$ & 20.00 & 152.78 & 226691 & 61.42 \\
\hline
\end{tabular}

An investigation of the model for different values of the production rate has been performed. The production rate, $\rho$, has been varied over the range 2500 to 4500 units/year, while keeping the values of the other input parameters unchanged. The results showed that pushing $\rho$ closer to $d$ results in increasing ExSI because the increment of the produced quantity per cycle, $q$, leads to a reduction in the value of $e(P)$ and consequently $E_{p}$ decreases. Additionally, the changes in $\rho$ at fixed rate of $d$ while the values of the other input parameters unchanged have been investigated. The model behaved in a similar manner to the previous case.

In the next step, the optimization of the net profit for $P$ and $\rho$ using the entropy and exergy approaches will be studied. The total profit for the entropy approach is total revenue, $P \cdot d(P)=-K_{P} P\left(P-P_{0}\right)$, minus the total cost in Eq. (5.14), minus the entropy cost in Eq. (5.24). The total profit for the exergy approach is the total revenue minus Eq. (5.17). The 
maximum profit for the entropy approach is 22538.22 when $P^{*}=41.89$ and $\rho^{*}=3965$, where $q=2710, E_{p}=38142 E x_{\text {waste }}=43078$, and ExSI $=78.8 \%$. Using the exergy approach, the maximum profit is 18379 when $P^{*}=42.62$ and $\rho^{*}=3746$, where $q=2634, E_{p}=38568$, $E x_{\text {waste }}=42290$, and $\mathrm{ExSI}=77.4 \%$. These results show that using the entropy approach results in higher profits, less entropy generation, and higher sustainability index. The production rate is slightly slower for the exergy approach as the model tries to push towards the lowest emissions that occurs at $\rho=3500$.

The $\operatorname{TExC}(P)$ in Eq. (5.18) is investigated for different values of the commodity price, of $P=52.5,50,47.5,45$ and 42.5 while keeping $P_{0}=55$, and by optimizing the production rate. The $T E x C$ values are $222,933,426,227,616,316,793,556$, and 957,265 MJ/year, corresponding to $\rho$ values of 4011, 4002, 3993, 3979, and 3944 units/year, with ExSI values of $55.2,61.0,66.8,77.4,77.6 \%$, respectively. These results show that as $P$ decreases (demand increase), $\operatorname{TExC}(P)$ and ExSI increase, suggesting that although more units are produced and pushed to the market, less exergy is wasted in the process. The production rate decreases gradually pushing towards the optimal $\rho$ and closer to demand to minimize emissions and inventory related costs. The $q_{x}$ values are $402,639,912,1318$, and 2285 units per cycle.

The EEA analysis of a production-inventory system provides a different view than the classical model, and provides a firm with a much better perception of the amounts of natural, financial and human resources consumed during the production process, manifested as "exergy." 
The results obtained from the new model provide useful information for decision makers. For instance, if a classical monetary cost approach is preferred, the optimally produced quantity will minimize the total costs. However, the monetary cost approach, which cannot be neglected from any business activity, is unable to provide any indicator about the global resources consumption. However, EEA is a cost as well as a sustainability indicator and provides more information than a purely monetary approach. The consumed exergy can be in the form of natural resources, energy, human power or environmentally related activities.

Because firms account for traditional costs only, the difference between traditional (non-entropic) and entropic (exergetic) costs is paid by societies, which create more disorder for the future. The difference between the non-entropic and the exergetic costs include the Joules of natural resources, capital, human resources and GHG emissions that are consumed in making and delivering a product. Some important implications of the real exergetic cost that affect individual firms and society over the long term may include, among others:

(i) A possible increase of environmental taxes or the need to introduce new pricing mechanisms to cover the unwise consumption of raw materials or an increase in GHG emissions.

(ii) Rapid depletion of natural resources because of production activities, which affect their availability and prices.

(iii) GHG emissions and landfill options by firms that pose higher health risks, increasing the national health bill for a country and subsequently raising taxes on income and increasing costs to a firm to provide better health and social benefits to its employees. 
This chapter investigates the relation between ExSI and commodity price for both models. Figure (5.6) shows the effect of changing the product price $(P)$ on the exergetic sustainability index $(\mathrm{ExSI})$ at a fixed market equilibrium price $\left(P_{0}\right)$. The behavior is due to the low ratio of exergy wasted to the total input exergy (capital, energy, labour and environment remediation). As demonstrated in Section 5.5, the lower the value of $E x_{\text {waste }}$, the higher is the value of ExSI.

Reducing $E x_{\text {waste }}$ generally can be achieved by minimizing waste and losses in natural resources and physical resources, which ultimately moves society towards more sustainable development. In addition to measuring the consumed exergy, ExSI measures the sustainability performance of a system. ExSI uses an analogy with the second law of thermodynamic. It indicates how efficient the production system is in matching the final product to its resources. Figure (2.3) shows that the less waste and losses (less wasted exergy) by a production system, the more products the same system will produce, which generally is a more prudent use of the resources. The sustainability index presented in this research can assist firms to determine their level of sustainability on a scale of $0-1$. When the sustainability index is close to 1 , a strong sustainability is achieved, whereas a weak sustainability is when this index is close to zero. In Eq. (5.27), if the entropy cost (the cost of wasted resources) increases for the same value of $\operatorname{TExC}(P)^{\emptyset}$, then ExSI reduces and vise versa. Since the entropy cost includes the cost of the resources (physical and human) wasted, then ExSI can provide an indication for these wasted resources. 
As a sustainability measurement method, the obtained results from the ExSI can provide a wider view for managers and decision makers review and understand how sustainable their firms' activities are. Thereafter, it is recommended that a plan-do-checkact (PDCA) framework (cycle) to assess and prioritize the activities that will help a firm achieve sustainability. PDCA cycle is a continuous quality improvement of processes, values, and rules of organization (Sitnikov \& Bocean, 2012). It has been employed to establish a framework for corporate sustainability, e.g., (Asif, Searcy, Zutshi, \& Fisscher, 2013). Briefly, the PDCA can be explained as follows (Sloan, Legrand, \& Chen, 2013):

- Plan: Identifying and analyzing the problem.

- Do: Developing and testing a potential solution.

- Check: Measuring how effective the test solution was, and analyzing whether it could be improved in any way.

- Act: Implementing the improved solution.

In this regard, it is highly recommended to implement PDCA to minimize the amount of wasted exergy (or minimizing the amount of generated entropy in a system). This can improve the level of sustainability a firm intend to achieve.

Balancing the objectives of sustainability and profit is of great importance to firms intending to switch or shift to sustainable strategies. This balance may be accomplished by selecting the optimal amount of production that spends money more wisely and minimizes GHG and energy and material waste. The integration of the results attained from the developed model, as seen in Figure (5.6), provides a picture of how economic performance is related to the sustainability of the model. It is evident from Figure (5.6) that reducing a 
commodity price can provide more economical and sustainable results. The developed model recommends firms to seek and examine any opportunities that can minimize the hidden costs that lead to increased consumption of exergy.

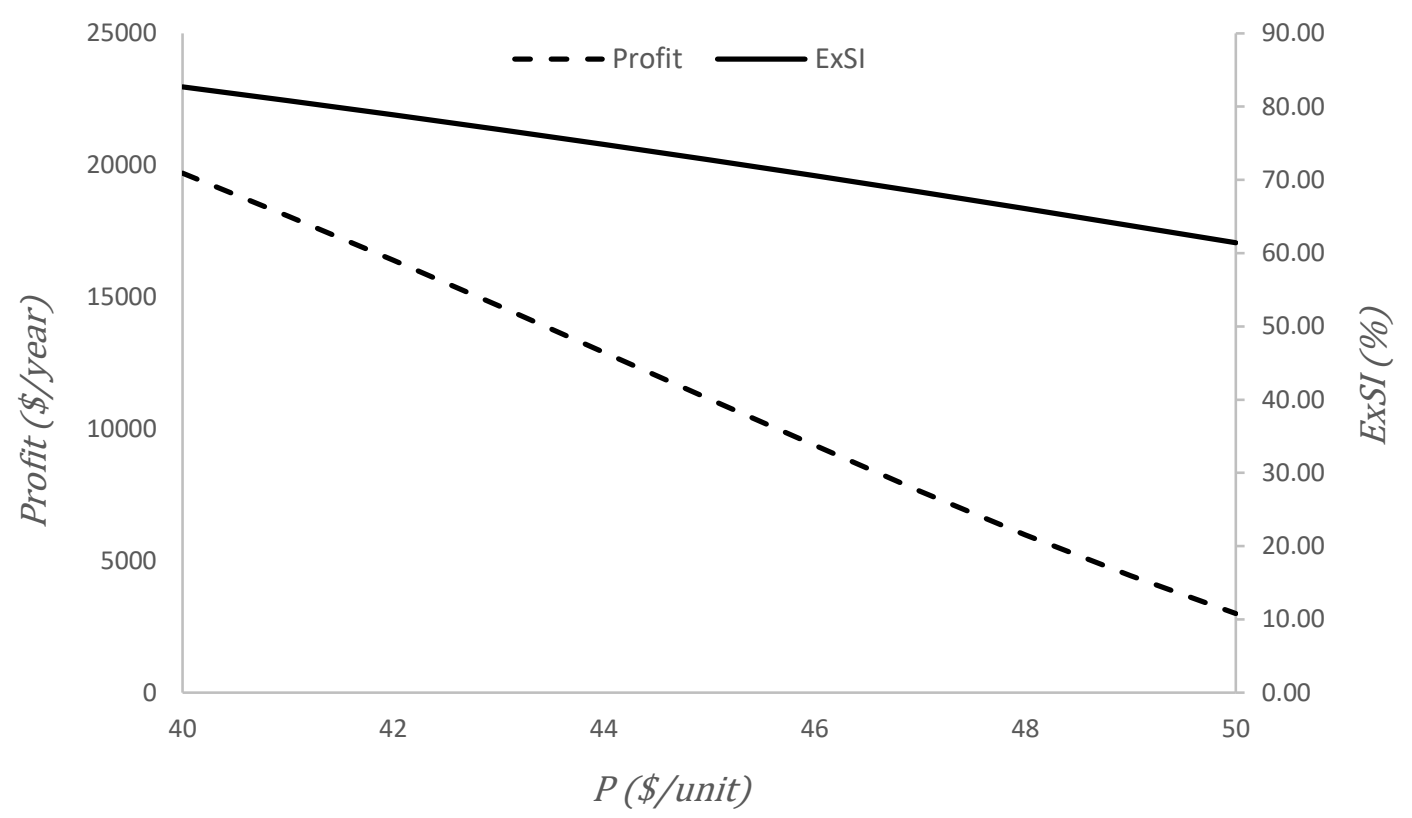

Figure 5.6. The relation between profitability and ExSI with commodity price for the developed model.

Instead of paying for such costs, firms can invest in developing more sustainable strategies, such as; improving labour payments and benefits, paying more attention to environmental remediation, making donations for societal improvement, etc. With the implementation of the exergetic model, firms can also preserve the exergetic contents of human, capital, energy and material and provide enhanced environmental remediation, all of which lead to more sustainable development. The results in Table (5.1) show that the developed model recommends producing larger lots to increase profits while being 
accompanied by a better ExSI level. The developed model in this thesis can help guide customers on the exergy scores if a sustainable nutrition label is attached to the product. Such a label can tell customers how many MJ have consumed to produce a product of interest. The developed sustainability index, ExSI, can also be provided on labels for a comparative purpose.

To determine the effect of $P_{0}$ on the generated entropy and level of ExSI, a sensitivity analysis was performed by varying both $P$ and $P_{0}$ while maintaining a fixed difference $P_{0}-P$ to keep demand at a fixed rate at $d=-K_{P}\left(P-P_{0}\right)=1375$. For this exercise, a range for $P$ of 40 to $70 \$ /$ unit and for $P_{0}$ of 45 to $75 \$ /$ unit was selected, while optimizing for the production rate $\rho$. This retains a fixed value of $\Delta P=P_{0}-P=5 \$$ unit where $q=646, d=$ $1375, T C_{1}(P)=35,616 \$$ year, $N W H=153$, and $\operatorname{TExC}(P)^{\emptyset}=226,598 \mathrm{MJ} /$ year remain unchanged. The results showed that for low $P_{0}$ and $P$ values, $P_{0}=45$ and $P=40$, there is a loss (-7501) \$/year when accounting for entropy cost, $E_{p}$. The loss turns to profit (32404) $\$ /$ year as $P_{0}$ and $P$ increase, say to $P_{0}=75$ and $P=70$, respectively. This suggest that when the cost of pushing one unit to the market, $e(P)$, is high, around $\$ 20$, ESxI is around $61 \%$, a firm has to consider producing higher priced products. For all cases, $\rho^{*}=3525$ units per year. The sustainability index, ESxI, was found to be low for all cases, around $60 \%$. The same example was reworked, but for $K_{p}=500$ corresponding to $d=2500$ units/year, where $q=1277, T C_{1}(P)=62,856, N W H=278, T E x C(P)^{\emptyset}=406,336$, and $\rho^{*}=3491$. The results showed the losses and profits increase significantly; i.e., the profit increased from -11745 ( $P_{0}=45$ and $\left.P=40\right)$ to $60810\left(P_{0}=75\right.$ and $\left.P=70\right)$, with ExSI remaining in the range of $60 \%$. The last test, repeats the first example of this section for $\Delta P=10$ where $q=1563, T C_{1}(P)=$ 
$68,763, N W H=306, T E x C(P)^{\emptyset}=44,6053$, and $\rho^{*}=3474(d=3000)$. The results showed the losses and profits increase significantly; i.e., the profits increase from $3837\left(P_{0}=50\right.$ and $P=40)$ to $69471\left(P_{0}=75\right.$ and $\left.P=65\right)$, with ExSI remaining in the range of $71 \%$. These suggests that an increase $\Delta P$, not $K_{p}$, increases (decreases) profits (losses), and the system's sustainability index.

The investigation shows that following some strategies may help to improve the ExSI level. For example, increasing NWH raises ExSI, while affecting profits. Increasing NWH means creating more employment opportunities and increasing the demand rate of customers, which in turn can help to build a more sustainable society. This strategy can be achieved by involving government departments, NGOs and agencies to introduce legislation and regulations that can control this parameter.

A sensitivity analysis suggests that reducing the value of $e e_{K}$ can significantly improve the level of ExSI. The task of reducing $e e_{K}$ requires actions and contributions of governments, individuals, societies and all other stakeholders. Since this parameter is controlled by the values of $E x_{i n}$ and M2, a great effort is needed from governments and financial institutions to achieve this task. The amount of $E x_{i n}$ can be controlled by regulating some economic activities such as import and export activities, extraction of ores and minerals, agriculture and fisheries activities. Firms can assist with this task by becoming more exporters than importers of goods. Further details about these activities and sectors are described elsewhere (Ertesvåg, 2005). An increase in M2 typically lowers interest rates, which implies more investment can be developed and consumers can circulate more money, enhancing spending. With more spending, usually the economy improves, more production 
is required to fulfill market demands, and the society's unemployment rate decreases (Investopedia, 2003). However, a question arises: What is the proper value of M2 in an economic system? The answer is that the proper M2 value should be sufficient to improve the GDP of a society, but not sufficient to cause inflation in the economic system of the society. Determining the level of M2 remains a challenge to goverments and financial institutions. Local and national governments can encourage companies to move towards sustainability, by providing incentives. Examples of such incentives may include but are not limited to:

- Offering tax credits/rebates: This incentive may result in lower $c_{E n v}$ that is paid by firms, which leads to lower $E E x_{E n v}$, which in turn reduces $T E x C$ of a system.

- Better and easier loan plans: Such an incentive allows firms to reduce expenses, which may lead to a decline in the total cost of producing a product.

- Discounted prices for energy and natural resources: When a company pays less for energy and/or raw materials, it has lower expenses, and therefore, there is a significant opportunity to reduce the total cost and TExC.

- Funding sustainable projects: The growing demand for sustainable projects can benefit societies by providing sustainable living standards, can generate additional business opportunities and, subsequently, can generate more employment opportunities. Thus funding such projects may increase benefits to societies, companies, and individuals. 


\subsection{Economic Manufacture Quantity (EMQ) Vs. Just-In-Time (JIT)}

This dissertation uses the EMQ model rather than JIT, produces a product when needed and delivers it when wanted by customers, and considers inventory as a waste to be reduced. There are several reasons for not considering JIT further in this dissertation. Here are some reasons for not to. The implementation of JIT may not succeed in all firms. Wijewardena \& De Zoysa (1999) reported that although many manufacturing firms experienced very low inventory holding costs, their transportation costs were significant. They also indicated that although JIT may work for Japanese firms, it is unlikely to be applicable in western countries. For example, manufacturing firms that are heavily unionized, where the interrupt of production due to strikes is more likely, may not be suited for JIT. Other drawbacks of the JIT are an increase in the idle labour time due to delays in supply, production or transportation of raw and or finished items, unexpected human errors, and difficulties in responding to unexpected demands (Kendall \& Steen, 1998). Further, a JIT policy has been criticized for increasing labour intensity, characterized by workload, stress, and fatigue (Godard, 2001). Producing and delivering short-life items in smaller lot sizes more frequently have been the JIT norm, which congests supply chains and traffic and generate more waste that has a negative environmental impact; e.g. packaging material, $\mathrm{CO}_{2}$ emissions, landfill, etc. (Bonney \& Jaber, 2011).

Jaber et al. (2004), who postulated that production systems resembled in their behavior thermodynamic systems and suggested that improvements can be achieved by applying the second (entropy) law of thermodynamics, advocated against the JIT on the basis that its entropy (order) cost is excessive. They based their analysis on varying the setup 
cost as it is the primary decision variable in a JIT system. However, they excluded from their analysis the costs of emissions, energy, transportation, and worker stress.

To support the decision of excluding JIT from this study, the analysis of (Jaber et al., 2004) is revisited. A new analysis is provided in Appendix (A). The results show that a JIT policy is much more expensive to operate than an EPQ policy.

\subsection{Summary and Conclusions}

The new methodology employs the first and second laws of thermodynamics to link thermodynamics to inventory management. The method accounts for the thermodynamic property "work" as the energy required to transfer heat from lower to higher temperature thermal reservoirs. Also, the method employs the second law efficiency to obtain a sustainable index that can provide a better perspective about how sustainable a firm can be. It brings attention to the thermodynamic property "exergy," which combines the first and second laws of thermodynamics, and can help to improve the efficiency of a system or a process. This chapter develops the classical EPQ model to introduce the cost of inventory for a production system expressed in energy units (Joules) instead of monetary units. This unit gives a clearer view of the amount of exergy consumed by society in the productioninventory system of a product. This chapter contributes to the literature by showing that following a sustainable strategy can be profitable for firms. The developed exergetic model places attention on all three pillars of sustainability: economic, environmental, and social, and computes their costs by considering money as an economic factor, environmental factor by paying for the remediation of the environment, and labour as a social factor. The three 
pillars of sustainability are modeled in terms of monetary as well as exergetic contents that can be consumed during the operations of a production-inventory system.

The results suggest considering the amount of consumed exergy in a production system as a sustainability indicator. An exergetic index was developed to measure the level of sustainability that a production-inventory system can attain. The results show that a product's price plays a major role in minimizing the entropy generation (exergy wasted) in a system, which changes ExSI in a proportional manner with the cost of entropy. Decision makers in production-inventory systems can benefit from the developed exergetic model by selecting the proper parameters to achieve more sustainable and yet profitable strategies for their firms. For instance, if the classical monetary cost approach is preferred, some parameters can minimize the total cost such as the optimally produced quantity, which is a function of the commodity price. From a sustainability point of view, the EEA methodology can be considered as a cost methodology as well as a sustainability indicator.

The EEA methodology provides more information than a purely monetary approach, which is unable to provide any indication of the consumption of global resources. Accordingly, the results show that firms are able to match the amount of the produced product with the required resources to achieve the desired level of sustainability. The units wasted in a production-inventory system play a major factor in deciding the level of sustainability of the system. Hence, wise consumption and utilization of resources are recommended to achieve a better value of the exergetic sustainability indicator introduced in this chapter. This study shows that following a sustainable strategy can be profitable for firms. This result has been demonstrated for cases of both fixed and changeable demand rates. These results can establish for a new paradigm of considering sustainability as a 
profitable approach that can be followed by firms. The results show that some parameters strongly affect the sustainability index of a company, such as the number of working hours, money supply of society, and market price of a product. Therefore, having governments and other authorities involved in shifting towards sustainability by providing a number of incentives to companies appears to be merited. 


\section{CHAPTER (6) - IMPROVING SUPPLY CHAIN SUSTAINABILITY USING EXERGY ANALYSIS}

\subsection{Introduction}

The planet has experienced several environmental, technological, and social changes that have had effects on individuals, societies, and world governments. Such changes have influenced the ways in which business firms are designed, organized, managed, and led (McKee, Kemp, \& Spence, 2012), which in turn raised the call for implementing sustainable development (SD) in many countries. In 1987, the World Commission on Environment and Development defined SD as "development which meets the needs of the present without compromising the ability of future generations to meet their own needs." (Drexhage \& Murphy, 2010). The report claims that it is commonly accepted that SD calls for a merging between the three pillars of economic development, social equity, and environmental protection.

Business firms have become conscious of the sustainability of their businesses and supply chains: being more economically, socially and environmentally responsible can provide a better firm performance and improve the competitive advantage (Massaroni, Cozzolino, \& Wankowicz, 2016). Based on the triple pillars of SD, Carter and Rogers (Carter \& Rogers, 2008) presented a framework for sustainable supply chain management (SSCM) that comprises the concepts of sustainability and supply chain management (SCM), which can provide a starting point for a common understanding of SSCM among supply chain managers. Many definitions for SSCM can be found in the literature (see (Carter \& Rogers, 2008) for example ). This study adopted the definition of SSCM by Seuring and 
Müller (Seuring \& Müller, 2008) who defined it as "the management of material, information, and capital flows as well as cooperation among firms in a supply chain while considering goals from all three aspects of SD that are derived from the requirements of the customers and stakeholders". Ahi and Searcy (2013) clearly explained how the voluntary nature of a business firm could assist in achieving sustainability. They, also, explained the importance of coordination in a supply chain that can efficiently and effectively manage the flow of material, information, and capital that is associated with the activities of a supply chain in order to meet stakeholder requirements and improve the profitability, competitiveness, and resilience of the organization over the short and long-term.

Numerous reasons motivate business firms to adopt the concepts of SSCM, such as (1) managing risk (including reputation, regulatory, security and quality of supply and litigation risks), (2) creating sustainable products and (3) minimizing costs by realizing inefficiencies in the supply chain (Hill \& Toth, 2013); (united nations Global Compact, 2011). World leaders adopted the 2030 Agenda for SD, which includes a set of seventeen Sustainable Development Goals (SDGs) to achieve a sustainable world ("UNDP," n.d., p. 12). The twelfth goal of the SDGs states that achieving economic growth and SD needs the urgent action of reducing the ecological footprint by changing the way to produce and consume products and resources to ensure sustainable consumption and production patterns ("UNDP," n.d.).

The earliest reported work that called for factoring environmental issues in inventory and supply chain management is that of (Bonney \& Jaber, 2011), which was presented at the International Symposium for Inventory Research in 2008. They identified the importance of inventory and some of its problems that need non-classical analyses, as well 
as discussing the hierarchy of inventory players, suggesting an inventory performance metrics (including non-cost measures), presenting an environmental inventory performance metrics, and identifying some implications of the discussion in their paper. They argued that inventory is part of a wider problem and concluded that there is a need to develop environmentally responsible inventory models. The work of (Bonney \& Jaber, 2011) triggered many researchers to develop inventory and supply chain models that account for environmental factors, mainly carbon emissions. Later, some researchers stretched these models further to encompass the three pillars of sustainability. For a more exhaustive survey of these works, readers may refer to the review papers of (Andriolo et al., 2014) and (Bushuev et al., 2015).

The relationship between SD and the consumption of natural resources, particularly energy, is crucial to societies. Attaining SD requires that sustainable energy resources be used, and is assisted if resources are used efficiently. Hence, methods that employ exergy (a thermodynamic property representing the available useful part of energy) analysis are necessary since they are helpful in improving efficiency. The relationships between exergy and energy and the environment make it notable that exergy is directly related to sustainable development (Dincer \& Rosen, 2012).

The second law of thermodynamics, or entropy, measures the wasted resources of a system due to process inefficiencies and has been argued to govern management thinking (Drechsler, 1968). Disorder (or entropy as per the second law of thermodynamics) manifests itself as common problems of inefficiency and related elements such as higher costs, lower outputs, greater wastes, lower profits, lowered capability to adapt to changes in the world, 
low morale, loss of motivation, business failure, rework, scrap, queues of material, machines, and finished products, energy losses, emissions, etc. (Drechsler, 1968).

Unlike the classical approaches to sustainability surveyed in (Andriolo et al., 2014) and (Bushuev et al., 2015). Jawad et al. (2015) developed a sustainable economic order quantity model by employing EEA and the laws of thermodynamics. The model places attention on all three pillars of sustainability and computes their costs by considering money as an economic/environmental factor by paying for the remediation of the environment, and labour as a social factor. They found that in some situations, sustainability can be profitable. In another study, a heat-pump cycle analogy was used to study "work-assisted pumping" of a commodity from a supplier to the market (Jawad, Jaber, Bonney, \& Rosen, 2016). This study builds on this line of research by using two heat pumps, analogous to a two-level supply chain, connected in series to better include and represent incurred inputs.

The Joint Economic Lot Sizing (JELS) is a coordination mechanism where members (e.g., a vendor and a buyer) in a supply chain jointly determine the size of orders and the frequency of shipments, so as to minimize the total cost of the supply chain and share savings among its members ( Jaber \& Zolfaghari, 2008; Glock, 2012). JELS models can be considered as useful planning tools in cases where firms have established long-term relationships with their suppliers and customers (Glock, 2012). Two forms of JELS exist. The first form, classic, where the vendor produces, accumulates inventory, and ships batches of equal sizes to the buyer at equal intervals. The bulk of inventory is held by the vendor. The second, consignment stock, where the vendor produces and ships each batch upon completion to the buyer who holds the bulk of the inventory as it is cheaper for the vendor. 
This chapter derives exergetic versions of the two forms of JELS to determine the consumed amount of exergy during the "local" producing and storing of an item with accounting to the cost of energy, emission, transportation, and its environmental and social effects. It also accounts for the presence of entropy in the supply chain and presents it as a cost of wasted exergy. The objective of this study is to assist supply chain managers in the decision of selecting which policy is more efficient to produce and order domestically based on the amount of the consumed resources. Additionally, it aims to provide managers with a tool to help them decide whether to import or locally produce and distribute the desired products when considering sustainability as a key factor in their businesses. Moreover, it provides some suggestions for governments to support local businesses and in controlling the import and export processes.

This study contributes to the literature by introducing a non-classical analysis of supply chain management that assumes a multi-echelon supply chain that behaves in an analogous manner to a combined thermal system, where the integration of systems can minimize the entropy generated in the whole system. This is established from the idea that the arrangement of two heat pumps connected in series can reduce the temperature stretch of each unit resulting in an improvement in the coefficient of performance (COP) of the overall system over the COP of one individual heat pump supplying the same thermal power (Piatti, Piemonte, \& Szegö, 1992). It is well established that the maximum COP can be obtained when minimum entropy is generated in the system (Cheng \& Liang, 2013). 


\subsection{Analogy}

\subsubsection{Entropy generation and exergy destruction of a heat pump system}

According to the second law of thermodynamics, all processes are bound to suffer from inevitable shortfalls - inefficiencies. No matter how hard one tries, entropy is generated in any process that exists whether natural or man-made. Put another way, destroyed exergy accounts for the irreversibility of a process within a system due to the progressively generated entropy (Leutz, 2001). This explains the great need for understanding entropy and the fundamental importance to investigate inefficiencies of a process. Generally, destroyed exergy in a system can be computed by finding the difference between the exergetic contents of the input and output streams. In other words: [Exergy change in a system] $=[$ Total exergy entering the system] $-[$ Total exergy leaving the system] $-[$ Total exergy destruction in the system]. Alternatively, the exergy destruction can be computed from a knowledge of the entropy generated in the system according to the Guoy-Stodola theorem (Bejan, 1995) by $E x_{\text {dest }}=T_{0} S_{\text {gen }}^{*}$

Consider a combined thermal system that consists of two heat pumps operating in series as shown in Figure (6.1). In general, a heat pump (HP) uses work input to "move" or transfer heat from a colder space to a warmer one. HP1 receives work, $W_{1}$, and extracts heat energy, $Q_{c 1}$, from the colder reservoir at temperature $T_{c 1}$ while rejecting heat energy, $Q_{H 1}$, into HP2 at temperature $T_{H 1}$. Assuming no connecting losses, HP2 receives this heat energy that was rejected by HP1, which can be considered as its colder reservoir at $T_{c 2}$. Hence, $T_{H 1}=T_{c 2}$. Subsequently, HP2 receives work, $W_{2}$, to help extract $Q_{c 2}$, and reject heat in the amount $Q_{H 2}$ to a hotter reservoir at $T_{H 2}$. 


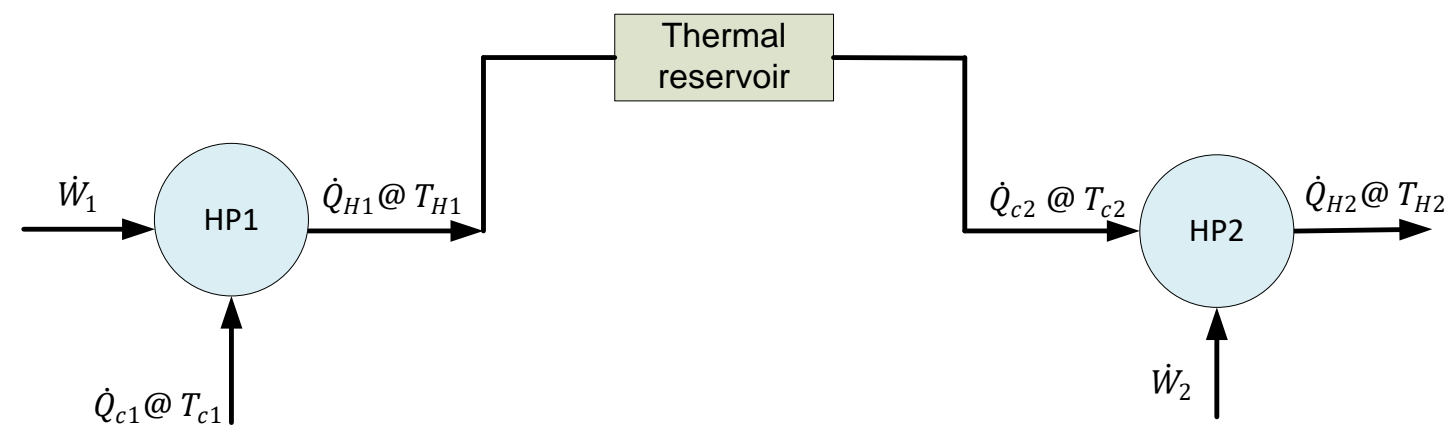

Figure 6.1. Schematic diagram of a thermal cycle consisting of two heat pump systems connected in series.

The steady state exergy rate balance for the system shown in Figure (6.1) can be expressed as:

$$
\dot{W}_{1}+\dot{Q}_{c 1}\left(1-\frac{T_{o}}{T_{c 1}}\right)+\dot{W}_{2}-\dot{Q}_{H 2}\left(1-\frac{T_{o}}{T_{H 2}}\right)-E x_{d e s t}=0
$$

It is worth mentioning that since work has an infinite temperature, the thermodynamic system will not deliver entropy within this path (i.e. $W / \infty=0$ ) (Grubbström \& Hultman, 1986) - work is entropy free. Dividing the remaining items of the above equation by $T_{o}$ can prove that the entropic generation owing to the heat transfer equals to $\Delta Q\left(\frac{1}{T c}-\frac{1}{T H}\right)$, which agrees with the work of (Paniagua et al., 2013), while the entropy rate balance for the same system at the steady state can be written as:

$$
0=-\frac{\dot{Q}_{H 2}}{T_{H 2}}+\frac{\dot{Q}_{c 1}}{T_{c 1}}+\dot{S}_{g e n}
$$

or 


$$
\dot{S}_{g e n}=\frac{\dot{Q}_{H 2}}{T_{H 2}}-\frac{\dot{Q}_{c 1}}{T_{c 1}}
$$

Note here that, by convention, any energy entering the system will be given a (+ve) sign, while that leaving the system will be assigned a (-ve) sign.

Jaber et al. (2004) were the first who showed the analogy between thermal and inventory systems. They claimed that the flow of a commodity from an inventory system into the market could be analogous to the heat that transfers from a hot into a cold region phenomenologically due to the existence of a driving force - a gradient. They used a onenode model connecting the supplier to the market (environment). This was then extended in (Jawad et al., 2016) to allow enhanced transfer of a commodity (or more) by adding work input (equivalent to cost inputs). That is, rather than only transferring an amount of commodity, $Q$, the addition of an amount of input (work) $W$, raises the transfer to $(Q+W)$ as required by the laws of conservation. In this work, a further refinement is the consideration of a combined system consisting of two heat pumps in series representing the manufacturer and the retailer consequently.

In their treatment, Jaber et al. (2004) considered, from the inventory point of view, the demand rate of a commodity to be analogous to the heat transfer rate and expressed it as $d(t)=-K_{P}\left(P(t)-P_{0}(t)\right)$, where, for simplicity and in line with the EOQ, $P(t)=P$ and $P_{0}(t)=P_{0}$ are constant for all $t \in[0, \tau]$. The commodity is postulated to flow from an inventory system (where its price to the end customer is lower than that of the market) into the market, then $P<P_{0}$. 


\subsubsection{A heat pump system as a supply chain}

In inventory management policies, managing inventory in a two-level supply chain strives to minimize the inventory level for each member while jointly meeting the goal of customer satisfaction. Each member of a supply chain seeks to improve its operations, minimize costs, and maximize profit through coordination. Members of a supply chain depend on each other with the need to coordinate by efficiently managing dependencies between them (Sundar, Narayanan, \& Nagaraju, 2012).

Figure (6.2) illustrates a schematic diagram of a two level (manufacturer and retailer) supply chain. From Figure (6.2) one can observe that a single manufacturer (analog to HP1 in Figure 6.1) produces a product at an ideal cost (no entropy generated in the system in term of losses and wastes) equal to $c_{m}=c_{w}+c_{m t r}$. Where, $d c_{w}$ and $d c_{m t r}$ are analogous to $\dot{W}_{1}$ and $\dot{Q}_{c 1}$, respectively.

At this point, the cost of the product can be found on the market at an equilibrium price of $c_{m 0}$. In order for the produced product to be in competition with the market price, the cost to produce the product should be less than its market equilibrium price. This chapter considers the flow of raw materials from the market to the manufacturer is similar to the flow of commodity as found by (Jaber et al., 2004). In other words, there is a market's equilibrium price that is greater than the price set by the manufacturer (i.e. $c_{m t r 0} \geq$ $\left.c_{m t r}\right)$.The finished product then goes to the warehouse to be shipped to the retailer at a price equal to $c_{p, r}=\left(1+m_{m}\right) c_{m}$, where $d c_{p, r}$ is analogous to $\dot{Q}_{c 2}$ in the thermal system. 


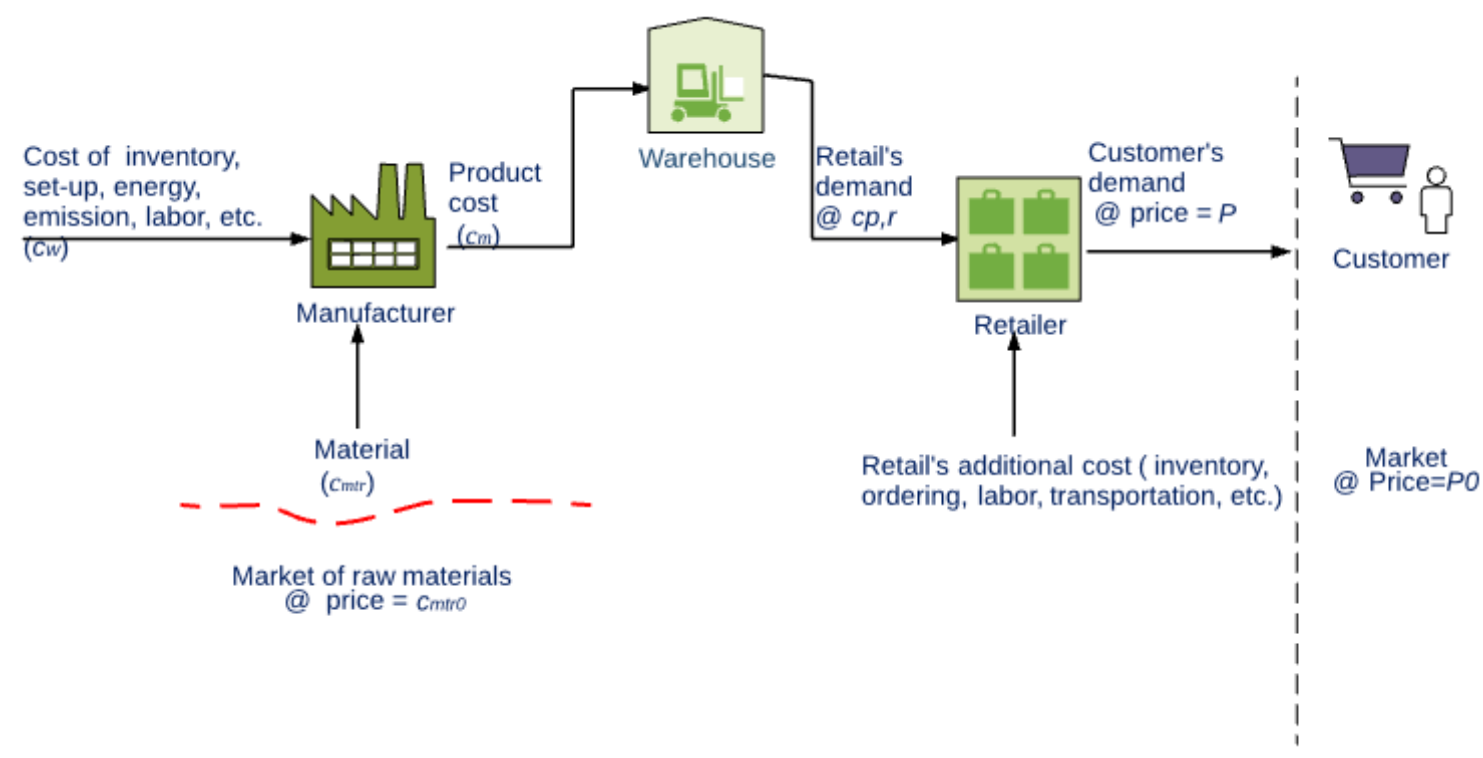

Figure 6.2. Schematic diagrams of a two-level supply chain (system-surrounding boundaries depicted as a dotted line)

Meanwhile, the retailer (analog to HP2) faces additional costs of inventory, ordering, labour, transportation, etc., which are analog to $\dot{W}_{2}$. These costs of the retailer plus its $c_{p, r}$ create the total cost of the retailer, $c_{r}$, which are required to be invested to fulfill the demand of the customers. The retailer, including a margin, sells the final product to the customer at a price equal to $P=\left(1+m_{r}\right) c_{p r}$.

The commodity will be sold to customers at a price of $P$ lower than the market $P_{0}$, which is analog to $T_{H 2}$ in the thermal system. Hence, one can postulate that the flow behavior of a multi-level supply chain emulates that of combined thermal systems to a large extent.

The wasted amounts of capital, raw materials, energy and labour efforts, which cannot be regenerated again, can be represented by the entropy generated in the combined system, $\dot{S}_{g e n}^{C}$, and this can be expressed in an analogous manner to Eq. (6.3) as: 


$$
\dot{S}_{g e n}^{C}=\frac{d P}{P_{0}}-\frac{d c_{m t r}}{c_{m t r 0}}
$$

The reasons for selecting the material cost to be a major input for the system include but not limited to;

- The material can be ordered/produced within an inventory model.

- They are considered as variable expenses that fluctuate with demand or production volumes

- Its availability affects the production systems.

- The major role that materials can play in the rapid growth in emerging markets, which causes a dramatic increase in demand for resources and supplies of many raw materials have become harder to secure. Companies could cut their product costs by $50 \%$ through reusing materials and components. Also, material costs can be controlled by selecting another designs and materials (Mohr, Somers, Swartz, \& Vanthournout, 2012).

- It's the most costly item (Cook \& Graser, 2001). For instance, an article in the "Market Realist" by Henry Kallstrom, the author claimed that raw materials are the biggest cost driver in the auto industry (Kallstrom, 2015).

Generally speaking, the entropy balance of a system is stated as the entropy change of a system during a process is equal to the net entropy transfer through the system boundary and the entropy generated within the system as a result of irreversibility (Cengel \& Boles, 2010). In other words, the entropy balance for a system can be represented by (Cengel \& Boles, 2010): (Total entropy entering) - (Total entropy leaving) + (Total entropy generated $)$ 
$=($ Change in the total entropy of the system $)$. For a steady state case, the change in the total entropy of the system equals zero. Hence, the entropy balance can be written as: (Total entropy generated $)=($ Total entropy leaving $)-($ Total entropy entering $)$. In the system selected in this study, $\frac{P}{P_{0}}$ is the total entropy leaving and $\frac{c_{m t r}}{c_{m t r}}$ is the total entropy entering, while the entropy accompanied with the cost of $c_{m}$ is included in the total entropy generated.

Rearranging the Eq. (6.4) with the substitution of $d=-K_{P}\left(P-P_{0}\right)$ gives:

$$
\dot{S}_{g e n}^{C}=-K_{P}\left(P-P_{0}\right)\left(\frac{P}{P_{0}}-\frac{c_{m t r}}{c_{m t r 0}}\right)
$$

Entropy cannot be negative, and therefore $\frac{P}{P_{0}}>\frac{c_{m t r}}{c_{m t r 0}}$.

Entropy occurs in the direction it increases, which is time. In inventory systems, entropy increases due to the movement of a product, from the initial state as a raw material, through all other stages of an inventory system. This movement causes more disturbance inside the system and increases irreversibility as a product is pushed close to customers. In turn, irreversibility increases entropy. Therefore, the entropy of the final stage, which is the selling stage $\left(\frac{P}{P_{0}}\right)$, should be always greater than that of the initial (buying raw material) stage, $\left(\frac{c_{m t r}}{c_{m t r 0}}\right)$. From Eq. (6.5), in order to obtain $\dot{S}_{g e n}^{C} \geq 0$, the term $\left(\frac{P}{P_{0}}-\frac{c_{m t r}}{c_{m t r 0}}\right)$ should be greater than or equal to zero. Hence, $\left(P \geq P_{0} \frac{c_{m t r}}{c_{m t r 0}}\right)$ should be always obtained in addition to the other constraint of $P<P_{0}$ and $c_{m t r} \leq c_{m t r 0}$. 
Andresen \& Gordon (1992) found that since exergy is a function of both the system and the surroundings, they then let the "reservoir's" temperature vary with time and observed what happened. It could be understood that the changes in the reservoir are the variations in the "immediate surroundings" rather than the environment, which cannot change as a result of a system event. Hence, one can claim that in inventory systems, the destroyed exergy (the monetary loss of the units not produced and sold because of inefficiencies) should be equal to $P \dot{S}_{g e n}^{C}$, with the assumption that the "immediate customers" represent the immediate surroundings for a production-inventory system (or the buyer i a multi echelon SC), while the market represents the environment.

To compute the cost of the lost units due to the disorder in the system, it was assumed that the units lost at a specific time remain constant, while the prices and/or costs change. Hence, the monetary loss of the units destroyed can be calculated by the following formula:

$$
E_{p}=P \dot{S}_{g e n}^{C}=P\left(-K_{P}\left(P-P_{0}\right)\left(\frac{P}{P_{0}}-\frac{c_{m t r}}{c_{m t r 0}}\right)\right)
$$

\subsection{An Exergetic Supply Chain Model}

\subsubsection{Entropy model assumptions and decision variables}

This chapter considers a coordinated two-level (manufacturer-retailer) supply, where the manufacturer delivers the finished products to the buyer. The objective of this study is to minimize the total cost, $T C$, of the developed supply chain model while focusing on the pillars of sustainable developments. 
To bind the research, the following assumptions have been considered in building the model:

- Retailer sells items to the customer at price $P$, which is less than the market price $P_{0}$ where $P_{0}>P$.

- The manufacturer ships $n$ lots of sizes $q$ each in every cycle.

- The retailer pays the transportation cost (As per the "Free on Board" (FOB) origin terms, when the buyer is responsible as an owner for the shipment in-transit (Coyle, Novack, Gibson, \& Bardi, 2010).

- The production rate, $\rho$, is faster than the consumption rate, $\rho>d$, to avoid shortages

- Produced items are of acceptable and consistent quality,

- Lead time is zero for a domestic supply chain, and

- The planning horizon is infinite.

The decision variables for the model of this study are price, $P$, number of shipments, number of trucks per shipment, $\mathcal{R}$ and the production rate, $\rho$.

\subsubsection{The mathematical model}

The first model of inventory that is investigated in this research has been introduced by (Hill, 1997) (for behavior of the model, the reader can visit (Hill, 1997)), where it is allowed for shipments from the manufacturer to the retailer to be delivered during the production cycle of the manufacture. According to this model, the first shipment of the manufacturer reduces its inventory to the zero level. The total cost per unit time as per Hill's model can be written as: 


$$
T C_{\text {Hill }}=\frac{d}{n q}\left(A_{m}+n A_{r}\right)+h_{m}\left(\frac{d q}{\rho}+\frac{\rho-d}{2 \rho} n q\right)+\frac{q}{2}\left(h_{r}-h_{m}\right)
$$

This chapter considers the supply chain can face other types of costs in addition to the aforementioned costs of Eq. (6.7). The following are a brief description for each of the considered costs:

- The cost of $\mathrm{CO}_{2}$ emission due to the production activities:

The amount of $\mathrm{CO}_{2}$ (in ton/unit) per unit of product that is emitted from a production process (see (M. Y. Jaber, Glock, \& Saadany, 2013)) can be computed by $\operatorname{Em}(\rho)=a \rho^{2}-b \rho+c$. The terms $a, b$ and $c$ can be empirically obtained as in Narita (Narita, 2012) who experimentally investigated the relation between emitted $\mathrm{CO}_{2}$ and the cutting speed of a machining tool. He found that the emissions of $\mathrm{CO}_{2}$ are convexly functioned to the cutting speed of the tool. Jaber et al. ( Jaber \& Glock, 2013) used a similar relationship derived for combustion engines.

- The cost of energy consumed during the production activities:

Thiriez (2006) showed that the energy requirements for actual material processing could be much less than the total energy and that at lower production rates the machining contribution is even smaller. The authors reported that the electrical “exergy" required to process a unit of product, $E_{g}$, is expressed as $E_{g}(\rho)=k_{0}+\frac{k}{\rho}$. Taking an injection machine as an example, $k_{0}$ is the variable power determined from the physics of the process such as increasing the shot size or the clamping force increases which in turn cause an increase of the variable power. $k$ is the fixed power 
required to sustain the machine during the idle period and it comes from machine's features required to support the process such as the power required to run the computer console, the power needed to keep the hydraulic pump running, and any power to maintain heaters idling (Thiriez, 2006).

- The cost of transportation and its social and environmental affects:

It was found that the transportation sector is responsible for some $25 \%$ of the world's energy usage and for almost $22 \%$ of the global energy emissions (Ortolani, Persona, \& Sgarbossa, 2011). The total transportation cost is the sum of both of internal and external transportation costs (Ortolani et al., 2011); (Forkenbrock, 1999); (Janic, 2007). In this study, it refered to the external part of the transportation cost as the social and environmental costs of transportation. The internal transportation cost is defined as the fixed and variable costs that are directly needed to own and operate a vehcile (Ortolani et al., 2011). It includes all of the fixed costs as any cost that do not increase with vehicle mileage such as vehicle purchase or lease, insurance, vehicle registration and taxes, whereas the variable costs are any cost that increases with the increase in travelled distance such as fuel and its taxes, oil and tires, maintenance and repair, parking and tolls fees and driver wages. For simplicity, this study considers the fixed cost only; i.e. $C_{t-i n t}=\mathcal{R} \frac{d}{q} F$ (Bazan et al., 2015). This is not unrealistic given that shipments are usually full or half-truckloads. The external transportation costs are defined as the expenses of the impact of logistics networks on a society and the environment such as local and global autmospheric pollution, traffic congestion, noise pollution, and traffic accidents (Janic, 2007). In this chapter, the external cost divided 
into; social costs, which include traffic congestion, noise pollution, and traffic accidents, and they can be expressed by the formula $S C_{t r}=\mathcal{R} \frac{d}{q} t_{c} \widetilde{D} \gamma c_{S L, j}$, and the environmental costs of transportation, which can be expressed as (Bazan et al., 2015): $E C_{t r}=\mathcal{R} \frac{d}{q} \mathrm{G} e_{t} c_{e s}$. Hence, the external cost of transportation can be expressed as: $C_{t-e x t}(q)=\mathcal{R} \frac{d}{q} t_{c} \widetilde{D} \gamma c_{S L, j}+\mathcal{R} \frac{d}{q} \mathrm{G} e_{t} c_{e s}$

\subsection{Domestic Vs. Global Supply Chains}

The theory of "comparative advantage" explains why "most" trade occurs among individuals, firms, and nations. This theory refers to the ability to produce goods and services at lower costs than other economic actors (Veseth, 2014). In the literature, global supply chain management refers to a group of operational processes, such as: global sourcing (the management of supplier relationships from a global perspective), global manufacturing (the management of manufacturing activities distributed all over the world) and global distribution (how companies manage their sales and distribution channels globally) (Caniato, Golini, \& Kalchschmidt, 2013).

Increased globalization has resulted in many firms sourcing some of their operations to an offshore party to save on technology, labour, and materials costs. Going global can make operations more complex as firms need to consider security, port issues, extra taxes and tariff, partnerships with local experts, cultural differences, technology abilities and capabilities and risk management (MacDonald, 2006). In addition, some security elements 
may disrupt global supply such as natural disasters, acts of war or terrorism, theft and local labour strikes or shutdowns (Thomas \& Vaduva, 2015).

The transportation of goods is critical to the success of global supply chains (Sople, 2011). One of the major factors that affect the selection of the transportation mode in global sourcing is the "transit time," which is the total time that is needed to transport a product from its point of origin to its destination. It can affect the inventory availability, shortages costs, and customer satisfaction. Hence, modal speed and its ability to perform pickup and delivery tasks greatly affect transit time. For a global supply chain, where the point of origin (manufacturer, supplier) is located overseas, the local market and in-transit inventory (ITI) should be considered. ITI is the order quantity in movement between the members of a supply chain, but not received yet and its cost equal to $d h_{T r} t_{T r}$. Regardless of which member of the chain owns the product, a holding cost for ITI is applied to the total cost of the supply chain. Generally, $h>h_{T r}$ since $h$ accounts for stocking activities such as paying for renting a warehouse and labours who manage products in warehouse (Ravindran $\&$ Warsing, Jr., 2012). Therefore, firms need to select the proper mode of transportation that can ship their products in less time to reduce the associated costs.

Since ordering from an overseas supplier needs more time to receive the order quantity, then it is required to consider the time that elapses between the initiation of the order and its completion (receiving the products by the retailer). The pipeline inventory is Ld. Substituting $d=-K_{P}\left(P-P_{0}\right)$, and the costs explained in Section 6.3.1 and in-transit holding cost to Eq. (6.7), then, the annual total cost function becomes: 


$$
\begin{aligned}
\left.T C_{\text {Hill }}=\frac{-K_{P}(}{n q}-P_{0}\right) & \left(A_{m}+n A_{r}\right) \\
& +h_{m}\left(\frac{\left(-K_{P}\left(P-P_{0}\right)\right) q}{\rho}+\frac{\rho-\left(-K_{P}\left(P-P_{0}\right)\right)}{2 \rho} n q\right) \\
& +\left[h_{r}\left(\frac{q}{2}+L d\right)-h_{m} \frac{q}{2}\right] \\
& +\left(-K_{P}\left(P-P_{0}\right)\right)\left(c_{m}+c_{L, m}+c_{L, r}+\mathcal{R} \frac{F}{q}+\mathcal{R} \frac{t_{c} \widetilde{D} \gamma}{q} c_{S L}\right. \\
& +\mathcal{R} \frac{\mathrm{G} e_{t}}{q} c_{e s}+h_{T r} t_{T r}+c_{e s}\left(a \rho^{2}-b \rho+c\right)+c_{e n g}\left(k_{0}+\frac{k}{\rho}\right) \\
& \left.+\delta P\left(\frac{P}{P_{0}}-\frac{c_{m t r}}{c_{m t r 0}}\right)\right)
\end{aligned}
$$

It is assumed that emission and energy costs for the retailer's facilities are very low compared to those of the manufacturer. Therefore, in this study, the emission and energy costs of the retailer have been neglected. Setting the first derivative of Eq. (6.8) to be equal to zero and solving for $q$ to obtain the optimal order quantity, $q^{*}$, that minimizes Eq. (6.8):

$$
q_{\text {Hill }}=\sqrt{\frac{-K_{P}\left(P-P_{0}\right)\left[\frac{A_{m}}{n}+A_{r}+\mathcal{R}\left(G e_{t} c_{e s}+t_{c} \widetilde{D} \gamma c_{S L}+F\right)\right]}{h_{m}\left(\frac{\left(-K_{P}\left(P-P_{0}\right)\right)}{\rho}+n \frac{\rho-\left(-K_{P}\left(P-P_{0}\right)\right)}{2 \rho}\right)+\frac{\left(h_{r}-h_{m}\right)}{2}}}
$$

$\mathcal{R}$ could be represented as a function of $q, \mathcal{R}=\frac{q}{t_{c}}$, which would make finding a closed form solution for Eq. (6.9) difficult. Therefore, for simplicity, it has been decided to treat it as a decision variable and introduce the constraint of $\mathcal{R} t_{c}-q \geq 0$, which has the same meaning of $\mathcal{R}=q / t_{c}$ (Bazan et al., 2015). In this thesis, a domestic market is where raw materials 
and goods flow freely within a country with no boarder-crossing occurs and the currency is the same, otherwise it is international (global). So, despite the proximity, Winnipeg is local to Toronto and Buffalo is international and the values of $e e_{K}$ and $e e_{L}$ are those of a country, e.g., Canada, and not of a specific province within Canada. Supply chain management is a result of trade explosion and globalization following the industrial revolution (Pappis, 2010).

Coordination between supply chain members improves information and data sharing, reduces uncertainties and increase profits. The unprecedented expansion of global trade expanded supply chains networks and increased their complexity (Lee \& Lee, 2007). Many business firms produce products and services in different countries and sell them globally. A company therefore must align its supply chain management practices with its global trade processes.

\subsection{Consignment Stock Policy in an Integrated Supply Chain}

Consignment Stock (CS) strategy reduces the vendor's (manufacturer) inventory cost since it uses the buyer's (retailer) facilities to store its own products, where these items are withdrawn from stock as needed by the buyer (Jaber, Zanoni, \& Zavanella, 2014a). CS is usually beneficial to both (vendor and buyer). For the vendor, it is cheaper to hold the inventory at the buyer's stock than at its end, while the buyer does not need to be concerned about managing its stock and invest in this matter (Jaber et al., 2014a). The per unit time total cost function of consignment stock model was given by (Braglia \& Zavanella, 2003) as: 


$$
T C_{C S}=\left(A_{m}+n A_{r}\right) \frac{d}{n q}+h_{r}\left(\frac{d q}{\rho}+\frac{\rho-d}{2 \rho} n q\right)-\left(h_{r}-h_{m}\right) \frac{d q}{2 \rho}
$$

This chapter considers that in addition to the costs considered in Eq. (6.10) and similar to the previous model in this chapter, the manufacturer incurs additional annual costs, which are the production cost, labour cost, energy cost and emission cost. The extra cost for the retailer are the purchasing, labour, transportation, the social and environmental impact of transportation costs. Adding these costs along with the cost of entropy to Eq. (6.10), to obtain:

$$
\begin{aligned}
T C_{C S}=\left(A_{m}+\right. & \left.n A_{r}\right) \frac{-K_{P}\left(P-P_{0}\right)}{n q} \\
& +h_{r}\left(\frac{-K_{P}\left(P-P_{0}\right) q}{\rho}+\frac{\rho-\left(-K_{P}\left(P-P_{0}\right)\right)}{2 \rho} n q\right) \\
& -\left(h_{r}-h_{m}\right) \frac{K_{P}\left(P-P_{0}\right) q}{2 \rho} \\
& -K_{P}\left(P-P_{0}\right)\left(c_{m}+c_{L, m}+c_{L, r}+\mathcal{R} \frac{F}{q}+h_{T r} t_{T r}\right. \\
& +\mathcal{R} \frac{\mathrm{G} e_{t}}{q} c_{e s}+\mathcal{R} \frac{t_{c} \widetilde{D} \gamma}{q} c_{S L, j}+c_{e s}\left(a \rho^{2}-b \rho+c\right) \\
& \left.+c_{e n g}\left(k_{0}+\frac{k}{\rho}\right)+\delta P\left(\frac{P}{P_{0}}-\frac{c_{m t r}}{c_{m t r}}\right)\right)
\end{aligned}
$$

Once $\partial T C_{C S} / \partial q$ is set equal to zero, the optimal batch size that minimizes the total cost can be found as: 


$$
\begin{aligned}
& q_{C S} \\
& =\sqrt{\frac{\frac{-K_{P}\left(P-P_{0}\right)}{n}\left(\left(A_{m}+n A_{r}\right)+n \mathcal{R}\left(G e_{t} c_{e s}+F+t_{c} \widetilde{D} \gamma c_{S L, j}\right)\right)}{h_{r}\left(\frac{-K_{P}\left(P-P_{0}\right)}{\rho}+n \frac{\rho-\left(-K_{P}\left(P-P_{0}\right)\right)}{2 \rho}\right)-\left(h_{r}-h_{m}\right) \frac{-K_{P}\left(P-P_{0}\right)}{2 \rho}}}
\end{aligned}
$$

\subsection{Application of the Exergetic Model}

The total consumed exergy can be represented by $T E x C$ (in MJ/unit time), which is the exergetic form of $T C_{H i l l}$ shown in Eq. (6.8) and can be written as:

$$
\begin{aligned}
T E x C_{H}=\frac{-K_{P}}{}\left(P-P_{0}\right) & n q_{x}\left(A_{x, m}+n A_{x, r}\right) \\
& +h_{x, m}\left(\frac{q_{x}\left(-K_{P}\left(P-P_{0}\right)\right)}{\rho}+\frac{\rho-\left(-K_{P}\left(P-P_{0}\right)\right)}{2 \rho} n q_{x}\right) \\
& +\left(h_{x, r}\left(\frac{q}{2}+L d\right)-h_{x, m} \frac{q}{2}\right) \\
& +\left(-K_{P}\left(P-P_{0}\right)\right)\left[e e_{k, m}\left(c_{m}+c_{e}\left(a \rho^{2}-b \rho+c\right)\right)\right. \\
& \left.+e e_{k, r}\left(\mathcal{R} \frac{F}{q}+\mathcal{R} \frac{\mathrm{G} e_{t}}{q} c_{e}+\mathcal{R} \frac{t_{c} \widetilde{D} \gamma}{q} c_{S L, j}+h_{T r} t_{T r}\right)\right] \\
& +\left(-K_{P}\left(P-P_{0}\right)\right)\left[\left(e e_{L, m} \frac{c_{L, m}}{s_{m}}+e e_{L, r} \frac{c_{L, r}}{s_{r}}\right)+3.6\left(k_{0}+\frac{k}{\rho}\right)\right. \\
& \left.+\delta P\left(e e_{k, r} \frac{P}{P_{0}}-e e_{k, m} \frac{c_{m t r}}{c_{m t r 0}}\right)\right]
\end{aligned}
$$


The number 3.6 represents the conversion factor between $\mathrm{kWh}$ and $\mathrm{MJ}$, where $1 \mathrm{kWh}$ $=3.6 \mathrm{MJ} . A_{x, i}$ and $h_{x, i}$ are the exergetic values of $A_{x, i}$ and $h_{x, i}$ for supply chain member $i=m, r$, which can be written as:

$$
\begin{aligned}
& A_{x, i}=e e_{K}\left(A_{K, i}+A_{E n v, i}\right)+\frac{e e_{L} A_{L, i}}{s_{i}} \\
& h_{x, i}=e e_{K}\left(h_{K, i}+h_{E n v, i}\right)+\frac{e e_{L} h_{L, i}}{s_{i}}
\end{aligned}
$$

Here, the subscripts $K, L$ and Env indicate the portion of capital, labour and environmental remediation of each cost $(A$ and $h)$, respectively. The optimal order quantity that minimizes Eq. (6.8), after replacing $A$ and $h$ with $A_{x}$ and $h_{x}$, respectively, can be written as:

$$
q_{x, \text { Hill }}=\sqrt{\frac{\left(-K_{P}\left(P-P_{0}\right)\right)\left[\frac{A_{x, m}}{n}+A_{x, r}+\mathcal{R} G e_{t} c_{e s}+\mathcal{R} F+\mathcal{R} t_{c} \widetilde{D} \gamma c_{S L}\right]}{h_{x, m}\left(\frac{\left(-K_{P}\left(P-P_{0}\right)\right)}{\rho}+\frac{\rho-\left(-K_{P}\left(P-P_{0}\right)\right)}{2 \rho} n\right)+\frac{\left(h_{x, r}-h_{x, m}\right)}{2}}}
$$

The same concepts of Eq. (6.13) can be used for the case when the manufacturer specifies the minimum order quantity that a retailer must sell, by using Eq. (6.11). Similarly, the total exergy consumed during production-inventory processes operating under Consignment Stock can be written as: 


$$
\begin{aligned}
& T E x C_{C S}=\left(A_{x, m}+n A_{x, r}\right) \frac{-K_{P}\left(P-P_{0}\right)}{n q_{x}} \\
&+h_{x, r}\left(\frac{-K_{P}\left(P-P_{0}\right) q}{\rho}+\frac{\rho-\left(-K_{P}\left(P-P_{0}\right)\right)}{2 \rho} n q_{x}\right) \\
&-\left(h_{x, r}-h_{x, m}\right) \frac{K_{P}\left(P-P_{0}\right) q_{x}}{2 \rho} \\
&-e e_{k}\left(K_{P}\left(P-P_{0}\right)\right)\left[c_{m}+c_{e s}\left(a \rho^{2}-b \rho+c\right)+\mathcal{R} \frac{F}{q}\right. \\
&\left.+\mathcal{R} \frac{\mathrm{G} e_{t}}{q} c_{e s}+\mathcal{R} \frac{t_{c} \widetilde{D} \gamma}{q} c_{S L, j}+h_{T r} t_{T r}+\delta P\left(\frac{P}{P_{0}}-\frac{c_{m t r}}{c_{m t r}}\right)\right] \\
&-K_{P}\left(P-P_{0}\right)\left(e e_{L}\left(\frac{c_{L, m}}{s_{m}}+\frac{c_{L, r}}{s_{r}}\right)+3.6\left(k_{0}+\frac{k}{\rho}\right)\right)
\end{aligned}
$$

Note here that $e e_{K}$ and $e e_{L}$ will be used for the local society (domestic) only. This is based on the the work of (Braglia \& Zavanella, 2003), who claimed that the policy of Consignment Stock needs a continuous exchange of information between the two members of the supply chain and they need to be close to each other so that a lot can be shipped as soon as it is ready in a production cycle. Therefore, it can be assumed that Consignment Stock is suitable for the domestic supply chain only. The exergetic optimal order quantity that minimizes Eq. (6.11) after replacing $A$ and $h$ with $A_{x, i}$ and $h_{x, i}$, respectively, can be written as:

$$
q_{x, C S}^{*}=\sqrt{\frac{\frac{-K_{P}\left(P-P_{0}\right)}{n}\left(\left(A_{x, m}+n A_{x, r}\right)+n\left(\mathcal{R} G e_{t} c_{e s}+\mathcal{R} F+\mathcal{R} t_{c} \widetilde{D} \gamma c_{S L}\right)\right)}{h_{x, r}\left(\frac{-K_{P}\left(P-P_{0}\right)}{\rho}+\frac{\rho-\left(-K_{P}\left(P-P_{0}\right)\right)}{2 \rho}\right)-\left(h_{x, r}-h_{x, m}\right) \frac{-K_{P}\left(P-P_{0}\right)}{2 \rho}}}
$$




\subsection{Solution Procedure}

This section shows the solution procedure employed to find the optimal solution (production rate, the number of trucks, the number of shipments, order quantity) that mimizes the total "monetary" and "exergetic" costs of the system. The solution procedure was programmed in Microsoft Excel, using Visual Basic for Applications (VBA) with nested search loops.

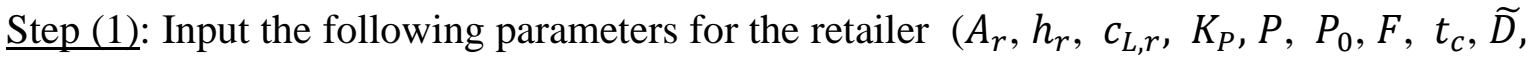
$\left.\gamma, \mathrm{G}, e_{t}, c_{S L}, h_{T r}, t_{T r}, c_{S L}, c_{e s, r}\right)$ and the manufacturer $\left(A_{m}, h_{m}, c_{L, m}, c_{m}, a, b, c, c_{m t r}\right.$, $\left.c_{m t r 0}, k_{0}, k, c_{e n g}, c_{e s, m}\right)$. A range of price, $P$, needs to be selected based on the equilibrium price, $P_{0}$, and other costs that involved in the manufacturing of a product. The annual demand, $d$, can be determined by employing the demand equation of $d=-K_{P}\left(P-P_{0}\right)$.

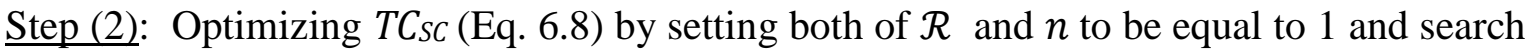
for the optimal production rate $\left(\rho_{1}\right)$ that gives the optimal order quantity, $q_{1}$, (Eq. 6.9) and results in minimization of Eq. (6.8). Let it be called $T C_{S C 1}$. In this step, this chapter introduces the constraint of $\mathcal{R} t_{c}-q \geq 0$, which has the same meaning as $\mathcal{R}=\frac{q}{t_{c}}$, which explained earlier.

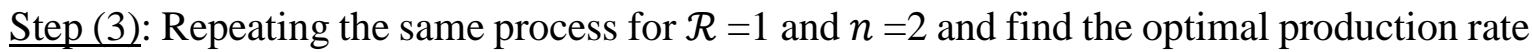
$\left(\rho_{2}\right)$ that gives a different value of the optimal order quantity, $q_{2}$, that results in another minimum value of the total cost, $T C_{S C 2}$.

Step (4): If $T C_{S C 1}\left(\rho_{1}, \mathcal{R}=1, n=1\right)<T C_{S C 2}\left(\rho_{2}, \mathcal{R}=1, n=2\right)$, then these values are the optimal, otherwise, $T C_{S C 2}\left(\rho_{2}, \mathcal{R}=1, n=2\right)$ becomes the basis value for comparison. 
Step (5): Repeating the previous process until the optimal values of $\rho$ and $n$ are reached, then $T C_{S C 1}\left(\rho_{i}, 1, n_{i}\right)$. If that does not provide the optimal solution, then the above processes is repeated by setting $\mathcal{R}=2$ and $n=1$, then $\mathcal{R}=2$ and $n=2$, etc. until the optimal values of $\rho_{2}, \mathcal{R}$ and $n$ that give the optimal solution for Eq. (6.8) can be found.

Step (6): For the optimal values of $\rho, \mathcal{R}, n$, and $q$ calculate the total exergetic cost, $T E x C_{1}$. Step (7): Repeating steps 1-6, but, optimizing TExC in Eq. (6.13). In this step, Eq. (6.15) is employed to find the optimal solution of $q_{x}^{*}(\rho, \mathcal{R}, n)$ that minimizes TExC for the same selected price range. The total cost, $T C_{S C}$, needs to be computed by substituting $q_{x}^{*}(\rho, \mathcal{R}, n)$ in Eq. (6.13).

Substitute $q_{x}^{*}(\rho, R, n)$ with the optimal values of $\rho, R, n$ found in steps (1-6) into the equation of the total "monetary" cost (example, Eq. 6.8) and the total "exergetic" cost (example, Eq. 6-15) to find the optimal $T C_{S C}$ and $T E x C$, respectively, to compare them with the corresponding results of Step (1-6).

\subsection{Results and Discussion}

This section presents and discusses the results of the developed models in the previous sections.

\subsubsection{Case 1-Hill's policy for a domestic supply chain}

In this numerical example, the manufacturer and retailer are both considered to be local Canadian firms. They coordinate with each other and operate under Hill's policy. Table 
(6.1) shows the input parameters that have been used for this case. The following assumptions have been considered:

- Trucking is the only mode of transportation used to transfer ordered products from the manufacturer to the retailer, with external costs and distance of each mode as illustrated in Table (6.2).

- $\quad P_{0}=95, P=81-90$, and $K_{P}=200$, corresponding to $d=2800-1000$ units/year.

The numerical examples in this section were solved using a process similar to that in (Bazan et al., 2015), by optimizing for $\rho, \mathcal{R}$ and $n$, subject to following constraint of $\rho \geq$ $1.1 d$ and $\mathcal{R} \geq q / t_{c}$. Also, as a safety margin, it was assumed that $c_{W}$ equals 1.75 times the total of labour, energy and emission costs of the manufacturer. Microsoft Excel Solver enhanced with Visual Basic for Applications was used to solve the numerical examples. Note that the purchasing costs are excluded here as they do not affect the inventory decision and overshadow the inventory costs.

Table 6.1. List of input parameters and their respective values.

\begin{tabular}{|l|l|l|l|l|l|l|l|}
\hline Parameter & Value & Parameter & Value & Parameter & Value & Parameter & Value \\
\hline$A_{r}$ & 100 & $S_{r}$ & 15 & $T_{T r}$ & $2 / 360$ & $a$ & $1.00 \mathrm{E}-$ \\
\hline$A_{m}$ & 500 & $S_{m}$ & 20 & $h_{T r}$ & 3 & $b$ & 7.0 E- \\
\hline$h_{r}$ & 13 & $F$ & 400 & $t_{c}$ & 250 & $c$ & 1.23 \\
\hline$h_{m}$ & 8 & ${ }^{1} e_{t}$ & 0.01008414 & $k$ & 28000 & $c_{e s}$ & 18 \\
\hline$c_{L, r}$ & 0.5 & ${ }^{2} G$ & 75 & $k_{0}$ & 10 & $3,4 e e_{K, r}$ & 3.40 \\
\hline$C_{L, m}$ & 2 & $\gamma$ & 1.5 & $c_{e n g}$ & 0.10 & ${ }^{4} e e_{L, r}$ & 68.61 \\
\hline
\end{tabular}

${ }^{1}$ Reference: (Bazan et al., 2015).

${ }^{2}$ Reference: (Narita, 2012).

${ }^{3}$ the original values are in $€$, which have been converted to $\$$ using (www.xe.com)

${ }^{4}$ Reference: (Sciubba, 2011) 
Table 6.2. Cost per ton-mile (in 2010 cents) for transportation external costs (GAO, 2011) and assumed distances.

\begin{tabular}{|l|l|l|l|}
\cline { 2 - 4 } \multicolumn{1}{c|}{} & Ship & Train & Truck \\
\hline Accidents & 0.00 & 0.24 & 2.15 \\
\hline Pollution & 1.87 & 0.38 & 1.67 \\
\hline Noise & 0.00 & 0.05 & 0.05 \\
\hline Congestion & 0.00 & 0.03 & 0.58 \\
\hline Climate Change & 0.25 & 0.51 & 2.95 \\
\hline Distance & 6719.50 & 621.40 & 300.00 \\
\hline
\end{tabular}

Table 6.3a and $\mathrm{b}$ illustrate how the search for the optimal solution was performed. To accelerate the search that mentioned in the solution procedure, any value of $n$ that provides an infeasible solution is excluded from the search. Only the values of $n$ that provide feasible solutions will be considered. Hence, the values of $n$ in term of $q$ from the equation of the total cost, $T C_{S C}(n, P, q, \rho, \mathcal{R})$, is needed. This can be done by setting the first partial derivative of $T C_{S C}(n, P, q, \rho, \mathcal{R})$ with respect to $n$ equal to zero and solving for $n$ to get: $n=$

$\frac{1}{q} \sqrt{\frac{2 d A_{m}}{h_{m}\left(1-\frac{d}{\rho}\right)}}$ where $\mathcal{R} t_{c}-q \geq 0$, which yields to $n=\frac{1}{\mathcal{R} t_{c}} \sqrt{\frac{2 d A_{m}}{h_{m}\left(1-\frac{d}{\rho}\right)}}$, which can be considered as the maximum number of shipment that can provide a feasible solution. 
Table 6.3 a. A sample search for the optimal solution when minimizing $T C_{S C}\left(P=81, t_{c}=500\right)$

\begin{tabular}{|c|c|c|c|c|c|c|c|}
\hline $\boldsymbol{\rho}$ & $\boldsymbol{R}$ & $\boldsymbol{n}$ & $\boldsymbol{q}$ & $\boldsymbol{T C}_{\boldsymbol{S C}}$ & $\boldsymbol{R t}_{\boldsymbol{C}}-\boldsymbol{q} \geq \mathbf{0}$ & Value 1 & Value 2 \\
\hline 3606 & 1 & 1 & 544 & $\$ 23,369$ & -43.58 & Infeasible & \\
\hline 3561 & 1 & 2 & 451 & $\$ 22,393$ & 48.73 & & \\
\hline $\mathbf{3 5 2 6}^{\text {a }}$ & $\mathbf{1}$ & $\mathbf{3}$ & $\mathbf{4 1 0}$ & $\mathbf{\$ 2 2 , 2 1 1}$ & $\mathbf{8 9 . 8 4}$ & $\mathbf{\$ 2 2 , 2 1 1}<\$ 22,393$ \\
\hline
\end{tabular}

\begin{tabular}{|l|l|l|l|l|l|l|}
\hline 3614 & 2 & 1 & 645 & $\$ 25,318$ & 354.73 & $\$ 22,211<\$ 25,318$ \\
\hline 3561 & 2 & 2 & 560 & $\$ 24,683$ & 439.68 & $\$ 22,211<\$ 24,683$ \\
\hline
\end{tabular}

\begin{tabular}{|l|l|l|l|l|l|l|}
\hline 3621 & 3 & 1 & 733 & $\$ 26,999$ & 766.94 & $\$ 22,211<\$ 26,999$ \\
\hline 3561 & 3 & 2 & 651 & $\$ 26,595$ & 848.64 & $\$ 22,211<\$ 26,595$ \\
\hline
\end{tabular}

${ }^{\text {an }}$ Optimal policy when minimizing $T C_{S C}$.

Table 6.3 b. A sample search for the optimal solution when minimizing $\operatorname{TExC}\left(P=81, t_{c}=500\right)$

\begin{tabular}{|c|c|c|c|c|c|c|c|}
\hline $\boldsymbol{\rho}$ & $\boldsymbol{R}$ & $\boldsymbol{n}$ & $\boldsymbol{q}_{\boldsymbol{x}}$ & $\boldsymbol{T E} \boldsymbol{x} \boldsymbol{C}$ & $\boldsymbol{R t}_{\boldsymbol{C}}-\boldsymbol{q} \geq \mathbf{0}$ & Value 1 & Value 2 \\
\hline 4020 & 1 & 1 & 500 & $2.206 \mathrm{E}+05$ & 0 & $\mathbf{2 0}$ & \\
\hline $\mathbf{4 0 0 3}^{\mathbf{b}}$ & $\mathbf{1}$ & $\mathbf{2}$ & $\mathbf{5 0 0}$ & $\mathbf{2 . 1 9 8 E + 0 5}$ & $\mathbf{0}$ & $\mathbf{2 . 2 0 6 E + 0 5}>\mathbf{2 . 1 9 8 E + 0 5}$ \\
\hline 4004 & 1 & 3 & 500 & $2.199 \mathrm{E}+05$ & 0 & $2.198 \mathrm{E}+05<2.199 \mathrm{E}+05$ \\
\hline
\end{tabular}

${ }^{\mathrm{b}}$ Optimal policy when minimizing TExC.

The results obtained from the above equation of $n$ have been compared with the results obtained from optimizing the equation of $T C_{S C}(n, P, q, \rho, \mathcal{R})$ by code written with VBA. It has been found that both methods give the same results.

Since the holding cost is usually intuitively set by managers rather than numerically, it was assumed that holding cost can be divided into $65 \%$ for capital $(K), 30 \%$ for labour $(L)$ and $5 \%$ for environment remediation $(E n v)$ during the holding stage. The setup and/or order costs, somehow, is easier to be controlled by using paperless orders and financial transactions, and electronic versions of communications. Hence, in this example, they are 
divided into the following fractions: $50 \%(K), 40 \%(L)$, and $10 \%(E n v)$. For the purpose of simplicity at this level, this study assumes these fractions are valid for both of manufacturer and retailer. A sensitivity analysis to study the effects of $A_{x, i}$ and $h_{x, i}$ has been performed and will be discussed later.

Optimizing Eq. (6.8) the minimum cost is $T C_{\text {Hill }}=\$ 24,909$, which occurs at $q=250$ units, $n=3, \mathcal{R}=1$ truck and at a rate of $\rho=3539$ units/year. The amount of exergy used (consumed resources) is 202,768 MJ/yr. The same example has been repeated, but minimizing $T E x C_{H i l l}$. The minimum $T E x C_{H i l l}$ value occurred at $187,136 \mathrm{MJ} / \mathrm{yr}, q_{x, H i l l}=$ $250, \mathcal{R}=1, n=3$, and $\rho=4003$. The corresponding $T C_{H i l l}=\$ 25,695$. This suggests that optimizing $T E x C_{H i l l}$ instead of $T C_{H i l l}$ is better as it uses less exergy $(202,768>187,136)$, but at higher cost $(\$ 25,695>\$ 24,909)$. The labour cost represents about $19.5 \%$ of the total cost. These results suggest that if the company minimizes $T C_{\text {Hill }}$ instead of $T E x C_{H i l l}$, the company saves \$786 (\$25,695-\$24,909) annually, but destroys 15,632 MJ/year $(202,768-187,136)$, which is a cost paid by the society of about $\$ 6183$, which can be an annually saving that can be computed by:

$$
S_{s v g}=\Delta E x\left(\left[\left(\frac{T C-C_{L}}{T C}\right) / e e_{K}\right]+\left[\left(\frac{C_{L}}{T C}\right)\left(s_{r}+s_{m}\right) / e e_{L}\right]\right)
$$

If the company minimizes $T E x C_{H i l l}$ instead of $T C_{H i l l}$, then it saves society $\$ 6183$ for just an additional cost as little as $\$ 786$, suggesting that it may not be costly to be sustainable. The results in Table (6.4-a) show that for a range of demand values, minimizing TEx $C_{\text {Hill }}$ instead of $T C_{H i l l}$ results in lower costs and lower exergy consumed (less resources used), and subsequently more savings to society. Table (6.4-b) replicates the examples in Table 
(6.4-a) for larger truck capacity, 500 instead of 250. The results show that even when increasing truck capacity optimizing $T E x C_{H i l l}$ favors shipping full truck loads rather than less than full truck loads. This is in agreement with Bouchery, Corbett, Fransoo, \& Tan (2016) who stated that using shipment consolidation and FTL (Full Truck Load) can lead to fewer trucks to be employed, which reduces GHG emissions and transportation costs. It was observed that optimization of $T C_{H i l l}$ can result in more spent capital and more consumed exergy. Also, optimization of $T C_{H i l l}$ results in more number of shipments that associated with more quantity to be ordered/produced than the case of optimizing $T E x C_{H i l l}$. That means firms pay more for internal and external costs of transportation, which also can negatively affect the society. Also, it has been noticed that optimizing $T E x C_{\text {Hill }}$ can result in more production rates than the case of optimizing the $T C_{H i l l}$, which means less times needed to produce the required demand. The difference in $\mathcal{R}, n$ and $q$ can be considered as a saving in time and resources, which can be considered as savings for both of society and firms. It is recommended that firms need to optimize for their consumed exergy rather than costs. By doing so, firms can gain some financial benefits and protect societies where they located in, from wasting natural resources.

Generally, it has been found that increasing the product's price results in more hidden cost, manifested as entropy, which results in increasing $e(P)$ (Eq. (6.6) divided by d) required to control the flow of an item from the retailer to the market. Accordingly, it is indicated that selling a commodity with a lower price generates less disorder in the system benefiting both, member firms and society. To investigate the effects of $A_{x i}$ and $h_{x i}$ on the optimal quantity, seven different cases with different values of $A_{x i}$ and $h_{x i}$ for both of retailer and manufacturer have been selected as illustrated in Table (6.4). Each value of $A_{x i}$ 
and $h_{x i}$ has been divided into capital $(K)$, labour $(L)$ and environment $(E n v)$. As previously mentioned, environment remediation is the cost to a firm to protect the environment, making it part of capital. The breakdown of the percentages that represent $K, L$ and $E n v$ in the setup, order and holding costs for the manufacturer and the retailer has been varied from those used in producing the results in Table (6.4). Results showed that the major effect of $A_{x i}$ and $h_{x i}$ has been found to be mainly on $q_{x, \text { Hill }}$ and $T E x C_{H i l l}$ and that when labour fraction is larger than that of capital, it causes less quantity to be produced/ordered. The results showed that increasing the labour fraction causes more exergy to be consumed, thereby increasing the total cost of the supply chain. These results showed the importance of labour efforts (exergy) in shaping the business performance. This, also can indicate that a labour force can be a key element in generating hidden costs (entropy) in a system, suggesting that more attention is needed to account for the importance of the consumed exergy of labour.

Table 6.4. Optimal policy for model $j=$ Hill when optimizing $T C_{j l}$ and $T E x C_{j}$, respectively.

\begin{tabular}{|c|c|c|c|c|c|c|c|c|c|c|c|c|c|c|}
\hline \multicolumn{2}{|c|}{ (a) $t_{c}=250$} & \multicolumn{6}{|c|}{ Optimization of $T C_{j}$} & \multicolumn{6}{|c|}{ Optimization of $T E x C_{j}$} & \multirow[b]{2}{*}{$S_{s v g}$} \\
\hline$P$ & $d$ & $\rho$ & $\mathcal{R}$ & $n$ & $q_{j}$ & $T C_{j}$ & $T E x C_{j}$ & $\rho$ & $\mathcal{R}$ & $n$ & $q_{x, j}$ & $T C_{j}$ & $\operatorname{TEx}_{j}$ & \\
\hline 81 & 2800 & 3495 & 1 & 5 & 250 & $\$ 23,033$ & 244,526 & 4003 & 1 & 4 & 250 & $\$ 24,307$ & 226,132 & 6,554 \\
\hline 82 & 2600 & 3495 & 1 & 5 & 250 & $\$ 24,041$ & 236,080 & 4003 & 1 & 4 & 250 & $\$ 25,152$ & 217,976 & 6,437 \\
\hline 83 & 2400 & 3518 & 1 & 4 & 250 & $\$ 24,677$ & 225,970 & 4003 & 1 & 3 & 250 & $\$ 25,701$ & 208,815 & 6,338 \\
\hline 84 & 2200 & 3531 & 1 & 3 & 250 & $\$ 24,994$ & 215,000 & 4003 & 1 & 3 & 250 & $\$ 25,859$ & 198,521 & 6,255 \\
\hline 85 & 2000 & 3539 & 1 & 3 & 250 & $\$ 24,909$ & 202,768 & 4003 & 1 & 3 & 250 & $\$ 25,695$ & 187,136 & 6,183 \\
\hline 86 & 1800 & 3539 & 1 & 3 & 250 & $\$ 24,490$ & 189,538 & 4003 & 1 & 3 & 250 & $\$ 25,198$ & 174,616 & 6,120 \\
\hline 87 & 1600 & 3553 & 1 & 2 & 250 & $\$ 23,710$ & 174,921 & 4003 & 1 & 2 & 250 & $\$ 24,288$ & 160,852 & 6,065 \\
\hline 88 & 1400 & 3558 & 1 & 2 & 250 & $\$ 22,463$ & 158,837 & 4003 & 1 & 2 & 250 & $\$ 22,969$ & 145,818 & 6,016 \\
\hline 89 & 1200 & 3563 & 1 & 2 & 250 & $\$ 20,845$ & 141,509 & 4003 & 1 & 2 & 250 & $\$ 21,279$ & 129,520 & 5,970 \\
\hline 90 & 1000 & 3563 & 1 & 2 & 241 & $\$ 18,842$ & 122,928 & 4003 & 1 & 2 & 250 & $\$ 19,204$ & 111,915 & 5,927 \\
\hline
\end{tabular}




\begin{tabular}{|c|c|c|c|c|c|c|c|c|c|c|c|c|c|c|}
\hline \multicolumn{2}{|c|}{ (b) $t_{c}=500$} & \multicolumn{6}{|c|}{ Optimization of $T C_{j}$} & \multicolumn{6}{|c|}{ Optimization of $T E x C_{j}$} & \multirow[b]{2}{*}{$S_{s v g}$} \\
\hline$P$ & $d$ & $\rho$ & $\overline{\mathcal{R}}$ & $n$ & $q_{j}$ & $T C_{j}$ & $T E x C_{j}$ & $\rho$ & $\mathcal{R}$ & $n$ & $q_{x, j}$ & $T C_{j}$ & $T E x C_{j}$ & \\
\hline 81 & 2800 & 3526 & 1 & 3 & 410 & $\$ 22,211$ & 241,100 & 4003 & 1 & 2 & 500 & $\$ 23,456$ & 219,813 & 7,633 \\
\hline 82 & 2600 & 3528 & 1 & 3 & 391 & $\$ 23,291$ & 232,911 & 4003 & 1 & 2 & 500 & $\$ 24,407$ & 212,165 & 7,486 \\
\hline 83 & 2400 & 3549 & 1 & 2 & 417 & $\$ 24,051$ & 223,295 & 4003 & 1 & 2 & 500 & $\$ 25,062$ & 203,511 & 7,362 \\
\hline 84 & 2200 & 3556 & 1 & 2 & 400 & $\$ 24,402$ & 212,579 & 4003 & 1 & 2 & 500 & $\$ 25,409$ & 193,809 & 7,256 \\
\hline 85 & 2000 & 3562 & 1 & 2 & 381 & $\$ 24,414$ & 200,753 & 4004 & 1 & 1 & 500 & $\$ 25,434$ & 183,015 & 7,165 \\
\hline 86 & 1800 & 3567 & 1 & 2 & 362 & $\$ 24,073$ & 187,754 & 4018 & 1 & 1 & 500 & $\$ 24,964$ & 170,883 & 7,090 \\
\hline 87 & 1600 & 3571 & 1 & 2 & 341 & $\$ 25,501$ & 173,521 & 4018 & 1 & 1 & 500 & $\$ 24,105$ & 157,577 & 7,024 \\
\hline 88 & 1400 & 3575 & 1 & 2 & 319 & $\$ 22,263$ & 157,990 & 4018 & 1 & 1 & 500 & $\$ 22,887$ & 143,050 & 6,964 \\
\hline 89 & 1200 & 3594 & 1 & 1 & 394 & $\$ 20,731$ & 140,860 & 4018 & 1 & 1 & 500 & $\$ 21,298$ & 127,261 & 6,909 \\
\hline 90 & 1000 & 3592 & 1 & 1 & 366 & $\$ 18,721$ & 122,312 & 4018 & 1 & 1 & 500 & $\$ 19,324$ & 110,165 & 6,856 \\
\hline
\end{tabular}

The results are in agreement with the study of Fukuda (Fukuda, 2003) who revealed that no distinction is needed between exergy from energy resources and labour exergy in production activities. Accordingly, in order to express the overall production activities in economies, it is adequate to compute the contributions of exergy from energy resources and of labour exergy analogously by introducing their productivities. According to Eq. (6.13), the labour fraction can be reduced by increasing $s$, which can be considered as a sustainable action to improve the labour lifestyle and reduce their hardship.

One can notice the importance of accounting for the consumed exergy rather than just considering the values in term of monetary units. Computing these costs based on their exergetic values can provide more flexibility for managers of supply chains to calculate the quantity based on the available resources and not confining this to the capital only. Flexibility, here, means the ability of managers to switch between monetary and exergetic measures. Therefore, SC managers should carefully measure and try to control the fractions $(K, L, E n v)$ in a way that can meet the requirements of their firms and the society in which 
they operate. Also, this could motivate firms to contribute more to protect the societies where they located to prevent the impacts of resources' lack.

The calculations of EEA are based on labour statistics and on the global monetary circulation (M2) in the country under examination. Therefore, investigating the effects of $e e_{k}$ and $e e_{L}$ on the consumed amount of exergy is important. We performed a simplified calculation for M2, primary energy supply, minerals and metals, total labour force and average working hours per person per year for Canada for the years 2005-2009. The primary energy sources included in this study were: coal, crude oil, natural gas, natural gas liquids, hydro and nuclear electricity. The obtained results are shown in Table (6.5).

Table 6.5. Calculated values of $e e_{K}$ and $e e_{L}$ for Canada for years 2005-2009

\begin{tabular}{|c|l|c|c|c|c|c|c|}
\cline { 2 - 7 } \multicolumn{2}{c|}{} & Sciubba 2011 & $\mathbf{2 0 0 5}$ & $\mathbf{2 0 0 6}$ & $\mathbf{2 0 0 7}$ & $\mathbf{2 0 0 8}$ & $\mathbf{2 0 0 9}$ \\
\hline$e e_{k}$ & $\mathrm{MJ} / \mathrm{CAD}$ & 3.40 & 4.41 & 3.23 & 2.78 & 2.41 & 2.51 \\
\hline$e e_{L}$ & $\mathrm{MJ} / \mathrm{WHr}$ & 68.61 & 66.60 & 51.34 & 47.01 & 44.36 & 52.14 \\
\hline
\end{tabular}

In Table (6.4), it was assumed $e e_{k}$ and $e e_{L}$ to be those provided in (Sciubba, 2011). Examples in Table (6.4-b) have been replicated for low values of $e e_{k}$ and $e e_{L}$ (year 2008). The results are shown in Table (6.5). The results showed that, when comparing to those in Table (6.4-b), lower values of $e e_{k}$ and $e e_{L}$ cause less exergy to be consumed and subsequently increased the savings to society. 
Table 6.6. Optimal policy for model $j=$ Hill when optimizing $T C_{j}$ and $T E x C_{j}$, respectively, for $e e_{L}=44.36$ and $e e_{K}=2.41$, and $t_{c}=500$.

\begin{tabular}{|c|c|c|c|c|c|c|c|c|c|c|c|c|c|c|}
\hline \multirow[b]{2}{*}{$\boldsymbol{P}$} & \multirow[b]{2}{*}{$d$} & \multicolumn{6}{|c|}{ Optimization of $T C_{j}$} & \multicolumn{6}{|c|}{ Optimization of $T E x C_{j}$} & \multirow[b]{2}{*}{$S_{s v g}$} \\
\hline & & $\rho$ & $\mathcal{R}$ & $n$ & $q_{x, j}$ & $T C_{j}$ & TExC $C_{j}$ & $\rho$ & $\mathcal{R}$ & $n$ & $q_{x, j}$ & $T C_{j}$ & TExC $C_{j}$ & \\
\hline 81 & 2800 & 3526 & 1 & 3 & 410 & $\$ 22,211$ & 221,961 & 4168 & 1 & 2 & 500 & $\$ 24,353$ & 205,628 & 8,533 \\
\hline 82 & 2600 & 3528 & 1 & 3 & 391 & $\$ 23,291$ & 212,499 & 4168 & 1 & 2 & 500 & $\$ 25,239$ & 196,753 & 8,351 \\
\hline 83 & 2400 & 3549 & 1 & 2 & 417 & $\$ 24,051$ & 201,915 & 4168 & 1 & 2 & 500 & $\$ 25,830$ & 187,165 & 8,196 \\
\hline 84 & 2200 & 3556 & 1 & 2 & 400 & $\$ 24,402$ & 190,646 & 4168 & 1 & 2 & 500 & $\$ 26,113$ & 176,833 & 8,064 \\
\hline 85 & 2000 & 3562 & 1 & 2 & 381 & $\$ 24,414$ & 178,603 & 4168 & 1 & 1 & 500 & $\$ 26,034$ & 165,681 & 7,951 \\
\hline 86 & 1800 & 3567 & 1 & 2 & 362 & $\$ 24,073$ & 165,738 & 4176 & 1 & 1 & 500 & $\$ 25,495$ & 153,580 & 7,856 \\
\hline 87 & 1600 & 3571 & 1 & 2 & 341 & $\$ 23,361$ & 152,006 & 4176 & 1 & 1 & 500 & $\$ 24,577$ & 140,646 & 7,772 \\
\hline 88 & 1400 & 3575 & 1 & 2 & 319 & $\$ 22,263$ & 137,359 & 4176 & 1 & 1 & 500 & $\$ 23,300$ & 126,846 & 7,695 \\
\hline 89 & 1200 & 3594 & 1 & 1 & 394 & $\$ 20,731$ & 121,540 & 4176 & 1 & 1 & 489 & $\$ 21,652$ & 112,151 & 7,624 \\
\hline 90 & 1000 & 3592 & 1 & 1 & 365 & $\$ 18,721$ & 104,782 & 4176 & 1 & 1 & 451 & $\$ 19,619$ & 96,530 & 7,556 \\
\hline
\end{tabular}

It is suggested that controlling, if possible, $e e_{k}$ and $e e_{L}$ can play a major role in moving a society towards sustainable development by minimizing its consumed exergy. It appears to be a complex task that requires great contributions and efforts from all stakeholders: governments, individuals, societies, business firms, scientists, etc. An example of such efforts is controlling and regulating the activities that can negatively affect the amount of $E x_{i n}$ (the total exergy input to a society). This may include but may not be limited to regulating the activities of importing and exporting products from and to the society, extraction of ores and minerals located within the control volume of the society, and agriculture and fisheries activities. Individuals, societies, and business firms can assist in this manner by encouraging locally produced products. This also can improve the rate of the labour force in the society by creating more job opportunities. On the other hand, the value of M2 can play an important role in controlling the consumed exergy within a society. M2 in a broad definition comprises all the currency in circulation plus savings accounts and non- 
interest bearing bank deposits ("Business Dictionary," n.d.). The importance of M2 is due to its influence on people's spending of income. An increase in the supply of money works both through lowering interest rates, which spurs investment, and through putting more money in the hands of consumers, making them feel wealthier, and thus stimulating spending. Business firms respond to increased sales by ordering more raw materials and increasing production. The spread of business activity increases the demand for labour and raises the demand for capital goods ("Business Dictionary," n.d.). Therefore, governments need to take the proper action on deciding the most proper value of M2 that significantly improves the value of GDP of a society while, at the same time not causing inflation in the economic system of the society.

The first derivative of the Eq. (6.5) with respect to $P$ gives;

$$
\frac{\partial \dot{S}_{g e n}^{C}}{\partial P}=-K_{P}\left(\frac{2 P}{P_{0}}-1\right)+K_{P} \frac{c_{m t r}}{c_{m t r 0}}
$$

Setting the above equation equal to zero and rearrange it to obtain:

$$
P=\frac{P_{0}\left(c_{m t r+c_{m t r 0}}\right)}{2 c_{m t r 0}}
$$

The relation between $P-\dot{S}_{g e n}^{C}$ is concave which means that $\dot{S}_{g e n}^{C}$ reaches its maximum value at a certain price which is $P_{E n t}=\frac{P_{0}\left(c_{m t r}+c_{m t r 0}\right)}{2 c_{m t r 0}}$. It is recommended to be away from this value as much as possible. In our example, $P_{E n t}=88$.

As illustrated in Figure (6.3), $\dot{S}_{g e n}^{C}$ increases with the price till it reaches its peak value at $P_{E n t}$. It starts to fall beyond this price. At the same time, $e(P)$ proportionally increases with price even beyond $P_{E n t}$. Hence, it is recommended to have the commodity 
price between $P_{\min }$ and $P_{E n t}$. This is due to $e(P)$ is at lower rate and demand rate is higher than the range between $P_{E n t}$ and $P_{0}$. Through their legislation and rules, governments play a critical role in establishing sustainability requirements for the private sector. Most business firms recognize that regulations are of high importance for supply chain sustainability as they set minimum standards for the respective markets, consistent frame expectations for market players and create a level playing field for companies across sectors to address several social, environmental health and safety issues (Ernst \& Young, 2016).

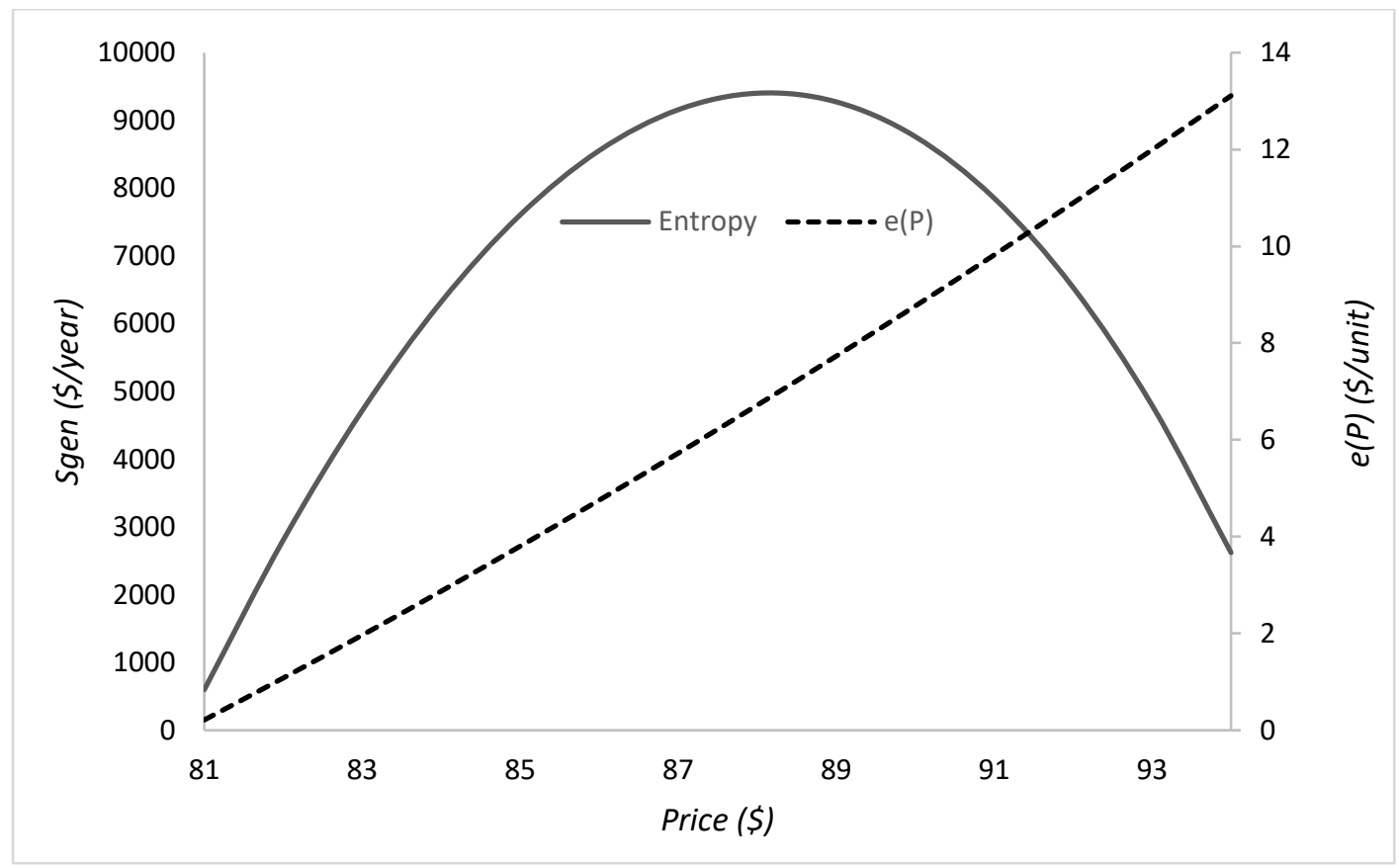

Figure 6.3. The relation between $\dot{S}_{g e n}^{C}, e(P)$ and $P$.

To improve the sustainability of society, governments can play major roles such as (Young \& Dhanda, 2012):

1- Vision/Goal setter: providing visions and strategies to integrate sustainability into public policies. 
2- Leaders by example: by improving the environmental performance of public procurements.

3- Facilitator: establishing open, competitive, and rightly framed markets that would including pricing of products and services, taxing wastes and pollutions, and dismantling subsidies.

4- Innovator/Catalyst: playing a strategic role in advancing innovations in all sectors of society since the advancement of sustainability will require changes.

\subsubsection{Case 2-A domestic supply chain operates under CS policy}

The results in Table (6.4) have been replicated for the CS policy; i.e. using Eqs. (6.11) -(6.17), with the results summarized in Table (6.7). The results in Table (6.7) show slightly higher costs and exergy consumed when compared with the results in Tables (6.4-a and b). For example, comparing the results in Table (6.4-a) with those in Table (6.7-a) for $P=85$, one notices that optimizing the classic cost, $T C_{C S}$ is $2.1 \%$ higher than $T C_{H i l l}$ where the CS policy recommends in producing in smaller lots than Hill's $(n q ; 500<750)$. Optimizing using the exergetic cost functions, the CS policy consumes $0.3 \%$ more resources than the model of Hill. Minimizing the exergetic cost function when adopting the CS policy saves the society $\$ 7016 /$ year for a little investment by the supply chain partners of 773 $(\$ 26,211-\$ 25,438)$. Using trucks with larger capacities reduces the number of shipments/trucks per year and increases the savings to the society by $17 \%$ (from 7016 to 8422). 
The vendor tends to use CS policy when it is cheaper to store its inventory at the retailer's facility. It has many advantages for both parties. The retailer does not pay for items until their withdrawal from inventory, thus freeing capital tied up in inventory. The vendor frees the space at its facility for other products. Although items are stocked at the retailer's warehouse, they remain to be the property of the vendor. The cost of money for the vendor will be almost negligible as the retailer will be paying continuously (say daily) for the withdrawn item. Waters (2003) suggested that cost of money accounts for about $50 \%$ of the holding cost, with the other $50 \%$ representing storage space, loss, handling, administration, insurance, etc. So, the unit holding cost of the retailer would be modified to $\tilde{h}_{r}=x h_{r}+$ $y h_{m}$, where $0<x, y<1$, and set to $\tilde{h}_{r}=(0.5) h_{r}+(0) h_{m}=6.5$.

Table 6.7. Optimal policy for the model $j=\mathrm{CS}$ when optimizing $T C_{j}$ and $T E x C_{j}$,, respectively.

\begin{tabular}{|c|c|c|c|c|c|c|c|c|c|c|c|c|c|c|}
\hline \multicolumn{2}{|c|}{ (a) $t_{c}=250$} & \multicolumn{6}{|c|}{ Optimization of $T C_{j}$} & \multicolumn{6}{|c|}{ Optimization of $T E x C_{j}$} & \multirow[b]{2}{*}{$S_{s v g}$} \\
\hline$P$ & $d$ & $\rho$ & $\mathcal{R}$ & $n$ & $q_{j}$ & $T C_{j}$ & $T E x C_{j}$ & $\rho$ & $\mathcal{R}$ & $n$ & $q_{j}$ & $T C_{j}$ & $T E x C_{j}$ & \\
\hline 81 & 2800 & 3475 & 1 & 4 & 250 & $\$ 23,520$ & 247,814 & 4006 & 1 & 3 & 250 & $\$ 24,901$ & 226,892 & 7,424 \\
\hline 82 & 2600 & 3475 & 1 & 4 & 250 & $\$ 24,555$ & 239,345 & 4006 & 1 & 3 & 250 & $\$ 25,722$ & 218,724 & 7,296 \\
\hline 83 & 2400 & 3510 & 1 & 3 & 250 & $\$ 25,186$ & 228,861 & 4006 & 1 & 3 & 250 & $\$ 26,247$ & 209,549 & 7,187 \\
\hline 84 & 2200 & 3510 & 1 & 3 & 250 & $\$ 25,491$ & 217,961 & 4006 & 1 & 2 & 250 & $\$ 26,464$ & 199,254 & 7,093 \\
\hline 85 & 2000 & 3535 & 1 & 2 & 250 & $\$ 25,438$ & 205,482 & 4006 & 1 & 2 & 250 & $\$ 26,211$ & 187,783 & 7,016 \\
\hline 86 & 1800 & 3544 & 1 & 2 & 250 & $\$ 24,928$ & 191,729 & 4006 & 1 & 2 & 250 & $\$ 25,625$ & 175,177 & 6,947 \\
\hline 87 & 1600 & 3552 & 1 & 2 & 250 & $\$ 24,073$ & 176,842 & 4006 & 1 & 2 & 250 & $\$ 24,693$ & 161,394 & 6,886 \\
\hline 88 & 1400 & 3552 & 1 & 2 & 250 & $\$ 22,859$ & 160,840 & 4006 & 1 & 2 & 250 & $\$ 23,402$ & 146,390 & 6,829 \\
\hline 89 & 1200 & 3552 & 1 & 2 & 250 & $\$ 21,274$ & 143,575 & 4006 & 1 & 1 & 250 & $\$ 21,800$ & 130,072 & 6,775 \\
\hline 90 & 1000 & 3582 & 1 & 1 & 250 & $\$ 19,135$ & 124,206 & 4007 & 1 & 1 & 250 & $\$ 19,472$ & 112,208 & 6,734 \\
\hline
\end{tabular}




\begin{tabular}{|c|c|c|c|c|c|c|c|c|c|c|c|c|c|c|}
\hline \multicolumn{2}{|c|}{ (b) $t_{c}=500$} & \multicolumn{6}{|c|}{ Optimization of $T C_{j}$} & \multicolumn{6}{|c|}{ Optimization of $T E x C_{j}$} & \\
\hline$P$ & $d$ & $\boldsymbol{\rho}$ & $\mathcal{R}$ & $n$ & $q_{j}$ & $T C_{j}$ & $T E x C_{j}$ & $\rho$ & $\mathcal{R}$ & $n$ & $q_{j}$ & $T C_{j}$ & $T E x C_{j}$ & $S_{\text {svg }}$ \\
\hline 81 & 80 & 3483 & 1 & 3 & 396 & 659 & 245 & 4007 & 1 & 2 & 500 & $\$ 23,886$ & 20,406 & 3,946 \\
\hline 82 & 600 & 3536 & 1 & 2 & 423 & $\$ 23,701$ & 236,021 & 4007 & 1 & 2 & 500 & $\$ 24,895$ & 212,828 & 3,773 \\
\hline 83 & 400 & 3548 & 1 & 2 & 404 & $\$ 24,420$ & 226 & 4007 & 1 & 1 & 500 & $\$ 25,506$ & 204,011 & 8,634 \\
\hline 84 & 200 & 3559 & 1 & 2 & 384 & $\$ 24,811$ & 215,349 & 4017 & 1 & 1 & 500 & $\$ 25,683$ & 194,098 & 8,520 \\
\hline 85 & 2000 & 3601 & 1 & 1 & 484 & $\$ 24,846$ & 203,275 & 4017 & 1 & 1 & 500 & $\$ 25,501$ & 183,095 & 8,422 \\
\hline 86 & 00 & 3600 & 1 & 1 & 465 & $\$ 24$ & 18 & 4017 & 1 & 1 & 500 & $\$ 24,986$ & 170,958 & 336 \\
\hline 87 & 1600 & 3598 & 1 & 1 & 444 & $\$ 23$, & 175 & 40 & 1 & 1 & 500 & $\$ 2$ & $15^{\prime}$ & 258 \\
\hline 88 & 1400 & 3596 & 1 & 1 & 421 & $\$ 22,348$ & 159,049 & 4017 & 1 & 1 & 500 & $\$ 22,904$ & 143,109 & 8,188 \\
\hline 89 & 1200 & 3596 & 1 & 1 & 395 & $\$ 20,750$ & 141,697 & 4017 & 1 & 1 & 500 & $\$ 21,312$ & 127,311 & 8,123 \\
\hline 90 & 1000 & 3596 & 1 & 1 & 366 & $\$ 18,738$ & 122,950 & 4017 & 1 & 1 & 500 & $\$ 19,336$ & 110,207 & 8,061 \\
\hline
\end{tabular}

Table 6.8. Optimal policy for the CS model when optimizing $T C_{C S}$ and $T E x C_{C S}$, respectively $\left(t_{c}=250 ; \tilde{h}_{r}=6.5, h_{m}=8\right)$.

\begin{tabular}{|c|c|c|c|c|c|c|c|c|c|c|c|c|c|c|}
\hline \multirow[b]{2}{*}{$\boldsymbol{P}$} & \multirow[b]{2}{*}{$d$} & \multicolumn{6}{|c|}{ Optimization of $T C_{C S}$} & \multicolumn{6}{|c|}{ Optimization of $T E x C_{C S}$} & \multirow[b]{2}{*}{$S_{s v g}$} \\
\hline & & $\rho$ & $\mathcal{R}$ & $n$ & $q$ & $T C_{C S}$ & $T E x C_{C S}$ & $\rho$ & $\mathcal{R}$ & $n$ & $q_{x}$ & $T C_{C S}$ & $T E x C_{C S}$ & \\
\hline 81 & 2800 & 3466 & 1 & 5 & 250 & $\$ 23,000$ & 245,630 & 4004 & 1 & 4 & 250 & $\$ 24,316$ & 226,307 & 6,885 \\
\hline 82 & 2600 & 3497 & 1 & 4 & 250 & $\$ 24,005$ & 236,486 & 4004 & 1 & 3 & 250 & $\$ 25,178$ & 218,137 & 6,761 \\
\hline 83 & 2400 & 3515 & 1 & 3 & 250 & $\$ 24,675$ & 226,533 & 4004 & 1 & 3 & 250 & $\$ 25,673$ & 208,928 & 6,659 \\
\hline 84 & 2200 & 3527 & 1 & 3 & 250 & $\$ 24,944$ & 215,365 & 4004 & 1 & 3 & 250 & $\$ 25,859$ & $\begin{array}{l}198,670 \\
\end{array}$ & 6,571 \\
\hline 85 & 2000 & 3527 & 1 & 3 & 250 & $\$ 24,892$ & 203,321 & 4004 & 1 & 2 & 250 & $\$ 25,734$ & 187,265 & 6,494 \\
\hline 86 & 1800 & 3545 & 1 & 2 & 250 & $\$ 24,462$ & 189,752 & 4004 & 1 & 2 & 250 & $\$ 25,133$ & 174,642 & 6,431 \\
\hline 87 & 1600 & 3552 & 1 & 2 & 250 & $\$ 23,589$ & 174,858 & 4004 & 1 & 2 & 250 & $\$ 24,186$ & 160,842 & 6,374 \\
\hline 88 & 1400 & 3552 & 1 & 2 & 250 & $\$ 22,357$ & $\begin{array}{l}158,839 \\
\end{array}$ & 4004 & 1 & 2 & 250 & $\$ 22,880$ & 145,821 & 6,322 \\
\hline 89 & 1200 & 3552 & 1 & 2 & 250 & $\$ 20,754$ & 141,556 & 4004 & 1 & 2 & 250 & $\$ 21,202$ & 129,537 & 6,274 \\
\hline 90 & 1000 & 3552 & 1 & 2 & 250 & $\$ 18,767$ & 122,967 & 4004 & 2 & 1 & 500 & $\$ 19,156$ & 111,864 & 6,228 \\
\hline
\end{tabular}


To illustrate, the examples in Table (6.7-a) was rerun with results summarized in Table (6.8). The results show that a reduction in the holding cost improves the performance of the CS in terms of lower cost and less consumed resources, when compared with Table (6.4-a) and (6.7-a).

\subsubsection{Case 3 - Global supply chain}

In this numerical example, a local Canadian retailer has been considered, while the manufacturer is located in China. Both of the members operate under the Hill's model. The same input parameters of Case 1 will be used here except the following.

Assuming that three modes of transportation have been used to transfer the ordered products from the manufacturer to the retailer with external costs and distance of each mode as illustrated in Table (6.2). For example, this search showed that shipping a 20 feet container from China to Canada costs about $\$ 3000$. It was also assumed that domestic transport by train could be used and would cost $\$ 400$. The total cost of transporting a container from the manufacturer in China to the retailer in Canada would cost about $\$ 3800$. This study assumes that a 20 feet container can carry 1000 units, and a truck can carry 500 units of the purchased items. So, now $\mathcal{R}$ represent the number of shipments from China and not the number of trucks. A minor modification to $F$ is made, for illustrative purposes, which is the shipping cost and it is calculated as $F=3000+400+400 \times(1000 / 500)=\$ 4200$. That is, a shipment leaves the port in China, arrives at the port in Canada, and is then transported by train close to the destination city, where trucks of capacity 500 each would be waiting to transport the items to the retailer. The following parameters will be used to reflect the reason 
of importing a product from China: $A_{m}=100, h_{m}=1, c_{L, m}=0.5, s_{m}=10, e e_{K}=14, L=T_{T r}=$ 45 and $e e_{L}=48.88$. Raw material is cheaper in China, say it costs $1 / 2$ of what it cost in Canada, so it was assumed $c_{m t r}=17$, and $c_{m t r 0}=20$.

The results are summarized in Table (6.9). The results show (when compared to Table 6.4) that outsourcing to an overseers manufacturer results in destroying more resources, which makes more sense to optimize $T E x C$ rather than $T C$.

Table 6.9. Optimal policy for the Hill-Overseas (HO) model when optimizing $T C_{H-O}$ and $T E x C_{H O}$, respectively $\left(t_{c}=21000\right)$.

\begin{tabular}{|c|c|c|c|c|c|c|c|c|c|c|c|c|c|}
\cline { 2 - 12 } \multicolumn{1}{c|}{} & \multicolumn{1}{c|}{ Optimization of $T C_{H O}$} & \multicolumn{5}{c|}{ Optimization of $T E x C_{H O}$} & \\
\hline $\boldsymbol{d}$ & $\boldsymbol{\rho}$ & $\boldsymbol{R}$ & $\boldsymbol{n}$ & $\boldsymbol{q}_{\boldsymbol{H} \boldsymbol{O}}$ & $\boldsymbol{T C}$ & $\boldsymbol{T E x} \boldsymbol{C}_{\boldsymbol{H} \boldsymbol{O}}$ & $\boldsymbol{\rho}$ & $\boldsymbol{R}$ & $\boldsymbol{n}$ & $\boldsymbol{q}_{\boldsymbol{H} \boldsymbol{O}}$ & $\boldsymbol{T C}$ & $\boldsymbol{T E x} \boldsymbol{C}_{\boldsymbol{H O}}$ & $\boldsymbol{S}_{\boldsymbol{s v g}}$ \\
\hline 2800 & 3557 & 1 & 1 & 1000 & 31,869 & 282,232 & 4013 & 1 & 1 & 1000 & 32,946 & 245,049 & 10936 \\
\hline 2600 & 3557 & 1 & 1 & 1000 & 32,308 & 271,305 & 3855 & 1 & 1 & 1000 & 32,736 & 236,217 & 10320 \\
\hline 2400 & 3557 & 1 & 1 & 1000 & 32,451 & 259,372 & 4027 & 1 & 1 & 1000 & 33,431 & 225,371 & 10000 \\
\hline 2200 & 3557 & 1 & 1 & 1000 & 32,286 & 246,390 & 4013 & 1 & 1 & 1000 & 33,134 & 213,976 & 9533 \\
\hline $\mathbf{2 0 0 0}$ & $\mathbf{3 5 5 7}$ & $\mathbf{1}$ & $\mathbf{1}$ & $\mathbf{1 0 0 0}$ & $\mathbf{3 1 , 8 0 0}$ & $\mathbf{2 3 2 , 3 1 7}$ & $\mathbf{4 0 1 3}$ & $\mathbf{1}$ & $\mathbf{1}$ & $\mathbf{1 0 0 0}$ & $\mathbf{3 2 , 5 7 1}$ & $\mathbf{2 0 1 , 4 9 3}$ & $\mathbf{9 0 6 6}$ \\
\hline 1800 & 3557 & 1 & 1 & 1000 & 30,980 & 217,108 & 4013 & 1 & 1 & 1000 & 31,674 & 187,875 & 8598 \\
\hline 1600 & 3557 & 1 & 1 & 1000 & 29,814 & 200,723 & 4013 & 1 & 1 & 1000 & 30,430 & 173,079 & 8130 \\
\hline 1400 & 3556 & 1 & 1 & 915 & 28,324 & 183,248 & 4013 & 1 & 1 & 1000 & 28,828 & 157,064 & 7701 \\
\hline 1200 & 3556 & 1 & 1 & 915 & 26,343 & 164,092 & 4013 & 1 & 1 & 1000 & 26,854 & 139,784 & 7149 \\
\hline 1000 & 3555 & 1 & 1 & 837 & 23,934 & 143,486 & 4013 & 1 & 1 & 1000 & 24,496 & 121,199 & 6555 \\
\hline
\end{tabular}

Compared to the case (1) of employing the same model for a domestic supply chain, ordering from a foreign source causes firms to pay more costs due to the hidden costs that are not accounted for in the classical models. This is under the condition of (a) producing the "same" product (with the same quality) that intend to import from an overseas source, and (b) accounting for the hidden (entropy/exergy wasted). The extra costs come mostly 
from the increased entropy costs and the external costs of transportation, suggesting that more exergy is consumed annually by the society. The difference in the costs between domestic and global supply chains becomes greater when optimizing $T E x C$. Therefore, outsourcing of production activities from local to overseas destination can result in more consumed resources. The consequence of outsourcing is global. For example, since there are no geographic borders that prevent emissions of GHG to spread, then this issue is not a domestic concern, but is in fact global.

From the exergetic point of view, these results show that producing domestically is more sustainable that offshoring. Offshore outsourcing could be beneficial for exporting countries by providing more employment opportunities for their people. However, for importing countries, it decimates their local economies and negatively impacts the highly skilled labour and professionals there by increasing the unemployment rates, which in turn can cause more social problems in their societies ( Munch, 2005); ( Munch, 2010).

Business opportunities that move overseas normally do not come back. Lower wages, salaries and operational and administrative costs in developing countries makes it cheaper for a company to relocate its operations, e.g., to China. This results in unemployment at home (Amadeo, 2017). Gurtu et al. (2016) claimed that the advantage of employment to people in outsource countries comes at the cost of an increase in unemployment and social cost in the outsourcing nation. For example, a number of Japanese industries moved their manufacturing plant to China to remain competitive and to gain a share of the growing Chinese market (Yee, 2010). As a result, many Japanese firms closed their operations at home. This increased the unemployment rate by $0.9 \%$ and decreased domestic sales by $2.3 \%$ for the period 1998-2000. Therefore, this study strongly 
recommends that governments of importing countries take serious action to encourage local production and to account for the barriers to sustainable development that can be generated in exporting countries due to the demand requested from their countries.

\subsection{Summary and Concluding Remarks}

This study investigated the important factors that can influence the cost of a supply chain, such as: labour, energy, emissions from production, emissions from transportation, social impacts of transportation and entropy. The study made an analogy between a combined thermal system with a two-level supply chain that is comprised of a single manufacturer and a single retailer. This helped in developing the amount of exergy wasted when consuming resources. The study used the Extended Exergy Approach to develop an exergetic cost function whose unit of measure is mega-joules per year. The study also discusses the importance of optimizing consumed exergy as a start on the way towards sustainable development. Two different mechanisms of coordination were evaluated, investigated, and compared: traditional (Hill's) and the consignment stock policies, from both costs and consumed exergy points of view. The results showed that optimising the exergetic cost function considerably increases the savings to society (less mega-joules wasted) for a little additional increase in cost on part of the supply chain. Of course, firms can benefit by receiving incentives (tax deductions) from a government for reducing the amount of resources they consume and for being more sustainable. Also, compared were the options of producing locally or importing from an overseas source. It was found, in addition to the greater costs paid for the latter option, that it may not be sustainable to import 
from a source located within a society that has a higher rate of exergy per unit of currency and a lower rate of exergy per working hour. The following condition can be considered as a limitation of the developed model: (a) producing the "same" product (that has he same quality) that is intended to be imported from an overseas source, and (b) accounting for the hidden (entropy/exergy wasted). Not following the above conditions can results in costs to the firm and society.

The study presented the concepts of computing the produced/order quantity based on the consumed exergy during the setup, ordering and holding stages. It illustrated the importance of computing these costs based on their exergetic values. Accordingly, results recommend producing/ordering in larger batch size to optimize the consumed exergy during all operations of a supply chain.

Based on the fractions of the three pillars of sustainability; capital, labour, and environment, results showed that increasing the labour fraction in the processes of setup, ordering and holding reduce the quantity to be produced/ordered. The manager may have to carefully calculate and control these fractions in a way that can meet the requirements of both their firms and the society in which they are located.

The study suggested that all stakeholders should contribute to minimize the consumed exergy and consume it in a wiser ways and rates. It is crucial that governments select the proper values of money supplies, interest rates, and labour force requirements within their societies. They, also, must strive to protect resources from unwise consumption by regulating the activities of importing and exporting products from and to the society, 
extraction of ores and minerals located within the control volume of the society, agriculture and fisheries activities. 


\section{CHAPTER (7) - SUMMARY AND CONCLUSIONS}

\subsection{Summary}

This work has extended the study that investigates the analogy between thermodynamic laws and inventory systems. Exergy is the main thermodynamic property that has been employed to study this analogy between these two different types of systems. The importance of employing exergy in inventory models come from the fact that exergy can be utilized as an indicator to measure the consumption of resources during all the processes of inventory/production.

Chapter (4) takes into account the hidden costs inherent in inventory systems, which are related to sustainability issues including environmental, social labour, and economic effects. This chapter considers some of these costs, referred to as the exergetic costs, and estimates them using the Extended Exergy Accounting, EEA, approach. An exergetic model has been developed to determine the EOQ inventory policies for three business firms operating in the USA, Germany, and China. This is to show the influence of equivalent exergy of capital, labour, and environment remediation costs on the EOQ inventory policy.

Chapter (5) introduces an exergetic version of the EPQ model to compute the amount of exergy consumed when producing and storing a product and uses it to select the proper level of sustainability. This chapter uses thermodynamic concepts to derive a new exergetic sustainability indicator for a production-inventory system to find that in some situations sustainability can be profitable to encourage companies to move towards sustainable 
strategies. It is the first attempt to employ the "thermodynamics" property of work to investigate the analogy between thermal and inventory systems.

Chapter (6) introduces exergetic models that compute and compare the consumed exergy for two coordination policies; Hill's model and CS policy. It, also, evaluates the consumed exergy when producing/ordering locally versus globally to recognizes the importance of financial, social and environmental aspects of choosing the most sustainable destination to produce and distribute a product. This chapter introduced some recommendations to governments and other stakeholders to take actions that are effective in making societies consume resources wisely to achieve more sustainable societies.

\subsection{Conclusions}

The principles conclusions of the present thesis can be summarized as follows:

- Using the exergetic cost approach may result in inventory policies that are different from those of the classical approach, and are more effective steps towards a sustainable business.

- It is of high importance to account for the consumed exergy rather than just considering the values in term of monetary units. Computing these costs based on their exergetic values can provide more flexibility for managers of supply chains to calculate the order quantity based on the available resources and not confining this to the capital only.

- The equivalent exergy of capital, labour, and environment remediation costs for each country (society) is of significant influence on the inventory policies that are followed 
in each country. For instance, producing in an OECD country (e.g., USA or Germany) can be cheaper than producing in developing countries (such as China).

- The lower production monetary costs in developing countries come at the expense of the global and local sustainability requirements, which cause producing in an OECD country to have less negative impact on global sustainability. This fact may encourage OECD countries to pay more attention to facilitating the establishment of local production businesses of whatever size is appropriate, including small to medium size enterprises (SME) to gain the benefits of localization.

- It has been shown that societies can gain more benefits from a wiser consumption of exergy, and firms can financially save some costs when producing and/or ordering domestically rather than overseas sourcing. It was found, in addition to the greater costs paid for the latter option, that it may not be sustainable to import from a source located within a society that has a higher rate of exergy per unit of currency and a lower rate of exergy per working hour.

- Based on the second law of thermodynamics, an exergetic index was developed to measure the level of sustainability that a production-inventory system can attain by considering the amount of consumed exergy in the system. Using the entropy approach results in higher profits, less entropy (exergy wasted) generation, and a higher sustainability index.

- A product's price plays a major role in minimizing the entropy generation in a system, which changes the Exergetic Sustainability Index in a proportional manner with the cost of entropy. 
- The units wasted in a production-inventory system play a major factor in deciding the level of sustainability of the system, which can be achieved by matching the amount of the produced products with the required resources. Therefore, the efficient consumption and utilization of resources are recommended to achieve a better value of the exergetic sustainability indicator introduced in this thesis.

- Following a sustainable strategy can be profitable for firms for both cases of fixed and changeable demand rates. These results can establish a new paradigm for considering sustainability as a profitable approach that can be followed by firms. The results show that some parameters strongly affect the sustainability index of a company, such as the number of working hours, money supply of society, and market price of a product. Therefore, having governments and other authorities involved in shifting towards sustainability by providing a number of incentives to companies appears to be merited.

- Whenever possible, controlling $e e_{K}$ and $e e_{L}$ can have a great impact on moving a society towards sustainable development by minimizing its consumed exergy, which requires great contribution and efforts from all stakeholders: governments, individuals, societies, business firms, scientists, etc. An example of such efforts is controlling and regulating the activities that can negatively affect the amount of the total exergy input to a society. This may include but may not be limited to regulating the activities of importing and exporting products from and to the society, extraction of ores and minerals located within the control volume of the society, agriculture and fisheries activities.

- A society can waste less exergy for a further little increase in cost on the part of the supply chain by optimizing the exergetic cost function instead of monetary cost. 
- The concepts of computing the produced/order quantity based on the consumed exergy during the setup, ordering, and holding stages have been presented in this thesis. It illustrated the importance of computing these costs based on their exergetic values. Accordingly, results recommend producing/ordering in larger batch size to optimize the consumed exergy during all operations of a supply chain.

- The components of the three pillars of sustainability; capital, labour, and environment, can have a significant influence on the quantity to be produced/ordered. For instance, increasing the labour fraction in the processes of setup, ordering, and holding reduces the order quantity. This is of significant benefits to SC managers who can carefully compute and control these elements in a way that can meet the needs of both their firms and the society in which they are located.

- The value of M2 can play a major role in controlling the consumed exergy within a society due to its influence on people's income expenditure. Hence, governments are recommended to consider the consumed exergy of society when deciding the most proper value of M2 that significantly improves the value of GDP of society, while, at the same time not cause inflation in the economic system of the society.

\subsection{Contributions}

This dissertation contributes to the area of sustainable inventory and logistic systems. Specifically, it introduces novel thinking and techniques to these fields by employing the rules of heat transfer together with the laws of thermodynamics to be implemented in 
inventory and logistic systems. The novel contributions of the present study include but not limited to the followings:

(i) Identified some hidden costs (exergy wasted) of inventory systems and studied how they affect a system's total cost and sustainability. New inventory models, based on the laws of thermodynamics, were developed for this purpose. The developed models use joules, not dollars, for example, to calculate the amount of exergy consumed in producing, stocking, distributing and disposing of a product.

(ii) Provided a meaningful comparison between firms that produce the same product in different locations and assist them in deciding whether to import or locally produce and distribute the desired product. The tools developed in this thesis advocate for decisions based on low exergy consumption not on cost. They may guide a firm in improving its exergetic 'efficiency' to overcome some of the advantages and disadvantages of specific locations (economies).

(iii) Presented a novel concept to measure the sustainability of an inventory system, the Exergetic Sustainability Index (ExSI). It tells a firm on scale 0 to 1 how sustainable it is, where zero is the worst level.

The exergy-based models developed in thesis showed that sustainability is profitable. This finding is contrary to what many discussed in the literature. 


\subsection{Recommendations for Future Works}

While the studies have managed to addressing problems in this dissertation, further studies and investigation are required to address other aspects of sustainability in inventory models. This section identifies some important ideas for future work that can be useful to continue this task towards its essential target. The research presented in this dissertation could be extended to study the following other interesting aspects of the analogy between thermal and inventory systems, such as:

- Investigation of the analogy between thermodynamics and inventory models with accounting for more thermal and physical properties other than "exergy." For example, the property of "volume" may refer to the production rate per unit time. Also, the profit per unit of product may be represented by the property of pressure.

- The exergetic inventory models developed herein could be investigated in a more complex setting such as a reverse logistics. It may be interesting to find out the relation between "reversibility" in thermodynamics and reverse logistics. Both of these systems may share the same idea of "reversibility."

- Further cooperation to be established with scientists from other disciplines to find out the exact exergetic contents of materials that are involved in the production of a commodity. Also, to compute the exact exergetic content of all GHG and wastes that are emitted and discharged due to all activities performed in the whole supply chain. 


\section{$\operatorname{APPENDIX}(\mathbf{A})$}

This appendix is based on the following paper:

Jaber. M.Y., Jawad, H. “An entropic comparison between the economic production quantity (EPQ) and just-in-time (JIT) models," The $45^{\text {th }}$ International Conference on Computer and Industrial Engineering (CIE 45) Proceedings, 28-30 October 2015, Metz / France.

Just-In-Time (JIT) advocates that inventory is a waste and should be reduced. However, having smaller and more frequent shipments generate more waste, consume more resources and congests a supply chain rendering the JIT policy unsustainable. This paper uses the second (entropy) law of thermodynamics to calculate the entropy generated in each of two systems; EPQ and JIT. To make the comparison meaningful, the EPQ model is modified to capture some of the costs that will work against/for EPQ and JIT. It then adds an entropic component to the cost models to capture the costs or disorder (entropic) in both systems that usually not accounted for in classical inventory analyses. The results show that a JIT policy is more expensive to operate than an EPQ policy.

\section{Mathmatical Model}

The classical EPQ model produces $q$ in $q / \rho$ and consumes it over $q / d$, where $\rho$ (units/year) and $d$ (units/year) are the production and demand rates, respectively, where $\rho>$ d. The total cost per unit of time, is: 


$$
T C(q)=\frac{A d}{q}+h \frac{q}{2}\left(1-\frac{d}{\rho}\right)+u_{p} d
$$

Where $A$ is the per order setup cost in unit of (\$) and $h$ is the unit holding cost (\$/unit/year), $u_{p}$ is the unit production cost (in this paper, it will represent the cost of material and labour only, in \$/unit). The other cost components that will be added to Eq. (A.1) are:

- Transportation cost: $C_{t}(q)=f+f_{0} q$, where $f$ is a fixed cost (\$/shipment) and $f_{0}$ is a variable cost(\$/unit).

- Emissions from transportation: $C_{t e}(q)=c_{e} \gamma$, where $\gamma$ (tons- $\mathrm{CO}_{2} /$ trip) is the greenhouse gases emissions per trip (for a fixed distance), assuming for simplicity that a truck capacity is larger than $q$, and $c_{e}$ is the cost of a ton of $\mathrm{CO}_{2}$ emissions ( $\$ /$ ton- $-\mathrm{CO}_{2}$ ).

- Defective items that are reworked: $C_{r}(q)=c_{r} \theta\left(1-\frac{q_{J}}{q}\right) q$, where $c_{r}$ is the unit rework $\operatorname{cost}\left(\$ /\right.$ unit), $\theta$ is the percentage of units that are reworked in a batch of size $q$, and $q_{J}$ is the order quantity according to JIT. That is, if $q$ reaches $q_{J}$, then $C_{r}\left(q_{J}\right)=0$ in line with what the JIT advocates. This is a simplistic relationship from that of Porteus (Porteus, 1986), but serves the same purpose, which is smaller lots produce less rework.

- Energy costs per cycle: $C_{\text {eng }}(q)=c_{\text {eng }}\left(k_{0}+\frac{k}{\rho}\right) q$, where $c_{\text {eng }}$ is the unit energy cost (\$/kwh), $k_{0}$ is in $\mathrm{kwh} / \mathrm{unit}$, and $k$ is in $\mathrm{kwh} / \mathrm{year}$.

- Emissions from production: $C_{p e}(q)=c_{e} q\left(a \rho^{2}-b \rho+c\right)$, where $a, b$ and $c$ are positive parameters.

- Work related stress: $C_{W S}(q)=\omega u_{p} \frac{q_{J}}{q}$, where $\omega$ is a percentage of the production cost. 
Several works have discussed that workers stress level is much more in a JIT system than it is in a traditional system (Godard, 2001). Without loss of generality, it was assumed that it is proportional to $q$. So, as $q$ approaches $q_{J}$, the unit production cost increases by $\omega u_{p}$ to account for worker related health costs.

The modified cost function in Eq. (A.1), $C(q)=T C(q)+\left[C_{t}(q)+C_{t e}(q)+\right.$ $\left.C_{e n g}(q)+C_{p e}(q)+C_{W S}(q)\right] d / q$. Since its inception, the EOQ model underwent extensive investigation and development to fit various requirements (Bushuev et al., 2015).

Jaber et al. (2004) introduced the concept of the "entropy cost" into the EOQ model. They postulated that the flow of a commodity (demand rate) and its price in an inventory system are similar to the heat flow and its temperature in a thermodynamic system. That is, heat flows from a high temperature reservoir to a surrounding of lower temperature during which some of the heat transferred because of the temperature differential is lost due to entropy. Analogously, a firm can heat up its market by lowering its price (hot body) below the market price (cold body) thus competing on the price front. Readers may refer to (Jaber et al., 2004) for a concise background to thermodynamic concepts and definitions. They expressed the demand rate as $d(t)$ to emphasize the time dependence, which can be written as:

$$
d(t)=-K_{P}\left(P(t)-P_{0}(t)\right)
$$

Where $P_{0}(t)$ is the market equilibrium price at time $t$ (\$/unit) and $P(t)$ is the product price at timet (\$/unit); where $P_{0}(t)>P(t) \forall t>0$. 
The term $K_{P}$ is identical to thermal capacity in thermodynamics and represents the increase in demand of a product for the reduction of its price by one monetary unit. The negative sign in Eq. (A.2) indicates that product flows from the system to the surroundings.

Jaber et al. (2004) who suggested using the second law of thermodynamics (entropy law) to account for inefficiencies in a production-inventory system, calculated the total entropy generated by time $t$ is:

$$
\sigma(t)=\int_{0}^{t} K_{P}\left[\frac{P(t)}{P_{0}(t)}+\frac{P_{0}(t)}{P(t)}-2\right] d t
$$

If it is assumed, just for simplicity, that $P(t)=P$ and $P_{0}(t)=P_{0}$, then the entropy cost per unit, $u_{e}(t)$, to be:

$$
u_{e}(t)=\frac{1}{\sigma(t)}=\frac{P P_{0}}{K_{P} t\left(P_{0}-P\right)^{2}}
$$

where, $u_{e}(t)$ is in \$/unit. Eq. (A.4) suggests that long cycles reduce the unit entropy cost. Accounting for entropy costs, $C(q)$ becomes:

$$
\begin{aligned}
C(q)=A \frac{d}{q}+ & u_{p}\left(1+\omega \frac{q_{J}}{q}\right) d+\frac{h}{2}\left(1-\frac{d}{\rho}\right) q+f \frac{d}{q}+f_{0} d+c_{e} \gamma \frac{d}{q} \\
& +c_{r} \theta\left(1-\frac{q_{J}}{q}\right) d+c_{e n g} d\left(k_{0}+\frac{k}{\rho}\right)+c_{e} d\left(a \rho^{2}-b \rho+c\right) \\
& +\frac{K_{P} P P_{0}}{q}
\end{aligned}
$$


The economic production quantity, $q^{*}$, that minimizes Eq. (A.5), can be obtained by setting its first partial derivative with respect to $q$ equal to zero and solving for $q$ to get:

$$
q^{*}=\sqrt{\frac{2 d\left(A+\omega u_{p} q+f+c_{e} \gamma-c_{r} \theta q_{J}\right)+2 \delta K_{P} P P_{0}}{h(1-d / \rho)}}
$$

Where $\delta=0,1$ indicating when (1) or when not (0) entropy is considered in calculating the lot size in (6) and $q_{J}=d / m$ where $m$ is the number of deliveries in a year when the system follows JIT. Assuming that the JIT lot size is $q_{J}, q_{J}<<q$, the Eq. (A.5) reduces to:

$$
\begin{aligned}
C_{J}\left(q_{J}\right)=A_{J} \frac{d}{q_{J}} & +u_{p}(1+\omega) d+\frac{h}{2 \rho} d q_{J}+f \frac{d}{q}+f_{0} d+c_{e} \gamma \frac{d}{q_{J}} \\
& +c_{e n g} d\left(k_{0}+\frac{k}{\rho}\right)+c_{e} d\left(a \rho^{2}-b \rho+c\right)+\frac{K_{P} P P_{0}}{q_{J}}
\end{aligned}
$$

Where $A_{J}$ is the setup cost for the JIT policy, and $A_{J}<<A$. Note that the holding cost per

year should reduce from $h\left(1-\frac{d}{\rho}\right) q_{J} / 2$ to $h d q_{J} / 2 \rho$ as $q$ reduces to $q_{J}$. Also, note that a JIT policy requires frequent start-ups and shutdowns of machines and equipment resulting in power (electrical energy) loses and excess emissions. These losses could be factored into the energy consumption and $\mathrm{CO}_{2}$ emissions equations, but it was assumed that it will be accounted for under the umbrella of entropy cost.

\section{Numerical Results}

Consider a production-inventory system that has the following input parameters: $\rho$ $=2000$ unit $/$ year, $P_{0}=\$ 105, P=\$ 100$ and $K_{P}=200$ units $/$ year $/ \$$ corresponding to $d=1000$ 
unit/year from Eq. (A.2), $u_{p}=60 \$ /$ unit, $h=12 \$ /$ unit/year (20\% of $u_{p}$ ), $f=\$ 200, f_{0}=1$ \$ unit, $c_{e}=20 \$ /$ unit, $c_{r}=12 \$ /$ unit, $\theta=5 \%, c_{e n g}=0.1 \$ / \mathrm{kwh}, k_{0}=100 \mathrm{kwh} / \mathrm{unit}$, and $k=125000$ kwh/year, $a=3.00 \mathrm{E}-7$ ton.year ${ }^{2} / \mathrm{unit}^{3}, b=12.00 \mathrm{E}-04$ ton.year/unit ${ }^{2}$ and $c=1.4$ ton/unit, $\omega=$ 0.3 , and $A=500 \$ /$ order. The emissions per trip, $\gamma=1.01$, calculated based on 44-Ton truck that has a $\mathrm{CO}_{2}$ factor of $62 \mathrm{~g} \cdot \mathrm{CO}_{2} / \mathrm{Km}$ and travels $400 \mathrm{~km}$ roundtrip. The following formula has been used to calculate the emission trip:

$$
\begin{aligned}
\gamma\left(g \cdot \frac{\mathrm{CO} 2}{\text { trip }}\right)= & \text { Transport Volume }(\text { ton }) * \text { Distance }(\mathrm{km}) \\
& * \text { Emission Factor }(\mathrm{g} \cdot \mathrm{CO} 2 / \mathrm{Km})
\end{aligned}
$$

Let us first assume that entropy is not factored into calculating $q$ in Eq. (A.6), i.e., $\delta=$ $0, q=514$ units at a total cost from Eq. (A.5) of $\$ 84,932 /$ year. The annual entropy cost for this case is $\$ 4089 /$ year, which the system will incur due to inefficiencies making the actual cost $\$ 89020 /$ year instead of $\$ 84747$ year, where the unit cost is about $\$ 89$ and the unit profit is $\$ 10.98$ per unit (100-89.02). On the other hand, accounting for entropy, $\delta=1, q=982$ units, the total annual entropic cost is $\$ 87740$ (entropy cost is $\$ 2139$ ) where the unit cost is $\$ 87.74$ with a unit profit margin of $\$ 12.26(100-87.74)$.

The setup cost for a JIT system, $A_{J}$ can be estimated from the classical EPQ formula, $q_{0}=\sqrt{2 A d / h\left(1-\frac{d}{\rho}\right)}$, by setting $q=q_{J}=d / m$ and solving for $A_{J}$ to get $A_{J}=d h(1-$ $d / \rho) / 2 m$, where $m=250$ days/year. The total entropic cost for the JIT system is calculated from Eq. (A.7) to be $\$ 679730$ of which $\$ 525000$ in entropy cost, which indicates that unless substantial improvements and investment are made to reduce inefficiencies in system, the 
implementation of a JIT policy will result in failure. Table (A1) summarises the results for the EPQ and JIT policies. Even without accounting for entropy costs, the JIT annual cost is still higher than that of the EPQ, i.e. $\$ 154730$ versus 85601 .

Table A1.Comparison between EPQ and JIT

\begin{tabular}{|l|c|c|}
\hline Annual cost component (\$/year) & EPQ & JIT \\
\hline Setup & 509.30 & 12.00 \\
\hline Production & 60000 & 60000 \\
\hline Worker stress & 73.34 & 18000 \\
\hline Holding & 2945.21 & 12 \\
\hline Transportation & 1203.72 & 51000 \\
\hline Emissions from transportation & 22.23 & 5456 \\
\hline Rework & 597.56 & 0 \\
\hline Energy & 16250.00 & 16250.00 \\
\hline Emissions from production & 4000.00 & 4000.00 \\
\hline Entropy & $\mathbf{8 7 7 4 0 . 4 3}$ & $\mathbf{6 7 9 7 3 0 . 0 0}$ \\
\hline Total & & 525000.00 \\
\hline & & \\
\hline
\end{tabular}


In the above examples, it was assumed that $\rho=2000$, which is the production rate that minimizes the emissions function where $\rho=b / 2 a$. Now, let us optimize Eq. (A.5) for $\rho$, where $\rho>d$. The optimal solution when accounting for entropy occurs at $\rho=2125$, where $q=954$ units at a total cost from Eq. (A.5) of $\$ 87,637.30 /$ year, which slightly better than when $\rho=2000$, i.e., $\$ 87,740$. The same was observed for JIT. Repeating the same example for $u_{p}=30 \$ /$ unit, $h=6 \$ /$ unit/year $\left(20 \%\right.$ of $\left.u_{p}\right), P_{0}=\$ 55, P=\$ 50$ and $K_{P}=200$ units/year $\$$, when $\delta=1, q=933$ units, $C=\$ 54350$ (entropy cost is $\$ 589$ ), while for JIT $q_{J}=4, C=$ $\$ 253218$ (entropy cost is $\$ 137500$ ).

Following on the previous example, assume the firm wants to heat up its market by lowering its price (hot body) below the market price (cold body). From Eq. (A.2), demand increases as $P-P_{0}$ increases. To illustrate, assume that $P$ reduces from $\$ 52.5$ to $\$ 50$ to 47.5 , while the other parameters remain unchanged. The results are summarised in Table A2. The results show that a JIT policy favours an increase in demand while the EPQ model does not. That is, as $d$ increases from 500 to 1000 to 1500 , JIT cost decreases significantly by about $32 \%$ (from 374337 to 253218 ) and $8 \%$ (from 253218 to 232932), respectively. The noticeable decrease is in the entropy cost, which reduces by about $52 \%$ (from 288750 to 137500) and $37 \%$ (from 137500 to 87083 ), respectively. The cost for the EPQ model increases by about $89 \%$ (from 28695 to 54350) and 46\% (from 54350 to 79572), respectively. An increase in d also decreased entropy cost for the EPQ model. 
Table A2. Comparison between EPQ and JIT at different demand rate

\begin{tabular}{|l|l|l|l|l|l|l|}
\cline { 2 - 7 } \multicolumn{1}{c|}{} & \multicolumn{3}{c|}{ EPQ } & \multicolumn{3}{c|}{ JIT } \\
\hline$P(\$ /$ unit $)$ & 52.5 & 50 & 47.5 & 52.5 & 50 & 47.5 \\
\hline$d$ (unit/year) & 500 & 1000 & 1500 & 500 & 1000 & 1500 \\
\hline$q($ unit/cycle) & 648.80 & 933 & 1498 & 2 & 4 & 6 \\
\hline$T$ (year) & 0.50 & 0.93 & 1.50 & $1 / 250$ & $1 / 250$ & $1 / 250$ \\
\hline$C$ (\$/year) & 28695 & 54350 & 79572 & 374337 & 253218 & 232932 \\
\hline Entropy (\$/year) & 890 & 589 & 349 & 288750 & 137500 & 87083 \\
\hline
\end{tabular}

The reduction in unit production cost and subsequently the selling price reduced the system cost. It has been documented in the literature that unit production cost and inefficiencies in a system can be cut in investment that improves learning (M. Y. Jaber, 2016). Perhaps for JIT to be successful, a firm must focus on learning how to reduce the inefficiencies over time through learning (Jaber, 2016). This is beyond the scope of this paper and therefore left for a future study.

\section{Conclusion}

This appendix extended the classical models of EPQ and JIT models to include transportation, defective items that need rework, work related stress, energy and greenhousegases emissions costs from transportation and production systems. Demand was modelled 
as a heat flow in thermodynamic systems where price is analogous to temperature. This allows for estimating the entropy (disorder) cost using the second law thermodynamics. This cost is usually not accounted for when analysing inventory systems. The results showed that a JIT policy, which advocates producing in small lots more frequently, is too expensive.

Although a JIT policy saves on some costs, like almost no defective items to rework, and holding inventory and setup costs, the cost of controlling the flow of items from a system to market is more expensive than for the EPQ policy. Also, the costs resulting from increased worker stress, as well as additional costs related to transportation and its emissions, are much higher for a JIT policy than for an EPQ policy. The results further showed that the JIT performance improved significantly for higher demand, while that of the EPQ model deteriorated. In line with the principles of thermodynamics, an increase in system entropy or disorder moves the system away from sustainability (Goran Wall, 2010). 


\section{References}

Abdallah, T. (2012). Green supply chains with carbon trading and environmental sourcing: Formulation and life cycle assessment. Applied Mathematical Modelling, 36(9), 4271-4285.

Abraham, J., Suganthi, L., \& Samuel, A. A. (2006). Entropy added taxing methodology: a case study with domestic refrigerators in India. International Journal of Exergy, 3(2), 150. https://doi.org/10.1504/IJEX.2006.009042

Abusoglu, A., \& Kanoglu, M. (2009). Exergoeconomic analysis and optimization of combined heat and power production: A review. Renewable and Sustainable Energy Reviews, 13(9), 2295-2308. https://doi.org/10.1016/j.rser.2009.05.004

Adriana, B. (2009). Environmental supply chain management in tourism: The case of large tour operators. Journal of Cleaner Production, 17(16), 1385-1392. https://doi.org/10.1016/j.jclepro.2009.06.010

Ahi, P., \& Searcy, C. (2013). A comparative literature analysis of definitions for green and sustainable supply chain management. Journal of Cleaner Production, 52, 329341. https://doi.org/10.1016/j.jclepro.2013.02.018

Ahi, P., \& Searcy, C. (2015). An analysis of metrics used to measure performance in green and sustainable supply chains. Journal of Cleaner Production, 86, 360-377.

Ahi, P., Searcy, C., \& Jaber, M. Y. (2016). Energy-related performance measures employed in sustainable supply chains: A bibliometric analysis. Sustainable Production and Consumption, 7, 1-15. https://doi.org/10.1016/j.spc.2016.02.001

Amadeo, K. (2017). 7 Causes of Unemployment. Retrieved March 18, 2017, from https://www.thebalance.com/causes-of-unemployment-7-main-reasons-3305596

Andresen, B., \& Gordon, J. M. (1992). Optimal paths for minimizing entropy generation in a common class of finite-time heating and cooling processes. International Journal of Heat and Fluid Flow, 13(3), 294-299. https://doi.org/10.1016/0142727X(92)90043-9

Andriolo, A., Battini, D., Grubbström, R. W., Persona, A., \& Sgarbossa, F. (2014). A century of evolution from Harris's basic lot size model: Survey and research 
agenda. International Journal of Production Economics, 155, 16-38.

https://doi.org/10.1016/j.ijpe.2014.01.013

Apaiah, R. K., Linnemann, A. R., \& van der Kooi, H. J. (2006a). Exergy analysis: A tool to study the sustainability of food supply chains. Food Research International, 39(1), 1-11. https://doi.org/10.1016/j.foodres.2005.04.006

Apaiah, R. K., Linnemann, A. R., \& van der Kooi, H. J. (2006b). Exergy analysis: A tool to study the sustainability of food supply chains. Food Research International, 39(1), 1-11. https://doi.org/10.1016/j.foodres.2005.04.006

Apratul Chandra Shukla, S.G. Deshmukh, \& Arun Kanda. (2009). Environmentally responsive supply chains: Learnings from the Indian auto sector. Journal of Advances in Management Research, 6(2), 154-171.

Arslan, M. C., \& Turkay, M. (2013). EOQ Revisited with Sustainability Considerations. Foundations of Computing and Decision Sciences, 38(4).

Asif, M., Searcy, C., Zutshi, A., \& Fisscher, O. A. M. (2013). An integrated management systems approach to corporate social responsibility. Journal of Cleaner Production, 56, 7-17. https://doi.org/10.1016/j.jclepro.2011.10.034

Atkins, P. (2007). Four Laws That Drive the Universe (1 edition). Oxford University Press.

Awaysheh, A., \& Klassen, R. D. (2010). The impact of supply chain structure on the use of supplier socially responsible practices. International Journal of Operations \& Production Management, 30(12), 1246-1268.

Ayres, R. U. (1998). Eco-thermodynamics: economics and the second law. Ecological Economics, 26(2), 189-209. https://doi.org/10.1016/S0921-8009(97)00101-8

Ayres, R. U., Bergh, J. C. J. M. van den, \& Gowdy, J. M. (1998). Viewpoint: Weak versus Strong Sustainability (Tinbergen Institute Discussion Paper No. 98-103/3). Tinbergen Institute.

Azevedo, S. G., Carvalho, H., \& Cruz Machado, V. (2011). The influence of green practices on supply chain performance: A case study approach. Transportation Research Part E: Logistics and Transportation Review, 47(6), 850-871. 
Balomenos, E., Panias, D., \& Paspaliaris, I. (2011). Energy and Exergy Analysis of the Primary Aluminum Production Processes: A Review on Current and Future Sustainability. Mineral Processing and Extractive Metallurgy Review, 32(2), 69

Battini, D., Persona, A., \& Sgarbossa, F. (2014). A sustainable EOQ model: Theoretical formulation and applications. International Journal of Production Economics, 149, 145-153. https://doi.org/10.1016/j.ijpe.2013.06.026

Bazan, E., Jaber, M. Y., \& Zanoni, S. (2015). Supply chain models with greenhouse gases emissions, energy usage and different coordination decisions. Applied Mathematical Modelling, 39(17), 5131-5151. https://doi.org/10.1016/j.apm.2015.03.044

Bejan, A. (1995). Entropy Generation Minimization: The Method of Thermodynamic Optimization of Finite-Size Systems and Finite-Time Processes. CRC Press.

Bejan, A. (1996). Entropy generation minimization: The new thermodynamics of finitesize devices and finite-time processes. Journal of Applied Physics, 79(3), 1191. https://doi.org/10.1063/1.362674

Bejan, A., \& Tsatsaronis, G. (1996). Thermal Design and Optimization. John Wiley \& Sons.

Belli, M., \& Sciubba, E. (2007). Extended Exergy Accounting as a general method for assessing the primary resource consumption of social and industrial systems. International Journal of Exergy, 4(4), 421-440.

Bera, S., \& Acharya, S. K. (2013). Estimatin of Social Entropy: The Dictum of NEO Modernism in Agricultural Knowledge Environment in India. International Journal of Agriculture and Food Science Technology, 4(10), 989-998.

Bligh, D. C., \& Ismet Ugursal, V. (2012). Extended exergy analysis of the economy of Nova Scotia, Canada. Energy, 44(1), 878-890.

Bonney, M. C. (1994). Trends in inventory management. International Journal of Production Economics, 35(1-3), 107-114. https://doi.org/10.1016/09255273(94)90070-1 
Bonney, M., \& Jaber, M. Y. (2011). Environmentally responsible inventory models: Nonclassical models for a non-classical era. International Journal of Production Economics, 133(1), 43-53. https://doi.org/10.1016/j.ijpe.2009.10.033

Bouchery, Y., Corbett, C. J., Fransoo, J. C., \& Tan, T. (2016). Sustainable Supply Chains: A Research-Based Textbook on Operations and Strategy. Springer.

Bouchery, Y., Ghaffari, A., Jemai, Z., \& Dallery, Y. (2012). Including sustainability criteria into inventory models. European Journal of Operational Research, 222(2), 229-240. https://doi.org/10.1016/j.ejor.2012.05.004

BPIR. (n.d.). Retrieved August 28, 2016, from http://www.bpir.com/green-supply-chainmanagement/menu-id-71/conclusion.html

Braglia, M., \& Zavanella, L. (2003). Modelling an industrial strategy for inventory management in supply chains: The "Consignment Stock" case. International Journal of Production Research, 41(16), 3793-3808.

Brammer, S., Homose, S., \& Millington, A. (2011). Managing Sustainable Global Supplychains; A Systematic Review of the Body of Knowledge. London, Ontario, Canada: Network for Business Sustainability. Retrieved from http://nbs.net/wpcontent/uploads/NBS-Systematic-Review-Supply-Chains.pdf

Brewer, P. C., \& Speh, T. W. (2001). Adapting The Balanced Scorecard To Supply Chain Management. Supply Chain Management Review, V. 5, NO. 2 (Mar./Apr. 2001), P. 48-56:ILL. Retrieved from /view.aspx?id=584125

Budnik, M., \& Stanek, W. (2011). Exergetic cost of steam power plant operation. Archives of Thermodynamics, 32(2). https://doi.org/10.2478/v10173-011-0008-2

Bushuev, M. A., Guiffrida, A., Jaber, M. Y., \& Khan, M. (2015). A review of inventory lot sizing review papers. Management Research Review, 38(3), 283-298.

Business Dictionary. (n.d.). Retrieved February 7, 2016, from http://www.businessdictionary.com/definition/money-supply.html Buytaert, V., Muys, B., Devriendt, N., Pelkmans, L., Kretzschmar, J. G., \& Samson, R. (2011). Towards integrated sustainability assessment for energetic use of biomass: A state of the art evaluation of assessment tools. Renewable and Sustainable Energy Reviews, 15(8), 3918-3933. https://doi.org/10.1016/j.rser.2011.07.036 
Caniato, F., Golini, R., \& Kalchschmidt, M. (2013). The effect of global supply chain configuration on the relationship between supply chain improvement programs and performance. International Journal of Production Economics, 143(2), 285-293. https://doi.org/10.1016/j.ijpe.2012.05.019

Carter, C. R., \& Liane Easton, P. (2011). Sustainable supply chain management: evolution and future directions. International Journal of Physical Distribution \& Logistics Management, 41(1), 46-62. https://doi.org/10.1108/09600031111101420

Carter, C. R., \& Rogers, D. S. (2008). A framework of sustainable supply chain management: moving toward new theory. International Journal of Physical Distribution \& Logistics Management, 38(5), 360-387.

Cascio, J. (2007). The Cheeseburger Footprint. Retrieved July 24, 2016, from http://www.openthefuture.com/cheeseburger_CF.html

Cengel, Y., \& Boles, M. (2010). Thermodynamics: An Engineering Approach (7 edition). New York, NY: McGraw-Hill Education.

Chaabane, A., Ramudhin, A., \& Paquet, M. (2010). Optimization and evaluation of sustainable supply chains. In Proceedings of the 8th. International Conference on Modelling and Simulation - MOSIM'10. Hammamet - Tunisia.

Chang, Y.-F. (2013). Social Physics Basic Laws in Social Complex Systems and Nonlinear Whole Sociology. International Journal of Modern Social Sciences, 2(1), 2 0-33.

Charles Scott, \& Roy Westbrook. (1991). New Strategic Tools for Supply Chain Management. International Journal of Physical Distribution \& Logistics Management, 21(1), 23-33. https://doi.org/10.1108/09600039110002225

Chen, C., \& Jo Min, K. (1991). Optimal Selling Quantity and Purchasing Price for Intermediary Firms. International Journal of Operations \& Production Management, 11(10), 64-68. https://doi.org/10.1108/EUM0000000001291

Chen, G. Q., \& Chen, B. (2009). Extended-exergy analysis of the Chinese society. Energy, 34(9), 1127-1144. https://doi.org/10.1016/j.energy.2009.04.023

Chen, X., Benjaafar, S., \& Elomri, A. (2013). The carbon-constrained EOQ. Operations Research Letters, 41(2), 172-179. https://doi.org/10.1016/j.orl.2012.12.003 
Cheng, X., \& Liang, X. (2013). Entransy and entropy analyses of heat pump systems.

Chinese Science Bulletin, 58(36), 4696-4702. https://doi.org/10.1007/s11434-0136096-4

Chikán, A. (2011). Managers' view of a new inventory paradigm. International Journal of Production Economics, 133(1), 54-59. https://doi.org/10.1016/j.ijpe.2010.09.009

Choi, T.-M. J. (2013). Handbook of EOQ Inventory Problems: Stochastic and Deterministic Models and Applications. Springer Science \& Business Media.

Cleveland, C. J., Kaufmann, R. K., \& Stern, D. I. (2000). Aggregation and the role of energy in the economy. Ecological Economics, 32(2), 301-317.

Cole, M. A., Elliott, R. J. R., \& Zhang, J. (2011). GROWTH, FOREIGN DIRECT INVESTMENT, AND THE ENVIRONMENT: EVIDENCE FROM CHINESE CITIES. Journal of Regional Science, 51(1), 121-138.

Cook, C. R., \& Graser, J. C. (2001). Military Airframe Acquisition Costs: The Effects of Lean Manufacturing. RAND Corporation.

Coyle, J. J., Novack, R. A., Gibson, B., \& Bardi, E. J. (2010). Transportation: A Supply Chain Perspective (7 edition). Mason, OH: South-Western College Pub.

Crisan, E., Parpucea, I., \& Ilies, L. (2011). The Relation Between Supply Chain Performance and Supply Chain Governance Practices. Management \& Marketing, 6(4), 637-644.

Cruz, J. M. (2013). Modeling the relationship of globalized supply chains and corporate social responsibility. Journal of Cleaner Production, 56, 73-85.

Cuadra, C. T., Valero, A., Delgado, A. V., \& Ramírez, M. D. (2009). Applying Thermoeconomics to The Analysis of The North American Food Chain (pp. 887894). Presented at the 22 nd International Conference on E fficiency, Cost, Optimization, Simulation and Environ mental Impact of Energy Systems, Paraná, Brazil.

Curtis, M. (2010). The New Resource Grab: How EU Trade Policy on Raw Materials is Undermining Development. Traidcraft Exchange, Oxfam Germany, WEED, AITEC, and Comhlámh. 
Cuthbertson, R., Cetinkaya, B., Ewer, G., Klaas-Wissing, T., Piotrowicz, W., \& Tyssen, C. (2011). Sustainable Supply Chain Management. Berlin, Heidelberg: Springer Berlin Heidelberg.

Czarnezki, J. J. (2011). The Future of Food Eco-Labeling: Organic, Carbon Footprint, and Environmental Life-Cycle Analysis. Stanford Environmental Law Journal, 3(3).

Daly, H., \& Farley, J. (2010). Ecological Economics: Principles and Applications (2nd ed.). Island Press.

De Benedetto, L., \& Klemeš, J. (2009). The Environmental Performance Strategy Map: an integrated LCA approach to support the strategic decision-making process. Journal of Cleaner Production, 17(10), 900-906.

Delmas, M. A., \& Grant, L. E. (2014). Eco-Labeling Strategies and Price-Premium: The Wine Industry Puzzle. Business \& Society, 53(1), 6-44.

Demirel, Y. (2007). Nonequilibrium Thermodynamics: Transport and Rate Processes in Physical, Chemical, and Biological Systems. Elsevier.

Dincer, I. (2002). The role of exergy in energy policy making. Energy Policy, 30(2), 137149. https://doi.org/10.1016/S0301-4215(01)00079-9

Dincer, I., \& Rosen, M. A. (2012). EXERGY: Energy, Environment and Sustainable Development. Newnes.

Drechsler, F. S. (1968). Decision Trees and the Second Law. OR, 19(4), 409-419. https://doi.org/10.2307/3008702

Drexhage, J., \& Murphy, D. (2010). Sustainable Development: From Brundtland to Rio 2012. United Nations Headquarters, New York. Retrieved from http://www.un.org/wcm/webdav/site/climatechange/shared/gsp/docs/GSP16_Background\%20on\%20Sustainable\%20Devt.pdf

Drezner, Z., Gurnani, H., \& Pasternack, B. A. (1995). An EOQ Model with Substitutions between Products. The Journal of the Operational Research Society, 46(7), 887891. https://doi.org/10.2307/2583971

El Saadany, A. M. A., Jaber, M. Y., \& M. Bonney. (2011). Environmental performance measures for supply chains. Management Research Review, 34(11), 1202-1221. https://doi.org/10.1108/01409171111178756 
Elwenspoek, M., \& Jansen, H. V. (2004). Silicon Micromachining (1st ed.). Cambridge University Press.

Encyclopedia Britannica. (2016). Retrieved December 16, 2015, from http://www.britannica.com/topic/returns-to-scale

Ernst \& Young. (2016). The state of sustainable supply chains: building responsible and resilient supply chains. Retrieved from https://www.unglobalcompact.org/docs/issues_doc/supply_chain/state-ofsustainable-supply-chains.pdf

Ertesvåg, I. S. (2005). Energy, exergy, and extended-exergy analysis of the Norwegian society 2000. Energy, 30(5), 649-675. https://doi.org/10.1016/j.energy.2004.05.025

European Commission - EU Ecolabel. (2016). Retrieved July 24, 2016, from http://europa.eu/youreurope/business/environment/eco-label/

Farese, L. S., Kimbrell, G., \& Woloszyk, C. A. (2001). Marketing Essentials (3 edition). McGraw-Hill.

Field, C. B. (2012). Managing the Risks of Extreme Events and Disasters to Advance Climate Change Adaptation: Special Report of the Intergovernmental Panel on Climate Change. Cambridge University Press.

Figge, F., \& Hahn, T. (2004). Sustainable Value Added-measuring corporate contributions to sustainability beyond eco-efficiency. Ecological Economics, 48(2), 173-187. https://doi.org/10.1016/j.ecolecon.2003.08.005

Foerstl, K., Reuter, C., Hartmann, E., \& Blome, C. (2010). Managing supplier sustainability risks in a dynamically changing environment - Sustainable supplier management in the chemical industry. Journal of Purchasing and Supply Management, 16(2), 118-130. https://doi.org/10.1016/j.pursup.2010.03.011

Forkenbrock, D. J. (1999). External costs of intercity truck freight transportation. Transportation Research Part, 33(7/8), 505-526.

Formentini, M., \& Taticchi, P. (2016). Corporate sustainability approaches and governance mechanisms in sustainable supply chain management. Journal of Cleaner Production, 112, Part 3, 1920-1933. https://doi.org/10.1016/j.jclepro.2014.12.072 
Freeman, R. E., \& Reed, D. L. (1983). Stockholders and Stakeholders: A New Perspective on Corporate Governance. California Management Review, 25(3), 88-106. https://doi.org/10.2307/41165018

Fukuda, K. (2003). Production of exergy from labour and energy resources. Applied Energy, 76(4), 435-448. https://doi.org/10.1016/S0306-2619(02)00175-7

Gaggioli, R., \& Reini, M. (2014). Panel I: Connecting 2nd Law Analysis with Economics, Ecology and Energy Policy. Entropy, 16(7), 3903-3938.

GAO. (2011). U.S. GAO - Surface Freight Transportation: A Comparison of the Costs of Road, Rail, and Waterways Freight Shipments That Are Not Passed on to Consumers. United States Government Accountabilit y Office. Retrieved from http://www.gao.gov/products/GAO-11-134

Gasparatos, A., El-Haram, M., \& Horner, M. (2009). Assessing the sustainability of the UK society using thermodynamic concepts: Part 1. Renewable and Sustainable Energy Reviews, 13(5), 1074-1081. https://doi.org/10.1016/j.rser.2008.03.004

Gaudreau, K., Fraser, R. A., \& Murphy, S. (2009). The Tenuous Use of Exergy as a Measure of Resource Value or Waste Impact. Sustainability, 1(4), 1444-1463. https://doi.org/10.3390/su1041444

Georgescu-Roegen, N. (1971). The Entropy Law and the Economic Process. NE: Harvard University Press.

Glock, C. H. (2012). The joint economic lot size problem: A review. International Journal of Production Economics, 135(2), 671-686.

Glock, C. H., Grosse, E. H., \& Ries, J. M. (2014). The lot sizing problem: A tertiary study. International Journal of Production Economics, 155, 39-51.

Godard, J. (2001). High Performance and the Transformation of Work? The Implications of Alternative Work Practices for the Experience and Outcomes of Work. Industrial and Labor Relations Review, 54(4), 776.

The government of Canada, I. (n.d.). Marketing for Sustainability - Corporate Social Responsibility [Case Studies; Reports]. Retrieved March 30, 2017, from https://www.ic.gc.ca/eic/site/csr-rse.nsf/eng/h_rs00573.html 
Grubbström, R. W., \& Hultman, P. (1986). Two basic economic models of exergy/energy storage. Linköping.

Grubbström, R. W., \& Hultman, P. (1989). Exergetic and inventory-theoretic aspects of energy storage. Engineering Costs and Production Economics, 15, 343-350.

Gupta, M. C. (1995). Environmental management and its impact on the operations function. International Journal of Operations \& Production Management, 15(8), 34-51. https://doi.org/10.1108/01443579510094071

Gurtu, A., Searcy, C., \& Jaber, M. Y. (2015). An analysis of keywords used in the literature on green supply chain management. Management Research Review, 38(2), 194-166.

Gurtu, A., Searcy, C., \& Jaber, M. Y. (2016). Effects of offshore outsourcing on a nation. Sustainable Production and Consumption, 7, 94-105.

Gutowski, T. G., Branham, M. S., Dahmus, J. B., Jones, A. J., Thiriez, A., \& Sekulic, D. P. (2009). Thermodynamic Analysis of Resources Used in Manufacturing Processes. Environmental Science \& Technology, 43(5), 1584-1590.

Harris, F. W. (1990). How Many Parts to Make at Once. Operations Research, 38(6), 947950. https://doi.org/http://dx.doi.org/10.1287/opre.38.6.947

Hassini, E., Surti, C., \& Searcy, C. (2012). A literature review and a case study of sustainable supply chains with a focus on metrics. International Journal of Production Economics, 140(1), 69-82. https://doi.org/10.1016/j.ijpe.2012.01.042

Heizer, J., \& Render, B. (2008). Principles of Operations Management (7 edition). Upper Saddle River, N.J: Prentice Hall.

Hervani, A. A., Helms, M. M., \& Sarkis, J. (2005). Performance measurement for green supply chain management. Benchmarking: An International Journal, 12(4), 330353. https://doi.org/10.1108/14635770510609015

Hill, R. M. (1997). The single-vendor single-buyer integrated production-inventory model with a generalised policy. European Journal of Operational Research, 97(3), 493499. https://doi.org/10.1016/S0377-2217(96)00267-6 
Hill, Y., \& Toth, E. (2013). Supply Chain Sustainability Shift: Embedding sustainability into supply chain management. orporate Citizenship. Retrieved from http://corporate-citizenship.com/wp-content/uploads/CC-SUPPLY-CHAIN.pdf

Hussen, A. M. (2004). Principles of Environmental Economics. Psychology Press.

Hutchins, M. J., \& Sutherland, J. W. (2008). An exploration of measures of social sustainability and their application to supply chain decisions. Journal of Cleaner Production, 16(15), 1688-1698. https://doi.org/10.1016/j.jclepro.2008.06.001

Infante, A. P., \& Lawler, J. H. . (2002). Social Entropy. Retrieved April 14, 2016, from http://www.nexialinstitute.com/social_entropy.htm

Investopedia. (2003, November 24). Money Supply. Retrieved April 2, 2017, from http://www.investopedia.com/terms/m/moneysupply.asp

Jaber, M. Y. (2009). Inventory Management: Non-Classical Views. CRC Press.

Jaber, M. Y. (2016). Learning Curves: Theory, Models, and Applications. CRC Press.

Jaber, M. Y., Glock, C. H., \& Saadany, A. M. A. E. (2013). Supply chain coordination with emissions reduction incentives. International Journal of Production Research, 51(1), 69-82. https://doi.org/10.1080/00207543.2011.651656

Jaber, M. Y., Nuwayhid, R. Y., \& Rosen, M. A. (2004). Price-driven economic order systems from a thermodynamic point of view. International Journal of Production Research, 42(24), 5167-5184. https://doi.org/10.1080/00207540412331281971

Jaber, M. Y., Nuwayhid, R. Y., \& Rosen, M. A. (2006). A thermodynamic approach to modelling the economic order quantity. Applied Mathematical Modelling, 30(9), 867-883. https://doi.org/10.1016/j.apm.2005.07.001

Jaber, M. Y., Saadany, A. M. A. E., \& Rosen, M. A. (2011). Simple price-driven Reverse Logistics system with entropy and exergy costs. International Journal of Exergy, 9(4), 486. https://doi.org/10.1504/IJEX.2011.043921

Jaber, M. Y., Zanoni, S., \& Zavanella, L. E. (2013). An entropic economic order quantity (EnEOQ) for items with imperfect quality. Applied Mathematical Modelling, 37(6), 3982-3992. https://doi.org/10.1016/j.apm.2012.07.046 
Jaber, M. Y., Zanoni, S., \& Zavanella, L. E. (2014a). A consignment stock coordination scheme for the production, remanufacturing and waste disposal problem. International Journal of Production Research, 52(1), 50-65.

Jaber, M. Y., Zanoni, S., \& Zavanella, L. E. (2014b). "Consignment stock” for a two-level supply chain with entropy cost. European J. of Industrial Engineering, 8(2), 244.

Jaber, M. Y, \& Zolfaghari, S. (2008). Quantitative Models for Centralised Supply Chain Coordination. In V. Kordic (Ed.), Supply Chain: Theory and Applications. I-Tech Education and Publishing.

Jaber, Mohamad Y., \& Rosen, M. A. (2008). The economic order quantity repair and waste disposal model with entropy cost. European Journal of Operational Research, 188(1), 109-120. https://doi.org/10.1016/j.ejor.2007.03.016

Jaber, M.Y., Bonney, M., \& Moualek, I. (2009). An economic order quantity model for an imperfect production process with entropy cost. International Journal of Production Economics, 118(1), 26-33. https://doi.org/10.1016/j.ijpe.2008.08.007

Jalil, M. N., Zuidwijk, R. A., Fleischmann, M., \& van Nunen, J. A. E. E. (2009). Spare Parts Logistics and Installed Base Information (ERIM Report Series Research in Management No. ERS-2009-002-LIS). Erasmus Research Institute of Management (ERIM). Retrieved from https://ideas.repec.org/p/ems/eureri/14529.html

Janic, M. (2007). Modelling the full costs of an intermodal and road freight transport network. Transportation Research Part D: Transport and Environment, 12(1), 3344. https://doi.org/10.1016/j.trd.2006.10.004

Jawad, H., Jaber, M. Y., \& Bonney, M. (2015). The Economic Order Quantity model revisited: an Extended Exergy Accounting approach. Journal of Cleaner Production, 105, 64-73. https://doi.org/10.1016/j.jclepro.2014.06.079

Jawad, H., Jaber, M. Y., Bonney, M., \& Rosen, M. A. (2016). Deriving an exergetic economic production quantity model for better sustainability. Applied Mathematical Modelling, 40(11-12), 6026-6039.

Jelinski, L. W., Graedel, T. E., Laudise, R. A., McCall, D. W., \& Patel, C. K. (1992). Industrial ecology: concepts and approaches. Proceedings of the National Academy of Sciences, 89(3), 793-797. https://doi.org/10.1073/pnas.89.3.793 
Jensen, A., Hoffman, L. H., Møller, B., \& Schmidt. (1998). Life Cycle Assessment Environment Policy and Protection of the Environment. European Environment Agency. Retrieved from http://bookshop.europa.eu/en/life-cycle-assessmentpbGH0797595/

Kallstrom, H. (2015). Raw materials - the biggest cost driver in the auto industry - Market Realist. Retrieved from http://marketrealist.com/2015/02/raw-materials-biggestcost-driver-auto-industry/

Kendall, K., \& Steen, A. (1998). Just-In-Time not so timely: an Australian perspective. The Australian Accountant : Journal of the Australian Society of Accountants, 68(7).

Khalil, E. E. (2013). Air Distribution in Buildings. CRC Press.

Khan, M., \& Jaber, M. Y. (2011). Optimal inventory cycle in a two-stage supply chain incorporating imperfect items from suppliers. International Journal of Operational Research, 10(4), 442. https://doi.org/10.1504/IJOR.2011.039712

Kimberly S. Goetz. (2010). Encouraging sustainable business practices using incentives: a practitioner's view. Management Research Review, 33(11), 1042-1053.

Kingdom. (1998). Use of performance indicators and performance benchmarking in the North American water industry-findings from studies recently completed for AWWA and WEF research foundations. Aqua, 47(6), 269-274.

Koivula, L. (2015). Modeling supply chain costs in the automotive manufacturing industry: The case of Valmet Automotive. Retrieved from https://aaltodoc.aalto.fi:443/handle/123456789/18355

Lai, K., \& Cheng, T. C. E. (2009). Just-in-Time Logistics. Farnham, England ; Burlington, VT: Gower.

Lee, H. L., \& Lee, C.-Y. (2007). Building Supply Chain Excellence in Emerging Economies. Springer Science \& Business Media.

Leontief, W. (1970). Environmental Repercussions and the Economic Structure: An InputOutput Approach. The Review of Economics and Statistics, 52(3), 262.

Leutz, R. (2001). Nonimaging Fresnel Lenses: Design and Performance of Solar Concentrators. Springer Berlin Heidelberg. 
Li, Yan. (2011). Research on the Performance Measurement of Green Supply Chain Management in China. Journal of Sustainable Development, 4(3), 101.

Li, Yingli, \& Ye, H. (2014). How to achieve a strategic sustainable supply chain management (SSCM)? : A case study of Swedish Global enterprise in wire and cable industry-Habia Cable. Retrieved from http://www.divaportal.org/smash/record.jsf?pid=diva2\%3A731961\&dswid=6422

MacDonald, A. (2006, July). The Difference Between Managing a Global vs. Domestic Supply Chain is a Matter of Degree. World Trade, 19(7), 66.

Madlool, N. A., Saidur, R., Rahim, N. A., Islam, M. R., \& Hossian, M. S. (2012). An exergy analysis for cement industries: An overview. Renewable and Sustainable Energy Reviews, 16(1), 921-932. https://doi.org/10.1016/j.rser.2011.09.013

Massaroni, E., Cozzolino, A., \& Wankowicz, E. (2016). Sustainability in Supply Chain Management - A Literature Review. Sinergie Italian Journal of Management, 331355. https://doi.org/10.7433/s98.2015.19

Maurer, M., \& Sachs, S. (2005). Implementing the Stakeholder View. Journal of Corporate Citizenship, 2005(17), 93-107.

McConnell, B. (2013). Resilience. Retrieved April 18, 2016, from http://www.resilience.org/stories/2013-02-06/the-joule-standard

McGregor, D. F. M., Barker, D., \& Evans, S. L. (Eds.). (1998). Resource Sustainability And Caribbean Development (1st edition). Kingston, Jamaica: University of the West Indies Press.

Mckee, A., Kemp, T., \& Spence, G. (2012). Management: A Focus on Leaders. Sydney Business School - Papers. Retrieved from http://ro.uow.edu.au/gsbpapers/370

McKee, A., Kemp, T., \& Spence, G. (2012). Management: A Focus on Leaders. Pearson Higher Education AU.

Mentzer, J. T., DeWitt, W., Keebler, J. S., Min, S., Nix, N. W., Smith, C. D., \& Zacharia, Z. G. (2001). Defining Supply Chain Management. Journal of Business Logistics, 22(2), 1-25. https://doi.org/10.1002/j.2158-1592.2001.tb00001.x

MERRIAM-WEBSTER. (n.d.). Retrieved March 30, 2017, from https://www.merriamwebster.com/dictionary/society 
Milia, D., \& Sciubba, E. (2006). Exergy-based lumped simulation of complex systems: An interactive analysis tool. Energy, 31(1), 100-111.

Miller, G. T., \& Spoolman, S. (2014). Living in the Environment (18th ed.). Brooks Cole.

Mohr, S., Somers, K., Swartz, S., \& Vanthournout, H. (2012). Manufacturing resource productivity | McKinsey \& Company. McKinsey \& Company. Retrieved from http://www.mckinsey.com/business-functions/sustainability-and-resourceproductivity/our-insights/manufacturing-resource-productivity

Moran, M. J., Shapiro, H. N., Boettner, D. D., \& Bailey, M. B. (2010). Fundamentals of Engineering Thermodynamics (7th ed.). Wiley.

Muckstadt, J. A., \& Sapra, A. (2009). Principles of Inventory Management - When You Are Down to Four, Order More. Springer.

Munch, Jakob R. (2010). Whose Job Goes Abroad? International Outsourcing and Individual Job Separations: Whose job goes abroad? Scandinavian Journal of Economics, 112(2), 339-360. https://doi.org/10.1111/j.1467-9442.2010.01607.x

Munch, Jakob Roland. (2005). International Outsourcing and Individual Job Separations. University of Copenhagen. Department of Economics. Retrieved from http://www.econ.ku.dk/english/research/publications/wp/2005/0511.pdf/

Narita, H. (2012). Environmental Burden Analyzer for Machine Tool Operations and Its Application. In F. Abdul Aziz (Ed.), Manufacturing System. InTech. Retrieved from http://www.intechopen.com/books/manufacturing-system/environmentalburden-analyzer-for-machine-tool-operations-and-its-application

Natural Resources Canada. (2017). Retrieved March 31, 2017, from http://www.nrcan.gc.ca/energy/products/energystar/12519

Neumayer, E. (2003). Weak Versus Strong Sustainability: Exploring the Limits of Two Opposing Paradigms. Edward Elgar Publishing.

Ni, D., Li, K. W., \& Tang, X. (2010). Social responsibility allocation in two-echelon supply chains: Insights from wholesale price contracts. European Journal of Operational Research, 207(3), 1269-1279.

Norde, W. (1997). Energy and entropy: a thermodynamic approach to sustainability. The Environmentalist, 17(1), 57-62. https://doi.org/10.1023/A:1018535529785 
Nuwayhid, R. Y., Jaber, M. Y., Rosen, M. A., \& Sassine, G. P. (2006). On the thermodynamic treatment of diffusion-like economic commodity flows. International Journal of Exergy, 3(1), 103.

O’Brien, K. A., \& Teisl, M. F. (2004). Eco-information and its effect on consumer values for environmentally certified forest products. Journal of Forest Economics, 10(2), 75-96. https://doi.org/10.1016/j.jfe.2004.05.001

O’Connor, D. E. (2004). The Basics of Economics. Greenwood Publishing Group.

Ortas, E., Moneva, J., \& Álvarez, I. (2014). Sustainable supply chain and company performance: A global examination. Supply Chain Management: An International Journal, 19(3), 332-350. https://doi.org/10.1108/SCM-12-2013-0444

Ortolani, C., Persona, A., \& Sgarbossa, F. (2011). External cost effects and freight modal choice: research and application. International Journal of Logistics Research and Applications, 14(3), 199-220. https://doi.org/10.1080/13675567.2011.609536

Owens, J. W. (1997). Life-Cycle Assessment: Constraints on Moving from Inventory to Impact Assessment. Journal of Industrial Ecology, 1(1), 37-49.

Oxford Dictionaries. (n.d.). Retrieved December 24, 2016, from https://en.oxforddictionaries.com/definition/ecological_footprint

Pan, S., Ballot, E., \& Fontane, F. (2013). The reduction of greenhouse gas emissions from freight transport by pooling supply chains. International Journal of Production Economics, 143(1), 86-94. https://doi.org/10.1016/j.ijpe.2010.10.023

Paniagua, I. L., Martín, J. R., Fern, C. G., Álvaro, Á. J., Carlier, R. N., \& [bar, P. P. (2013). A New Simple Method for Estimating Exergy Destruction in Heat Exchangers. Entropy, 15(2), 474-489. https://doi.org/10.3390/e15020474

Pappis, C. (2010). Climate Change, Supply Chain Management and Enterprise Adaptation: Implications of Global Warming on the Economy: Implications of Global Warming on the Economy. IGI Global.

Pascale, A. de. (2012). Role of Entropy in Sustainable Economic Growth. International Journal of Academic Research in Accounting, Finance and Management Sciences, 1(2), 293-301. 
Peiró, L. T., Méndez, G. V., Sciubba, E., \& i Durany, X. G. (2010). Extended exergy accounting applied to biodiesel production. Energy, 35(7), 2861-2869.

Petrakopoulou, F., Lara, Y., Morosuk, T., \& Boyano, A. (2012). The Relationship Between Costs and Environmental Impacts in Power Plants: An Exergy-Based Study (pp. 237-249). Presented at the The 25th International Conference on Efficiency, Cost, Optimization and Simulation of Energy Conversion Systems and Processes, Perugia, Italy.

Piatti, A., Piemonte, C., \& Szegö, E. (1992). Planning of Geothermal District Heating Systems. Boston: Kluwer Academic.

Porteus, E. L. (1986). Optimal Lot Sizing, Process Quality Improvement and Setup Cost Reduction. Operations Research, 34(1), 137.

Puckett, J. (2003). Recycling: no excuse for global environmental injustice (Waste Management World) (pp. 83-90). Basel Action Network (BAN). Retrieved from http://archive.ban.org/library/whyban.pdf

Rathore, M. M. (2010). Thermal Engineering. Tata McGraw-Hill Education.

Ravi, V., Shankar, R., \& Tiwari, M. K. (2005). Analyzing alternatives in reverse logistics for end-of-life computers: ANP and balanced scorecard approach. Computers \& Industrial Engineering, 48(2), 327-356. https://doi.org/10.1016/j.cie.2005.01.017

Ravindran, A. R., \& Warsing, Jr., D. P. (2012). Supply Chain Engineering: Models and Applications. CRC Press.

Rayner, A. D. M. (2010). Inclusionality and sustainability - attuning with the currency of natural energy flow and how this contrasts with abstract economic rationality. Environmental Economics, 1(1), 102-112.

Rhonda R. Lummus, \& Robert J. Vokurka. (1999). Defining supply chain management: a historical perspective and practical guidelines. Industrial Management \& Data Systems, 99(1), 11-17. https://doi.org/10.1108/02635579910243851

Rocco, M. V., Colombo, E., \& Sciubba, E. (2014). Advances in exergy analysis: a novel assessment of the Extended Exergy Accounting method. Applied Energy, 113, 1405-1420. https://doi.org/10.1016/j.apenergy.2013.08.080 
Rosen, M. A. (2008). A Concise Review of Exergy-based Economic Methods. In Proceedings of the 3rd IASME/WSEAS International Conference on Energy \& Environment (pp. 136-144). Stevens Point, Wisconsin, USA: World Scientific and Engineering Academy and Society (WSEAS).

Ross, D. F. (1998). Competing Through Supply Chain Management: Creating MarketWinning Strategies Through Supply Chain Partnerships. Springer.

Sahu, J. K. (2014). Introduction to Advanced Food Process Engineering. NW: CRC Press. Salameh, M. K., \& Jaber, M. Y. (2000). Economic production quantity model for items with imperfect quality. International Journal of Production Economics, 64(1-3), 59-64. https://doi.org/10.1016/S0925-5273(99)00044-4

Salciccioli, J. D., Crutain, Y., Komorowski, M., \& Marshall, D. C. (2016). Sensitivity Analysis and Model Validation. In MIT Critical Data, Secondary Analysis of Electronic Health Records (pp. 263-271). Cham: Springer International Publishing.

Schlör, H., Fischer, W., \& Hake, J.-F. (2009). Is the German Energy System Sustainable? An Analysis Based on the German Sustainability Strategy. Presented at the 5th Dubrovnik Conference on Sustainable Development of Energy, Water and Environment Systems, Dalmatia, Croatia.

Schwaller, R. L. (1988). EOQ Under Inspection Costs - ProQuest. Production and Inventory Management, 29(3), 22-24.

Sciubba, E. (1999). Exergy as a direct measure of environmental impact. Presented at the Advanced Energy Systems Division - 1999 (The ASME International Mechanical Engineering Congress and Exposition).

Sciubba, E. (2001). Beyond thermoeconomics? The concept of Extended Exergy Accounting and its application to the analysis and design of thermal systems. Exergy, An International Journal, 1(2), 68-84. https://doi.org/10.1016/S11640235(01)00012-7

Sciubba, E. (2004). From Engineering Economics to Extended Exergy Accounting: A Possible Path from Monetary to Resource-Based Costing. Journal of Industrial Ecology, 8(4), 19-40. https://doi.org/10.1162/1088198043630397 
Sciubba, E. (2011). A revised calculation of the econometric factors $\alpha$ - and $\beta$ for the Extended Exergy Accounting method. Ecological Modelling, 222(4), 1060-1066.

Sciubba, E. (2013). Can an Environmental Indicator valid both at the local and global scales be derived on a thermodynamic basis? Ecological Indicators, 29, 125-137.

Sciubba, E., Bastianoni, S., \& Tiezzi, E. (2008). Exergy and extended exergy accounting of very large complex systems with an application to the province of Siena, Italy. Journal of Environmental Management, 86(2), 372-382.

Sciubba, E., Manfrida, G., \& Desideri, U. (2012). ECOS 2012 The 25th International Conference on Efficiency, Cost, Optimization and Simulation of Energy Conversion Systems and Processes (Perugia, June 26th-June 29th, 2012). Firenze University Press.

Searcy, C. (2011). Updating corporate sustainability performance measurement systems. Measuring Business Excellence, 15(2), 44-56.

Searcy, C. (2016a). It Is Time to Develop and Apply a Set of Standardized Sustainability Metrics. Retrieved January 14, 2017, from http://www.sustainablebrands.com/news_and_views/new_metrics/cory_searcy/it_ti me_develop_apply_set_standardized_sustainability_metrics

Searcy, C. (2016b). Measuring Enterprise Sustainability: Measuring Enterprise Sustainability. Business Strategy and the Environment, 25(2), 120-133.

Seckin, C., \& Bayulken, A. R. (2013). Extended Exergy Accounting (EEA) analysis of municipal wastewater treatment - Determination of environmental remediation cost for municipal wastewater. Applied Energy, 110, 55-64.

Seckin, C., Sciubba, E., \& Bayulken, A. R. (2013). Extended exergy analysis of Turkish transportation sector. Journal of Cleaner Production, 47, 422-436.

Selen, W. J., \& Wood, W. R. (1987). Inventory Cost Definition in an Eoq Model Application. Production and Inventory Management Journal, 28(4), 44.

SERI. (2009). Overconsumption? Our Use of the World's Natural Resources. Retrieved from http://www.foeeurope.org/sites/default/files/publications/foee_overconsumption_0 909.pdf 
Seuring, S. (2013). A review of modeling approaches for sustainable supply chain management. Decision Support Systems, 54(4), 1513-1520.

Seuring, S., \& Müller, M. (2008). From a literature review to a conceptual framework for sustainable supply chain management. Journal of Cleaner Production, 16(15), 1699-1710. https://doi.org/10.1016/j.jclepro.2008.04.020

Simchi-Levi, D., Kaminsky, P., \& Simchi-Levi, E. (2002). Designing and Managing the Supply Chain w/ Student CD-Rom: Concepts, Strategies, and Case Studies (2 edition). Boston: McGraw-Hill Higher Education.

Simchi-Levi, D., Kaminsky, P., \& Simchi-Levi, E. (2008). Designing and Managing the Supply Chain: Concepts, Strategies, and Case Studies. McGraw-Hill/Irwin.

Sitnikov, C. S., \& Bocean, C. G. (2012). Corporate Sustainability and Organizational Change. Case of OMV Petrom. The AMFITEATRU ECONOMIC Journal, 14(32), $323-332$.

Sloan, P., Legrand, W., \& Chen, J. S. (2013). Sustainability in the Hospitality Industry 2nd Ed: Principles of Sustainable Operations. Routledge.

Sokolowski, J. A., \& Banks, C. M. (2011). Principles of Modeling and Simulation: A Multidisciplinary Approach. John Wiley \& Sons.

Sople, V. V. (2011). Supply chain management. Pearson India.

Speth, P., Christoph, M., \& Diekkrüger, B. (Eds.). (2010). Impacts of Global Change on the Hydrological Cycle in West and Northwest Africa. Berlin, Heidelberg: Springer Berlin Heidelberg.

Srivastava, S. K. (2007). Green supply-chain management: A state-of-the-art literature review. International Journal of Management Reviews, 9(1), 53-80.

Stank, T. P., Keller, S. B., \& Daugherty, P. J. (2001). Supply Chain Collaboration and Logistical Service Performance. Journal of Business Logistics, 22(1), 29-48.

Stapenhurst, T. (2009). The Benchmarking Book: A How-to-guide to Best Practice for Managers and Practitioners. Routledge.

Stougie, L., Van der Kooi, H. J., \& Stikkelman, R. M. (2012). Electricity production from renewable and non-renewable energy sources: a comparison of environmental, economic and social sustainability indicators with exergy losses throughout the 
supply chain. Presented at the Proceedings of Ecos 2012 - The 25th International Conference on Efficiency, Cost, Optimization, Simulation and Environmental Impact of Energy Systems, Perugia, Italy: Firenze University Press.

Stougie, Lydia, \& van der Kooi, H. J. (2016). Possibilities and consequences of the Total Cumulative Exergy Loss method in improving the sustainability of power generation. Energy Conversion and Management, 107, 60-66. https://doi.org/10.1016/j.enconman.2015.09.039

Sundar, K. S., Narayanan, S., \& Nagaraju, D. (2012). Coordination in Two Level Supply Chain with Price Dependent Demand. Applied Mathematical Sciences, 6(74), 3687-3703.

Sustainability Store. (n.d.). Retrieved December 25, 2016, from http://www.sustainabilitystore.com/sustainable/

Szargut, J., Morris, D. R., \& Steward, F. R. (1987). Exergy analysis of thermal, chemical, and metallurgical processes.

Szargut, Jan, Morris, D. R., \& Steward, F. R. (1988). Exergy analysis of thermal, chemical, and metallurgical processes. Hemisphere Publishing Corporation.

Tachizawa, E., \& Yew Wong, C. (2014). Towards a theory of multi-tier sustainable supply chains: a systematic literature review. Supply Chain Management: An International Journal, 19(5/6), 643-663. https://doi.org/10.1108/SCM-02-2014-0070

Telò, M. (2016). European Union and New Regionalism: Competing Regionalism and Global Governance in a Post-Hegemonic Era (2nd edition). Ashgate Pub Co.

The World Bank. (n.d.). The World Bank, Money and quasi money (M2) (current LCU) | Data | Table, 2015. Retrieved July 15, 2016, from http://data.worldbank.org/indicator/FM.LBL.MQMY.ZG

Thermodynamics. (2009). Retrieved April 2, 2017, from https://www.cs.mcgill.ca/ rwest/link-suggestion/wpcd_2008-

09_augmented/wp/t/Thermodynamics.htm

Thiriez, A. (2006). An environmental analysis of injection molding (Thesis).

Massachusetts Institute of Technology. Retrieved from http://dspace.mit.edu/handle/1721.1/35646 
Thomas, A. R., \& Vaduva, S. (Eds.). (2015). Global Supply Chain Security. NY: Springer New York.

Tseng, S.-C., \& Hung, S.-W. (2014). A strategic decision-making model considering the social costs of carbon dioxide emissions for sustainable supply chain management. Journal of Environmental Management, 133, 315-322.

Tsoulfas, G. T., \& Pappis, C. P. (2008). A model for supply chains environmental performance analysis and decision making. Journal of Cleaner Production, 16(15), 1647-1657. https://doi.org/10.1016/j.jclepro.2008.04.018

UN Global Compact. (n.d.-a). Retrieved April 1, 2017, from https://www.unglobalcompact.org/what-is-gc/mission/principles

UN Global Compact. (n.d.-b). Retrieved March 3, 2016, from https://www.unglobalcompact.org/

UNDP. (n.d.). Retrieved March 15, 2016, from http://www.undp.org/content/undp/en/home/sdgoverview/post-2015-developmentagenda/goal-12.html

UNESCO. (n.d.). Retrieved December 25, 2016, from http://www.unesco.org/new/en/culture/themes/culture-and-development/ united nations Global Compact. (2011). Supply chain sustainability: A practical guide for continuous improvement.

unleashedsoftware.com. (2015, September 23). Retrieved April 27, 2016, from https://www.unleashedsoftware.com/blog/what-are-inventory-ordering-holdingand-shortage-costs

Vachon, S., \& Mao, Z. (2008). Linking supply chain strength to sustainable development: a country-level analysis. Journal of Cleaner Production, 16(15), 1552-1560.

Valero, A., \& Cuadra, C. T. (2004). Thermoeconomic Analysis. In Exergy, Energy System Analysis and Optimization (1st ed., Vol. 2). UNESCO - EOLSS.

Valero, A., Usón, S., Torres, C., \& Valero, A. (2010). Application of Thermoeconomics to Industrial Ecology. Entropy, 12(3), 591-612. https://doi.org/10.3390/e12030591

Van Hoek, R. I. (1999). From reversed logistics to green supply chains. Supply Chain Management: An International Journal, 4(3), 129-135. 
Veseth, M. (2014). Introductory Microeconomics. Academic Press.

Villanueva, R., García, J. L., \& Adame, W. (2013). Green Supply Chain Management; a competitive advantage. Presented at the International Congress on Logistics \& Supply Chain, CILOG 2013, Sanfandila, Queretaro, Mexico.

Wall, G. (1994). Exergy, ecology and democracy concepts of a vital society or a proposal for an exergy tax (pp. 111-121). Presented at the 2nd European Congress on Economics and Management of Energy in Industry, Estoril, Portugal.

Wall, Göran. (1977). Exergy - a useful concept within resource accounting. Chalmers tekniska högskola, Göteborgs universitet.

Wall, Goran. (2010). On Exergy and Sustainable Development in Environmental Engineering. The Open Environmental Engineering Journal, 3(1), 21-32.

Waters, C. D. J. (2003). Inventory Control and Management. Wiley.

White, L. A. (1943). Energy and the Evolution of Culture. American Anthropologist, 45(3), 335-356. https://doi.org/10.1525/aa.1943.45.3.02a00010

White, L. A. (2016). The Evolution of Culture: The Development of Civilization to the Fall of Rome. Routledge.

Wijewardena, H., \& De Zoysa, A. (1999). A comparative analysis of management accounting practices in Australia and Japan: An empirical investigation. The International Journal of Accounting, 34(1), 49-70.

Woolsey, G. (1990). A requiem for the EOQ (economic order quantity): an editorial. Hospital Materiel Management Quarterly, 12(1), 82-90.

World Energy Outlook. (2004). Organisation for Economic Co-operation and Development.

Wu, G.-C., Ding, J.-H., \& Chen, P.-S. (2012). The effects of GSCM drivers and institutional pressures on GSCM practices in Taiwan's textile and apparel industry. International Journal of Production Economics, 135(2), 618-636.

$\mathrm{Xu}, \mathrm{X}$. (1992). Exergy analysis on a vapor compression system using R12, R134a and R290 as refrigerants (pp. 231-240). Presented at the International Refrigeration Conference, Purdue University. 
Xu, X., \& Gursoy, D. (2015). Motivators and Inhibitors of Implementing Sustainable Hospitality Supply Chain Management. In Collaboration in Tourism Businesses and Destinations: A Handbook (pp. 299-320). Bingley, England: Emerald.

Yee, H. S. (2010). China's Rise - Threat Or Opportunity? Routledge.

Young, S. T., \& Dhanda, K. K. (2012). Sustainability: Essentials for Business. SAGE Publications.

Zailani, S., Jeyaraman, K., Vengadasan, G., \& Premkumar, R. (2012). Sustainable supply chain management (SSCM) in Malaysia: A survey. International Journal of Production Economics, 140(1), 330-340.

Zangwill, W. I. (1987). From EOQ Towards ZI. Management Science, 33(10), 1209-1223. https://doi.org/10.1287/mnsc.33.10.1209

Zhihong Wang, \& Joseph Sarkis. (2013). Investigating the relationship of sustainable supply chain management with corporate financial performance. International Journal of Productivity and Performance Management, 62(8), 871-888.

Zhou, X., Zhang, Q., Zhang, M., \& Li, X. (2008). Research on Evaluation and Development of Green Product Design Project in Manufacturing Industry. In 2008 4th International Conference on Wireless Communications, Networking and Mobile Computing (pp. 1-5). https://doi.org/10.1109/WiCom.2008.1902

Zurcher, U. (2011). Nonequilibrium Thermodynamics for Living Systems: Brownian Particle Description. In M. Tadashi (Ed.), Thermodynamics. InTech. 